NASA Contractor Report 4491

\title{
Concept Definition Study for an Extremely Large Aerophysics Range Facility
}

Hallock F. Swift

Physics Applications

Dayton, Ohio

Prepared by Physics Applications,

California Research and Technology, Inc.,

Titan Industries, under subcontract

from Lockheed Engineering \& Sciences Company

for Langley Research Center

under Contract NAS1-19000

\section{N/SA}

National Aeronautics and

Space Administration

Office of Management

Scientific and Technical

Information Program

1993 

TABLE OF CONTENTS

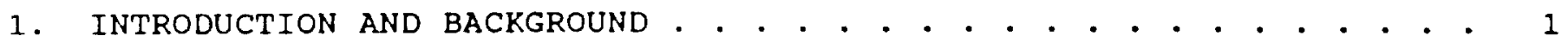

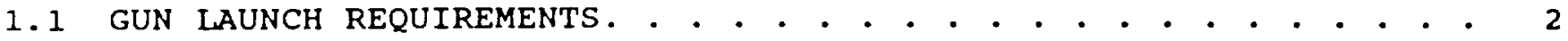

1.2 GUN LAUNCH OPTIONS . . . . . . . . . . . . . . . . . . . . . . . . 2

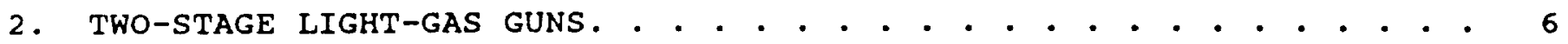

2.1 DETERMINING LIGHT-GAS GUN CONFIGURATIONS . • . . • • • • . . • •

2.1 .1 Computational Routines . . . . . . . . . . . . . . . . . 6

2.1 .2 Light-Gas Gun Configuration. . . . . . . . . . . . . . . . 6

2.1.2.1 Launch Tube Length... . . . . . . . . . . . . . . . . 7

2.1.2.2 Pump Tube Diameter . . . . . . . . . . . . . . . . . . . 7

2.1.2.3 Pump Tube Length . . . . . . . . . . . . . . . . . . . . 7

2.1.2.4 Transition Shape. . . . . . . . . . . . . . . . . . . . 8

2.1 .2 .5 Piston Mass. . . . . . . . . . . . . . . . . 8

2.1 .3 Geometry Selection for the Light-Gas Gun . . . . . . . . . 8 2.1.3.1 Optimum Pump Tube Diameter \& Length. . . . . . . . . . . 10 2.1.3.2 Launch Tube Length . . . . . . . . . . . . . . . . . 10

2.1.4 Estimated Mass-Throwing Capability . . . . . . . . . . . . . 14

2.2 LIGHT-GAS GUN DESIGN . . . . . . . . . . . . . . 15

2.2 .1 Introduction ................. 15

2.2 .2 Piston Launch considerations . . . . . . . . . . . . . 17

2.2 .2 .1 Solid Propellant . . . . . . . . . . . . . . . . . . 17

2.2 .2 .2 Gas Combustion . . . . . . . . . . . . . . . . . . . 19

2.2.2.3 Gas Compression. . . . . . . . . . . . . . . . . . . 22

2.2 .3 Structural strength considerations . . . . . . . . . . . . . 27

2.2 .3 .1 Sources of Launch Stress . . . . . . . . . . . . . . . . 27

2.2.3.2 Reaction of Gun Components to Applied Forces... . . . . 32

2.2.4 Design of Light-Gas Gun Components . . . . . . . . . . . . . 37

2.2 .4 .1 The Piston Driver Gas Reservoir Assembly . . . . . . . . 37

2.2.4.2 Pump Tube. . . . . . . . . . . . . . . . . . . . . 43

2.2.4.3 Central Breech...................... . 47

2.2.4.4 Launch Tube. . . . . . . . . . . . . . . . . . . 51 
TABLE OF CONTENTS (Continued)

2.3 LIGHT-GAS GUN MOUNT. • . . . . . . . . . . . . . . . . . . . . . 62

2.3.1 Launcher Movement During its Firing Sequence . . . . . . . . 62

2.3 .2 Gas Gun Mounting Structure . . . . . . . . . . . . . . . . . 64

2.3 .2 .1 Pump Tube Mount . . . . . . . . . . . . . . . . . . . 67

2.3.2.2 Central Breech Support. . . . . . . . . . . . . . . . 69

2.3.2.3 Launch Tube Support... . . . . . . . . . . . . . 78

2.4 SUPPORT EQUIPMENT FOR THE TWO-STAGE LIGHT GAS GUN. . . . . . . . 79

2.4 .1 Pump Tube Driver Gas Loading System. . . . . . . . . . . . . 79

2.4 .1 .1 System Evacuation. . . . . . . . . . . . . . . . . . . . 80

2.4.1.2 Initial Gas Loading. . . . . . . . . . . . . . . . . . . 80

2.4 .1 .3 Post-Shot Gas Recompression. . . . . . . . . . . . . . . 82

2.4.1.4 Gas Transfer to the Helium Holding Tanks . . . . . . . . 83

2.4.1.5 Control Panel Configuration. . . . . . . . . . . . . . 83

2.4 .2 Compression Piston . . . . . . . . . . . . . . . . . . . . 84

2.4 .3 Hydrogen Gas Fill System . . . . . . . . . . . . . . . 85

2.4 .4 Piston Breaker . . . . . . . . . . . . . . . . . . . 88

2.4 .5 Piston Retriever . . . . . . . . . . . . . . . . 89

2.4 .6 Launch Tube Hone Assembly. . . . . . . . . . . . . . . . . . 91

3. THE TEST RANGE. . . . . . . . . . . . . . . . . . . . . . . . . . . 94

3.1 RANGE COMPONENTS . . . . . . . . . . . . . . . . . . . . . . . . . 94

3.1 .1 Tankage Used for Supporting Launcher Operations . . . . . 99

3.1.1.1 Blast Tank . . . . . . . . . . . . . . . . . . . .

3.1.1.1.1 Fast Opening valve (FOV) . . . . . . . . . . . . . . . 106

3.1.1.1.2 Driver gas expulsion from blast tank . . . . . . . . . 108

3.1.1.2 Sabot Discard Tank . . . . . . . . . . . . . . . . 110

3.1.1.2.1 Aerodynamic sabot separation . . . . . . . . . . 110

3.1.1.2.2 Sabot separation via mild impact. . . . . . . . . . 116

3.1.1.2.3 Sabot segment disruption . . . . . . . . . . . . 126

3.1 .2 Tankage Used for Performing Experiments . . . . . . . . . . 134

3.1.2.1 Main Experiment Tank . . . . . . . . . . . . . . . 136

3.1.2.2 Diaphragms for Separating Range Tankage Atmospheres. . 138

3.1.2.3 Rail Guided Firings. . . . . . . . . . . . . . . . . . 145

3.2 Range Evacuation Systems (Completed by NASA Langley Staff) • . 152 
4. STTE, BUILDING AND COST REQUIREMENTS ................... 153

4.1 SITE REQUIREMENTS. . . . . . . . . . . . . . . . 153

4.2 BUILDING REQUIREMENTS. . . . . . . . . . . . . . 153

4.3 ELCTRICAL POWER REQUIREMENTS FOR THE RANGE.......... 156

4.4 PROVISION FOR ALTERNATIVE MODEL LAUNCH TECHNOLOGIES....157

4.4 .1 D. C. Electromagnetic Rail Gun Velocity Amplifiex...157

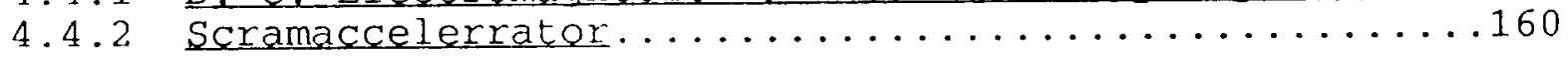

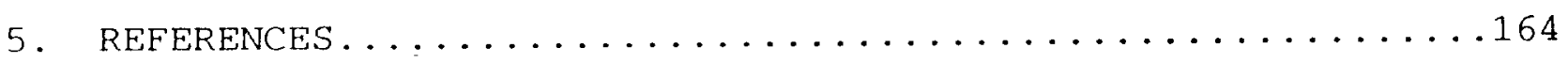




\section{INTRODUCTION AND BACKGROUND.}

The Space Systems Division of the NASA Langley Research Center has identified a national need for an aeroballistic range facility considerably larger than any that has yet been built or ever considered seriously.(1) The facility is needed because of its unique capability to conduct detailed aerodynamic and aerothermo-dynamic studies of large, highly instrumented models at hypervelocity, high enthalpy conditions representative of flight. It is important to note that the chemistry of the free stream atmosphere of the range tankage can be made to simulate if not duplicate the quiescent atmospheres through which hypervelocity vehicles operate. Whereas in aeroballistic range testing, the energy required to support the occurrence of aerothermodynamic phenomena (particularly real-gas effects) is supplied primarily by the velocity of the model, other types of ground-based hypervelocity test facilities supply energy to the test gas itself. Energizing the gas produces either insufficient enthalpy levels and/or flow over the model which is already predissociated and, therefore, not representative of actual flight conditions. The large model size provides not only volume to house significant onboard instrumentation for measuring model surface pressures and temperatures (and possibly even flight control equipment), but provides thick shock/boundary layers and the opportunity to study the real-gas effects controlling aerodynamic and aerothermodynamic phenomena.

NASA specified a two-stage light-gas gun as the model launcher/accelerator. (1) The rationale was that the light-gas gun is proven technology, and that a scaled up version of such a gun has a lower risk than other candidate launchers. Nominal requirements for the gun were a $250 \mathrm{~mm}$ launch bore diameter and capability of launching $14.0 \mathrm{~kg}$ launch packages to $6 \mathrm{~km} / \mathrm{sec}$. Two emerging launcher technologies which could lead to higher launch velocities, larger payloads, and lower acceleration rates are the electromagnetic launcher (a rail gun specifically) and the ram accelerator. Herein these are considered only from the standpoint of the provisions required to permit their incorporation into the facility at a later date, should the technologies mature sufficiently. Peak accelerations produced by the launch cycle must be minimized to protect the instrumentation onboard the models and to minimize the launch mass required to maintain the structural integrity of models and sabots. The range itself was to provide for two types of tests; models in free flight and models constrained to the centerline of the range tankage by a system of rails. Methods for decelerating and/or recovery of models are addressed.

This report describes the design and operational aspects of the launcher, the test chambers, the model deceleration and/or recovery systems, and the provisions required for incorporating advanced technology launchers into the facility at some later date. 


\subsection{GUN LAUNCH REQUIREMENTS.}

The staff at NASA Langley Research Center have established that the minimum launch conditions for an effective vehicle are as follows:

- launch package diameter; $250 \mathrm{~mm}$

- minimum velocity capability; $6.1 \mathrm{~km} / \mathrm{sec}$

- minimum launch package mass; $14.0 \mathrm{~kg}$

- maximum peak acceleration; $85,000 \mathrm{~g}^{\prime} \mathrm{s}$ (which infers a peak base pressure of $238 \mathrm{MPa}$ )

The effort covered by this report was aimed at establishing the feasibility of achieving these performance levels with a launcher that can be fabricated using current technology or reasonable extensions of it.

\subsection{GUN LAUNCH OPTIONS.}

It was established during earlier studies ${ }^{(1)}$ that only three technologies are available with reasonable prospects for meeting launch requirements for the desired facility: D.C. electromagnetic rail guns; scram accelerators; and two-stage light-gas guns.

D.C. electromagnetic rail guns have been the subject of intense $R$ \& $D$ activity for the past decade. They have potential for launching very large payloads to velocities exceeding 15.0 $\mathrm{km} / \mathrm{sec}$. Potential exists for conducting very gentle launches where peak acceleration levels which the models must withstand are minimized. Unfortunately, laboratory experiments with electromagnetic launchers have been disappointing when velocities above $4.0 \mathrm{~km} / \mathrm{sec}$ have been attempted with meaningful launch masses. For this reason, immediate consideration of electromagnetic launchers for the task at hand has been suspended although they may again become important if the velocity limitations are solved. One configuration of special interest is to use an E.M. launcher as a velocity amplifier to be added ahead of the two-stage light-gas gun so that the velocity regimes above $6.0 \mathrm{~km} / \mathrm{sec}$ can be investigated.

The second approach, scram accelerator, is an interesting new concept that is just now being subjected to careful scrutiny. Basically, fuel for the launch is stored in the launch tube itself. Projectiles consist of a central fuselage somewhat smaller in diameter than the bore and fins which extend from it to ride the bore walls. The bore is filled with an atmosphere of fuel gas and oxygen (air) whose combustion energy is used to accelerate the projectile. The projectile is launched by other means into the rear end of the scramjet tube at a velocity above mach-one in the fuel/oxidizer mix. A shockwave attached to the nose of the projectile compresses and heats the gas mixture. Reflection of this shock off the tube wall continues the gas heating/compression until the gas is ignited at a point somewhere 
behind the largest diameter of the vehicle's fuselage. Pressure in the gas increases as it burns by a factor of 5 to 8 above its shocked value. This pressure bearing on the rear of the projectile accelerates it along the tube. Gas chemistry must be shifted from time to time as projectile velocity increases to assure that gas ignition does not occur prematurely. If ignition occurs early, the scram tube acts as a net projectile decelerator.

To date, scram-accelerators have been tested at the University of washington in the velocity regime between 1.0 $\mathrm{km} / \mathrm{sec}$ and $2.7 \mathrm{~km} / \mathrm{sec}$ where the gas must be ignited after shock compression. Plans (1) are in-hand to test the concept in the velocity regime between $4.0 \mathrm{~km} / \mathrm{sec}$ and $5.0 \mathrm{~km} / \mathrm{sec}$ where shockwave detonation may be expected.

Theoretical studies indicate that velocities up to somewhat over $7.0 \mathrm{~km} / \mathrm{sec}$ are obtainable with this technique. The beauty of the approach is that it is scalable readily to very large tube diameters and the required launcher equipment is fundamentally inexpensive. However, none of the technology has yet been investigated experimentally in velocity regimes of interest to the current effort. For these reasons, the range is being designed to accept a very large ram accelerator (with a bore diameter as large as $600 \mathrm{~mm}$ ) but no plans are being made at present to supply such an accelerator.

The two-stage light-gas gun represents a low risk solution to the projectile launch problem. It's demonstrated velocity capabilities exceed $8.0 \mathrm{~km} / \mathrm{sec}$ and both theoretical and experimental studies have indicated that gas guns can be operated effectively at $6.0 \mathrm{~km} / \mathrm{sec}$ with launch cycles where peak accelerations are a small multiple of their average ones.

The operation of a generic light-gas gun is presented schematically in Figure 1.1. Basically, the rear portions of the launcher are a conventional solid propellant gun which is used as a free piston gas compressor. In principal, the gas may be compressed isentropically with a subsonic piston or it may be shock-compressed to higher temperatures with a supersonic piston. In either case, the hot, high pressure gas is expelled from the pump tube through a transition section to a smaller-diameter launch tube which contains the projectile payload. The payload is accelerated along it's own launch tube to a velocity of several times the peak velocity of the gas compression piston. The high temperature and low molecular weight of the driver gas charge allows projectile velocities to be achieved which are far above even theoretical velocity limits for solid propellant guns.

The largest two-stage light-gas gun built, to date, is operated by the French Atomic Energy Commission at their laboratory in chattilion, France. (7) It has an $80 \mathrm{~mm}$ diameter launch tube an a $300 \mathrm{~mm}$ diameter pump tube. The accelerator needed for the facility currently under consideration must have a 


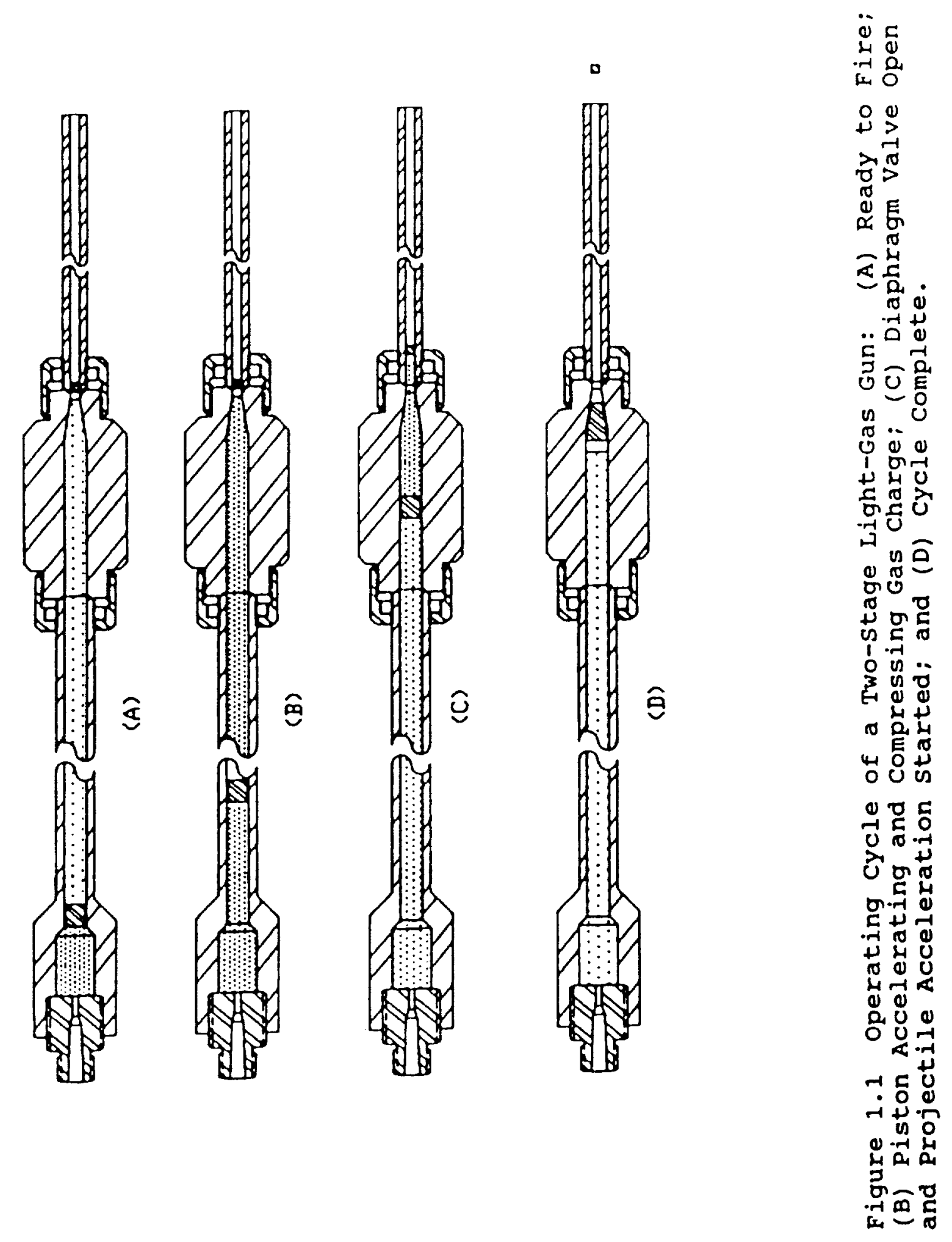


launch tube diameter some 3.13 times larger than that of the French gun. If the launcher is scaled from the French gun it will be 3.13 times as long and will weigh 30.5 times as much. Serious questions arise about whether a launcher of this size can be built using current technology and can be operated

effectively. A large portion of the remainder of this report treats that subject. As stated above, the first main issue considered by the remainder of this paper is the size requirements (or configurational needs) for a two-stage light-gas gun launcher that meets the acceleration requirements effectively. Questions considered are: the sizes and masses of various components, choice of a technology for powering the accelerator, evaluating performance expected from a point design, considering whether various components can be fabricated with currently available commercial sources, design of a mounting structure to support the gun and evaluating the feasibility of providing the various supporting functions that such a launcher may require. 


\section{TWO-STAGE LIGHT-GAS GUNS.}

\subsection{DETERMINING LIGHT-GAS GUN CONFIGURATION.}

\subsubsection{Computational Routines.}

We have used, as our principal design tool for sizing a required light-gas gun configuration, the computer program developed at General Motors Defense Research Laboratories (GMDRL) to predict operation of the second-largest two-stage light-gas gun ever built. (2) This gun has a pump tube diameter of $250 \mathrm{~mm}$ (10") and a variety of launch tube diameters up to $76 \mathrm{~mm}$ (3.0"). Thus, it is substantially smaller than the launcher contemplated in this study. Its predictive program should be accurate within small multiplicative corrections. A similar program developed by Arnold Engineering Development Center (AEDC) accounts for some factors such as heat-transfer to the bore walls which are expected to affect some important aspects of the calculation. NASA Langley obtained the program from AEDC and ran a few calculations to establish final gun parameters.

Basically, both programs use a method-of-characteristics scheme for solving differential equations of motion for the piston, the gas masses and the projectile package within a twostage light-gas gun. The piston is divided into several segments along its length so that effects of material compression may be considered. The walls of the gun are considered rigid. The gas is modeled with a viral equation-of-state which accounts for real-gas effects that develop when high densities are reached during later stages of compression cycles. A straightforward propellant burning analysis is used along with a viral equation of state for propellant burn products to model the piston-launch portion of the firing cycle.

The GMDRL code, in its current configuration, has several important limitations. The most vexing is that it locks up if the piston comes to rest during the launch cycle before it deforms its downstream end into the transition section between the pump tube and launch tube. A second problem is that the program has a history of over-predicting projectile package velocities by up to $15 \%$ when velocities are sought between 6.0 $\mathrm{km} / \mathrm{sec}$ and $7.0 \mathrm{~km} / \mathrm{sec}$. For this reason, we have assumed that launch velocities will reach only $85 \%$ of predicted values. (i.e. the program must predict muzzle velocities near $7.0 \mathrm{~km} / \mathrm{sec}$ for us to be sure that muzzle velocities of at least $6.1 \mathrm{~km} / \mathrm{sec}$ can be achieved. Note that the AEDC code is claimed to have no such discrepancy so velocity of $6.1 \mathrm{~km} / \mathrm{sec}$ were sought when using it.

\section{1 .2 Light-Gas Gun Configuration.}

Since the computer code was developed to predict the operation of a light gas gun much smaller than the one contemplated, we chose to start our analysis by verifying that performance of the code was independent of launcher dimensions as 
long as they were scaled linearly. We used the code to compare results of a $50 \mathrm{~mm}-16 \mathrm{~mm}$ light gas gun with those of a $75 \mathrm{~mm}-25 \mathrm{~mm}$ gun and a $113 \mathrm{~mm}-38 \mathrm{~mm}$ gun. Physics Applications has fabricated all of these guns and has convinced itself that their performance is relatable to one-another via linear scaling relationships. We considered launch of packages scaled linearly from the $250 \mathrm{~mm}$ diameter package weighing $14.0 \mathrm{~kg}$ to each of the size scales and we chose firing conditions which produced muzzle velocities near $6.1 \mathrm{~km} / \mathrm{sec}$. A substantial number of computational runs was required to establish piston launching parameters that matched one-another (since the propellant burn equation is strongly nonlinear). Results showed that muzzle velocity was reproduced with an accuracy better than 3\% across the size range investigated when peak piston velocities were equilibrated within $1.5 \%$.

We next considered the problem of variables to use during our investigation of gun geometry. The following is a listing of these variables together with notes discussing their importance.

\subsubsection{Launch Tube Length.}

It a truism to state that launch velocity of a gun is maximized by lengthening the launch tube. As a corollary, we should be able to design guns with gentler acceleration profiles if we use long launch tubes. Lengthening the launch tube is only effective, however, when performance increases significantly with launch tube length. obviously, launcher expense increases at least slowly with launch tube length and launcher useability reduces as the launch tube is lengthened since the gun structure becomes progressively more cumbersome. Therefore, a trade-off must be made on launch tube length with respect to optimizing launcher effectiveness.

\subsubsection{Pump Tube Diameter.}

The diameter of a pump tube relative to that of the launch tube has a profound effect upon launcher performance. Small ratios produce "anemic guns" which have difficulty achieving acceptable performance levels and only reach them with inefficient reservoir pressure profiles. A range of acceptable pump tube diameter ratios exists above the anemic range. Finally, launchers with unduly large pump tube diameters are hard to operate without producing unacceptable spikes in projectile base pressure profiles. clearly, the pump tube is a major element in determining both the cost and size of the launcher. Pump tube diameter affects both of these parameters in a very sensitive manner so that its proper selection becomes mandatory.

\subsubsection{Pump Tube Length.}

Length of the pump tube in comparison to its diameter controls directly the temperature of the gas during the critical high pressure portions of the firing cycle. Gas temperature, in 
turn, affects sound speed within the gas reservoir and the launch tube which controls directly motion of characteristic waves that transmit pressure between the reservoir and the projectile base. Gas temperature is also a principal factor in determining heat input to the walls of the transition section and upstream portions of the launch tube which cause surface "heat checking" if allowed to grow too large. Hence, gun heating becomes a relatively sensitive function of pump length. obviously, both the cost and the size of the launcher are affected significantly by pump tube length since the pump tube is, by far, the largest (and, possibly, most costly) component of the contemplated launcher.

\subsubsection{Transition Shape.}

Originally, the shape of the transition between the pump tube and the launch tube was thought to affect light-gas gun operation strongly. Experience has shown that almost any shape serves as well as any other. The most extreme shape tested thus far is a flat end. . . which worked well at AEDC. For this reason, we propose to use a transition shape that optimizes mechanical survival of the central breech. A cone has been chosen with an included angle of $40^{\circ}$ through use of results from an AEDC study which identified this geometry as producing the best compromise between gas pressure and piston deformation forces.

\subsubsection{Piston Mass.}

Mass of the compression piston affects the launch cycle in a fundamental manner since it determines directly the rate of gas compression and piston deceleration once high driver gas pressures are achieved. Piston mass is, perhaps, the easiest parameter to change from shot-to-shot to affect a two-stage launchers firing cycle other than initial driver gas pressure, piston kinetic energy, and projectile release pressure. Compression pistons are either wholly or partially expended during each firing so their cost can become a significant factor in establishing the overall cost of launcher operations.

\subsubsection{Geometry Selection for the Light-Gas Gun.}

We employed the computer program described in the first paragraph of this memo to search for appropriate sizes of components to be used with the launcher. The components sizes considered were: launch tube length, pump tube length, and pump tube diameter. We have chosen, at least for the moment, to set launch tube diameter at $250 \mathrm{~mm}$, projectile package mass at $14.0 \mathrm{~kg}$ and a launch velocity at $6.1 \mathrm{~km} / \mathrm{sec}$. We feel confident in our ability to scale the results of our investigation to treat other gun geometric parameters which may become interesting. We have also chosen to ignore piston launching considerations at this time (other than to develop piston velocity criteria) because they form a separate problem unto themselves. We choose instead 
to assume that pistons of appropriate mass can be launched in one way or another to appropriate velocities for our purpose. The remainder of the variables controlling light-gas gun operation can be adjusted from shot to shot. Therefore, they are treated as inputs to the problem. These variables include piston mass, hydrogen gas loading pressure, and projectile release pressure (burst pressure of the valve across the base of the launch tube). We took this step to keep the number of independent variables as

small as possible to relieve awkwardness in carrying out the next step to investigate dependence of launcher performance upon size and shape of the major gun components.

This geometry was used for each operation except that one variable was stepped through its range of potential values. At each step, the adjustable input variables are treated in a moreor-less systematic manner through 10-30 firings to determine optimum performance combinations for the launcher. We establish optimum performance as the lowest peak projectile base pressure that is calculated to produce a muzzle velocity of $7.0 \mathrm{~km} / \mathrm{sec}$ (an assorted actual projectile package velocity of $6.1 \mathrm{~km} / \mathrm{sec}$ ). We also monitor peak pressure predicted within the central breech. We feel that peak pressure levels must be maintained less than $680 \mathrm{MPa}$ (100 ksi) if reasonable launcher lifetime is to be maintained. Under any credible emergency, peak pressures within the central breech must be maintained below $1.0 \mathrm{GPa}(150 \mathrm{ksi})$ and the breech must not receive sensible damage from such an occurrence. Although enough shots are fired at each geometry considered to assure that at least near-optimum performance has been achieved, but no claim is made that an actual optimum has been discovered for each datum. For this reason, the graphs describing launcher performance should be looked upon as reasonably close approximations to optimized reality rather than as hard data. We feel, however, that all the important trends have been represented accurately.

A standard light-gas gun geometry was chosen for this study on the basis of our earlier efforts as follows:

- Launch Tube Length

- Pump Tube Diameter

- Pump Tube Length

- Projectile Release Pressure

- Piston Mass

- Launch Velocity Sought

(so that actual velocities

of at least $6.1 \mathrm{~km} / \mathrm{sec}$ can be achieved).

- Peak Reservoir Pressure Sought

- Peak Permissible Reservoir Pressure

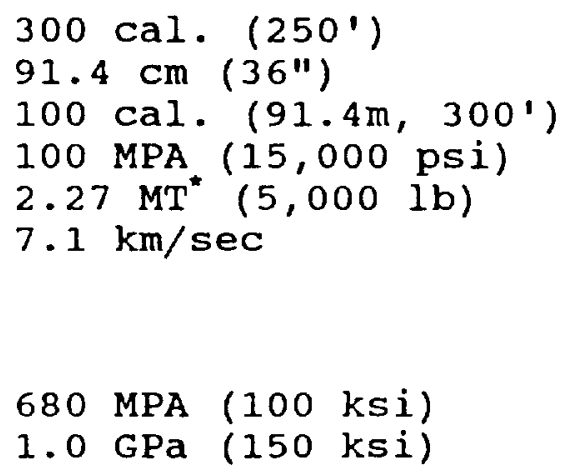

* For a $91.4 \mathrm{~cm}$ pump tube. Otherwise, piston mass is cube-root scaled to P.T. diameter. 
2.1.3.1 Optimum Pump Tube Diameter and Length.

The first study was aimed at determining the optimum diameter for the pump tube. We chose here to consider a very long launch tube ( $300 \mathrm{cal}$.$) plus a relatively light piston of$ $2.27 \mathrm{MT}(5,000 \mathrm{lbs})$. In Figure 2.1 , peak piston velocity is plotted against pump tube length expressed in calibers of its own diameter (aspect ratio) for a variety of pump tube diameters ranging from $81.3 \mathrm{~cm}\left(32^{\prime \prime}\right)$ to $112 \mathrm{~cm}\left(44^{\prime \prime}\right)$. We were struck by the relative consistency of piston velocity (and hence, required input energy to the launcher vs. pump tube aspect ratio when a $91.5 \mathrm{~cm}$ (36") diameter pump tube was chosen $\left(D_{p t} / D_{l t}=3.60\right)$. In Figure 2.2, peak base pressure experience by the model (in psi) is plotted vs. pump tube aspect ratio for the same range of pump tube diameters. Note that results for all piston bore diameters are bunched fairly closely at an aspect ratio of $L_{p t} / D_{p t}=100$ and trended downward slowly beyond that point. Figure $2.3^{\mathrm{t}}$ contains plots of peak reservoir pressure in psi vs. pump tube length (aspect ratio) for the pump tube diameters being considered. Pump tubes with diameters of $91.5 \mathrm{~cm}$ (36") and aspect ratios near 100 require the lowest peak driver gas pressure to produce acceptable peak reservoir pressures.

on the basis of this first study, we have chosen to continue our investigation assuming that the pump tube has a diameter of $91.5 \mathrm{~cm}$ (36") and an aspect ratio of 100 (i.e. $91.5 \mathrm{~m}, 300 \mathrm{ft}$ long). This decision was made on the basis of the data which indicates it is entirely acceptable and that the dimensions are not critical to success of the project. Also considered is the fact that 0.916 (36") pump tube diameter is nearly the upper limit of feasible fabricatability using available technology.

\subsubsection{Launch Tube Length.}

These dimensions were used for the next part of the effort where launch tube length was investigated. Here, standard parameters were employed to determine the minimum velocity of a $2.27 \mathrm{MT}(5,000 \mathrm{lb})$ piston which would provide a nominal launch velocity of $7.1 \mathrm{~km} / \mathrm{sec}$. Results are presented in Figure 2.4 . Critical piston velocity needed to achieve desired performance falls rapidly with increasing launch tube lengths up to $300 \mathrm{cal}$.. Furthering increases in launch tube length produce no significant further reductions. On the basis of this result, a launch tube aspect ratio of 300 was chosen $\left(75 \mathrm{~m}, 250^{\prime}\right)$ even though it is considerably longer than current practice because large values of launch tube aspect ratio can be achieved with less cost and inconvenience than almost any other major gun geometry available. The result from Figure 2.4 is supported massively by results presented in Figure 2.5 where maximum reservoir pressure is plotted vs. launch tube length for the same geometrical

parameters. Note that pressure falls monatomically and rapidly with increasing launch tube aspect ratio until an aspect ratio of 300 is reached and then continues its fall more slowly as this aspect ratio is exceeded. The curve also shows that we require a 


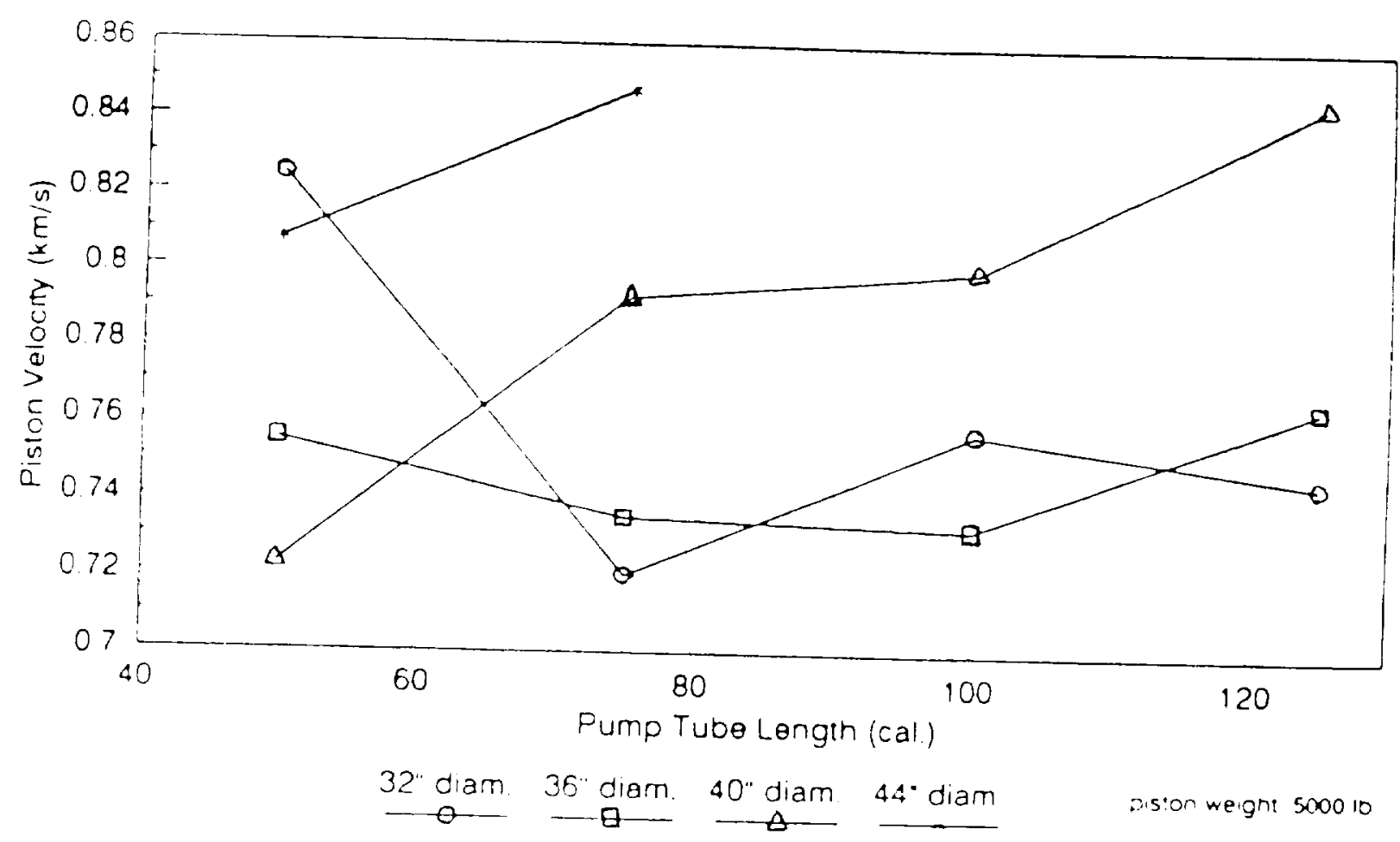

Figure 2.1 Piston Velocity vs. Pump Tube Length for Various Pump Tube Diameters.

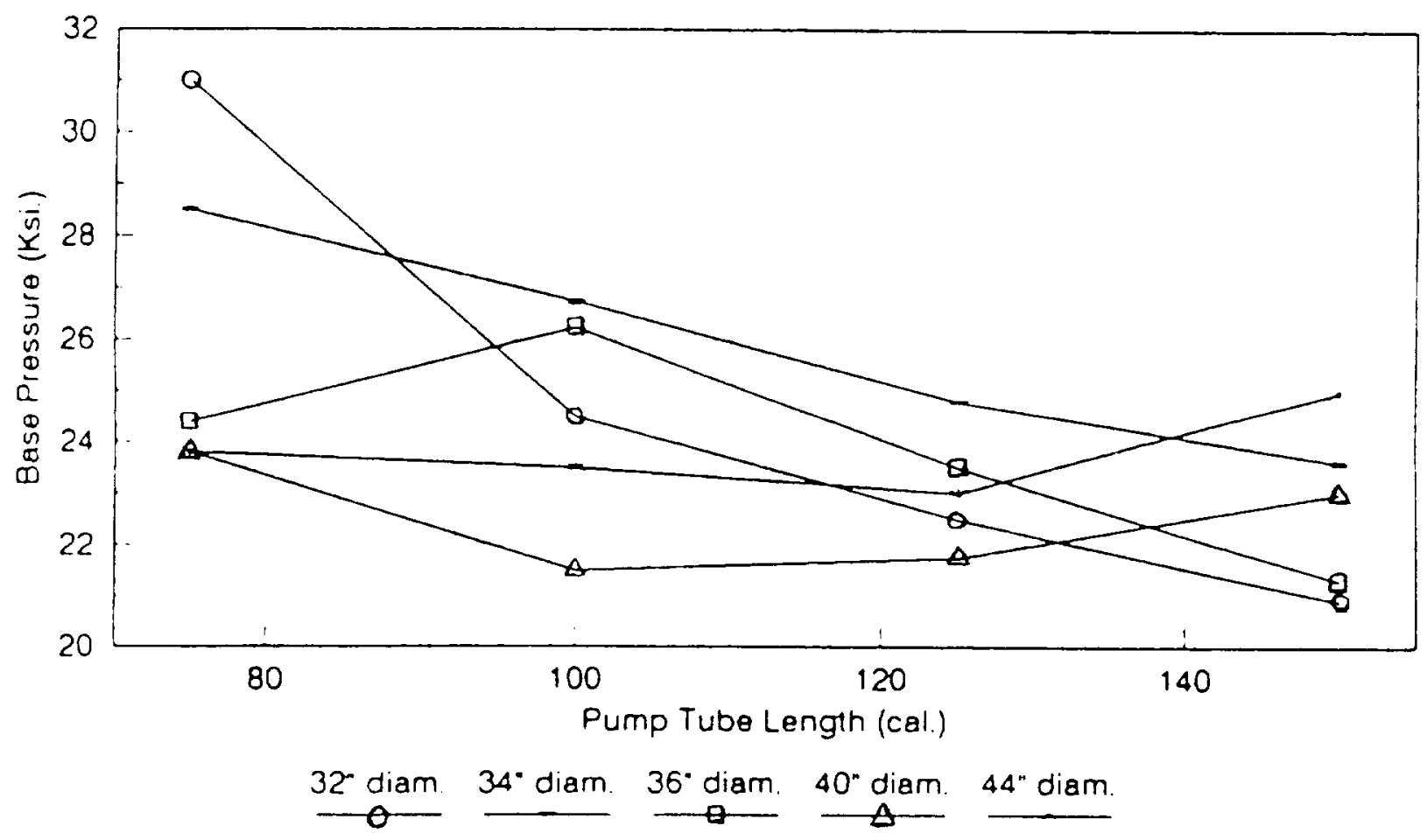

Dision weignt 5000 to

Figure 2.2 Peak Model Base Pressure vs. Pump Tube Length for Various Pump Tube Diameters. 


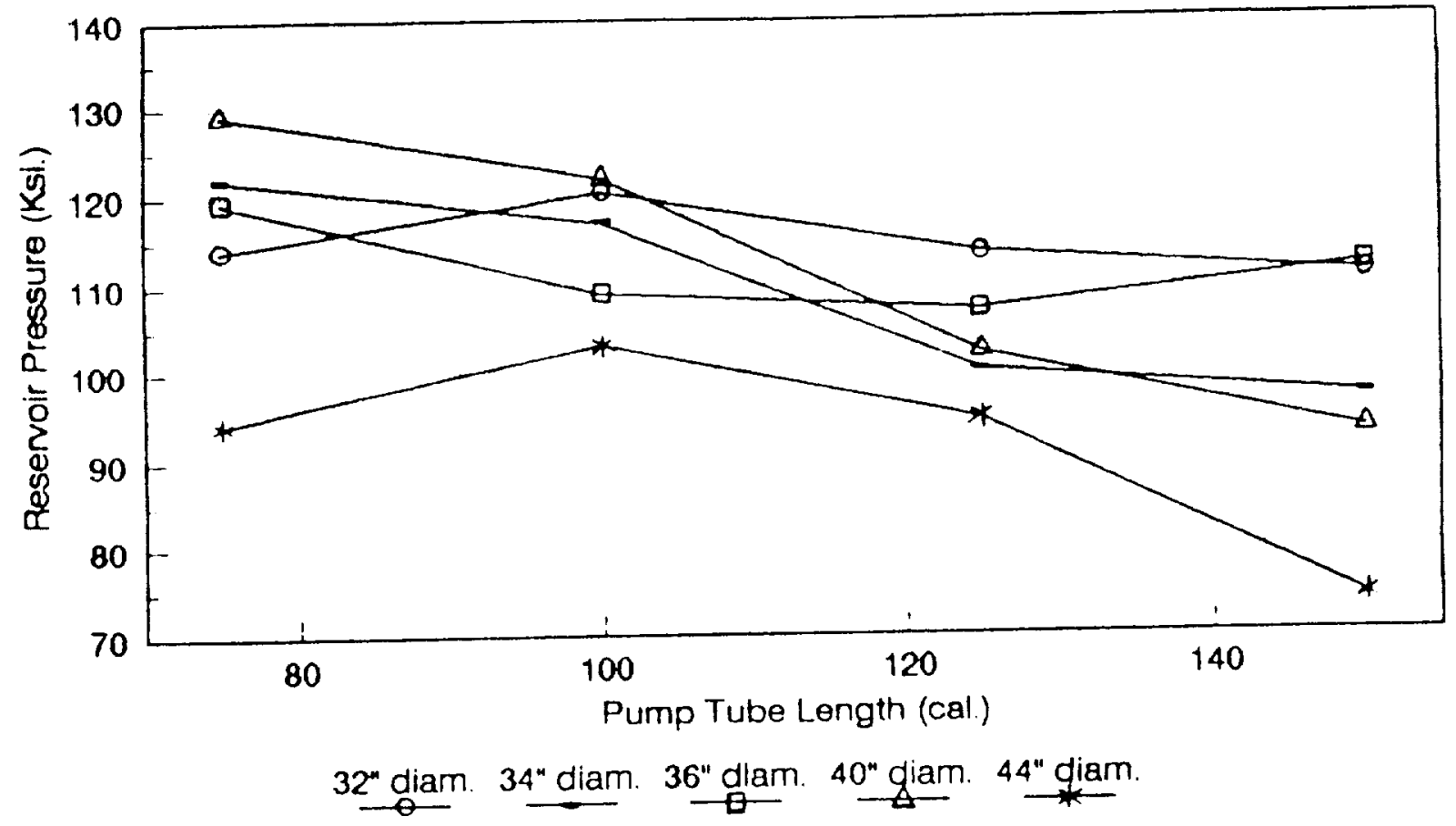

Figure 2.3 Peak Reservoir Pressure vs. Pump Tube Length for Various Pump Tube Diameters.

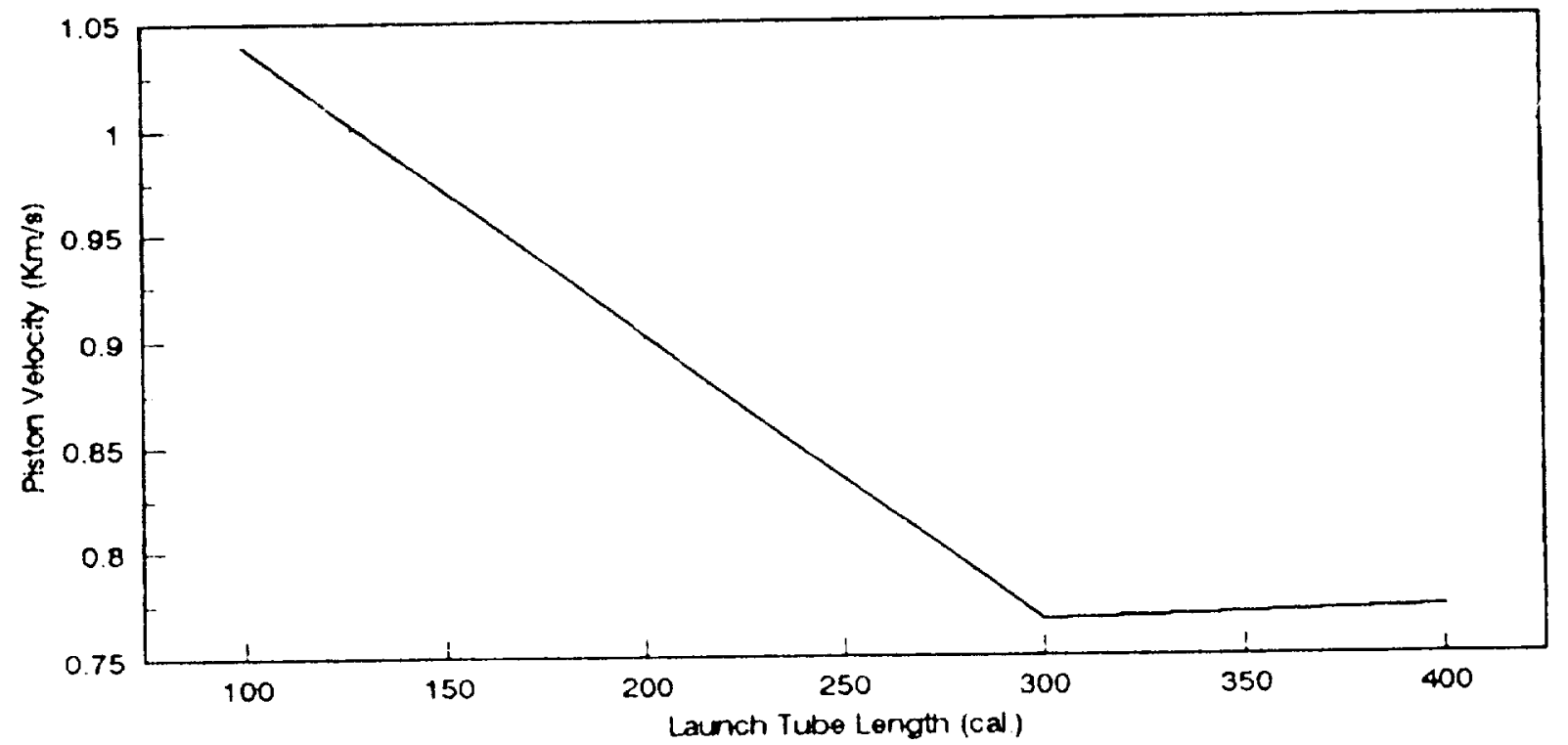

Muno lutie benght: $75 \mathrm{ce}$

piston weight: 5000 th

prston dien: : 36"

Figure 2.4 Peak Velocity Required for a standard Piston vs. Launch Tube Length Required to Reach Nominal Launch Conditions. 


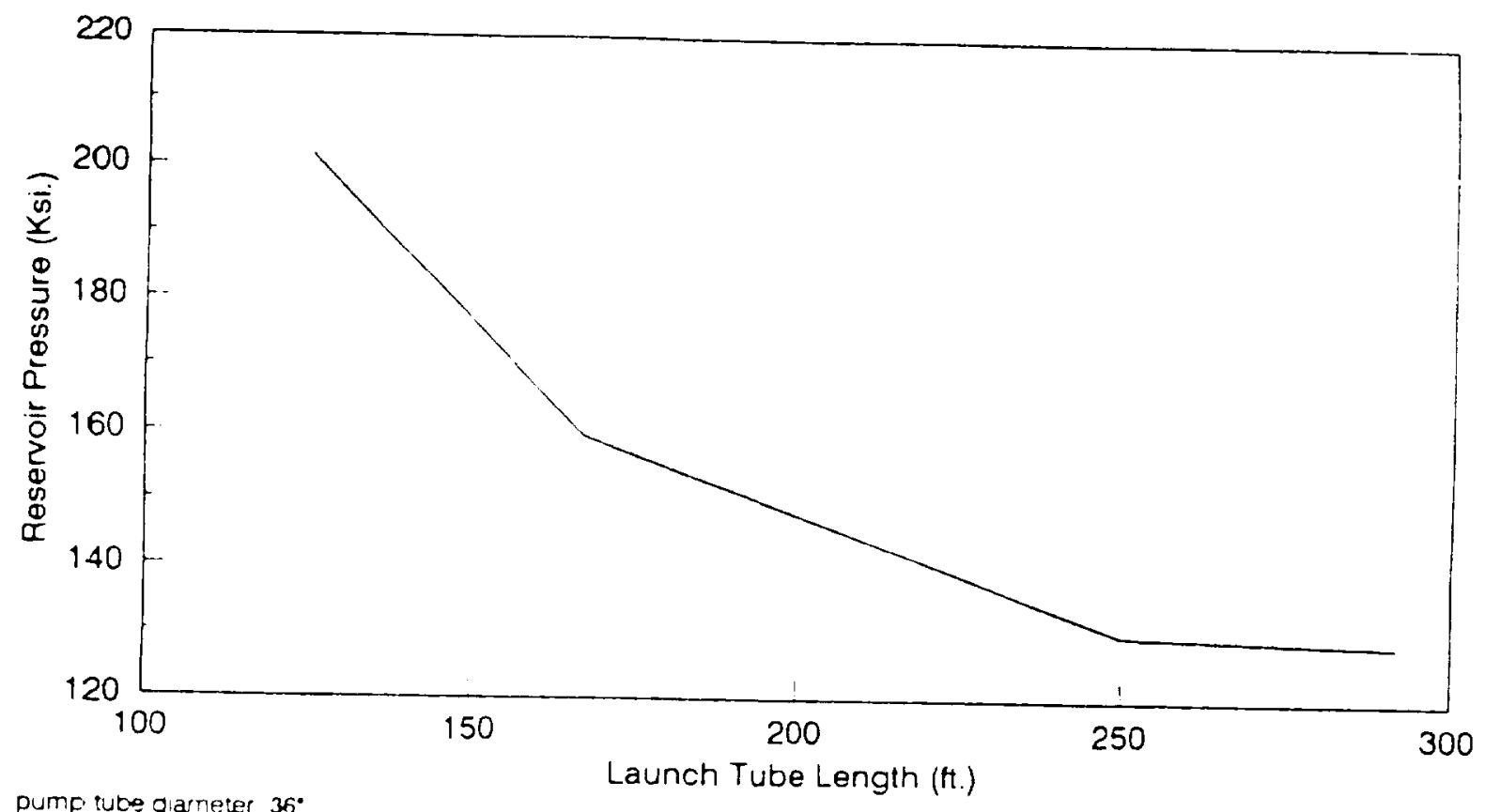

pumf tube dianeter $36^{\circ}$

pistori wergnt $5000 \mathrm{ll}$

Figure 2.5 Peak Reservoir Pressure Required to Produce Standard Performance vs. Launch Tube Length for the Standard Light-Gas Gun Configuration.

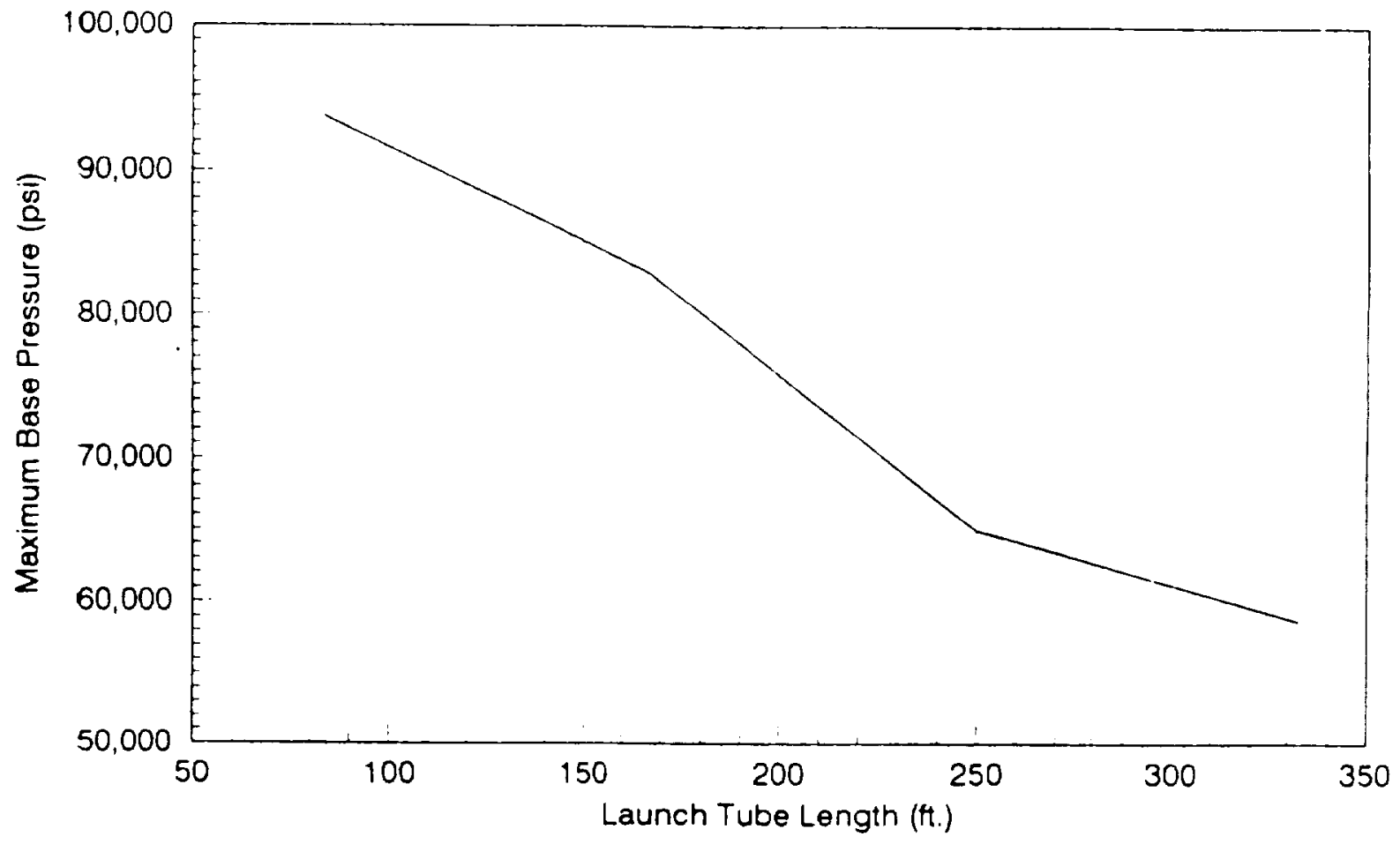

Figure 2.6 Peak Model Base Pressure vs. Launch Tube Length for the Standard Light-Gas Gun Configuration. 
launch tube aspect ratio of 300 to just meet our boundary condition that peak reservoir pressure be maintained below 150,000 psi. Figure 2.6 continues this argument. Maximum base pressure on the model is plotted as a function of launch tube aspect ratio. Again, maximum base pressure falls rapidly with increasing launch tube length until an aspect ratio of 300 is reached and then falls only slowly for larger aspect ratios.

\subsubsection{Estimated Mass-Throwing Capability.}

The final question to be considered in this portion of the study is the mass-throwing capability of the launcher. Peak performance capability was considered for several projectile package masses between $14.0 \mathrm{~kg}$ (the standard) and $100 \mathrm{~kg}$. The results are presented in Figure 2.7 . The results indicate that the launcher becomes somewhat more efficient as progressively heavier projectile packages are considered. A curve of constant launcher efficiency (constant projectile kinetic energy) is presented for comparison.

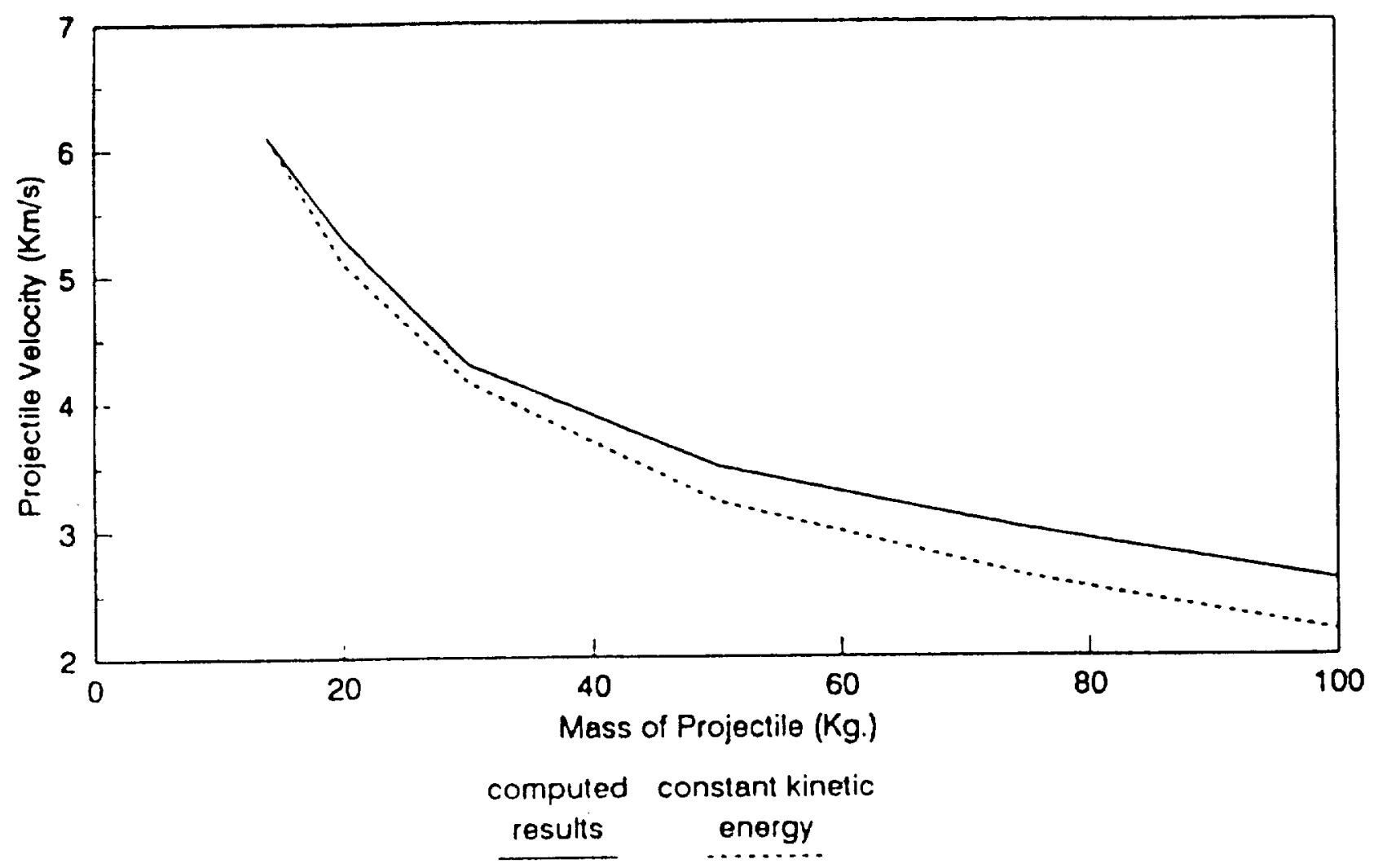

Figure 2.7 Projectile Mass-Throwing Capability of the standard Light-Gas Gun Configuration. 


\subsection{LIGHT-GAS GUN DESIGN.}

\section{2 .1 Introduction.}

In paragraph 2.1.2, theoretical trade-off studies were reported which indicated the way toward an optimum configuration for a $250 \mathrm{~mm}$ light-gas gun launcher capable of projecting $14.0 \mathrm{~kg}$ payloads to peak velocities above $6.1 \mathrm{~km} / \mathrm{sec}$. A major effort was made to depress peak acceleration levels to their lowest possible values so that relatively delicate model/sabot packages could be launched without damage. The results were quite encouraging but they specified a gun of gargantuan proportions. Its critical parameters are presented in Table 2.1 .

TABLE 2.1 LIGHT-GAS GUN DIMENSIONS AND RELATED DATA.

- Pump Piston $M_{p t}=2268 \mathrm{Kg}$

$\mathrm{U}_{\mathrm{pt}}^{\mathrm{pt}}=750 \mathrm{M} / \mathrm{sec}$.

$E_{p t}^{p t}=637.6 \mathrm{MJ}$.

- Pump Tube $d_{p}=0.915 m$ (36")

$l_{p}^{p}=100 d_{p}=91.5 \mathrm{~m}(300 \mathrm{ft}$.
$v_{p t}^{p}=60.17 \mathrm{~m}^{3}$
$P_{\text {load }}=680 \mathrm{KPa}(100 \mathrm{psi})$
$\mathrm{N}_{\text {load }}=17,250$ moles $(69.0 \mathrm{Kg})$

- HP Section $\theta_{\text {cone }}=40^{\circ}$

$\mathrm{p}_{\max }=1.0 \mathrm{GPa}(150 \mathrm{ksi})$

$\mathrm{P}_{\text {entrance }}=100 \mathrm{MPa}(15 \mathrm{ksi})$

- Launch Tube $d_{1 t}=250 \mathrm{~mm}$ (10")

$$
l_{l t}=300 d_{l t}=75 \mathrm{~m}(250 \mathrm{ft} .)
$$


Thus, the total launcher may be expected to have a length of somewhat over $170 \mathrm{~m}$ (560 ft.). Results presented later in this chapter indicate that its minimum mass must be near 678 MT as presented in Table 2.2 .

TABLE 2.2 MASSES (AND WEIGHTS) OF THE CONTEMPLATED LIGHT-GAS GUN COMPONENTS.

GAS CHAMBER

weight (lbf) wass (MT)

$$
\begin{array}{r}
\text { tanks (4) } \\
\text { discs (5) } \\
\text { manifolds (4) } \\
\text { sleeve } \\
\text { breech } \\
\text { breech plug } \\
\text { sub total }
\end{array}
$$

PUMP TUBE

CENTRAL BREECH

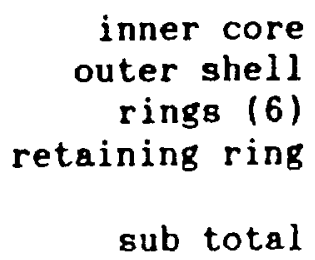

inner core

outer shell

rings (6)

retaining ring

sub total

LAUNCH TUBE

GRAND TOTAL
115939.41

35963.55

27558.63

7953.88

10481.86

4589.40

202486.73

61134.76

22023.45

203845.82

3172.92

290176.95

387771.30
175.86

678.12

52.24

16.31

12.50

3.61

4.75

2.08

91.49

279.17

27.73

9.99

92.45

1.44

131.60 
The clear question which must be raised is: "Can a gun of this size and shape (or variations of it) be built using current manufacturing technology." clearly, the sizes of many of its components are near the upper limits of available fabrication facilities. Absolute dimensions of the proposed launcher appear to be within these limits but problems exist concerning component masses. Thus, the fabricatability of the proposed light-gas gun will be determined by success in conceiving individual components with masses within current handling limitations.

Three subsidiary questions must also be considered in determining an appropriate design for such a large launcher.

- (1) "How is the piston to be launched"?

- (2) "What is a practical gun configuration"?

- (3) "Can an effective mounting arrangement be developed that will allow gun components to be handled conveniently while providing necessary support and alignment rigidity"?

The remainder of this chapter addresses these questions.

\subsubsection{Piston Launching Considerations.}

\subsubsection{Solid Propellant.}

Virtually every two-stage light-gas gun built to date operates with solid propellant as the power source for launching its piston so this was the first means for propulsion considered here. Many years ago, Frankford Arsenal (F.A.) in Philadelphia, PA. developed a series of normalized curves for estimating geometry and propellant requirements for launching projectile payloads from normal guns. (3) The normalization feature allows these curves to be applied to guns of virtually any size. The mass/velocity regime was limited to that of interest to ordnance activities. Although the piston mass under consideration is near the lower limit of ordnance interest, (the piston weighs only as much as a steel slug whose length is $38 \%$ of its diameter) the velocity is within the central zone of interest. The curves should give a close approximation of the propellant mass required. One curve of the F.A. series is presented in Figure 2.8. It shows that a velocity of $0.75 \mathrm{~km} / \mathrm{sec}$ can be achieved with normal gun geometry if the propellant mass is one-third that of the projectile $(756 \mathrm{Kg}=1,670 \mathrm{lb})$. Since most chemical propellant has a specific energy density near $4.4 \mathrm{MJ} / \mathrm{Kg}$. , energy release from burning a charge of this mass is near $E_{c}=3.34 \mathrm{GJ}$. Thus, a powder gun of this configuration would produce an efficiency near $19.1 \%$ when launching the standard piston $\left(E_{p t}=\right.$ $637.6 \mathrm{MJ}$.$) . The specific curve presented is for a peak gun$ chamber pressure of $400 \mathrm{MPa}(60,000 \mathrm{psi})$, but similar curves showing similar results exist for other pressures in the same general region.

One point not addressed by the Frankford Arsenal curves is the burning rate properties of the propellant. Propellant burning rate (surface recession rate, $x$ ) for almost all homogeneous propellant is specified by Equation 2.1 . 


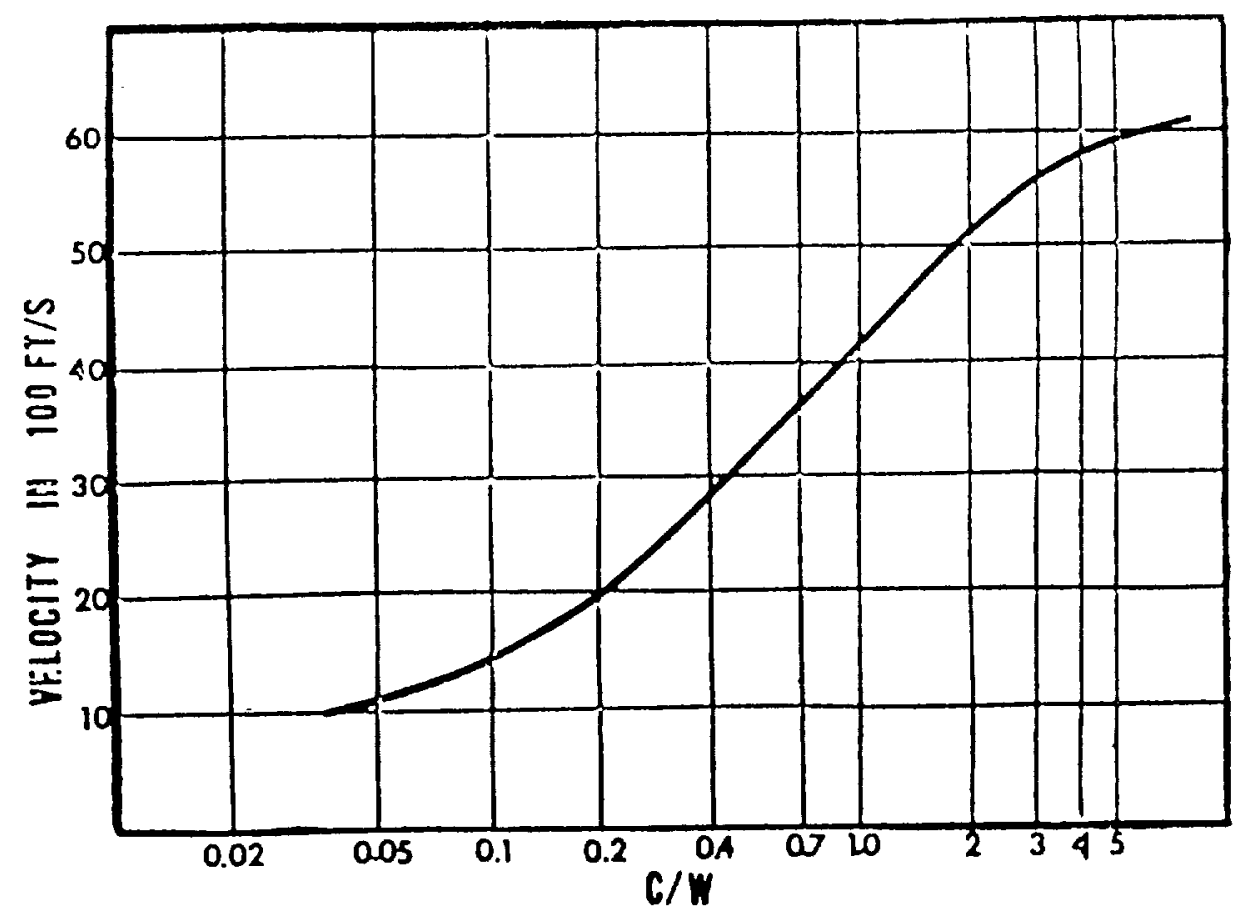

Figure 2.8. Frankford Arsenal Curve for a Typical Gun Configuration Presenting Muzle Velocity as a Function of Propellant Charge Mass (Normalized to Projectile Mass).

$$
\dot{x}=C_{1} P^{C_{2}}
$$

where:

$\mathrm{P}=$ chamber pressure; and

$c_{1}, c_{2}=$ burning rate constants (dependent upon propellant chemistry and surface preparation).

Gas evolution rate from a propellant bed, $\dot{m}$, can be derived from Equation 2.1 plus propellant shape factors as is presented in Equation 2.2.

$$
\dot{m}=n_{g} A_{g}(t) x=n_{g} A_{g}(t) C_{1} P^{c_{2}}
$$

where:

$$
\begin{aligned}
& \mathrm{n}_{\mathrm{g}}=\text { Number of propellant grains; } \\
& \mathrm{A}_{\mathrm{g}}(\mathrm{t})=\text { Surface area of a typical grain (as a function of } \\
& \text { time). }
\end{aligned}
$$

Clearly, propellant gas mass evolution rate is a principal factor controlling gas pressure profile during any normal gun launch. Since the burn rate coefficients, $c_{1}$ and $c_{2}$ are nearly 
identical for most propellant materials, grain geometry is the main factor controlling the entire launch process. Proper propellant burning produces a curve of nearly minimum piezometric ratio for the launch cycle. The Frankford Arsenal curves are all configured under the assumption that propellant burning rate is optimum. If the propellant burns too slowly, it is not consumed efficiently and kinetic energy of the projectile suffers. If the burning rate is too large, the gun may operate very efficiently but peak pressure exceeds its designated value. The problem here is that no solid propellant configuration is currently available with a sufficiently low burning rate for a gun the size of the proposed pump tube. For this reason, overly fast propellant must be specified which means that the peak chamber pressure must exceed that specified and the chamber must be designed to withstand launch pressures considerably above values specified in the F.A. curves. We estimate that pressures 1.5 times larger than those specified will be needed if propellant for sixteen-inch Naval guns can be acquired.

These two limitation (requirement for 1,660 lbs."* of propellant per firing; and peak propellant pressures near $600 \mathrm{MPa}$ $=90,000$ psi) effectively preclude use of solid propellant for a gun of the size under consideration.

\subsubsection{Gas Combustion.}

The next technology considered was burning of a fuel/gas mixture to propel the compression piston. When a fuel/gas mixture is ignited and burns stoichiometrically"**, a pressure increase up to a factor of 10-12 may be produced. This pressure comes about through intense heating of the burn products by the energy of chemical reaction so the burn products are very hot.

Let us consider burning of methane $\left(\mathrm{CH}_{4}\right)$ in air. The controlling equation for burning a single mole of methane is presented as Equation 2.3.

- Piezometric ratio: Ratio of peak projectile base pressure to its value averaged along the launch tube.

*" Both safety and storability of large masses of powder propellant become extreme obstacles for effective facility operation when very large masses must be considered.

*** stoichiometric chemical process: one where amounts of the active chemicals are balanced so that all of them are just consumed during the reaction (and maximum energy is emitted/absorbed). 


$$
\mathrm{CH}_{4}+3 \mathrm{O}_{2}+12 \mathrm{~N}_{2} \rightarrow \mathrm{CO}_{2}+2 \mathrm{H}_{2} \mathrm{O}+12 \mathrm{~N}_{2}+890.7 \mathrm{KJ}
$$

The pressure increase can be evaluated for the limiting conditions of perfect gas by evaluating the volume required to house the members on the left side of Equation 2.3 for some initial temperature and pressure and using the basic relationship between energy content and volume of a perfect gas presented in Equation 2.4.

$$
E=\frac{\delta P V}{\gamma-1} ; \quad \delta P=\frac{(\gamma-1) E}{V}
$$

where:

$E$ = energy added to a closed system;

$\delta \mathrm{P}=$ gas pressure increase

$\gamma=$ ratio of specific heats of the resultant gas

$\mathrm{V}=$ fixed chamber volume.

The most straightforward initial conditions to conduct this evaluation is to consider the volume occupied by the gases on the left-hand side of Equation 2.3 when they are at room temperature and pressure. A total of 16 moles of gas at standard temperature and pressure $\left(\mathrm{T}_{0}=273^{\circ} \mathrm{K} ; \mathrm{P}_{0}=0.1 \mathrm{MPa}\right)$ require a volume of $0.02240 \mathrm{~m}^{3} / \mathrm{mole} \times 16 \mathrm{moles}=0.3584 \mathrm{~m}^{3}$. Thus, the reference volume is: $V=0.3584 \mathrm{~m}^{3}$. The value for the composite ratio of specific heats, $\gamma$, of the burn products is $\gamma=1.36\left(\gamma_{\text {CO2, }}{ }_{\text {H2O }}=1.2\right.$; $\left.\gamma_{N 2}=1.4\right)$. Equation 2.4 may now be used to evaluate the pressure rise from burning the methane stoichiometrically under these conditions as $\delta P=0.8947 \mathrm{MPa}$. Since the original pressure was $\mathrm{P}_{0}=0.100 \mathrm{MPa}$, the final pressure is $\mathrm{P}_{0} \mathrm{t} \delta \mathrm{P}=.9947 \mathrm{MPa}$ which is, essentially ten times the original pressure. Since the process is conducted at constant volume, the ideal gas law equation (presented as Equation 2.5) may be used to evaluate a limiting approximation of the final gas temperature.

$$
\frac{P_{0} V_{o}}{T_{o}}=\frac{P_{f} V_{f}}{T_{f}}
$$

where:

subscript, o denotes pre-burn conditions; and subscript, f denotes post-burn conditions.

Since $V_{0}=V_{f}$, the final temperature becomes:

$$
T_{t}=T_{0} P_{f} / P_{0}
$$

If $\mathrm{T}_{0}=295^{\circ} \mathrm{K}$, the final temperature is near $\mathrm{T}_{f}=2950^{\circ} \mathrm{K}$. 
Later computations indicate that a chamber volume near

$\mathrm{V}_{c}=12.5 \mathrm{~m}^{3}$ charged to an initial pressure near $10.0 \mathrm{MPa}(1500$

psi) is required to launch the piston to its required velocity

(after burning has increased gas pressure to $100 \mathrm{MPa}, 15,000$

psi). The perfect gas equation-of-state can be used to evaluate

the amount of gas required:

$$
P_{0} V_{0}=n R T_{0} ; \quad n=\frac{P_{0} V_{0}}{R T_{0}}
$$

where:

$\mathrm{n}=$ total number of moles loaded;

$\mathrm{R}=8.314 \times 10^{7}=$ Universal gas constant (CGS units) ;

$\mathrm{P}_{0}=10^{8} \mathrm{dyn} / \mathrm{cm}^{2} ; \mathrm{V}=12.5 \times 10^{6} \mathrm{~cm}^{3} ; \mathrm{T}_{0}=295^{\circ} \mathrm{K}$

For these conditions, the number of moles to be loaded

is $\mathrm{n}=50,970$.

Since the left side of Equation 2.3 shows 16 moles ( 1 of $\mathrm{CH}_{4} ; 3$ of $\mathrm{O}_{2}$; and 12 of $\mathrm{N}_{2}$ ), only $\mathrm{n} / 16=3,185$ moles of $\mathrm{CH}_{4}$ must be loaded into the gun. Since each mole provides $890.7 \mathrm{~kJ}$ of energy (as presented in Equation 2.3), the total energy release during burning of the gas charge is $E_{r}=890.7 \times 3,185=2.837$ GJ. Since the desired kinetic energy of the piston is $637.6 \mathrm{MJ}$, the launcher is expected to operate at an efficiency of $E_{c o m p}=$ $22.4 \%$ (which is comparable to the expected efficiency of the gun powered by conventional solid propellant, $E_{p t}=19.18$ ).

Is this efficiency reasonable? It is if the speed-of-sound in the gas within the reservoir is above the desired peak piston velocity $\left(U_{p}=0.75 \mathrm{~km} / \mathrm{sec}\right)$. Gas sound speed within the reaction chamber, $a_{0}$, can be evaluated approximately according to Equation 2.8 by assuming that the gas is perfect.

$$
a_{\circ}=\sqrt{\frac{\gamma R T}{m}}
$$

where:

$$
\begin{aligned}
\gamma= & 1.36, \text { ratio of specific heats for the composite burn } \\
\text { products; } & \\
\mathrm{T}= & 2950^{\circ} \mathrm{K} \text { as evaluated using Equation } 2.6 \text {; and } \\
\mathrm{m}= & 16.5 \mathrm{gm} / \mathrm{mole}, \text { composite value for the identified burn } \\
& \text { products. }
\end{aligned}
$$

The result is that $a_{0}=1.422 \mathrm{~km} / \mathrm{sec}$ which is nearly twice its minimum value of $U_{p i}=750 \mathrm{~m} / \mathrm{sec}$.

Two problems afflict the use of gas combustion for driving the piston of the contemplated light-gas gun. First, the chemical reaction may occur through deflagration or detonation. Each has its problems. When fuel air mixtures react through deflagration, the reaction front proceeds along a thermal boundary between the unreacted and reacted regions within the 
chamber containing the gas at speeds as low as a few tens of centimeters per second. (4) This low speed requires that the propellant be ignited nearly simultaneously at a vast number of points within a large chamber so that the combustion energy may become available quickly enough to make the gas mixture serve as an effective piston propellant. Typically, the energy should be available within 0.1 sec. after ignition which means that all ignition points can be separated from each other by distances averaging only a few centimeters.

Alternatively, the mixture may detonate. . . where the reaction occurs across a shock front that propagates through the unburned gas mixture at multiple kilometers-per-second. The energy becomes available in times short enough to make the gas mixture effective for projectile launching but the burn products are accelerated by the shockwave and collide violently with the chamber walls. Pressure multiplications may range up to factors of more than 8 above the nominal increase calculated using Equation 2.4 so the chamber must be designed to withstand pressures in the order of 10 times those required for piston launching (near $1.0 \mathrm{GPa}, 150 \mathrm{Ksi}) .^{(4,5)}$

The resulting chamber designs are clearly out of the question for a launcher of the size contemplated, so a difficult problem presents itself to the gun designer. He must build a complex system for igniting the gas at many points within the volume of a chamber to allow deflagration to operate effectively. simultaneously he must reduce probability of gas detonation to negligible since gas detonation would burst the gas-containment vessel. Experimentation has been conducted on fuel/gas mixtures which indicate a good chance of designing a system safe from detonation if methane/air mixtures are considered. (4)

Unfortunately, introduction of even trace amounts of heavier hydrocarbons, such as ethane and propane, increase probability of detonation markedly. (4) The only effective source of the massive amounts of methane required for a very large gun is mains gas (used for industrial and household heating). In the Eastern portion of the United States, such gas is contaminated substantially with ethane at all times and may contain significant amounts of propane from time to time. For these reasons, we have chosen to eliminate burning fuel/gas mixtures as a candidate for piston launching.

\section{2 .2 .3 Gas Compression.}

The final candidate for powering the light-gas gun is simple compressed gas (with adequate sound speed available). A chamber of gas under high pressure is released behind a compression piston which is accelerated to its appropriate velocity along the rear portions of the pump tube within the light-gas gun. Such acceleration is achieved efficiently when the piston is launched to valooitlon below mound apeed in the gan ohamber. Under these conditions, pressure drops along the launch tube can be maintained within reasonable values as is shown in Equation 2.9. 


$$
P_{b}=P_{r e}\left[1+\frac{(\gamma-1) U_{p_{1}}{ }^{2}}{2 a^{2}}\right] \frac{-\gamma}{(\gamma-1)}
$$

where:

$\mathrm{P}_{\mathrm{b}}=$ pressure at the base of the projectile package;

$\mathrm{P}_{\text {re }}=$ reservoir pressure;

$\gamma=$ ratio of specific heats;

$\mathrm{U}_{\mathrm{pi}}=$ projectile velocity; and

$a^{p}=$ sound speed in the reservoir.

Large pressure differentials develop as the piston velocity exceeds sonic velocity in the reservoir with resulting gross loss of mechanical efficiency as can be seen from the plot of $\mathrm{P}_{\mathrm{b}} / \mathrm{P}_{\mathrm{re}} \mathrm{vs}$. $\mathrm{U}_{\mathrm{pi}} / \mathrm{a}$ presented in Figure 2.9. The required piston launch velocity of $0.75 \mathrm{~km} / \mathrm{sec}$ exceeds by a substantial amount the sound speeds of many normal gases at room temperature so only gases with unusually high sound speeds (unusually low molecular weights) are effective for such a purpose. The only two viable candidates are hydrogen and helium. Hydrogen may be eliminated without much further consideration because the vast amounts required produce an explosive hazard at a level impossible to handle in almost any conceivable facility. Helium, on the other hand, is also effective, although it has some problems of its own. Its outstanding advantage is its chemical inertness which eliminates danger from chemical explosion or fire. It is relatively expensive especially when considered in the amounts required for this effort. Its high ratio of specific heats of $\gamma=1.67$ increases substantially the amount of electro-mechanical energy required to compress the helium while decreasing its effectiveness for driving pistons.

The concept chosen here to contain cost of the helium involves retaining the helium within the light-gas gun during each firing cycle and recovering it for reuse so that most of the gas charge may be used over and over again as the facility is exercised. This approach allows the helium charge to be treated as a semi-expendable component which can be replaced at only a slow rate.

The problem of gas compression is also containable. We have used the AEDC computer program for evaluating light-gas gun performance to evaluate the size chamber needed to drive the standard piston hard enough for producing the required projectile package launch velocity when the chamber is charged to an initial pressure of $100 \mathrm{MPa}(15,000 \mathrm{psi}) .{ }^{(2)}$ (This pressure is the current threshold between conventional gas compression for industrial applications and exotic compressions for scientific purposes. Several acceptable launch cycles were discovered which required chamber volumes of $V_{c} \leq 12.5 \mathrm{~m}^{3}$ so this value was chosen for further consideration. $A^{c}$ plot of projectile acceleration vs. position along the launch tube which is proportional to base pressure $(33,500 \mathrm{psi}=85.2 \mathrm{Kg} / \mathrm{s})$ is presented in Figure 2.10 . 


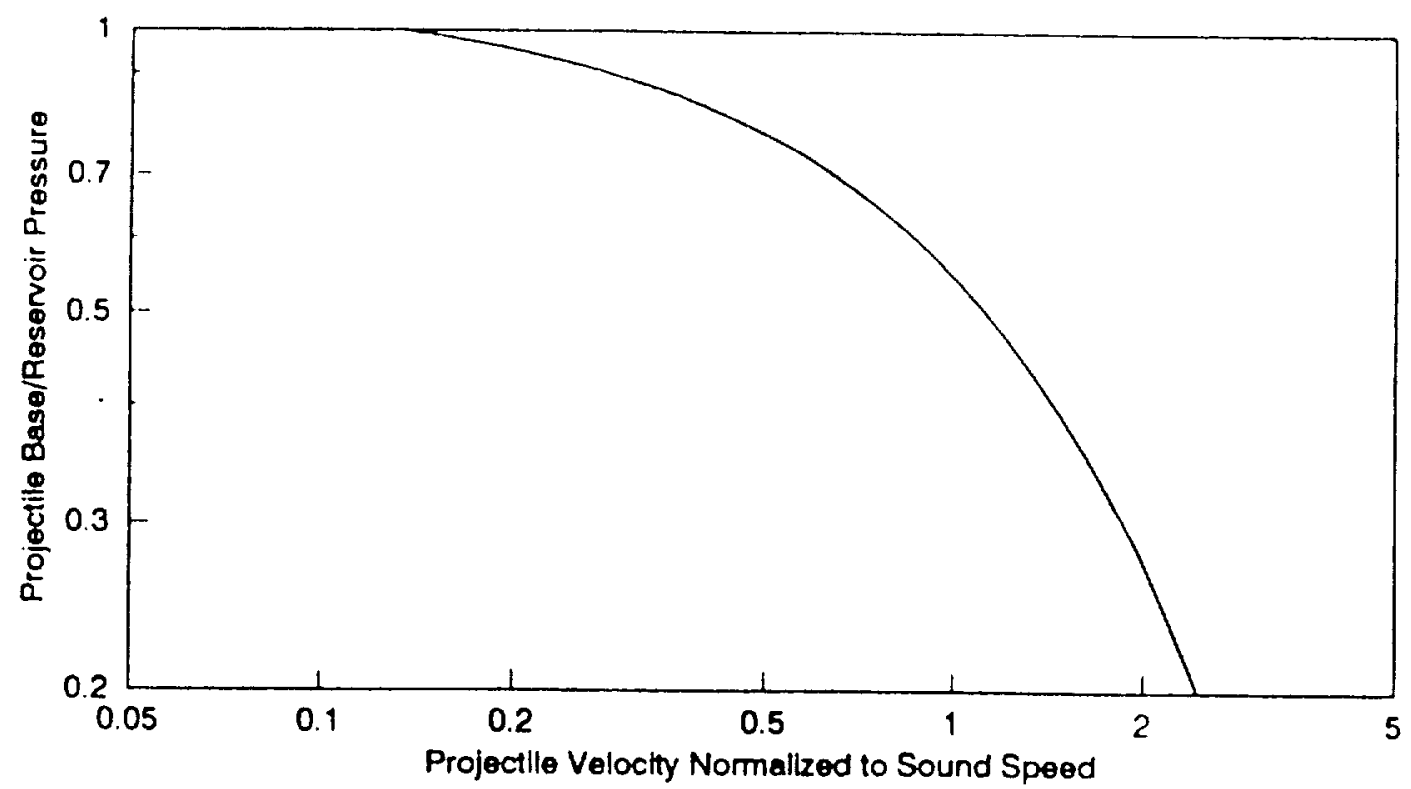

Figure 2.9 Reduction of Projectile Base Pressure Caused by Projectile Velocity as Calculated Using Equation 3.9.

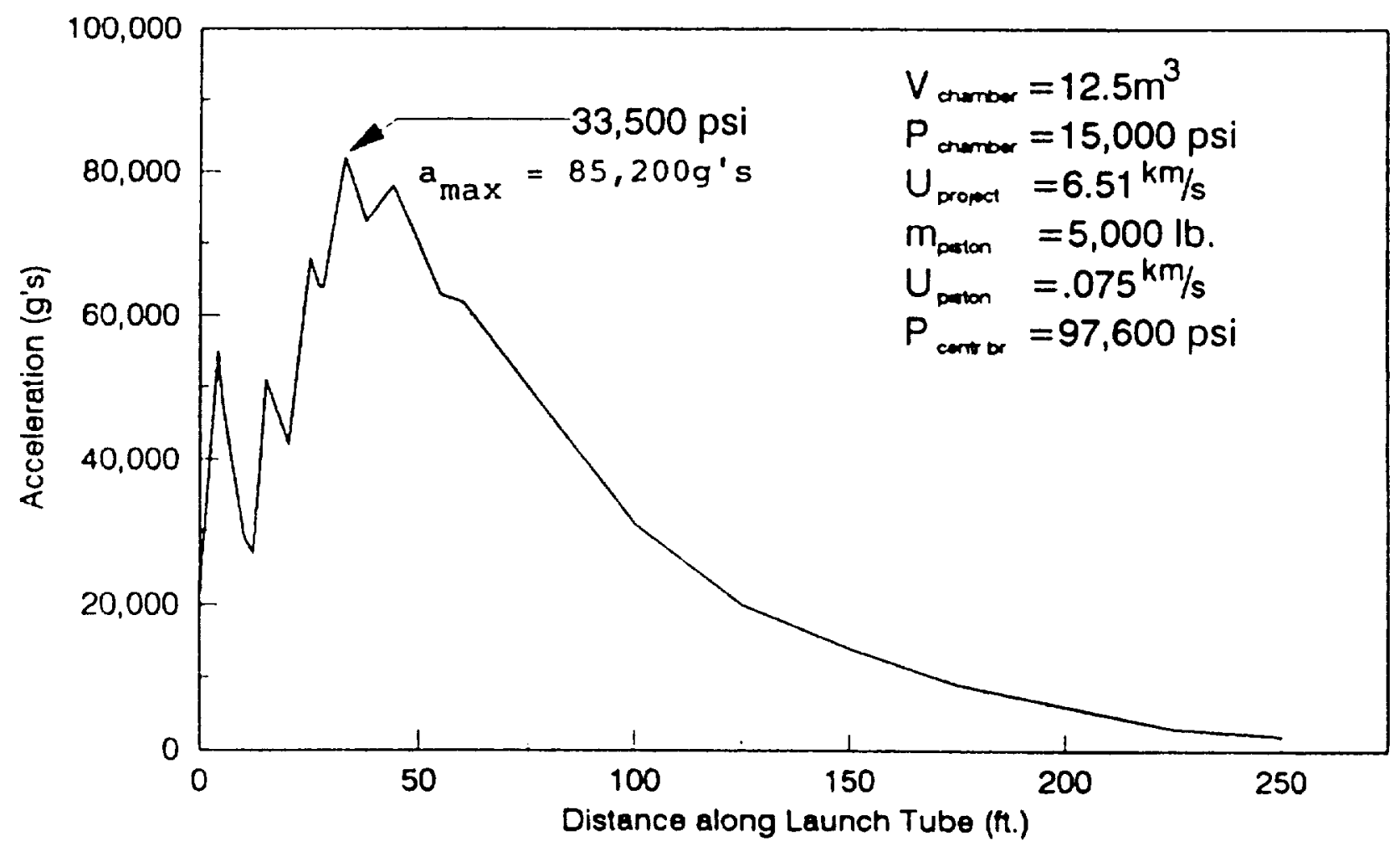

Figure 2.10 Performance Estimate Produced by the AEDC LightGas Gun Program that shows Adequate Performance with Driving the Compression with Compressed Helium. 
Room-temperature helium gas compressed to $\mathrm{P}_{c}=100 \mathrm{MPa}$ (15,000 psi) is far from ideal because the helium molecules, themselves, take up nearly half the volume of the chamber containing them. The Able-Nobel equation-of-state describes this situation simply but quite accurately:

$$
P(V-n b)=n R T
$$

where:

$$
\mathrm{b}=23.7 \mathrm{cc} / \mathrm{mole}=\text { molar volume of helium molecules. }
$$

Note that this equation is the perfect gas equation-of-state presented in Equation $2.7 \mathrm{with}$ the chamber volume replaced by the volume available for molecular movements.

Let us start the analysis by estimating the amount of helium needed to fill the $12.5 \mathrm{~m}^{3}$ chamber to a pressure of $\mathrm{P}_{0}=100 \mathrm{MPa}$ $(15,000 \mathrm{psi})$. Equation 2.10 is solved for the number of moles in the gas charge, $n_{c h}$, as presented in Equation 2.11 .

$$
n_{c h}=\frac{P_{c h} V_{c h}}{P_{c h} b+R T_{0}}
$$

where:

$$
\begin{aligned}
& \mathrm{P}_{\mathrm{ch}}=10^{9} \mathrm{dyn} / \mathrm{cm}^{2}=\text { chamber pressure; } \\
& \mathrm{V}_{\text {ch }}=1.25 \times 10^{7} \mathrm{cc}=\text { chamber volume; } \\
& \mathrm{T}_{0}=295^{\circ} \mathrm{K}=\text { room temperature }
\end{aligned}
$$

here, $n_{c h}=2.592 \times 10^{5}$ moles of $H_{e}$, which is 205,000 standard cubic feet of gas. It weighs $1,037 \mathrm{~kg}$ (just over one metric ton) and might be contained in 1,000 standard $200 \mathrm{ft}^{3}$ gas bottles.

The next task is to verify that the gas reservoir possesses adequate sound speed for launching pistons effectively at velocities up to $U_{p i}=0.75 \mathrm{~km} / \mathrm{sec}$. The most conservative approach is to consider the ideal gas sound speed evaluated using Equation 2.8. Where: $\gamma=1.67 ; \mathrm{T}=295^{\circ} \mathrm{K}$ and; $\mathrm{m}=4.0 \mathrm{gm} / \mathrm{mole}$. Here, $a_{0}=1.012 \mathrm{~km} / \mathrm{sec}$ which is safely above the desired piston speed. A more realistic approach (at least for the early portions of the piston launch) is to use the sound speed, $a$, computed from the Able-Nobel equation-of-state. The equation for real-gas sound speed, $a$, appearing as Equation 2.12 is derived by taking the square root of the derivative of gas pressure from Equation 2.10 with respect to density at constant entropy.

$$
a=\frac{V}{V-n b} \sqrt{\frac{\gamma R T}{m}}
$$


Evaluating this real-gas sound speed for the same set of parameters used for Equation 2.11 provides a value of $a=2.073 \mathrm{~km} / \mathrm{sec}$. This initial sound speed in the reservoir provides a substantial cushion of safety for assuring proper operation of the contemplated light-gas gun.

It may now be instructive to evaluate the gas settling pressure when equilibrium is reachieved after the launch cycle has been completed and the piston is wedged into the transition section between the pump tube and the launch tube. In this gun configuration, the gas charge fills the pump tube as well as the storage reservoir. The pump tube has a volume of $V_{p t}=60.17 \mathrm{~m}^{3}$ so the gas occupies a total volume of $V_{\text {tot }}=V_{p t}+V_{c h}$
$={ }^{2} 72.67 \mathrm{~m}^{3}$. The Able-Noble equation-of-state (Equation 2.10 may now be used to evaluate the gas settling pressure, $P_{f}$. Here: $\mathrm{V}_{\text {tot }}=7.267 \times 10^{7} \mathrm{~cm}^{3} ; \mathrm{n}=2.592 \times 10^{5}$ mole; and $\mathrm{T}_{0}=295^{\circ} \mathrm{K}$. The resulting pressure is $P_{f}=9.556 \mathrm{MPa}$ (1400 psi).

Finally, let us calculate the energy which must be added to the gas as it is pumped from the pump tube back into the reservoir to prepare the launcher for its next shot. The potential energy increase of gas in the reservoir through increasing its pressure may be evaluated under the accurate assumption of Able-Noble gas using Equation 2.13.

$$
E_{r e}=\frac{\delta P\left(V_{r e}-n b\right)}{\gamma-1}
$$

where:

$$
\begin{aligned}
& \delta \mathrm{P}=\mathrm{P}_{0}-\mathrm{P}_{f}=90.44 \mathrm{MPA}\left(9.044 \times 10^{8} \mathrm{dyn} / \mathrm{cm}^{2}\right) ; \\
& \mathrm{V}_{\mathrm{re}}=12.5 \times 10^{6} \mathrm{~cm}^{3}=\text { reservoir volume; } \\
& \mathrm{n}=2.592 \times 10^{5} \text { moles; and } \\
& \mathrm{b}=23.7 \mathrm{cc} / \mathrm{mole} \\
& \gamma=1.67
\end{aligned}
$$

The energy added to the reservoir is: $E_{r e}=7.942 \times 10^{15}$ ergs $=$ $794.2 \mathrm{MJ}$. Thus, the expansion cycle's efficiency in driving the compression piston is expected to be nearly $80 \%$ !

The final potential problem that might affect compressed gas launching feasibility is the between-shot gas compression requirements. A "first-look" at this problem can be developed by considering that high pressure gas compression facilities are already operational at NASA Langley Research Center that use $1200 \mathrm{hp}$ of electric motor power to produce helium gas pressures up to $10,000 \mathrm{psi}$. This facility operates at an overall efficiency near 50\%. Similar equipment should be available to produce the required $15,000 \mathrm{psi}$. The time, $T_{c}$, required to conduct the necessary pumping may be evaluated from first principles using Equation 2.14. 


$$
\tau_{c}=\frac{E_{r \theta}}{\xi P_{h p}}
$$

where:

$$
\begin{aligned}
& \mathrm{E}_{\mathrm{re}}=794.2 \mathrm{MJ}=\text { energy added to the reservoir: } \\
& \xi^{r}=.50=\text { pumping efficiency; and } \\
& \mathrm{P}_{\mathrm{HP}}=8.952 \times 10^{5} \text { watts }=1200 \mathrm{HP} .
\end{aligned}
$$

Here, $\tau_{c}=1775$ sec., 29.6 minutes. This result indicates that pumping times on the order of a single hour should be sufficient
for the task at hand.

Thus, the use of compressed helium that is largely retained within the light-gas gun between firings appears to be an entirely feasible technology for powering very large light-gas guns like the one contemplated here. Since problems with levels ranging from extremely serious to lethal plague all alternatives, a decision was taken to pursue helium gas compression as the principal approach for powering the contemplated launcher.

\subsubsection{Structural strength Considerations.}

The principal remaining design problem for the $250 \mathrm{~mm}$ launcher is to develop a structural design which is strong enough to contain safely all stresses associated with launch cycles while, at the same time, allowing components to be made small enough so that they can be fabricated in existing facilities.

\subsubsection{Sources of Launch stress.}

The most obvious source of stress produced in the gun structure by the launch cycle are developed by high gas pressure. The reservoir used for driving the compression piston must withstand internal gas pressure of $100 \mathrm{MPa}(15,000 \mathrm{psi})$. The breech at the rear end of the pump tube, the valve mechanism, and the rear portions of the pump tube must all withstand similar expansion of the driver gas occurs and pressure decays. We may use isentropic expansion of an Able-Noble gas to provide a conservative estimate of maximum piston driver gas pressure, $P$, vs. position along the launch tube through use of Equation 2.15 .

$$
P=P_{0}\left(V_{x}-n b\right)^{\gamma}(V-n b)^{-\gamma}
$$

Where:

$$
\begin{aligned}
& \mathrm{V}_{r}=\text { the volume of the reservoir; } \\
& \mathrm{V}^{\prime}=\text { the volume of the reservoir plus the portion of the pump } \\
& \text { tube behind the compression piston as it moves forward; }
\end{aligned}
$$


$P_{0}=$ initial gas pressure;

$\mathrm{n}=$ Number of moles of gas; and

$\mathrm{b}=$ gas covolume.

A curve derived from Equation 2.15 is presented in Figure 2.11.

The pump tube segments must withstand this pressure against rupture. Cross-sectional areas of joints between the tube I.D.'s and the gas seals are also exposed to this pressure. A force is
produced on these surfaces which tends to separate the joints. The pressure in the hydrogen gas ahead of the compression piston increases rapidly during the compression stroke and reaches a value near $100 \mathrm{MPa}(15,000 \mathrm{psi})$ as the piston face enters the central breech.

This is also the pressure required to break the diaphragm valve currently planned for the upstream end of the launch tube whose opening signifies start of the projectile package acceleration. A relatively complex chain of events occurs at this point where the oncoming compression piston tends to compress the gas within the chamber while the gas flowing into

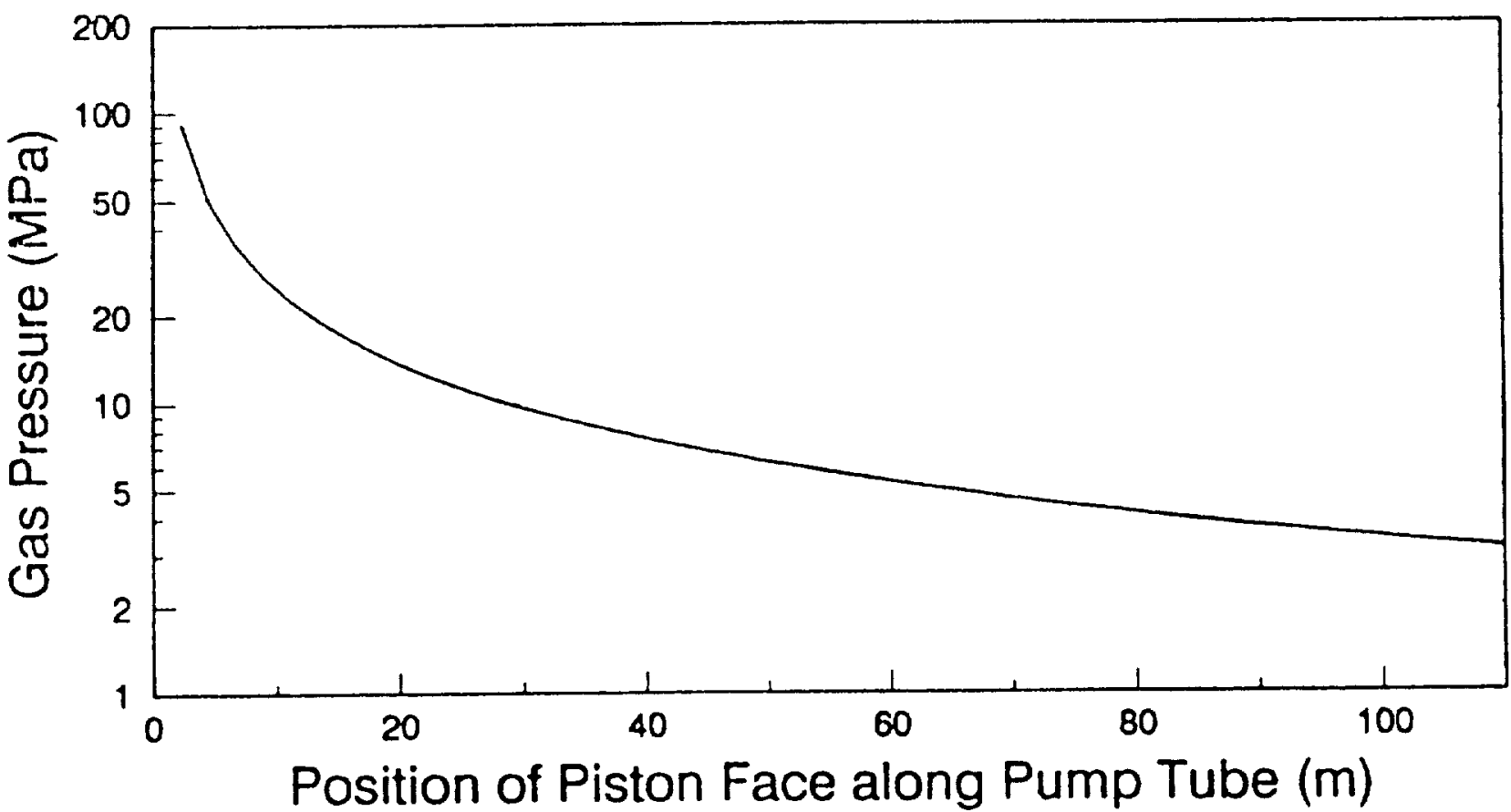

Figure 2.11 Piston Driver Gas Pressure vs. Piston Position Along the Pump Tube. 
the launch tube tends to produce expansion. Initially, piston compression dominates the process and pressure rises as the piston advances until a peak value near $680 \mathrm{MPa}$ is reached. After this point, gas expansion along the launch tube dominates the process and the pressure falls precipitously. A conservative approach which works well for design purposes is to assume that the diaphragm fails to open and the gas is compressed

isentropically until a pressure of $150 \%$ of the estimated maximum (1.0 GPa) is reached. A central breech section that can withstand this loading can, obviously, withstand any realistic pressures applied. Figure 2.12 is a plot of the design pressure vs. position within the central breech of the launcher.

Similar pressure profiles are applied to the interior wall and upstream end of the launch tube. clearly, the tube segment must be built robust enough to prevent radial deformation and bursting and the joints must withstand pressure loadings which tend to separate them. Identifying possible peak pressures as a function of position along the launch tube is a relatively complex process which requires use of gun performance predicting computer codes. Figure 2.13 is a plot derived from such a code output which indicates a "worst case" peak pressure profile along the launch tube bore.

A second source of stress applied to the light-gas gun structure arises from axial accelerations of the structure produced by motion of the compression piston. The first such disturbance arises from initial acceleration of the compression piston. The same gas pressure applied to the base of the compression piston is also applied to the pump tube breech block which closes the rear end of the pump tube. This force may be identified as the conventional recoil force of any normal gun firing. It produces a rearward-directed acceleration of the entire launcher structure which is interconnected rigidly. Each component of the launcher must both undergo this recoil acceleration and transfer it to all components mounted beyond it. The net effect of this argument is systematic mitigation of the recoil force as one's viewpoint moves forward along the gun (leaving progressively larger portions of the gun mass between the viewpoint and the breech block). The recoil force, $f_{\text {re }}$ may be evaluated using Equation 2.16.

$$
f_{x e}=\frac{\pi P_{x e} d_{p t}^{2}}{4}
$$

where:

$$
\begin{aligned}
& \mathrm{d}_{\mathrm{pt}}=0.914 \mathrm{~m}=\text { pump tube inner diameter and; } \\
& \mathrm{P}_{\mathrm{re}}=100 \mathrm{MPa}=\text { peak reservoir pressure. }
\end{aligned}
$$

The peak recoil force under these conditions is, $f_{\text {re }}=$ $6.567 \times 10^{7} \mathrm{~N}\left(14.76 \times 10^{6} \mathrm{lbf}\right)$. This force produces a recoil acceleration, $A_{\text {re }}$ which may be evaluated using Equation 2.17 . 


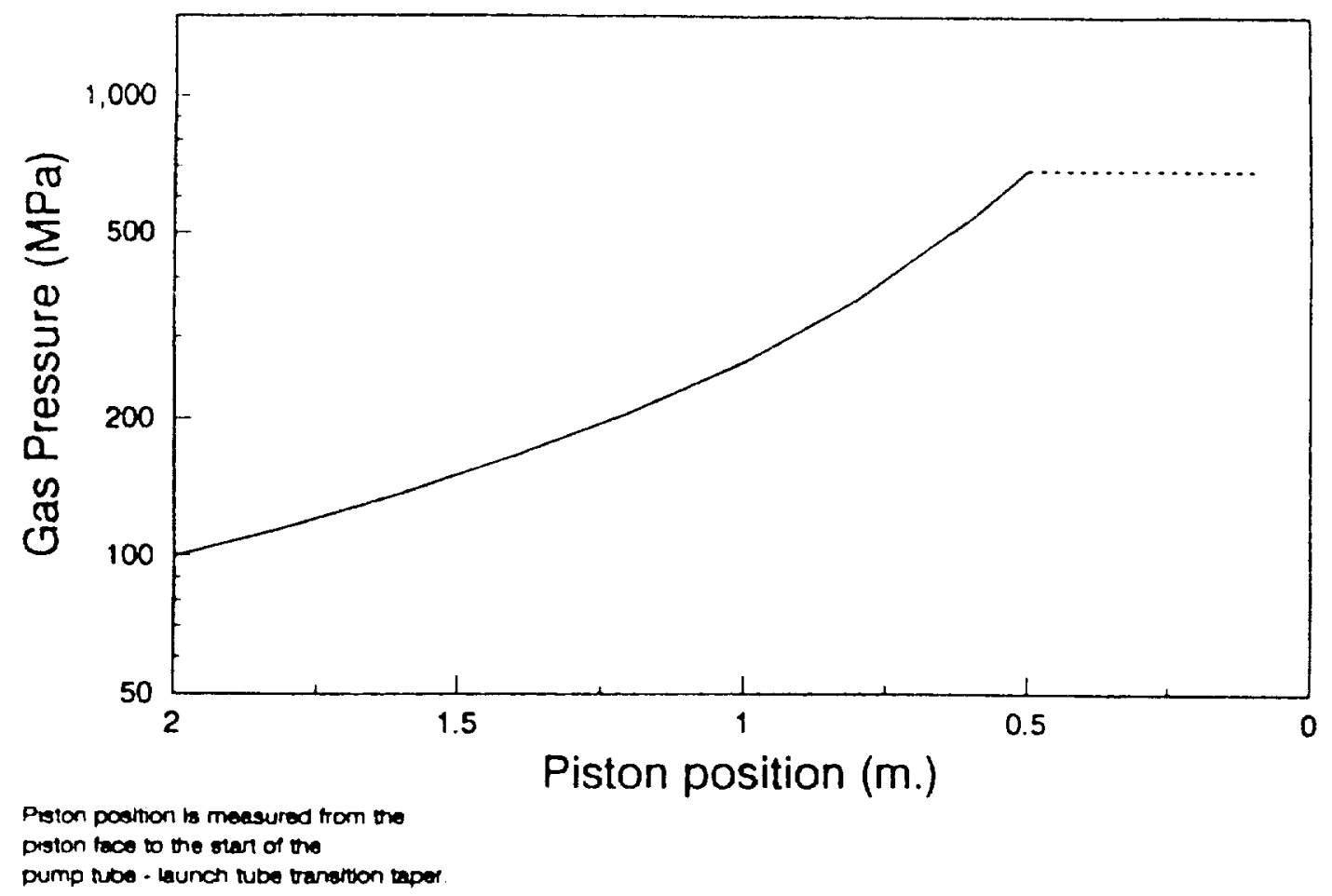

Figure 2.12 Hydrogen Gas Pressure within the Central Breech vs. Piston Position.

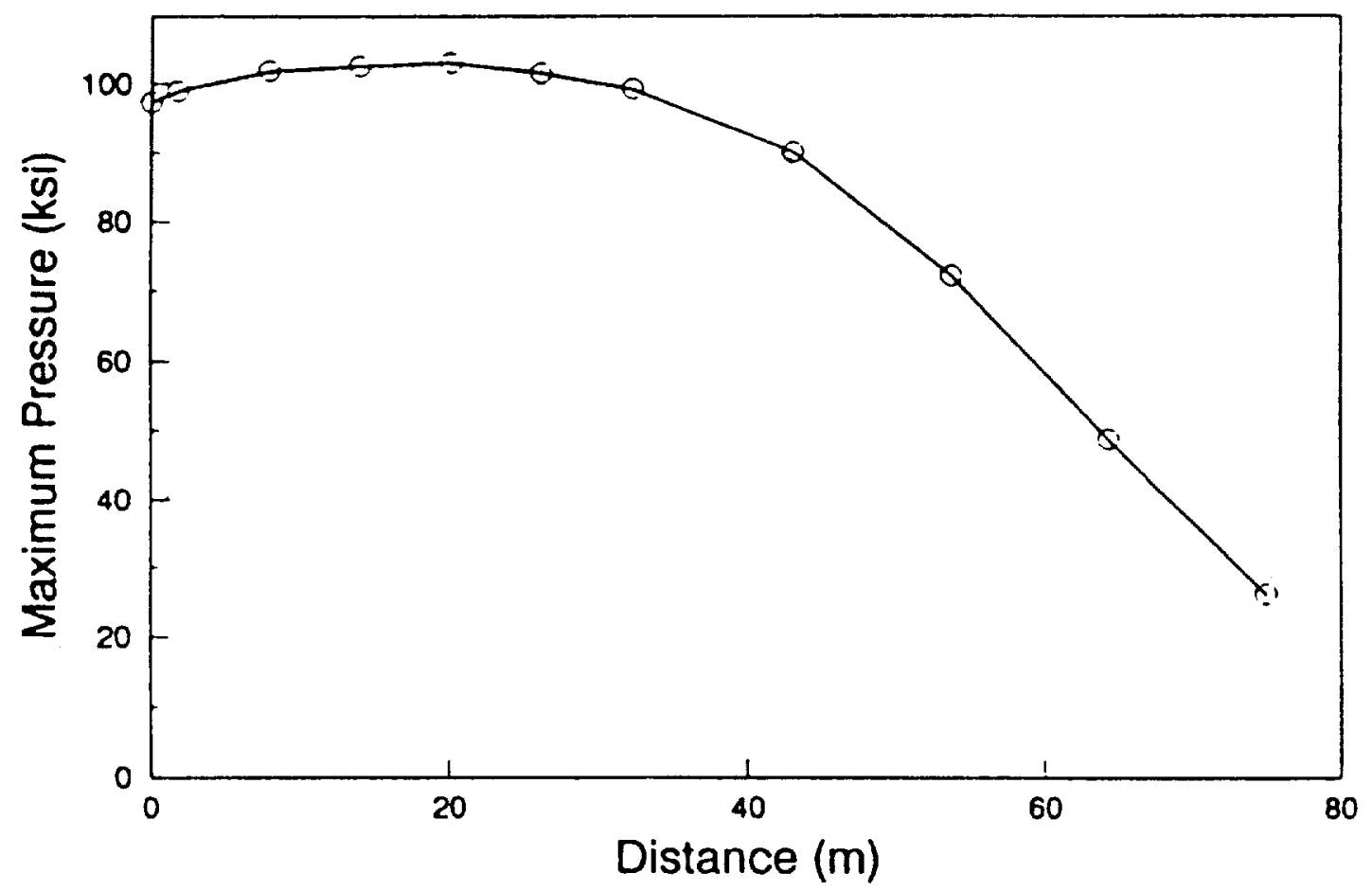

Figure 2.13 Maximum Pressure Experienced by the Launch Tube Bore Wall vs. Position Along the Launch Tube. 


$$
A_{I \theta}=\frac{f_{I \theta}}{M_{g}}=\frac{\pi P_{r e} d_{p t}^{2}}{4 M_{g}}
$$

where:

$M_{g}=678 \mathrm{MT}=$ total mass of the launcher structure.

$a_{r e}=98.84 \mathrm{~m} / \sec ^{2}\left(9.88 \mathrm{~g}^{\prime} \mathrm{s}\right)=$ the peak recoil acceleration.

It should be noted here that the mass of the launcher structure was evaluated by considering the strength needed to withstand the forces applied to it. In this case, the forces applied are a function of the mass (through recoil acceleration) so an iterative process is required to arrive at an optimum sensible gun design.

Now, the recoil force applied to any plane through the gun, $f_{r}$, may be evaluated using Equation 2.18 .

$$
f_{I}=\frac{f_{r e^{M_{f}}}}{M_{g}}=\frac{\pi P_{r e} d_{p t}^{2} M_{f}}{M_{g}}
$$

where:

$$
\begin{aligned}
& M_{f}= \text { the mass of all launcher components (and the sections } \\
& \text { thereof) which are not located between the plane } \\
& \text { considered and pump tube breech. }
\end{aligned}
$$

A substantially greater force is produced when the piston is stopped by high gas pressure and, possibly, material deformation within the central breech. We choose here to consider the maximum force on the piston as it faces the peak design pressure for the launcher of $1.0 \mathrm{GPa}$. Simple inspection of Equation 2.16 , 2.17 , and 2.18 indicates that the deceleration force, launcher deceleration, and forces produced on individual components are just 10 times those produced by piston acceleration since the peak piston deceleration pressure is 10 times the peak launching pressure. The deceleration force, $f_{\text {fe' }}$ is applied to the transition cone of the central breech and is directed downstream (in the same direction as projectile travel. clearly, the acceleration produced by this force is directed downstream. Thus, the joint between the central breech and the launch tube and the launch tube joints are loaded in compression by this force, $f_{\text {gre }}$ The joint between the central breech and the pump tube, all pump tube joints and many of the joints associated with the gas reservoir are loaded in tension by $f_{\text {are }}$ (some of the joints in the reservoir are also loaded in compression by this acceleration). The magnitude of the acceleration is substantial ( $a_{\text {are }}=98.84 \mathrm{~g}^{\prime} \mathrm{s}$ ) so that the forces produced by it dominate mechanical loading of many of the critical areas of the light-gas gun structure. 
2.2.3.2 Reaction of Gun Components to Applied Forces.

A readily manipulatable analysis must be developed for determining approximate stress levels produced within critical launcher components by launch cycles in order to assure that they are designed strong enough to withstand forces applied to them. one important group of components are tubes containing large internal pressure. In some cases, the tubes are capped to form closed tanks so that the pressure is exerted in directions to compress their wall thicknesses, cause them to enlarge in diameter, and to stretch in length. At other times the tubes are subjected to acceleration forces (recoil and anti-recoil forces) which produce axial loads which are related only casually to ones produced directly by interior gas pressure. In general, material on the walls of the gun tubes is stressed triaxially. Internal pressure produces radial stress which equals the containment pressure on the inner surface of the tube and fades to zero on the outer surface as presented in Equation 2.19.

$$
\left.\mathbf{\sigma}_{x}=\frac{-P_{i}\left(K^{2}-k^{2}\right)}{k^{2}\left(K^{2}-1\right)} ; \quad \mathbf{o}_{x}=-P_{i} \quad \text { (when } k=1\right)
$$

where:

$$
\begin{aligned}
\sigma_{r}= & \text { radial component of applied stress; } \\
\mathbf{P}_{\mathbf{i}}= & \text { internal gas pressure; } \\
\mathbf{K}= & \text { ratio of tube outer radius to inner radius; and } \\
\mathrm{k}= & \text { ratio of radial position of a point of interest within } \\
& \text { the tube wall to interior radius. }
\end{aligned}
$$

The maximum value for, $o_{r}$ occurs at the inner tube wall as shown by the second portion of Equation 2.19. The negative signs in the Equation denote the fact that the radial stress is inherently compressive.

The second stress is directed tangentially around the tube cixcumference. It also is maximum at the tube's inner wall but falls to an intermediate value at the tube's outer diameter. Tangential stress, $\sigma_{t}$ may be evaluated using Equation 2.20.

$$
\left.\sigma_{t}=\frac{P_{1}\left(K^{2}+k^{2}\right)}{k^{2}\left(K^{2}-1\right)} ; \quad \sigma_{t}=\frac{P_{i}\left(K^{2}+1\right)}{K^{2}-1} \quad \text { (when } k=1\right)
$$

Finally, the axial stress is produced in the tube wall by the longitudinal tension (or compression that the tube experiences). In general, this axial load is constant across the cross-section of the tube wall. It may be evaluated using Equation 2.21 . 


$$
\sigma_{a}=\frac{P_{i}}{K^{2}-1} ; \quad \sigma_{a}=\frac{4 f_{a}}{\pi\left(d_{o}^{2}-d_{i}^{2}\right)}
$$

where:

$$
\begin{aligned}
& \mathrm{f}_{\mathrm{o}}=\text { the axial load born by the tube, } \\
& \mathrm{d}_{0}=\text { the tube's outer diameter and; } \\
& \mathrm{d}_{\mathrm{i}}=\text { the tube's inner diameter. }
\end{aligned}
$$

The right-hand Equation in 2.21 treats an externally applied load, while the left-hand one treats a load produced by the internal pressure when the tube is capped.

A number of formalisms have been developed for evaluating the equivalent stress produced by triaxial material loading. A conservative approach to this problem is the von Mises formalism which evaluates and equivalent stress, $\sigma_{\mathrm{m}}$, according to Equation 2.22 .

$$
\sigma_{v m}=\frac{1}{\sqrt{2}} \sqrt{\left(\sigma_{x}-\sigma_{t}\right)^{2}+\left(\sigma_{t}-\sigma_{a}\right)^{2}+\left(\sigma_{a}-\sigma_{x}\right)^{2}}
$$

when this stress is well below published values for tensile yield stress of the material in question, the material may be expected to react elastically. Material deformation is expected whenever the von Mises stress approaches closely or exceeds yield stress levels.

other components within the launcher may not be treated as tubes. Principal among these are gib clamps and threads, both of which fail through shear deformation. Generally, shear strength of ductile metal is approximately two-thirds of its tensile strength. Shear loading of threaded sections may be calculated approximately by dividing the load into one-half the area of the threaded section. The factor of one-half is introduced since only half the material need fail to cause thread stripping. An equation for evaluating the tensile holding force of threaded sections is presented in Equation 2.23 along with a solution for evaluating thread shear stress.

$$
f_{t}=\frac{\pi \sigma_{s t} d_{t} I_{t}}{2} ; \quad \sigma_{s t}=\frac{f_{t}}{2 \pi d_{t} I_{t}}
$$

where:

$$
\begin{aligned}
& f_{t}=\text { the applied force to the threaded section; } \\
& \sigma_{s t}=\text { the resulting shear stress in the threads; } \\
& d_{t}=\text { mean thread diameter; and } \\
& I_{t}=\text { length of the thread engagement. }
\end{aligned}
$$


Gib connectors have been specified widely throughout the proposed launcher because of their low fabrication cost in large sections and their relative ease of use. The basic gib shown in Figure 2.14 consists of a trapezoidal "ear" on the exterior diameters of tubular components to be connected. The two gibs are spanned by a segmented ring with interior surfaces that mate with the gib ears. The ring forces the gib ears together as it is drawn radially inward. The ring is generally held in place by external bolts which are also used to prevent it being bent open when stressed. It is important to note when designing connecting gibs that the angle, $\phi$ in Figure 2.14 must be maintained below the critical friction angle for the mating gib materials, $\phi_{c}$, so that no outward-directed force component is provided to the clamp when separating forces are applied to the joint. This criterion is met when the tangent of the gib angle is less than or equal to coefficient of friction between the gib surfaces as presented in Equation 2.24 .

$$
\phi_{c} \leq \tan ^{-1} \mu
$$

where:

$$
\begin{aligned}
& \phi_{c}=\text { the critical friction angle, and } \\
& \mu=\text { the coefficient of friction between the gib and clamp } \\
& \text { surfaces. }
\end{aligned}
$$

For a coefficient of friction of $\mu=.25$ (which is somewhat conservative for steel-on-steel) the critical friction angle $\phi_{c}=14^{\circ}$.

Separating force may now be seen to apply shear stresses to the gib joint components. Shear stress is applied to the ears of the gib and to the clamp in a manner similar to a single-thread screw joint. The strength of the gibing arrangement, $f_{g}$, can, thus, be evaluated by multiplying the material shear strength by the cross-sectional area of the gib halfway up its extent as is accomplished in Equation 2.25.

$$
f_{g}=\pi \sigma_{s} d_{g} T_{g}
$$

where:

$$
\begin{aligned}
\sigma_{s}= & \text { shear strength of the gib material; } \\
\mathrm{d}_{9}= & \text { mean diameter of the gib ear; and } \\
\mathrm{T}_{\mathrm{g}}= & \text { central thickness of the gib ears... as sketched } \\
& \text { in Figure } 2.14 .
\end{aligned}
$$

It is important to note here that the female gib clamp must be strong enough to withstand $f$ in tension across its center section as evaluated in Equation 2.26.

$$
f_{g} \leq \pi \sigma_{c}\left(d_{g}+H_{g}+T_{g c}\right) T_{g c}
$$




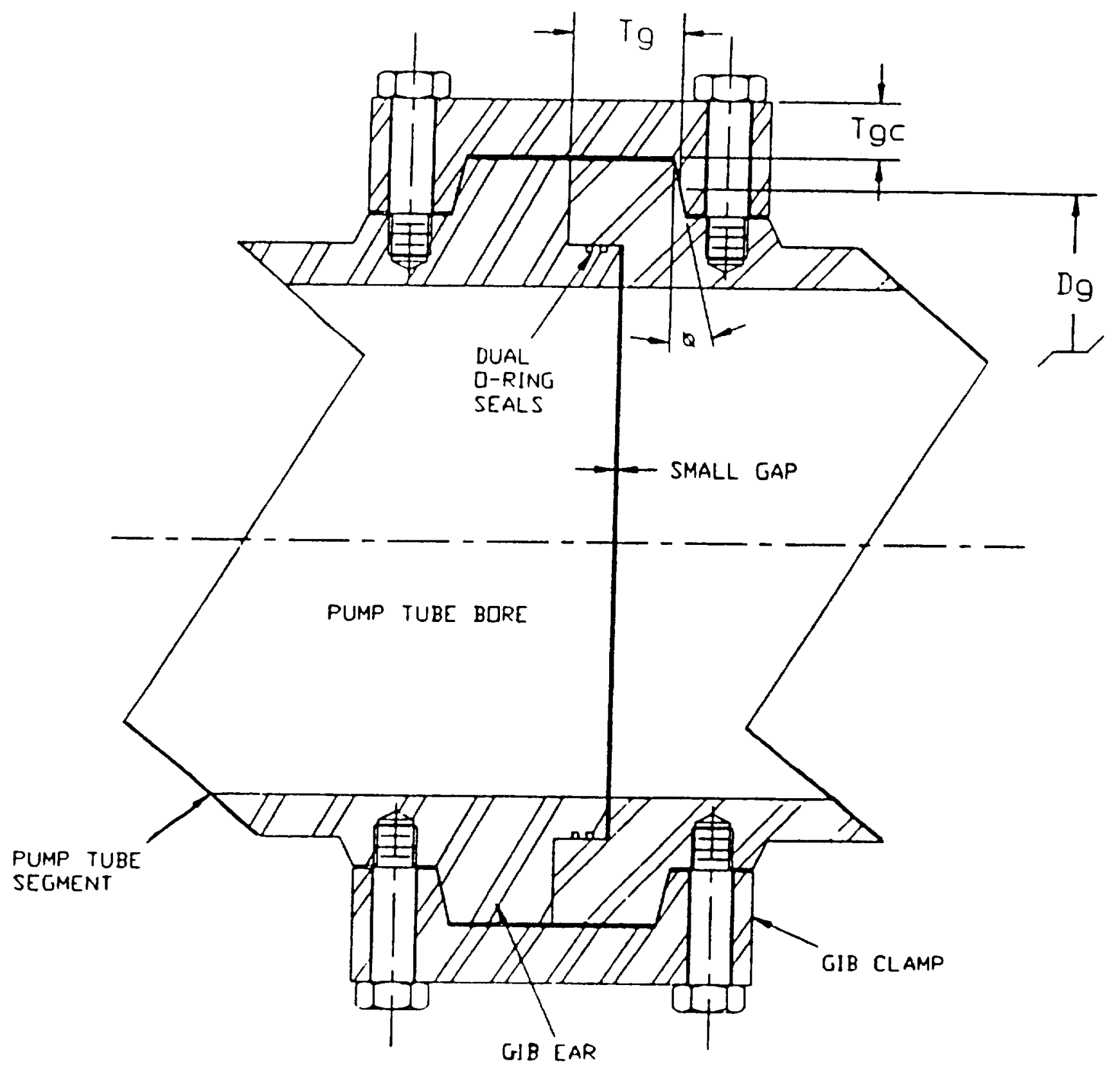

Figure 2.14 Gib Connector Assembly Used to Join Pump Tube Components. 


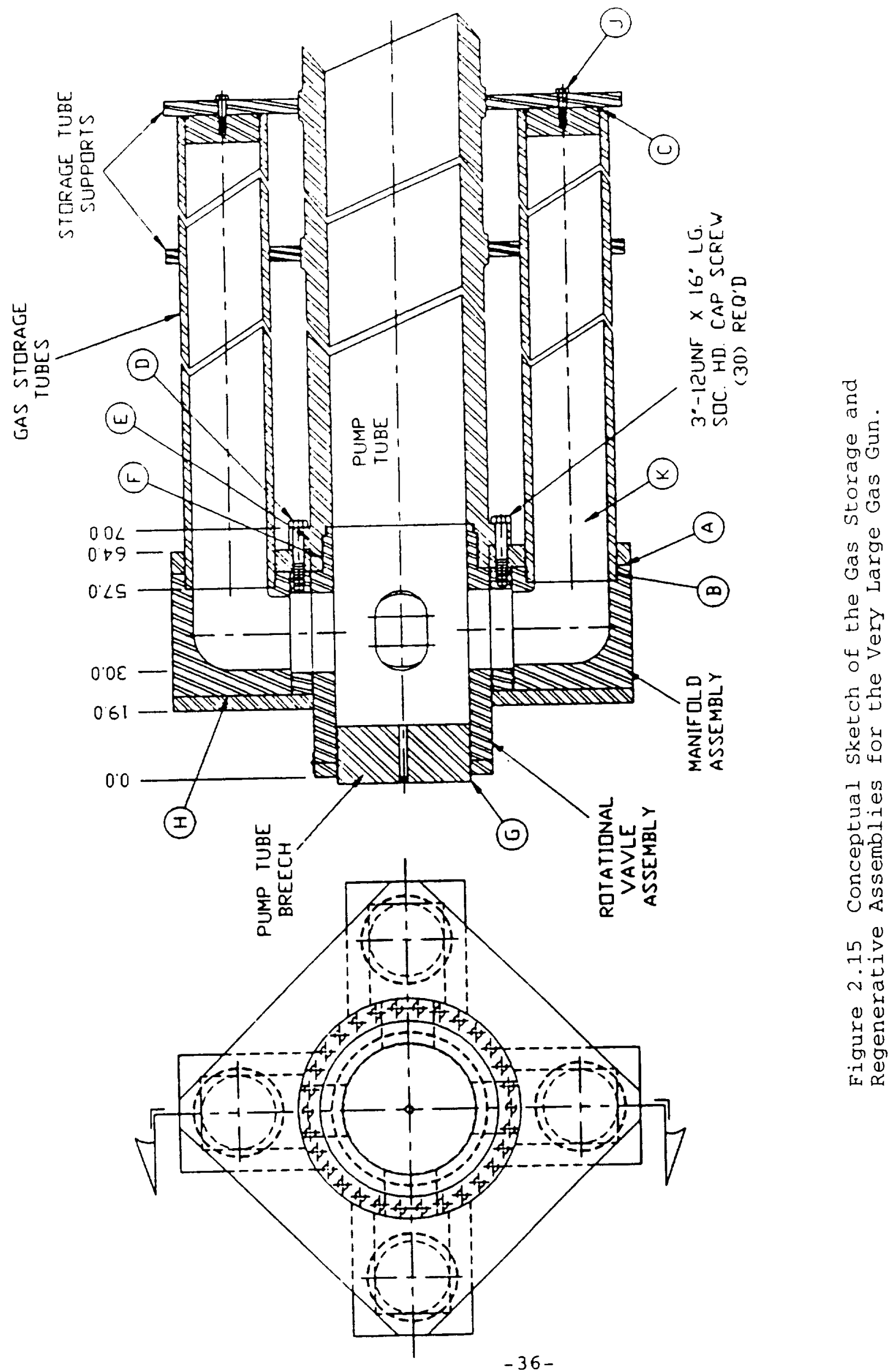


where:

$\sigma_{t}=$ tensile strength of the gib material;

$\mathrm{H}_{\mathrm{g}}=$ radial heighth of the gib ears; and

$\mathrm{T}_{\mathrm{gc}}^{\mathrm{g}}=$ thickness of the bridge across the female gib clamp.

The bridge between the two ears on the female gib clamp can also bend outward to allow clamp disengagement. The most materialefficient means of preventing such bending is to bolt down the extreme ends of the female gib clamp to the objects being interconnected. Relatively small bolts can produce countertorque necessary to protect the bridge from bending. An alternative technique for strengthening the female gib clamp is to make the bridge inherently rigid enough to prevent bending. It may either be made thick or it may be gusseted to provide the necessary rigidity.

\subsubsection{Design of Light-Gas Gun Components.}

The previous sections of this chapter provide necessary input information for designing the $250 \mathrm{~mm}$ bore two-stage lightgas gun capable of accelerating

$14.0 \mathrm{Kg}$ packages to peak velocities above $6.1 \mathrm{~km} / \mathrm{sec}$. For convenience, the design has been broken down into the piston driver gas storage assembly, the pump tube assembly, the central breech assembly, and the launch tube assembly.

\subsubsection{The Piston Driver Gas Reservoir Assembly.}

Gun performance computations conducted at the Langley Research Center (LRC) have shown that a chamber with a volume of $12.5 \mathrm{~m}^{3}$ charged with helium to a pressure of $100 \mathrm{MPa}(15,000 \mathrm{psi})$ is sufficient for accelerating a standard compression piston to a peak velocity of $0.75 \mathrm{~km} / \mathrm{sec}$. along the pump tube of the contemplated light-gas gun which is sufficient for operating the gas gun satisfactorily. The computation assumes that no significant impediment is placed in the flow-field between the gas reservoir and the base of the piston. After considering manufacturability and operability of several alternative designs, a concept sketched in Figure 2.15 was chosen.

Here, an assembly of four tubes with bore diameters of $0.5 \mathrm{~m}$ (20") and lengths of $16 \mathrm{~m}$ (52.5') serve as the gas storage reservoir. The gas storage tubes are long enough to require special handling. Three support rings are needed to hold them in position with their axes parallel to that of the pump tube. The extreme downstream support is bolted to the center of the end plug of each of the storage tubes. This ring is equipped with a central hole that makes sliding contact with a small raised section on the O.D. of the pump tube. The two intermediate rings contain holes for each of the four gas storage tubes plus a central hole for a raised section of the pump tube. All three rings are affixed rigidly to the gas storage tubes, but are allowed to move freely in the axial direction along the pump tube. Each of these tubes is screwed into a massive steel 
rectangle where the half meter bore diameter is turned inward through $90^{\circ}$. The cubes, in turn, are welded to the O.D. of a massive short section of tube with extended circular holes machined in its side wall in alignment with the holes in the inner surfaces of the steel rectangles. The elongated holes have areas equal to those of the tank cross-sections but their total widths are somewhat less than half the circumference of the inner wall of the tube. The assembly is completed by enclosing the four steel rectangles and the tube between two square plates of $100 \mathrm{~mm}$ thick steel which are welded massively at all contacted surfaces. A hole 48" in diameter is machined through the center of the structure to allow a slip-fit over the 48" diameter O.D. of the rear end of the pump tube. An ear 6" wide by 6" thick is included almost at the rear end of the pump tube. This ear is perforated 30 times to accept 3" diameter fine thread socket head cap screws which engage threaded holes in the end of the central tube of the reservoir assembly. This joint forms the only rigid connection between the gas storage structure and the pump tube. The single coupling plane concept was chosen to eliminate stresses that would otherwise be produced through differential expansion of gas storage components produced during loading of the driver gas reservoir. The gas storage tubes are expected to extend nearly $2 "$ during loading to internal pressures near $100 \mathrm{MPa}(15,000 \mathrm{psi})$.

A short extension of the rear end of the pump tube (the rotational value unit) is threaded into a socket within the rear end of the main pump tube structure. This section of the pump tube contains four elongated holes which match four holes in the interior of the reservoir assembly. The rotational valve unit also contains dual o-ring seals capable of withstanding pressurization to 15,000 psi surrounding the four holes in its side wall. Finally, it contains circumferential o-ring seals located just upstream and downstream from the four holes to prevent gas escape axially along the outer surface of the tube. When the rotational valve unit is screwed into place in the socket at the rear end of the pump tube, its holes align with those in the reservoir yoke to provide free access for gas between the reservoir and the rear end of the pump tube. When the rotational valve unit is unscrewed through $45^{\circ}$ of rotation, the openings in the pump tube extension and the reservoir yoke are in quadrature with one-another and the o-ring seals separate the reservoir from the pump tube. Helium gas can be pumped from the pump tube to the reservoir volume when the valve assembly is so positioned. The assembly is completed by including a massive breech plug threaded into the rear end of the rotational valve unit and sealed in place with dual o-rings. (A special fixture has been included for handling the breech plug which must be opened and closed between each firing. A very short extension of the main pump tube extension is also threaded to accept the breech plug. It is hinged to the rotational valve unit with the hinge oriented horizontal when the valve is in gas pumping orientation. In this way, the breech plug may be screwed out of the main pump tube extension while still being captured in the 
extra extension. It can then be swung out of the gun's axis with little difficulty by a single operator.)

The gun is prepared for firing by rotating the rotational valve unit until the wall openings are in quadrature with one another, thus sealing the gas reservoir. The reservoir may then be evacuated and refilled with helium gas to the desired pressure (up to $100 \mathrm{MPa}$ ). A piston is then be loaded into the pump tube from the rear and positioned so that circumferential seals in the pump tube wall, just upstream and downstream from the four gas ports, are engaged properly. The pump tube breech may now be closed and plumbing not shown in Figure 2.15 may be used to valve gas into the port sections in the rotational valve unit to equilibrate pressure with the reservoir. The seals on the interior and exterior walls of the rotational valve assembly prevent this gas from escaping. Also not shown in Figure 2.15 is a gear/worm assembly which is used to rotate the rotational valve unit through $45^{\circ}$ to close its threaded joint with the pump tube. This action realigns holes in the manifold assembly with those in the rotational yoke assembly, thus permitting free access for the stored gas into the pump tube once the piston has been moved forward. After the remainder of gun firing preparations have been completed, more plumbing not shown in Figure 2.15 is used to valve gas from the reservoir through the pump tube breech into the pump tube immediately behind the compression piston. This high pressure gas pushes the piston downstream relatively slowly until its rear end starts to clear the four main gas access ports. At this point, gas flow behind the piston increases very rapidly as force builds up on the base of the piston and its downstream acceleration increases. The valve assembly now operates in a regenerative manner until the rear of the piston clears the downstream end of the access ports and full gas flow and piston acceleration are achieved. The gas flow continues during the remainder of the acceleration profile and the lightgas gun firing cycle. At the end of the cycle, the piston effectively seals the downstream end of the pump tube and the settling pressure of $10 \mathrm{MPa}(1,500 \mathrm{psi})$ is established in the pump tube/reservoir volume.

The first step in preparing the light-gas gun for its next firing is to re-rotate the rotational valve unit by unscrewing it through $45^{\circ}$ which separates the pump tube volume from that of the gas storage tubes (the gas reservoir). A compressor assembly is then activated to draw gas from the pump tube and insert it into the four gas storage tubes. This process is continued until the pump tube pressure has fallen to a low value (near 1 atmosphere) and the gas storage tubes have been returned to nearly their original pressure. A small amount of helium may now be added through the compressor system to complete charging the gas storage tubes and the remainder of helium in the pump tube may be vented away. The pump tube breech may now be opened, the piston may be extracted and the processes described above repeated in preparation for the next firing. 
The design effort continues by considering the stresses applied to various critical locations within the overall design of the piston-launch hardware by internal gas pressure, launcher recoil (caused by piston acceleration) and anti-recoil (caused by piston deceleration).

The sketch in Figure 2.15 shows various surfaces and joints whose strengths are critical to proper and safe operation of the facility. Table 2.3 lists these joints together with the maximum gas pressure and mass to be accelerated across them. The maximum force, the shear stress, and the tensile stresses produced by maximum loadings are presented. Forces arising from internal pressure, gun recoil, and gun anti-recoil are presented for each situation where they are of potential importance. Scanning of the predicted stresses indicates the relative safety factors designed into each of the structural elements. Bear in mind that this entire structure is to be fabricated from steel with a tensile yield strength of at least 120,000 psi and a critical shear stress of 80,000 psi.

The total mass of the piston driver gas storage facility in its configuration presented in Figure 2.15 is $91.5 \mathrm{MT}$. The four gas storage tubes together weigh $52.24 \mathrm{MT}$. The manifold assembly weighs $12.5 \mathrm{MT}$, the rotational valve assembly $3.6 \mathrm{MT}$, the pump tube breech $4.75 \mathrm{MT}$, and the five disks which support the gas storage tubes weigh a total of $16.31 \mathrm{MT}$.

The joint between the gas storage tubes and the manifold blocks ( $A$ in Figure 2.15) must withstand tensile loading from launcher recoiling (which must impart an acceleration of $9.88 \mathrm{~g}^{\prime} \mathrm{s}$ to the tubes and the disks which support them). The joint must also contain the tubes against internal gas pressure of $100 \mathrm{MPa}$ $(15,000 \mathrm{psi})$. The recoil force of $1.847 \times 10^{6} \mathrm{~N}\left(4.159 \times 10^{5}\right.$ lbf.) produces a shear stress across $6 "$ of threads of $18.77 \mathrm{MPa}$ $(2,760 \mathrm{psi})$. The pressure within the tanks produces $2.092 \mathrm{x}$ $10^{f} \mathrm{~N}(4.71 \mathrm{million}$ lbf.) of tensile force at this joint which produces a shear stress of $212.6 \mathrm{MPa}(31,250 \mathrm{psi})$.

Surface $B$, between the tank end wall and the manifold block is loaded in compression by the anti-recoil acceleration. Here, the force is $1.843 \times 10^{7} \mathrm{~N}(4.15$ million $1 \mathrm{bf.})$ caused by accelerating the gas storage tubes and support disks downstream along the range axis at a peak level of $98.84 \mathrm{~g}^{\prime} \mathrm{s}$. The tank has an internal diameter of $0.5 \mathrm{M}$ and a wall thickness of $62.5 \mathrm{~mm}$ which produces enough surface area to reduce the compressive loading to $200 \mathrm{MPa}(30,000 \mathrm{psi})$.

The opposite (downstream) ends of the gas storage tubes are closed by $300 \mathrm{~mm}$ thick disks which are held in place with $50 \mathrm{~mm}$ thick circumferential welds (C). A load produced by the internal pressure in the tank of $2.092 \times 10^{7} \mathrm{~N}(4.71$ million lbf.) produces a stress within the weld of $255 \mathrm{MPa}(37,500 \mathrm{psi})$. This stress is disturbingly high because of the variable and generally unknown strengths of weld joints. For this reason, consideration 


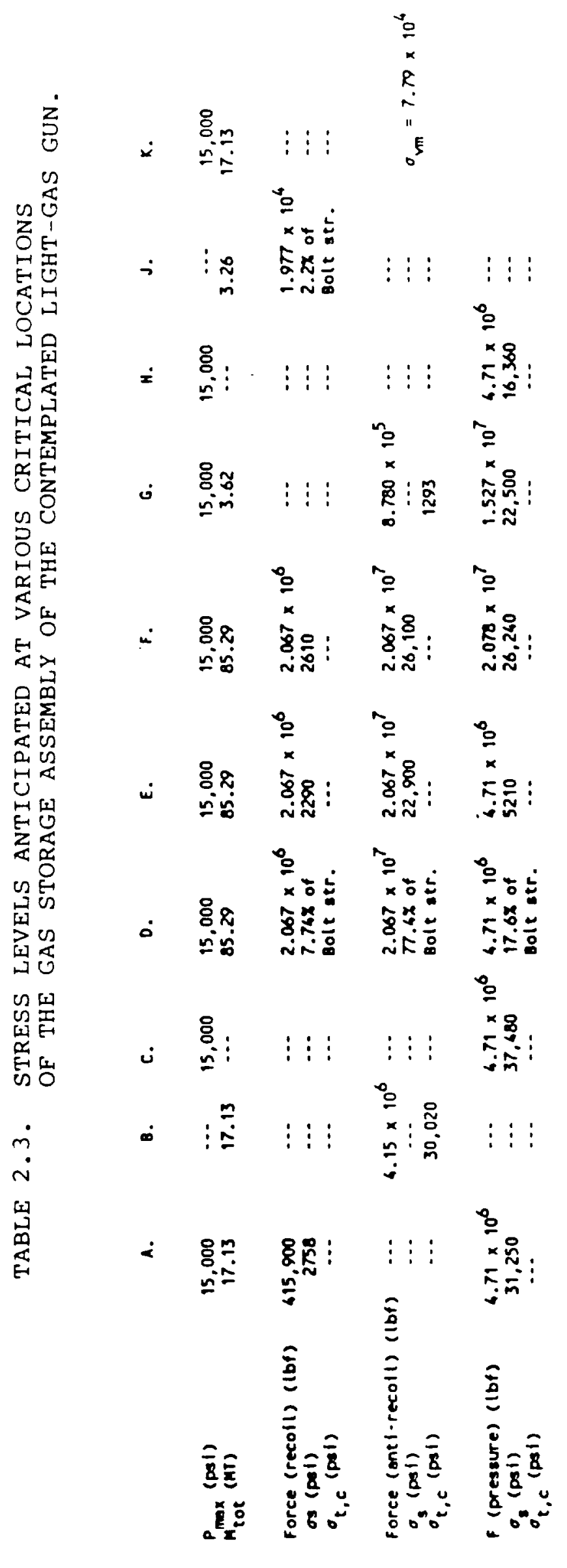


ought to be given to threading the plug into place or enlarging the welds from $50 \mathrm{~mm}$ to $100 \mathrm{~mm}$.

The 30 bolts located at position $D$, hold the gas reservoir assembly to the rear end of the pump tube. They must sustain acceleration forces from both gun recoil and anti-recoil. Each is a 3" diameter socket head cap screw made from high strength steel which allows them to be rated to withstand $3.95 \times 10^{6} \mathrm{~N}$ ( 890,000 lbf.) in tension. These bolts support the reservoir assembly against both recoil and anti-recoil accelerations as well as gas pressure applied across the pump tube diameter. The recoil force and the gas pressure force are applied simultaneously so must be added to each other. Thus, the bolts are loaded to $17.6 \%+7.74 \%=25.34 \%$ of their rated strength during early portions of the launch cycle according to Table 2.3 and $77.4 \%$ of their strength during anti-recoil acceleration which occurs later in the gun firing cycle. Since the rated strength for the bolts already has a substantial safety factor built into it, stressing the bolts this near their rating is acceptable from a safety standpoint.

The ear on the pump tube whose base area is identified as (E) in Figure 2.15, must also withstand the forces applied to the 30 bolts designated $D$. The stress produced at this point is in shear. The interior diameter of the lip interior is $1.22 \mathrm{~m} \mathrm{(48")}$ and the lip is $150 \mathrm{~mm}$ (6") thick which produces a shear stress of $156 \mathrm{MPa}(22,900 \mathrm{psi})$ when it supports the anti-recoil load from the entire assembly of $91.8 \times 10^{6} \mathrm{~N}(20.67 \mathrm{million} 1 \mathrm{bf})$. This stress reduces to just one-tenth of this anti-acceleration value, $15.6 \mathrm{MPa}(2,290 \mathrm{psi})$ when the recoil acceleration is considered. The force produced by peak gas pressure is $20.9 \times 10^{6} \mathrm{~N}(4.71$ million lbf.) which produces a stress of $35.4 \mathrm{MPa}(5,210 \mathrm{psi})$. Since the peak pressure and the recoil stresses must be sustained simultaneously, the peak stress during the early portion of the cycle is $5,210+2,290=7,500 \mathrm{psi}$. None of these stresses are large enough to create serious concern.

The threads (F from Figure 2.15 which connect the rotational valve assembly to the pump tube must withstand recoil and antirecoil accelerations for the entire gas storage assembly mass plus peak gas pressure exerted across the pump tube I.D. Their 12 " length is stressed to $177.6 \mathrm{MPa}(26,100 \mathrm{psi})$ in shear during anti-recoil when the acceleration of the gun components reaches $99.84 \mathrm{~g}$ 's. Obviously, the stress produced by conventional recoil is one-tenth of this amount or $17.8 \mathrm{MPa}(2,610 \mathrm{psi})$ since recoil acceleration is only $9.98 \mathrm{~g}^{\prime} \mathrm{s}$. Force produced by gas pressure is $92.3 \times 10^{6} \mathrm{~N}(20.78 \mathrm{million}$ lbf.) which produces a shear stress of $178.5 \mathrm{MPa}(26,240 \mathrm{psi})$. Since this stress is applied simultaneously with peak recoil stress, the total stress during the early portions of the acceleration profile is $196 \mathrm{MPa}(28,850$ psi). Again, all of these stresses are well within the safe limits. 
The threads on the breech block, (G in Figure 2.15), must withstand forces produced by gas pressure, recoil and antirecoil. Shear stress produced by gas pressure is 153.1 MPa $(22,500 \mathrm{psi})$ and anti-recoil stress is only $8.8 \mathrm{MPa}(1,293 \mathrm{psi})$. Again, no problem here.

The manifold blocks into which the gas storage tubes are screwed must withstand outward-directed gas pressure forces at their weld joints to the support plates, ( $\mathrm{H}$ in Figure 2.15). The force on each block produced by gas pressure is $20.92 \times 10^{6} \mathrm{~N}$ (4.71 million lbf.). If $100 \mathrm{~mm}$ (4") welds are used all around these blocks to affix them to the plates, stresses within the weld joints may be reduced to $110.9 \mathrm{MPa}(16,300 \mathrm{psi})$ which may be regarded as "safe". A relatively simple calculation was carried out to evaluate the tensile load on the four bolts, ( $J$ in Figure 2.15), which connect the downstream ends of the gas storage tubes to the most downstream storage tube support. Here, the mass of the storage tube support must be accelerated to $9.88 \mathrm{~g}^{\prime} \mathrm{s}$ during conventional recoil (the joint is pushed closed during the later anti-recoil acceleration). A total force of $8.88 \times 10^{4} \mathrm{~N}(20,000$ lbs.) is produced which represents only $2.2 \%$ of the designated 3 " socket head cap screw's strength.

The final computation involves the wall of the gas storage tube near its upstream end ( $\mathrm{K}$ in Figure 2.15). Here, the wall is subjected to the radial tangential and axial stresses associated with high gas pressure plus the additional axial stress produced by conventional recoil acceleration. We use thick-tube theory and the von Mises formalism described in paragraph 2.2.3.2 of this report to evaluate the total equivalent stress on the wall material as $530.0 \mathrm{MPa}(77,900 \mathrm{psi})$. This is, by a substantial amount, the largest stress applied to any component of the piston driver gas storage system. A decision will have to be made during detailed design of the facility about whether or not to reduce this stress by increasing wall thickness of the gas storage tubes. Making such an increase will substantially increase the mass of the launcher which, in-turn, affects recoil and anti-recoil acceleration levels plus the stresses they produce at many locations in the gun structure.

\subsubsection{Pump Tube.}

The pump tube is, by far, the largest and most massive component of the contemplated $250 \mathrm{~mm}$ launcher. It is expected to weigh near $250 \mathrm{MT}$. It is, basically, a pipe .914m (36") in diameter by $91 \mathrm{~m}$ ( $300 \mathrm{ft}$.$) long whose side walls must withstand$ peak pressures near $100 \mathrm{MPa}(15,000 \mathrm{psi})$ and substantial axial forces near both ends produced by both recoil and anti-recoil accelerations, Figure 2.16 is a plot of peak internal gas pressures experienced by the pump tube wall as a function of piston position along the 100 meters of tube length. Note that the helium driver gas pressure falls rapidly from its initial value of $100 \mathrm{MPa}(15,000 \mathrm{psi})$ near the rear end of the tube to 


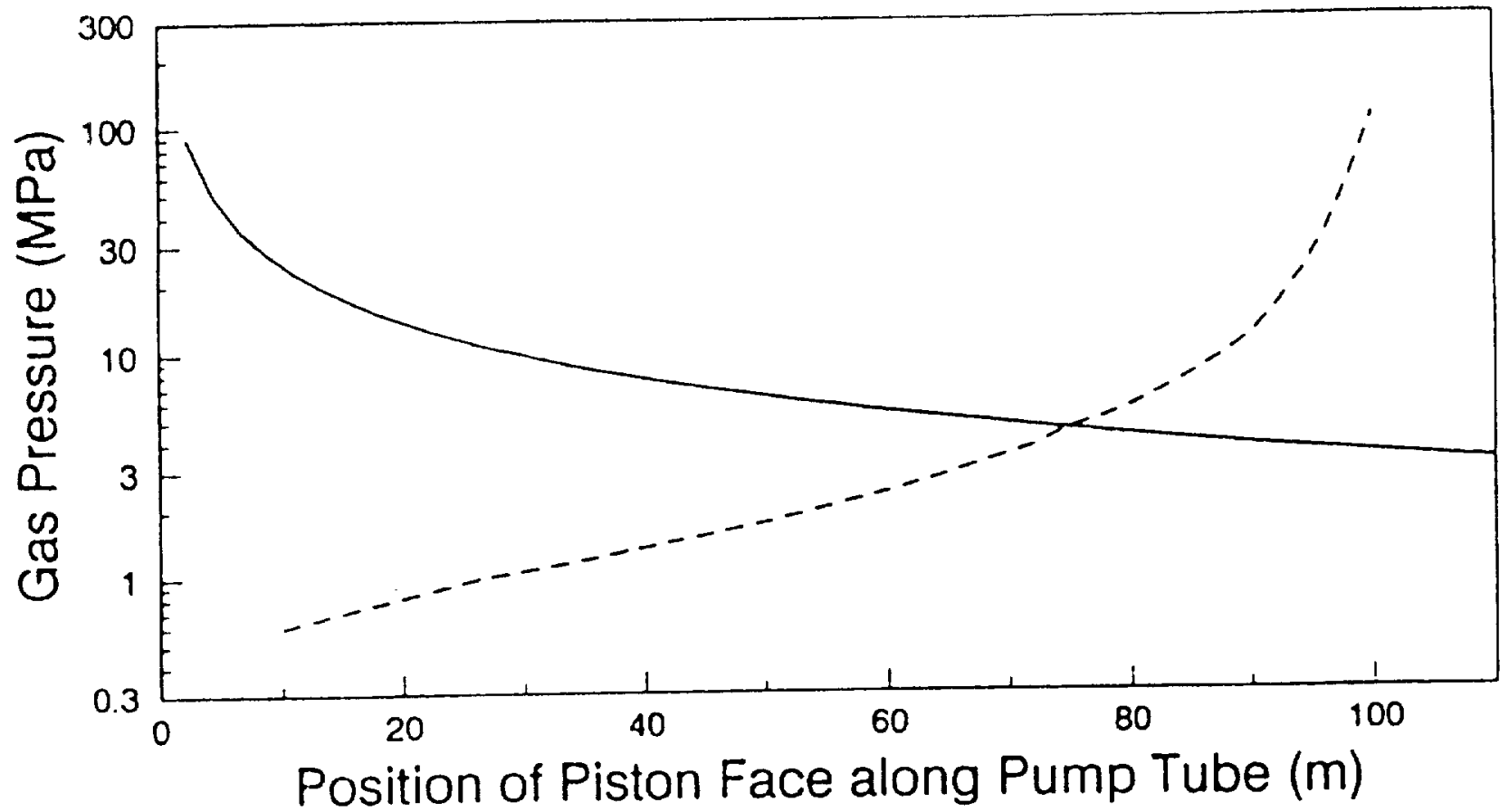

behind piston ahead of piston

Figure 2.16 Helium Driver Gas Pressure behind Piston and Hydrogen Gas Pressure Leading Piston vs. Distance of the Piston from the Rear End of the Pump Tube.

3.0 MPa $450 \mathrm{psi}$ at the downstream end of the tube. Meanwhile, hydrogen gas pressure ahead of the piston rises rapidly from an initial pressure of $680 \mathrm{KPa}$ as piston position advances downstream until it equals helium pressure at the 75 meter mark. It then continues to rise rapidly and reaches $100 \mathrm{MPa}(15,000$ psi) as the piston enters the central breech located immediately downstream of the pump tube.

Unfortunately, the longest sections of pump tube which can be manufactured conveniently are $10.7 \mathrm{~m}$ (35 ft.) long when the pump tube wall thickness is $100 \mathrm{~mm}$ (4") and less. Pump tube sections requiring $150 \mathrm{~mm}$ ( $6^{\prime \prime}$ ) thick walls must be limited in length to $5.5 \mathrm{~m}$ (18 ft.) to maintain their masses below $20 \mathrm{MT}$ which is the handling limit in many machine shops such as National Forge Corp.. For these reasons, the pump tube must be divided into fifteen segments so a premium must be placed upon designing efficient and cost-effective joints between ends of the individual tube segments. The concept chosen is a gib clamp arrangement presented in Figure 2.14. The heart of the joint is a boss/receptacle pair near the tube bore which is used to assure proper alignment of the components and to support dual "O"-ring seals needed to make the entire tube gas-tight. Flat faces 
extend from these components that bear the closure loads at the joint. (The end of the boss is designed to clear the end of the receptacles by somewhat less than $0.1 \mathrm{~mm}(0.004 ")$. The outer surfaces of trapezoidal gib "ears" are more-or-less identical on the male and female sides of a joint. A female gib clamp spans these trapezoidal surfaces and engages them with matched female equivalents. The extreme ends of the female gib clamps are bolted to the tube walls just beyond the gib ears. The gib clamps are, actually, sectors of a circular structure which surrounds the gib. Each of the eight components which represents somewhat less than $45^{\circ}$ of the circle is installed separately and held in place with four bolts. These bolts need to provide no radial constraint to the female gib clamps if the joint is designed with the gib angle, $\phi$, less than the critical friction angle, $\phi$, defined in Equation 2.24. The bolts serve the dual purpose of providing clamping force and preventing the female gib clamp sections from being bent outward under the action of massive axial forces trying to open the joint.

Since peak gas pressures in the pump tube and the joints at each end are limited to $100 \mathrm{MPa}$, conventional o-ring seals may be used to contain them. The joint depicted in Figure 2.14 shows a boss and receptacle pair that are used both to assure proper alignment of the tube components and to support the dual "O"-ring seals. The joints are designed to close against the large surface areas outside of the boss and receptacle rather than at the upstream end of the boss (where a gap of $50 \mathrm{u} . \mathrm{m}$. to $100 \mathrm{u} . \mathrm{m}$. is specified).

clearly, the most heavily stressed gib joint is the one at the downstream end of the pump tube which connects it to the upstream end of the central breech. (Joint 16 listed in Table 2.4) This gib joint must transfer enough force to the pump tube and the gas storage assemblies (which weigh a total of $371 \mathrm{MT}$ ) to produce recoil and anti-recoil accelerations. The anti-recoil acceleration of $98.84 \mathrm{~g}$ 's produces a separation of force of $3.59 \times 10^{8} \mathrm{~N}$ (81 million lbf.). The gib arrangement we have chosen has "ears" $100 \mathrm{~mm}$ tall by $200 \mathrm{~mm}$ wide. Its strength according to Equation 2.25 is $f_{g}=4.37 \times 10^{8} \mathrm{~N}(98.4 \mathrm{million}$ lbf.). The safety margin for this design appears to be adequate.

The tube wall immediately upstream from the gib flange in question must also sustain the same axial load as the gib while simultaneously containing internal pressure of $100 \mathrm{MPa}(15,000$ psi). The von Mises equivalent stress applied to the material near the inner wall is $\sigma_{\mathrm{vm}}=713 \mathrm{MPa}(104,800 \mathrm{psi})$. This stress is the highest yet encountered in the launcher design and would normally indicate that the tube wall should be thickened well beyond 150mm. Unfortunately, this course is unavailable because the masses of the individual tube sections already restrict their length to only 5.5M. Steel is available for these tubes with yield strengths in excess of $1.2 \mathrm{GPa}(175,000 \mathrm{psi})$. It is an effective necessity that steel of this strength level be used for several of the launch tube segments. 


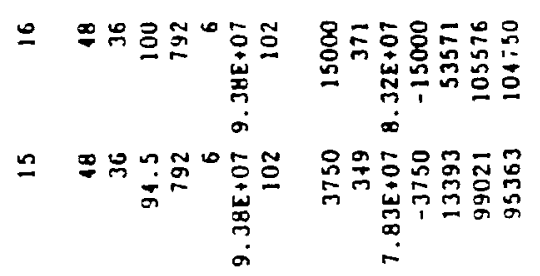

曼

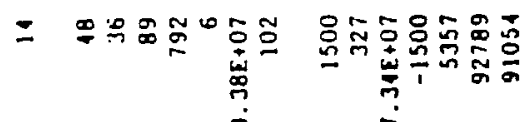

$=$ 융

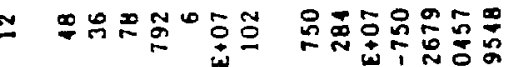

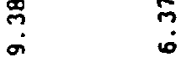

賕员

o

묀

虽吕

분

官。

क

茫空

3 톤

国

a

थ

is

国

悹

$\circ 0$

品昆

봉

잉

iv

=

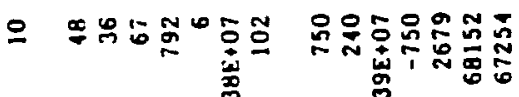

-

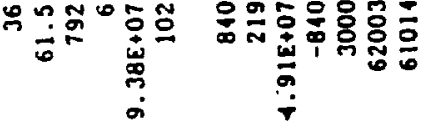

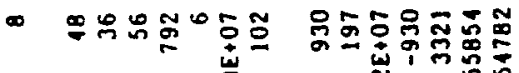

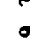

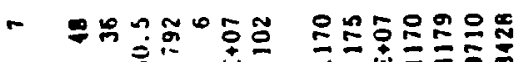

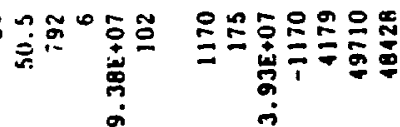

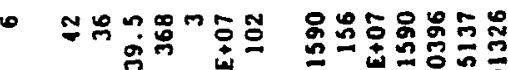

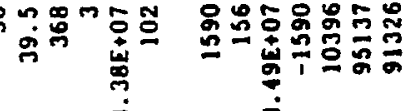

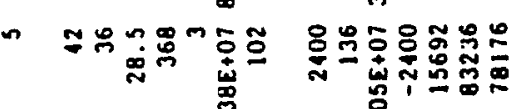

$\infty$

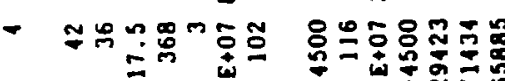

:

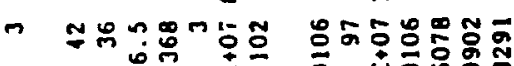

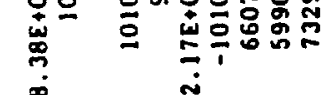

岂

옹

秃.

芒

E)

崩

点

Q

$+\stackrel{4}{4}$

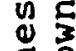

동

运

$0 \stackrel{0}{1}$

岳芒

in the

$\rightarrow \stackrel{0}{1}$

茫

คั

$\ddot{0}$

i.

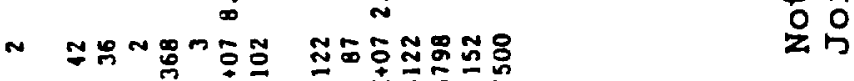

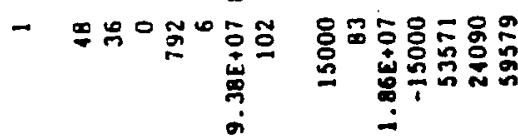

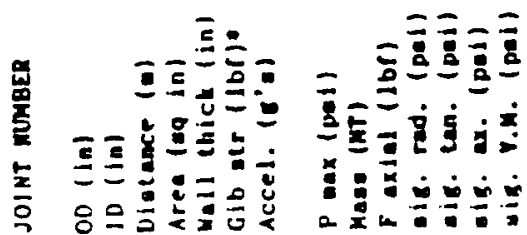


The remainder of Table 2.4 treats the 16 joints required for the pump tube assembly. As we consider joints upstream from the first one, the pressure to be contained falls rapidly since it is dominated by that of the hydrogen gas being compressed by the oncoming piston. The force required to impart anti-recoil acceleration to the remaining upstream portions of the pump tube and the gas storage facility drops steadily due to the fact that part of the pump tube is already downstream from the joints in question so they need not transmit acceleration forces to them. peak stresses remained high enough to assure the need for $150 \mathrm{~mm}$ pump tube walls for the first 11 tube segments (55M), at which point, the von Mises stress has fallen to $329 \mathrm{MPa}(48,400 \mathrm{psi})$. Note that the axial component of the force falls monatomically with increasing joint number due to the steadily decreasing mass lying beyond the joint. The radial and tangential components of the von Mises stress pass through a minimum between joints 5 and 6 and then increase for the remainder of the joints up to a maximum of $100 \mathrm{MPa}$ which is the gun's gas loading pressure. This increase is due to the fact that the upstream $75 \mathrm{~m}$ of the pump tube has its internal gas pressure dominated by the piston driver charge.

At joint 6 , the total load on the pump tube wall falls to the point where its thickness can be cut in half (to $76 \mathrm{~mm}, 3$ "). The von Mises stress increases to $621 \mathrm{MPa}(91,300 \mathrm{psi})$ due to the reduction of wall thickness. This stress then recommences it's drop toward the uprange end of the tube. Stress levels produced in the most upstream launch tube segment (1.0m long) has been considered in an earlier paragraph.

\subsubsection{Central Breech.}

By far, the most complex design task for the $250 \mathrm{~mm}$ light-gas gun is the central breech because of its size and the stresses under which it must operate. A sketch of the design we have chosen is presented in Figure 2.17. Basically, it consists of an interior core made from two pieces shrink-fit together and a stack of 6 massive disks which fit over it. Total mass of the assembly just exceeds $131 \mathrm{MT}$. A gib arrangement is included at each end of the core to allow effective connection to the pump tube and the launch tube. The interior surface of the core consists of a slightly convergent taper which reduces the bore diameter from $0.914 \mathrm{~m}$ (36") that aligns with that of the pump tube to $0.864 \mathrm{~m} \mathrm{(34")}$ over a distance of $2.54 \mathrm{~m}$ (100"). The taper angle increases to $40^{\circ}$ included beyond this point which reduces the bore diameter to $248 \mathrm{~mm}$ (9.76") at a distance of $3.33 \mathrm{~m}$ (131") from the downstream end of the pump tube. This hole diameter is maintained to the downstream end of the section.

The core dimensions are insufficient to provide strength necessary for containing the high internal pressures produced during gas gun firings. A series of massive steel disks are added to the outer diameter of the breech core opposite areas where intense internal pressure is produced. Each disk is $2.74 \mathrm{~m}$ 

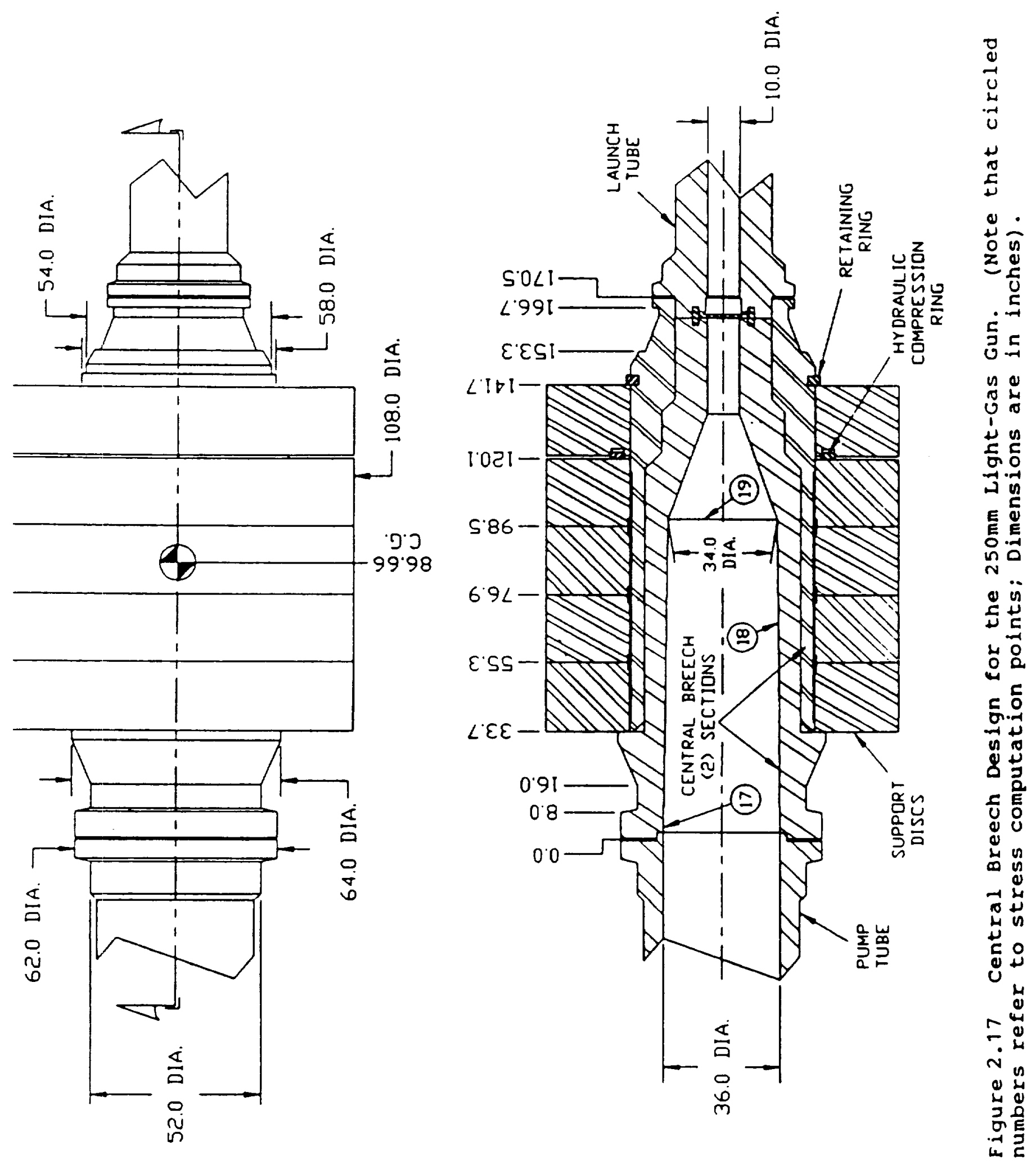
(108") in diameter by $0.45 \mathrm{~m}$ (18") thick and weighs $15 \mathrm{MT}$. A small gap (approximately $6.35 \mathrm{~mm}$ (.25") wide is left between the disk I.D. and the O.D. of the core. This continuous gap is filled with molten wood's metal during on-site installation which is allowed to harden to form a hydrostatic bond between the disks and the outer wall of the core. The bond allows radial stresses to be transmitted from the core to the disks relatively unimpeded so that the full mass and strength of the disks can be employed to support the core walls against radial expansion.

The stresses induced along the inner wall of the core assembly are presented in Table 2.5. Locations of the stations are identified in Figure 2.17. The Von Mises formalism was used to evaluate expected composite stress levels. The internal pressures were established by making the conservative assumption that the diaphragm at the end of the launch tube never opens. Isentropic compression of the hydrogen gas charge continues as the piston advances until a pressure of $680 \mathrm{MPa}(100,000 \mathrm{psi})$ is reached. We then assume that pressure remains constant during the remainder of the piston advance. The results are presented in Figure 2.18. The curve is also continued to a pressure of 1.0 $\mathrm{GPa}(150,000 \mathrm{psi})$ which represents the absolute maximum gas pressure considered. Radial stress is, simply, the negative of local pressure. Tangential stress is calculated by assuming: (1) that the disks are available to provide support against diametral growth and; (2) that the shrink-fit of the outside collar preloads the material at the inner surface to its yield strength in tangential compression (i.e. $\sigma_{\text {to }}=-1.0 \mathrm{GPa}$ ). Finally, we assume that the core composite supports the entire axial stress produced by anti-recoil at the same time that it is loaded radially and tangentially by internal pressure.

The results are that extreme peak Von Mises equivalent stress reach $935 \mathrm{MPa}(137,400 \mathrm{psi})$ which is within $20 \%$ of the material's elastic limit. Under these circumstances, only negligible plastic deformation may be expected but the metal will fatigue which eventually will lead to breech failure. This result is only to be expected since central breeches of all light-gas guns built to date have finite lifetimes. The situation becomes more critical at stations 17 and 18 when a misfire is considered that produces peak gas pressures near 1.0 GPa $(150,000 \mathrm{psi})$. Equivalent stress levels then rise to 1.53 $\mathrm{GPa}(225,000 \mathrm{psi})$. Such loading can be contained by the central breech structure but it will produce substantial permanent material deformation that will lead to an early failure.

Care must be taken to assure that the disks remain in position during gun firing when recoil and anti-recoil forces tend to move them axially. The recoil acceleration tends to force the disks downstream against the retaining ring at their downstream end and also against the hydraulic compression ring used to clamp the disk assembly together. The total mass of the disks is $92.5 \mathrm{MT}$. When subjected to recoil acceleration, a force 
TABLE 2.5 STRESS LEVELS AT THE BORE SURFACE WITHIN THE CENTRAL BREECH.

\begin{tabular}{llrrr} 
& POSITION NUMBER & 17 & 18 & 19 \\
C OD (in) & 62 & 108 & 108 \\
E ID (in) & 36 & 35 & 34 \\
N Distance (m) & 0 & 1.5 & 2 \\
$T$ Area (sq in) & 2001 & 8199 & 8253 \\
R Wall thick (in) & 13 & 36.5 & 37 \\
A Gib str (lbf)* & $9.72 E+07$ & --- & --- \\
L Accel. (g's) & 101 & 101 & 101 \\
B P max (psi) & \multicolumn{4}{c}{} \\
R Mass (MT) & 15000 & 87022.10 & 100000 \\
E Faxigl (lbf) & $1.53 E+07$ & $12.37 E+07$ & 120 \\
E sig. rad. (psi) & -15000 & -87022.1 & -100000 \\
C sig. tan. (psi) & -134741 & -57554 & -42998 \\
H sig. ax. (psi) & 7630 & 63041 & 43788 \\
& sig. V.M. (psi) & 132513 & 137714 & 125411 \\
& * Value given is the sheer strength of the gib
\end{tabular}

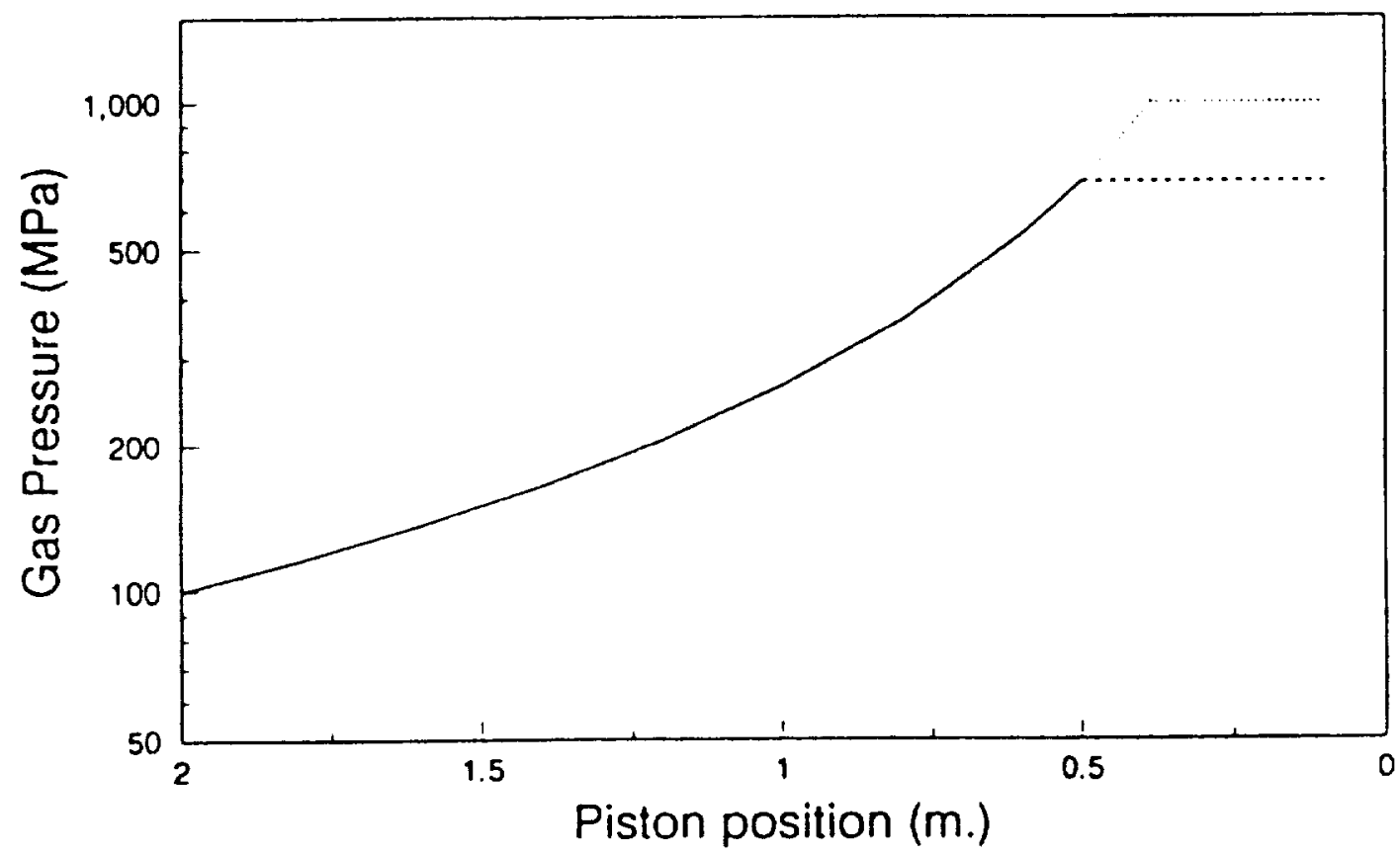

Figure 2.18 Hydrogen Gas Pressure vs. Piston Position as the Piston Completes its Compression stroke within the Central Breech. 
of $8.97 \times 10^{6} \mathrm{~N}(2.02 \mathrm{million}$ lbf.) is produced. Anti-recoil acceleration produces a force of $8.97 \times 10^{7} \mathrm{~N}(20.2 \mathrm{mill}$ ion lbf.) This force distributed over the loading surface of an ear extending from the breech core at the upstream end of the disk stack produces a surface compressive stress of $258 \mathrm{MPa}(38,000$ psi) which represents no serious design problem. (together with the lower shear stress induced across the base of the ear) During conventional recoil, the load is borne in shear by a $150 \mathrm{~mm}$ $x 150 \mathrm{~mm}$ retaining ring which is loaded in shear to $13.5 \mathrm{MPa}$ $(1,980 \mathrm{psi})$.

A toroidal hydraulic compression piston (ring) is mounted in the upstream surface of the most downstream strengthening disc. It is used to clamp all of the discs firmly into the space supplied for them. A similar, but smaller, ring is operating successfully with a light-gas gun located at the U.S. Naval Weapons center in California. The hydraulic compression ring must bear $5 / 6$ of the conventional acceleration force plus $1 / 6$ of the anti-recoil force (which amounts to $16 \times 10^{6} \mathrm{~N}(3.6 \mathrm{mill}$ ion lbf.). If the ring which has an interior diameter of $1.62 \mathrm{~m}$ (64") and an exterior diameter of $1.93 \mathrm{~m}$ ( $76^{\prime \prime}$ ) is charged to a pressure of $68 \mathrm{MPa}(10,000 \mathrm{psi})$, it produces a compression force of $5.8 \mathrm{x}$ $10^{7} \mathrm{~N}$ (13.2 million lbf.) which is 3.63 times larger than necessary. Thus, the stack of strengthening disks may be counted upon to remain in place during firings of the light-gas gun and to lend their strength to the central breech core, thereby insuring its safety and longevity.

\subsubsection{Launch Tube.}

The launch tube is exposed to pressures nearly as high as those experienced by the downstream end of the central breech (between $680 \mathrm{MPa}$ and $1.0 \mathrm{GPa}$ ). It is, basically, a tube $75 \mathrm{~m}$ long with a precision bore whose diameter is near $250 \mathrm{~mm}$. The first 36 meters of the tube have an $O . D$. of $0.75 \mathrm{~m}$ (30") which is required to support peak internal pressures which achieve momentary values as high as $680 \mathrm{MPa}(100,000 \mathrm{psi})$. The next 18 meters have an $0 . D$. of $60 \mathrm{~cm}$ (24") reflecting the progressive reduction in potential peak pressures to be experienced. The final 20 meters of the tube have an O.D. Of $.45 \mathrm{~m}$. The tube is made up of a total of 10 segments. Again, care must be taken to assure that joints are relatively economical to manufacture. The massive tube segments at the upstream end of the launch tube assembly are limited by weight constraints to lengths near $6.0 \mathrm{~m}$ each. The remainder of the tubes are limited by fabrication technology to lengths of approximately $10 \mathrm{~m}$ each.

Provision must be made at the joint between the central breech and the launch tube to accept a petaling diaphragm used for switching gas flow into the launch tube once a critical gas pressure has been achieved. The diaphragm assembly chosen is presented in Figure 2.19. It consists of the diaphragm, itself mounted in the upstream end of the launch tube, a toroidal surface behind it where the torn segments (petals) can open and a pair of facing grooves to accommodate a high pressure seal "diamond seal" used to prevent escape of the projectile driver gas. A secondary (D.C.) seal prevents the gas charge from leaking past the diaphragm after the gun is prepared for firing but before it is fired. 


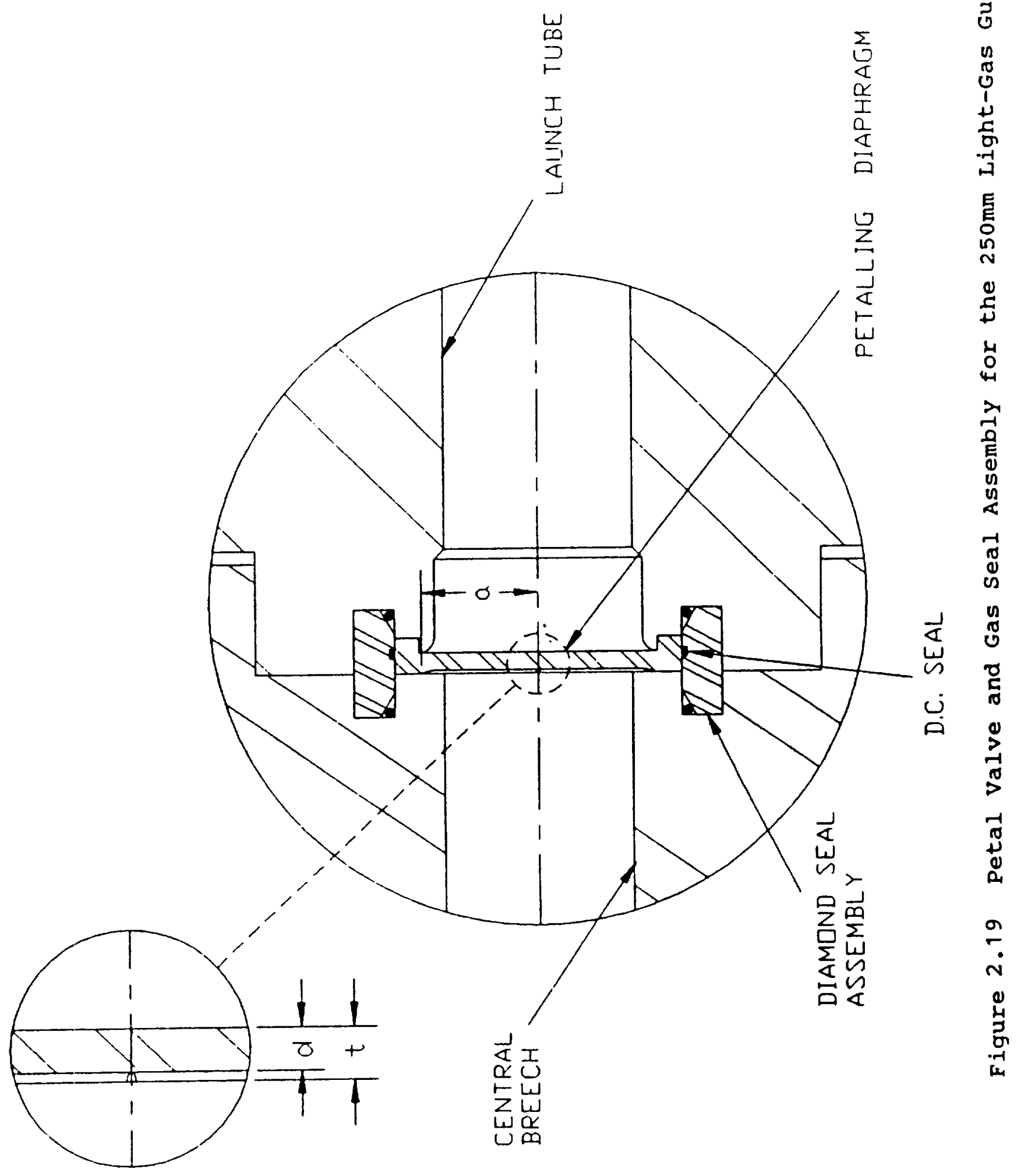


In operation, the diaphragm first bulges into its receptacle and then tears along three grooves machined into its face to form six petals that fold back into a shallow recess surrounding the opening into the launch tube to expose the launch tube bore to unobstructed gas flow. A rim is added around the diaphragm to terminate tearing and form a step to hold it in place. Diaphragm blanks are, traditionally, formed from AISI 302 or AISI 304 stainless steel because of its reasonable tensile strength $\sigma_{t}=578 \mathrm{MPa}(85,000 \mathrm{psi})$ and enormous elongation-to-failure $\left(\epsilon_{\text {rupt. }}>75 q\right)$. They are sized to rupture at a predetermined pressure using an analysis developed originally for the Navy(6). Basically, a factor, $\epsilon_{\text {au }}$, is calculated for a diaphragm design according to Equation 2.27:

$$
\epsilon_{a u}=\frac{\sigma_{u I t}}{E} \frac{d}{t}
$$

where:

$$
\begin{aligned}
& \sigma_{u l t}=578 \mathrm{MPa}(85,000 \mathrm{psi})=\begin{array}{c}
\text { Ultimate tensile yield strength } \\
\text { for AISI } 304 \text { stainless steel. }
\end{array} \\
& \mathrm{E}=190 \mathrm{GPa}\left(28 \times 10^{6} \mathrm{psi}\right)=\begin{array}{l}
\text { Elastic Modulus of AISI } 304 \\
\text { stainless steel. }
\end{array} \\
& \mathrm{d} / \mathrm{t}=0.8 \text { (See Figure } 2.19 \text { for specific definitions. }) \\
& \bar{\epsilon}_{\mathrm{au}}=.0024
\end{aligned}
$$

The value for $\epsilon_{\text {au, }}$ is used to determine which curve in Figure 2.20 is used for evaluating rupture strength, $P_{r}$ (normalized to elastic modulus, E) vs. total diaphragm thickness, $t$, (normalized to free span radius, a, from Figure 2.19) For instance, the calculated value of $\epsilon_{\text {au }}=.0024$ is mid-way between $\epsilon_{\text {au }}=.0023$ and .0025 . A desired rupture pressure of $\mathrm{P}=100 \mathrm{MPa}$ $\left(\mathrm{P} / \mathrm{E}=.526 \times 10^{-3}\right)$ infers a ratio $t / a=0.103$. If $a=150 \mathrm{~mm}$, then the total diaphragm thickness, $t=15.45 \mathrm{~mm}$ (.608").

The diamond seal which surrounds the diaphragm blank has proven uniquely effective for sealing ultra high pressure gas. It is, basically, a steel ring that spans to grooves cut opposite one-another in facing surfaces of a joint to be sealed. Triangular openings made by chamfering the two inner corners of the ring are filled with "O"-rings. In operation, pressurized gas enters the inner portion of the grooves but is prevented from passing the "O"-rings until pressures approach $500 \mathrm{MPa}(73,000$ psi) which is sufficient to extrude the "O"-ring material. Simultaneously, this pressure forces the ring to expand outward against the outer walls of the grooves where a tight metal-tometal seal forms that only tightens as gas pressure increases. Lack of gas flow protects the "O"-rings from being extruded which 


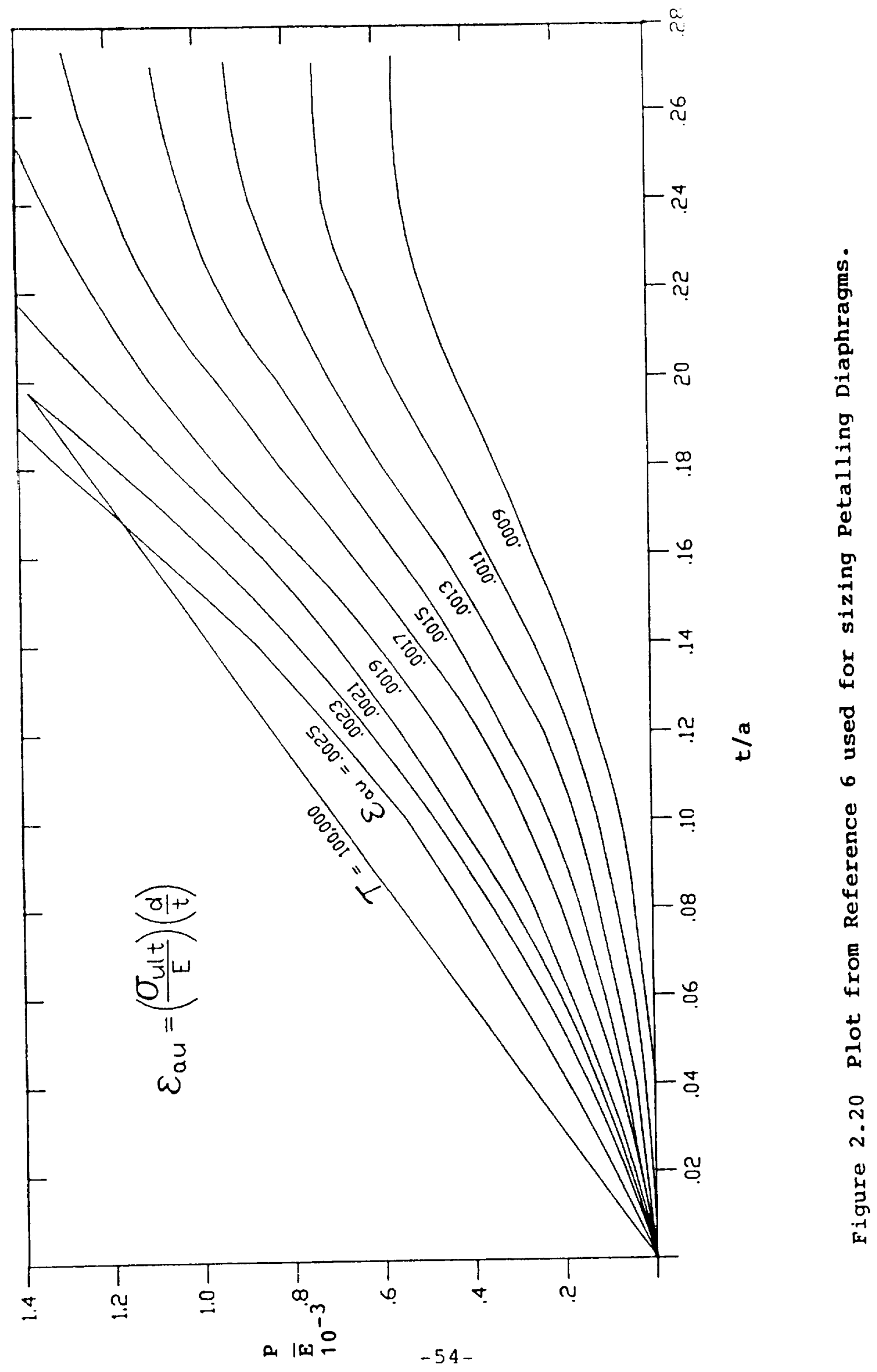


allows them to survive. Diamond seals have operated effectively at gas pressures well above the highest anticipated here, $\mathrm{P}_{\max } \geq$ $1.0 \mathrm{GPa}$.

of critical importance to proper operation of the launcher is the straightness, circularity, diametral constancy, and finish of the composite launch tube bore. Also included in this category are the joints between the launch tube segments. The requirement for extreme bore conditions arises because of the high speed of the projectile/sabot package as it passes along the tube (particularly downstream portions of it). Impacts with steep obstructions, even tiny ones, produce shockwaves of extreme intensity in both the sabot and bore wall materials. Impacts between strong plastic material (typical of sabots) and steel at velocities near $6.1 \mathrm{~km} / \mathrm{sec}$ produce shockwaves with normal stresses exceeding $100 \mathrm{GPa}$ ( $15 \mathrm{million} \mathrm{psi}$ ). This pressure far exceeds the strength of both materials so it causes substantial deformation. In the bore wall, such deformation produces even larger bore interrupting surfaces which, in turn, cause destruction to grow at a regenerative rate during subsequent firings. Deformation is produced locally near the impact point on the sabot and propagating shockwaves produced by the impact cause a variety of mischiefs deep within the sabot structure and within models they contain. For this reason, the bore surface must be kept smooth when it is manufactured, must be treated carefully during launcher assembly, and must be monitored and honed periodically during gun operation. Opinions vary about how often bore tubes should be honed. Some facilities hone between every firing while others allow up to 100 shots to elapse between honings. Probably cursory honing every 5 to 10 firings would be prudent with the contemplated launcher.

obviously, positive steps in the bore wall are anathema! such steps become unavoidable when simple boss receptacle joints are used to interconnect tube segments if steps are not taken to prevent them. Clearances must be allowed between the male bosses and the female receptacles. Three approaches have been employed to eliminate such steps. The most conservative is to "bellmouth" the upstream-facing end of each launch tube segment. Basically, a very slight taper is machined into the bore wall which starts $300 \mathrm{~mm}$ (12") or so from the upstream end of each segment and causes progressive bore growth to the upstream end of the segment. An exaggerated view of the situation is presented in Figure 2.21. The growth must exceed twice the diametral clearance between the boss and receptacle if all possibility of a positive step forming is to be eliminated. Typical diametrical clearances between a boss and mating receptacle of the size required for the $250 \mathrm{~mm}$ bore tube is $100 \mathrm{u.m}$. (.004") so the "bell-mouth" must exceed $200 \mathrm{u} . \mathrm{m}$. (.008") diameter. This procedure leads to impacts between the oncoming projectile and the conical portion of the bore wall but these impacts occur at grazing angles of incidence. For the example cited above, the 


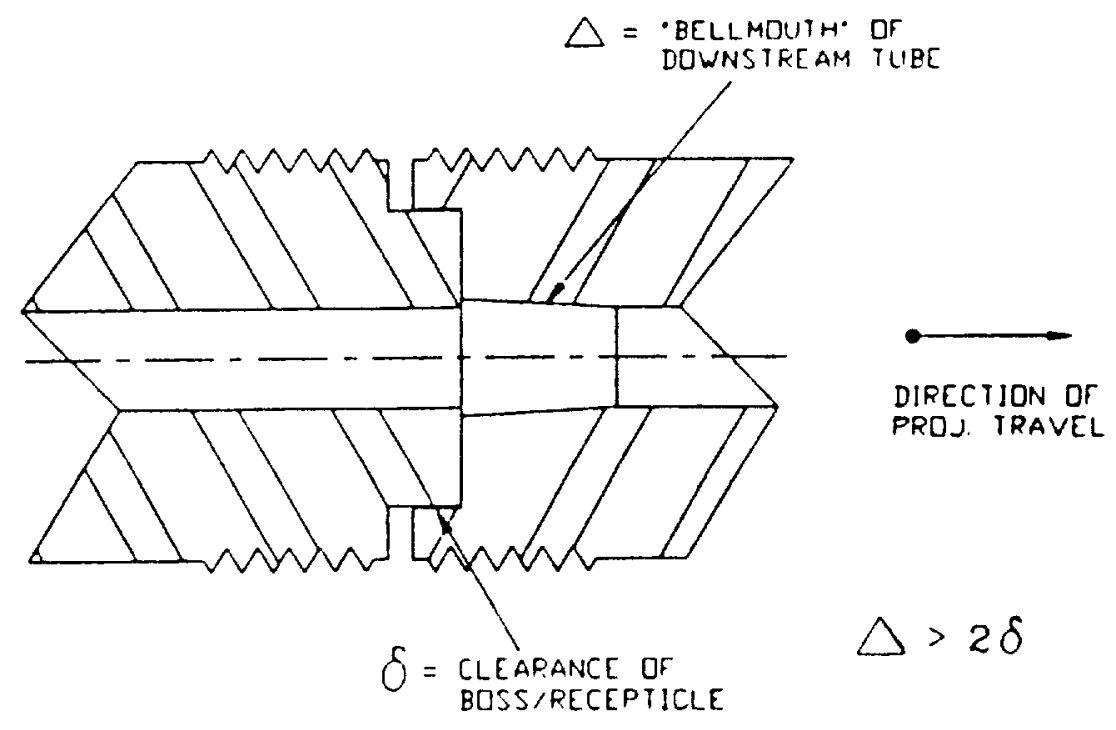

Figure 2.21 Demonstration of "Bellmouthing" Used to Eliminate steps in a Bore Wall that Face Upstream.

highest normal velocity component (which is responsible for producing shock stress) is, merely, $2.0 \mathrm{~m} / \mathrm{sec}$. Resulting shockwaves from such impacts may be ignored safely.

The next more aggressive approach is to fabricate the boss to make a mild interference fit with its mating receptacle. The interference fit eliminates lateral play in the joint once it is assembled so that deviation between bore axes of the two components is limited to machining errors (which can be reduced to $25 \mathrm{u} . \mathrm{m}$. (.001"). The downstream bore "bell mouthing" required in this situation is, again twice the maximum deviation, or 50 u.m. (.002"). The problem with using interference fits is that the joint must be forced together during assembly with typical forces up to $10,000 \mathrm{~N}(2,200 \mathrm{lbf})$ and the joints must be pried apart with similar forces whenever they are opened.

The most aggressive solution to the problem is to make the joint adjustable so that it may be driven all the way to zero alignment error. Basically, a boss and receptacle joint is fabricated with substantial clearance (typically $0.5 \mathrm{~mm}$ ) (.02"). A series of large-diameter set screws are employed to drive the bore within the boss into precise alignment with the bore just beyond the receptacle. A special bore straightness gauge is then used to sense local bore misalignments with a sensitivity somewhat better than $2.5 \mathrm{u} . \mathrm{m}$. (.0001"). Once four principal set screws are positioned, an additional larger number (typically 12) are tightened into position to stabilize the joint which may now be closed finally and reinforced. 
The adjustable joint is, clearly, the most elegant solution to the problem and produces the very finest quality bore. A true statement about mechanical systems has been made by many investigators "the stability of any adjustment is inversely proportional to its adjustability". Applying this viewpoint to the situation at hand provides the warning that adjustable joints can readily go out of adjustment, so care must be taken to monitor such joints almost continuously. Probably the best solution to the joint alignment problem for the gun being contemplated is either the conventional boss receptacle joint with bore "bell mouthing" or, possibly, the interference bossreceptacle joint with limited bore "bell mouthing".

The other problem with bore condition is straightness. Deviations from straightness can be produced both by misalignment of launch tube segments and bore curvature within the segments. Misalignment can, in principal, be eliminated through careful assembly of the launcher and periodic monitoring of gun geometry. Care must also be taken to assure that the ends of each segment are machined precisely perpendicular to the local axis of the bore as it emerges from each end of the segment. Deviation from perpendicularity at these locations produce discontinuous changes in the direction of the bore axis which produce high lateral acceleration levels in launched projectile/sabot packages. The remaining problem involves curvature of the bore within the segment. The transverse acceleration produced on the projectile by such curvature, ar may be evaluated in terms of projectile velocity, $U_{p}$ and radius of curvature, $R_{r}$ using Equation 2.28 .

$$
a_{Y}=\frac{U_{P}^{2}}{R_{I}}
$$

As an example of this effect, consider a gun tube bore bent into a radius of curvature of $\mathrm{R}_{r}=1.0 \mathrm{Km}$ near the downstream end of the gun's launch tube where projectile velocity is near $\mathrm{U}_{\mathrm{p}}=6.0 \mathrm{~km} / \mathrm{sec}$. The transverse acceleration experienced by the projectile package is $a_{r}=3670 \mathrm{~g}^{\prime} \mathrm{s}$ which is near a maximum that should be permitted. A'minimum radius of curvature for the contemplated gun's launch tube should be placed near $R_{r}=1.0 \mathrm{~km}$. Measuring such a radius of curvature directly is awkward, so an indirect measurement approach is generally used. If a span along the bore, $h$, is considered, deviation of the bore axis from a straight line connecting the centers of the bore at the end of the span, $\delta$ becomes a measure of bore curvature. Radius of curvature, $R_{r}$, the span chosen, $h$, and deviation of the bore axis, $\delta$, may be interrelated using Equation 2.29.

$$
\delta=R_{x}-\sqrt{R_{x}^{2}-h^{2}}
$$


If Equation 2.29 is evaluated with a span length of $\mathrm{h}=1.0 \mathrm{~m}$ we find that a radius of curvature of $\mathrm{R}_{r}=1000 \mathrm{~m}$ produces a deviation of $\delta=0.5 \mathrm{~mm}(.02 ")$. Much literature on the subject of bore and shaft straightness refers to "Total Indicator Run-out" (TIR) which is just twice $\delta$ from Equation 2.29. Thus, the bore must have a TIR of less than $1.0 \mathrm{~mm}$ (.040") per meter (39.4") of span. Either measurement of $\delta$ or TIR curvature may be carried out readily on bore segments of the size contemplated using standard but large measuring instruments.

The next matter to be considered is the forces applied to the launch tube by firing cycles and the launch tube's response to them. The first force arises from the pressure of the driver gas as it flows down the tube bore to the base of the accelerating projectile package. Estimates of this gas pressure profile may be deduced from computer program outputs describing launcher performance. The results are only an estimate of reality because they are definitely not the base pressure experienced by the projectile but rather are an intermediate pressure between that experienced by the projectile and that in the central breech at the time the projectile passes a given point along the launch tube. The results of this exercise are presented earlier in the text as Figure 2.13 where estimated peak gas pressure experienced by the launch tube wall is plotted as a function of position along the tube. The slight increases in pressure short distances downstream from the rear of the tube over pressure at the rear of the tube occur because of shockwaves within the gas column that reflect off the base of the projectile and nearly double local pressure momentarily.

These pressures are large enough for the first $40 \mathrm{~m}$ of launch tube length to produce stresses beyond those sustainable by any reasonable steel from which the launch tube segments might be fabricated. For this situation, the launch tube O.D. is made three times its I.D. which produces as strong a practical configuration as is available and the tubes are "autofrettaged" before final bore preparation. Autofrettaging is a process where the drilled tube blanks are loaded hydraulically before the bore is finish-machined to a pressure somewhat above that anticipated during a firing at maximum performance. The inner-wall of the tube undergoes plastic deformation and the depth of the surface bounding plastic and elastic materials response sinks

progressively deeper into the bore wall as internal pressure is increased. Typically, this surface moves between $10 \%$ and $25 \%$ of the way through the wall during autofrettaging of a practical gun tube. After the internal pressure is removed, the metal that has deformed plastically remains permanently deformed and is loaded in compression by the remainder of the tube wall which deformed only elastically during the loading process. The only externally observable effect of this process is that the bore diameter increases by a small amount (typically less than 200 u.m.), (.008") for a tube of the size considered. Bore fabrication may then be completed by finishing the bore to its final desired diameter. Upon loading during a firing, the first substantial 
portion of the internal gas pressure rise is expended applying tensile stresses to the bore wall material that, simply, subtract from the compressive stress induced by autorrettaging. only when higher internal pressures are applied does net tensile stress first appear at the bore wall. properly conducted autofrettaging is more than sufficient for preparing gun tubes whose O.D.'s are three times their I.D.'s for internal pressures as high as are anticipated during firings of the contemplated light-gas gun. Autofrettaging can, in principal, be used to preload the material at the bore wall with tangential stress equal to the material tensile yield strength for the bore wall material being considered for this application (1.1 GPa, 165,000 psi).

The launch tube is also loaded in tension and compression in the axial direction by recoil and anti-recoil forces respectively. The tensile recoil forces must be large enough to provide $9.88 \mathrm{~g}$ 's of recoil acceleration to the launch tube's 175 ton mass. Anti-recoil forces produce $98.84 \mathrm{~g}$ 's of anti-recoil acceleration. The anti-recoil force is so large that it must be spread over the maximum possible area across the upstream end and at early joints of the launch tube in order to provide adequate support for it. For this reason, the joints are designed so that seals and bosses are located as close to the bore wall as possible and a small gap (typically $50 \mathrm{u} . \mathrm{m} ., .002 "$ ) is left between the end of the boss and the end of the receptacle as is sketched in Figure 2.22. Thus, the axial force is borne upon the flat faces of the joint extending outward from the boss to the outer limits of the gibs which are used to hold the launch tube segments together. The gibs are similar in design to those used on the pump tube but they can be made of much lighter construction since they need only hold the tube segments together against recoil forces and for alignment assurance. The only separation forces experienced by the launch tube assembly are produced by conventional gun recoil where the most highly stressed joints must provide the 175.9 ton mass of the launch tube a recoil acceleration of $9.88 \mathrm{~g}^{\prime} \mathrm{s}$. The recoil force is $17.05 \times 10^{6} \mathrm{~N}\left(3.83 \times 10^{6} \mathrm{lbf}\right)$. A listing of each launch tube joint together with its geometry and stresses it must bear is presented in Table 2.6 .

The joint between the launch tube and the central breech must be opened after every firing to remove the opened petal valve, renovate the seals, break free the compression piston, clean the launch and pump tubes, and reload the launcher with a new projectile package and burst diaphragm. A serious difficulty with conventional gib joints is the awkwardness of joint uncoupling/coupling which necessitates removal and replacement of four times as many bolts as individual gib elements (typically, 32 bolts/joints). We propose to eliminate this problem for this one joint by mounting the gib segments on the shafts of small hydraulic cylinders which pull them radially outward with a minimum of difficulty thus freeing the joint for opening after a firing. The joint can be reclosed after inter-shot tasks have been performed and the hydraulic cylinders used for compressing 


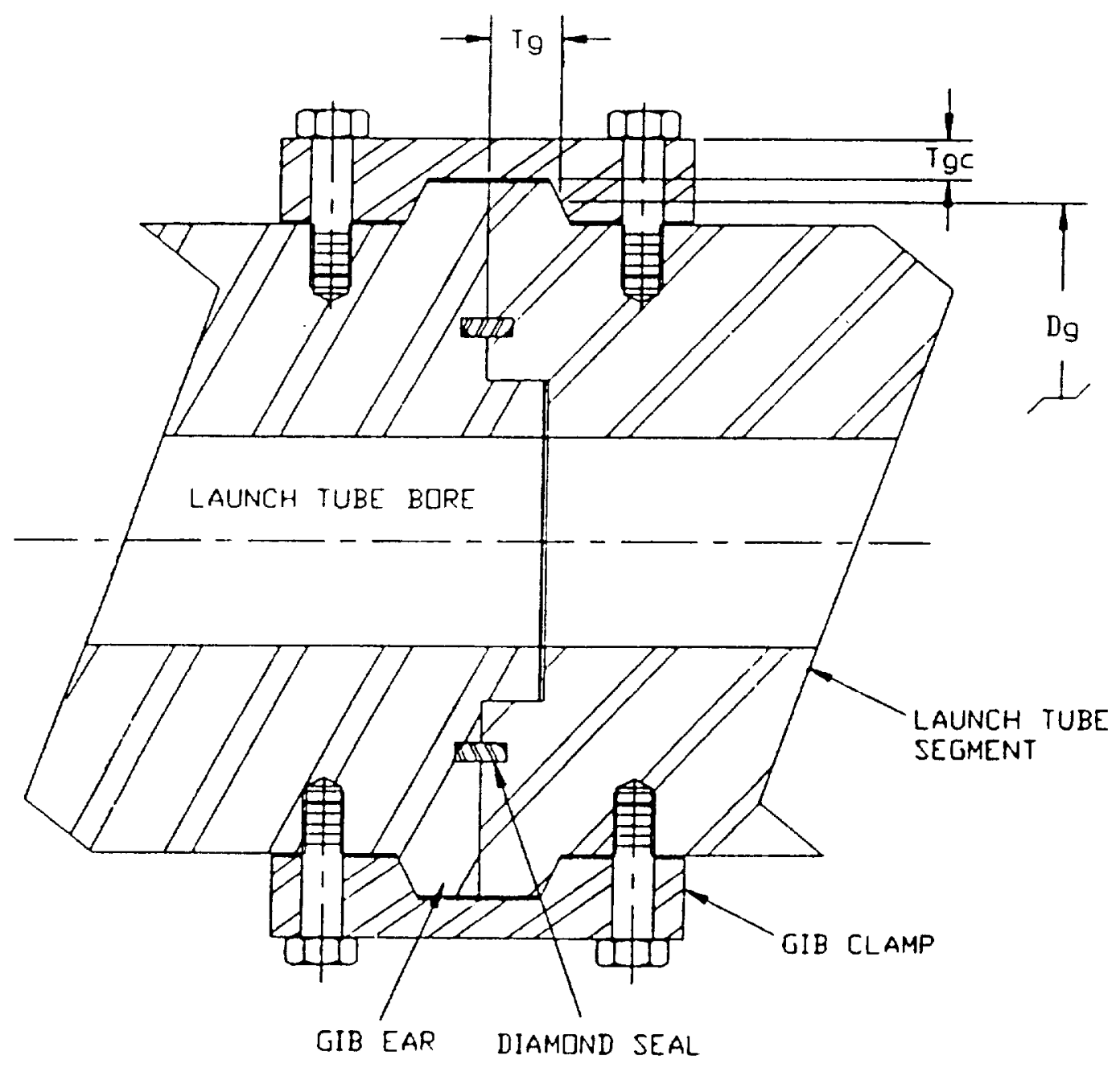

Figure 2.22 Typlcal Launch Tube Joint for the $250 \mathrm{~mm}$ Light-Gas Gun. 


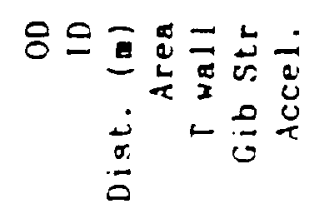

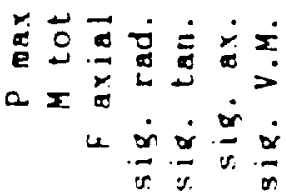

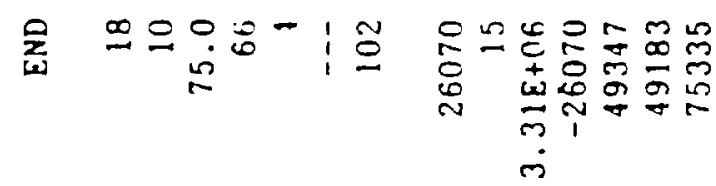

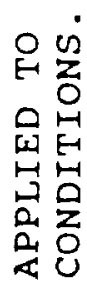

थी

空

至

的

的突

닌

世

z놀

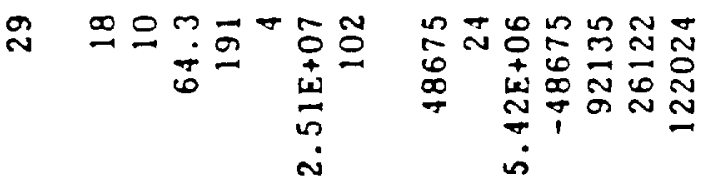

觉

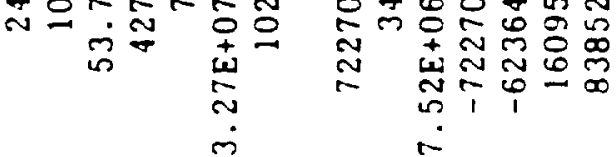

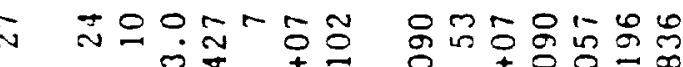

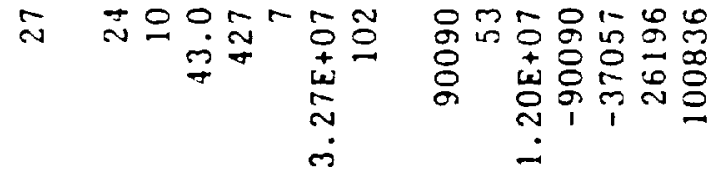

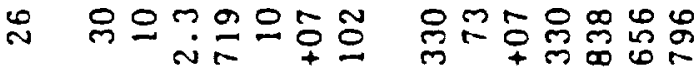

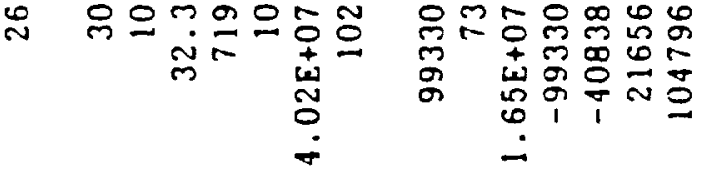

少呈

以

品

正要

趈

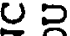

尔毕

ن

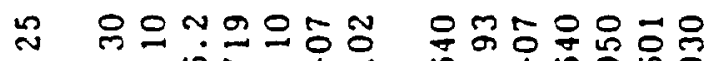

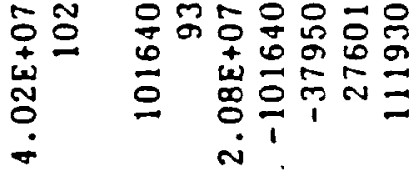

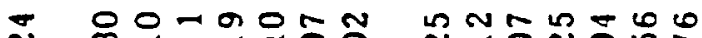

N

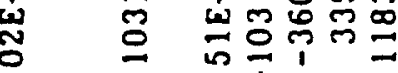

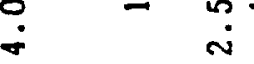

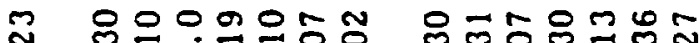

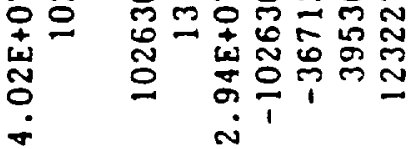

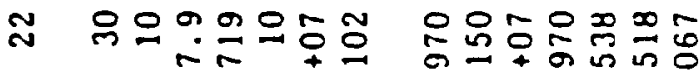

岕

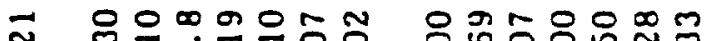

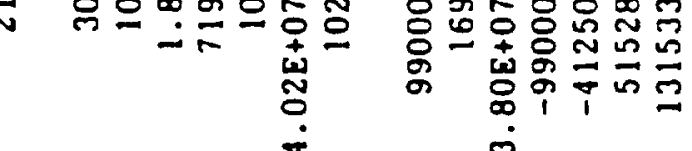

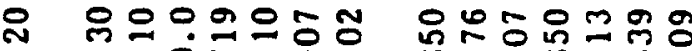

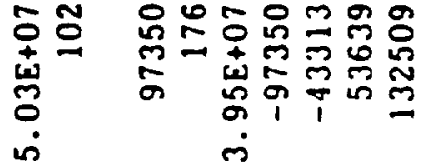

$\stackrel{\circ}{\frac{0}{2}}$

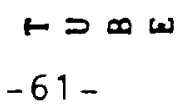


seals as the joint is locked shut. The cylinders can produce only a negligible fraction of the separating force experienced by the joint during its operation. If the gib surfaces are designed properly (with gib angles below critical friction angles),

outward-directed forces on the gibs may be counted upon to remain at zero when the joint is subjected to axial tension.

The first seven individual joint segments must have O.D.'s near $750 \mathrm{~mm}$ and be autofrettaged to withstand peak predicted internal pressures without accumulating damage. This requirement limits their length to $6.1 \mathrm{~m}$ in order to maintain their masses below $20 \mathrm{MT}$ each which are required to allow machining. After the seventh segment (at $32.3 \mathrm{~m}$ downrange), segment O.D.'s may be reduced to $600 \mathrm{~mm}$ which increases their permissible lengths to $11 \mathrm{~m}$. Finally, the last (tenth) segment can have its $0 . \mathrm{D}$. reduced to $450 \mathrm{~mm}$ which extends the total launch tube length to $75 \mathrm{~m}$.

\subsection{LIGHT-GAS GUN MOUNT.}

The $250 \mathrm{~mm}$ two-stage light-gas gun whose design has been developed earlier in this chapter must be supported properly if it is to meet its operational requirements. First and foremost, all of the independent components must be supported separately with their central axes in precise alignment with each other and that of the range tankage. Second, the assembled launcher and its components must be free to move and be moved in the axial direction while being supported rigidly in the other two directions. Axial movement is required to carry out launcher disassembly/assembly between firings and to support major assembly and maintenance functions that are required during range set-up and from time-to-time thereafter. The gas gun structure also moves axially during each firing cycle under the influence of forces too large to be resisted. Finally, the mounting system must either accommodate mounting requirements for other launchers to be used with the range facility in the future or it must be removable and reinstallable with a minimum of operator effort to accommodate the same purpose.

The following paragraphs: describe and evaluate light-gas gun motion during a firing sequence; and describe the mounting structure we suggest for the pump tube (with the piston driver gas reservoir assembly), the central breech and the launch tube.

\subsubsection{Launcher Movement During its Firing sequence.}

Recoil motion of a two-stage light-gas gun is unique to this type of gasdynamic device. Specifically, it is quite different from recoil of normal single stage guns. Basically, the piston starts from rest at the rear of the pump tube and returns to rest just upstream from the transition section within the central breech. The helium gas used to drive the piston starts at rest from the reservoir tubes at the rear end of the launch tube and returns to rest spread evenly between the reservoir and the 
launch tube volume. These movements shift the center-of-mass of the light-gas gun structure forward (downstream) but they impart no net momentum to the gun structure, so they leave the gun at rest. If the gas gun is free to move axially, it moves rearward (upstream) during the period of piston movement just far enough to offset downstream movement of the c.g. (so that the c.g. remains fixed in the laboratory frame-of-reference). Thus, the portion of the recoil produced by the piston movement is, simply, an upstream displacement of the gas gun structure. The

tremendous forces that produce this movement need not be borne by the mount structure provided that no resistance is offered to the gas gun's axial movement.

Upstream movement of the light-gas gun, $\delta \mathrm{x}$ due to action of the piston recoil/anti-recoil force may be evaluated using Equation 2.30.

$$
\delta X=\left(L_{p t}+L_{c b}-L_{p i}\right) \quad \frac{M_{p i}+0.5 M_{g P}}{M_{p 1}+M_{g p}+M_{g}}
$$

where:

$$
\begin{aligned}
& \mathrm{L}_{\mathrm{pi}}=2.0 \mathrm{~m}=\text { piston length; } \\
& \mathrm{L}_{\mathrm{pt}}=91.5 \mathrm{~m}=\text { pump tube length; } \\
& \mathrm{L}_{\mathrm{cb}}=2.0 \mathrm{~m}=1 \text { length of rear portion of central breech; } \\
& \mathrm{M}_{\mathrm{g}}=678.12 \mathrm{MT}=\text { mass of light-gas gun; } \\
& \mathrm{M}_{\mathrm{pi}}^{=}=2.27 \mathrm{MT}=\text { mass of piston; and } \\
& \mathrm{M}_{\mathrm{gp}}=1.04 \mathrm{MT}=\text { mass of piston driver gas. } \\
& \hline \delta \mathrm{X}=0.375 \mathrm{~m}\left(14.75^{\prime \prime}\right)
\end{aligned}
$$

Thus, the light-gas gun structure may be expected to move rearward a distance of somewhat over ( $1 \mathrm{ft}$.) due to movement of the compression piston and the gas column behind it.

The light-gas gun also launches a projectile package away from its structure as well as the gas column which drives it. Net impulse from these launches produce a slight rearward (upstream) movement of the gun structure, $U_{g r}$, which may be evaluated using the conventional and familiar gun recoil equation (2.31). An assumption widely made during analysis of recoil is that the average velocity of gas used to launch a projectile is one-third of projectile velocity. This assumption has not been validated carefully for two-stage light-gas guns operating near the center of their velocity range but even a gross error here has a small effect upon the final result.

$$
U_{g r}=U_{p} \frac{M_{p}+M_{g p p} / 3}{M_{g}}
$$


where:

$\mathrm{U}_{\mathrm{p}}=$ projectile package velocity; and

$\mathrm{M}_{\mathrm{gpp}}^{\mathrm{p}}=$ mass of the projectile driver gas charge

The recoil equation predicts that the gun completes its firing cycle with a residual rearward-directed velocity of $\mathrm{U}_{\mathrm{gr}}=0.226$ $\mathrm{m} / \mathrm{sec}$. The kinetic energy associated with the gas gun moving upstream with this velocity is $17.32 \mathrm{Kj}$. This residual recoil energy can be removed from the gas gun structure by a small mechanical dashpot affixed to one of its mounting frames.

\subsubsection{Gas Gun Mounting structure.}

Several mounting schemes have been employed to support a wide range of two-stage light-gas gun sizes. As component mass increases with gun size, supporting components on rollers becomes mandatory. Rollers, in turn, become extremely large when very heavy components must be supported. One pleasant exception to this trend is, "Roundway Bearings" manufactured by Thompson Industries, Inc. Photographs of these bearings appear in Figure 2.23. They consist of endless treads made from small precision "May West" shaped rollers which engage circular shafts made from hardened steel. These bearing sets range from small units which engage $12 \mathrm{~mm}$ (1/2") diameter shafts to support masses up to $1.0 \mathrm{MT}$ to massive units which engage $100 \mathrm{~mm}$ (4") diameter shafts to support masses up to $35 \mathrm{MT}$. These units come in dual-tread configurations which engage their circular shafts at two orthogonal points and in single-tread units which engage only the top surface of their shaft. The dual-tread units are capable of following rod direction precisely while the single-tread units can accommodate a small amount of misalignment with the shaft. In general, we propose to make one of the shafts (the left-hand shaft facing downrange) an alignment standard for the entire gun structure. This shaft must be surveyed precisely level, straight, and parallel with the range axis. All Roundway bearing sets operated on this shaft are of dual-tread construction so that shaft alignment information is transferred directly to the gun components. The opposite shaft is mounted as near parallel to the alignment shaft as feasible and is spaced far enough from it to accommodate the structural elements connected to each launcher component. Its precision of alignment need not be quite as great as for the standard shaft, however.

In general, each launcher component is supported by two or more structures which surround its down-facing side and are bolted to it securely. An example of this configuration (applied to the gas gun's launch tube is presented in Figure 2.24) Flat bottoms on these structures serve as horizontal supports for two Roundway bearings each (one two-tread unit that engages the alignment shaft and one single tread unit that engages the follower shaft. Thus, a total of four Roundway bearings are installed under each tubular gun component. Provision is made at the juncture between each Roundway bearing and the component 


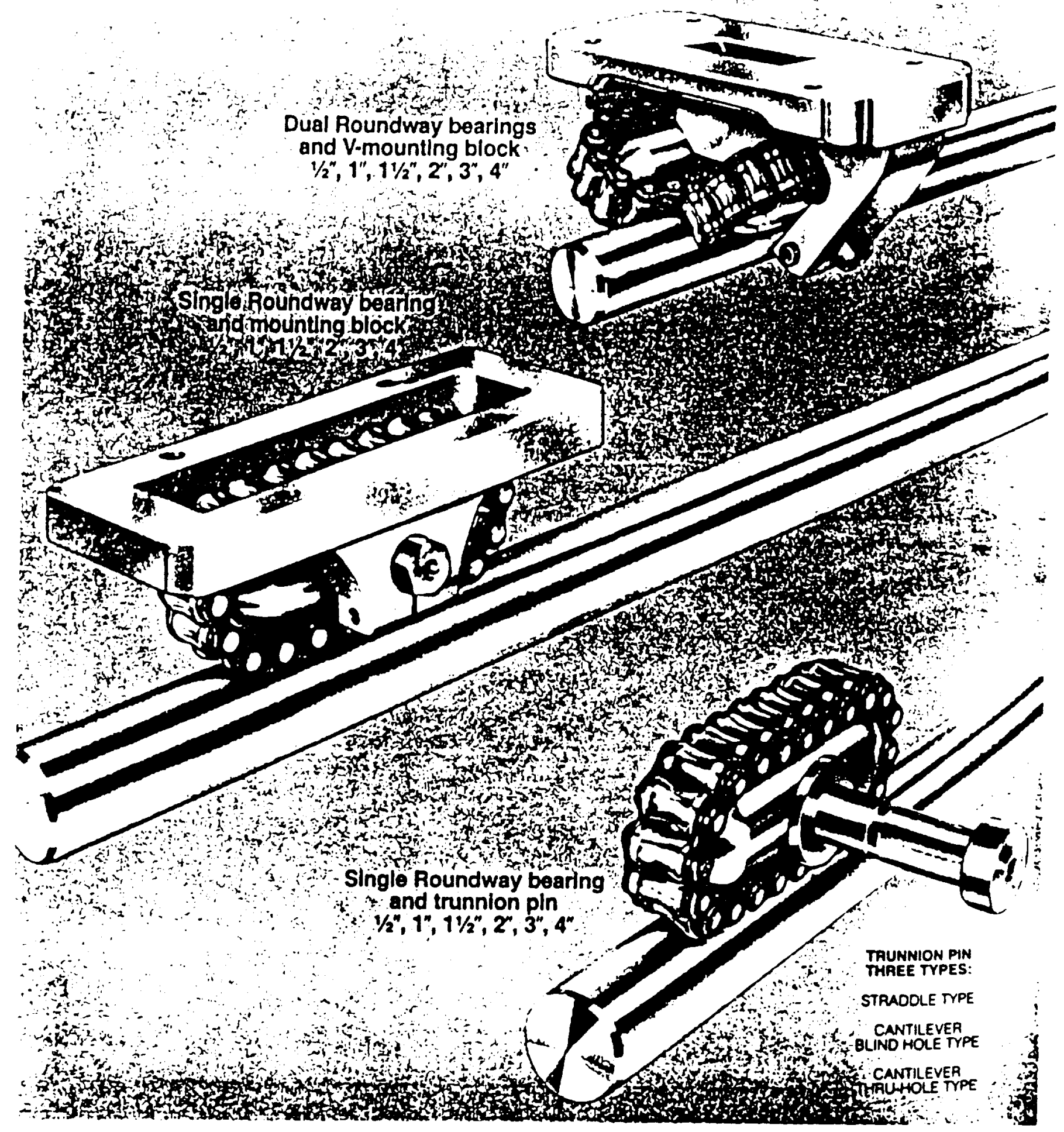

Figure 2.23 Roundway Series Bearings suitable for supporting Very Heavy Loads. 


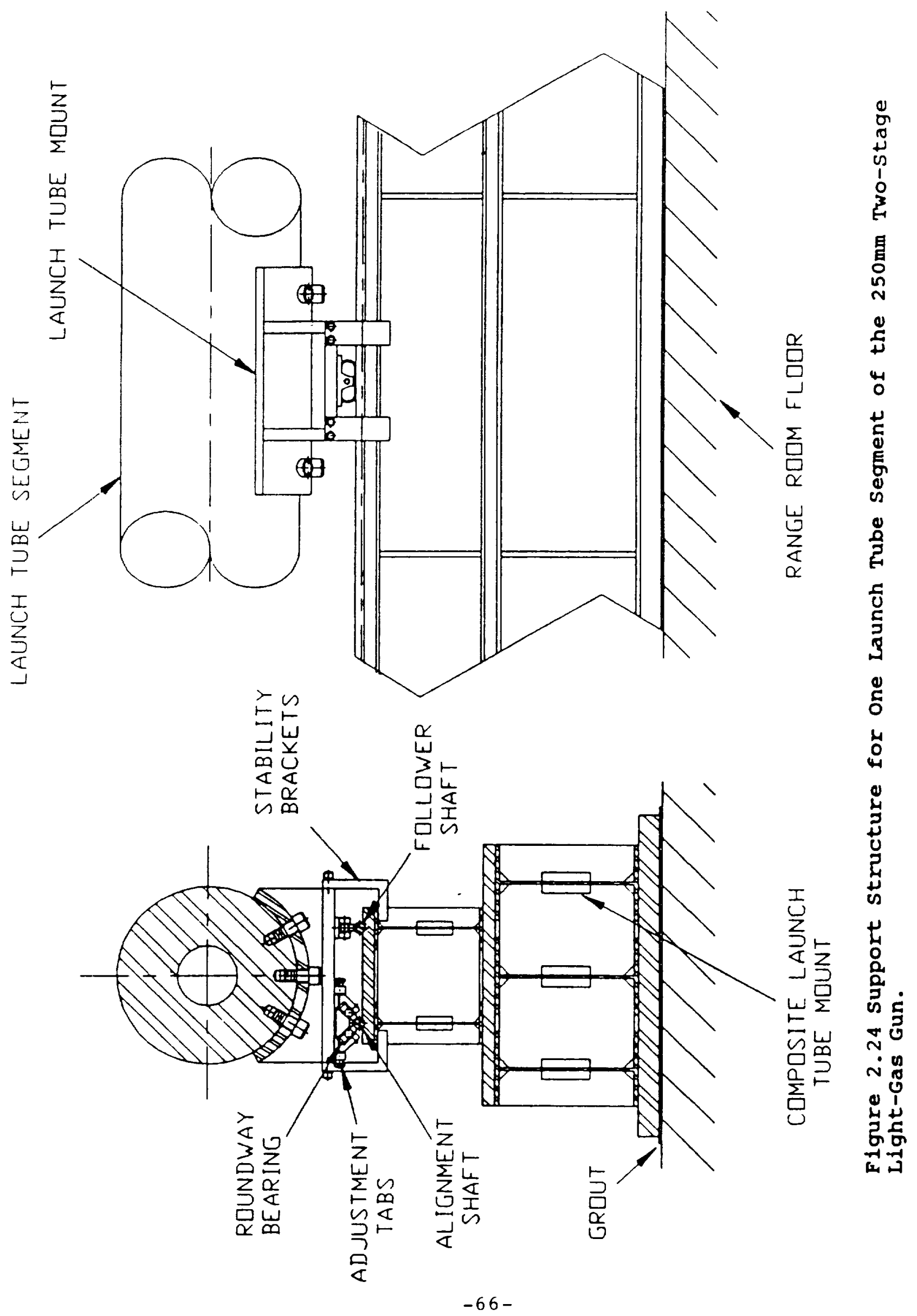


support for moving the bearings laterally with respect to the component in order to bring the component's axis into alignment with that of the rest of the launcher and of the range. The Roundway bearings contain eccentric shaft adjustments which provide sufficient vertical movement to align the component axis with that of the range and to insure that all four bearing units engage their shafts properly.

\subsubsection{Pump Tube Mount.}

The shafts, of course, must be connected rigidly to the building foundation since they must support the entire mass of the launcher (678 MT) without significant deflection. After some consideration, we decided to locate the axis of the range and the gun approximately $2.0 \mathrm{~m}$ above the range room floor and to support the pump tube on a structural steel frame attached rigidly to the floor. A view of the pump tube mount facing downrange from near its uprange end is presented in Figure 2.25. The frame consists of two 36" high heavy-flange I-beams gusseted together to provide maximum rigidity. A thick steel plate which spans the upper flanges of I-beams is used to support the Roundway bearing shafts in hemi-cylindrical slots. The plates are fabricated in short sections and supported on bolts above the I-beam flanges which allow the shafts to be adjusted precisely level and parallel to the range axis. High-compression-strength epoxy is then injected under the plates to fill the volume between them and the beam flange. Once proper alignment has been achieved, loads borne by the Roundway shafts are spread effectively over the beam structures. These beam structures are mounted slightly above the range room floor and concrete grout is used to spread the load they bear to the floor slab upon which the gun is supported. The pump tube support structures are fabricated in $9.0 \mathrm{~m}$ lengths which are bolted together with plaques that interconnect the individual beam webs. Ten of these segments are needed to support the entire pump tube assembly.

Let us consider, for example, the rear-most pump tube mount which must support the rear end of the pump tube plus the rear portion of the gas chamber. Referring to Table 2.2 , this rearmost mount must support one-sixth the mass of the four tanks (8.71 MT), the masses of two disks $(6.52 \mathrm{MT})$, the four manifolds (12.5 MT), the sleeve (3.61 MT), the breech $(4.75 \mathrm{MT})$ and the breech plug (2.08 MT) for a total of $38.23 \mathrm{MT}(84,300 \mathrm{lbf})$. Each Roundway bearing must support half of this load or $19.1 \mathrm{MT}$ $(42,150$ lbf.). The largest Roundway bearings which engage $100 \mathrm{~mm}$ (4") diameter shafts can support $31.75 \mathrm{MT}$ (70,000 lbs.) each. Their use provides a substantial safety margin. The next three downrange component supports must handle both pump tube segments and the gas storage assembly, so massive Roundway bearings encasing $100 \mathrm{~mm}$ shafts are specified.

Each of the pump tube segments downrange from the gas atorage asambly is ilmited in mass to $20 \mathrm{MT}$ (44,000 1ba.) by fabrication considerations. Four Roundway mounts supporting each 


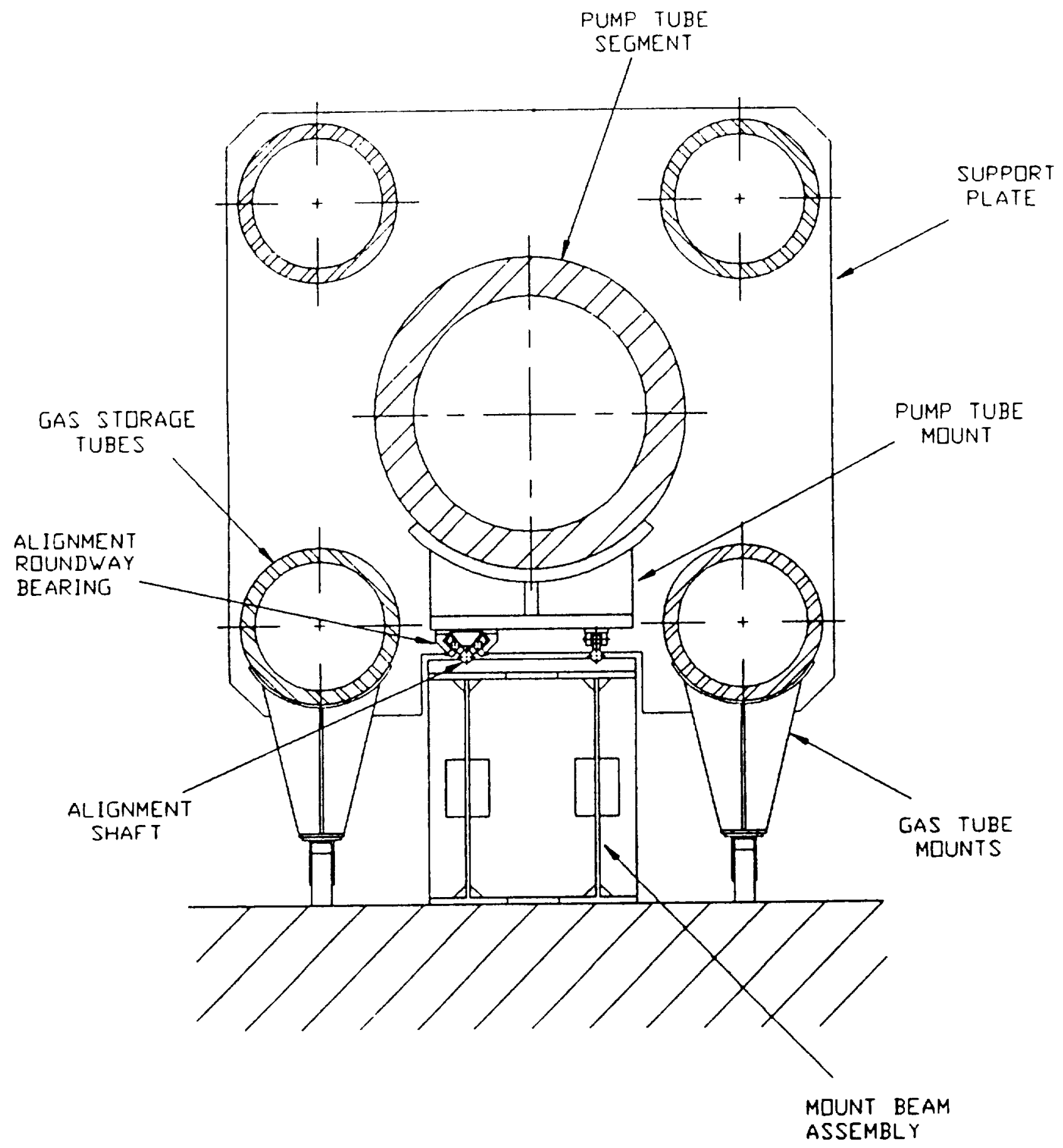

Figure 2.25 Section View of the $250 \mathrm{~mm}$ Light-Gas Gun Near its Rear End which shows Details of its Mounting structure. 
unit must bear only 5 MT $(11,000$ lbs.) each which can be handled readily by smaller Roundway bearings which engage $50 \mathrm{MM}$ (2") diameter shafts. For this reason, we have chosen to specify making the rear-most portion of the shafts $100 \mathrm{~mm}$ in diameter and the remainder from $50 \mathrm{~mm}$ diameter shafts to engage smaller bearings. A sketch of this situation is presented in Figure 2.26 .

Before leaving the rear of the gun, let us consider stability of its rear-most portion which contains the four tube reservoir gas storage system. Inspection of Figure 2.25 indicates that this portion of the light-gas gun is marginally stable and in danger of "toppling over". We have chosen to eliminate this problem with "gas tube mounts" which are supports that extend down from the two lower storage tanks to massive casters set to almost engage the range room floor. Care must be taken to elevate these caster wheels approximately 2 . $0 \mathrm{~mm}$ above the floor so that they pass over it without touching when the Roundway bearings are engaged properly. Any tipping moment applied to the gun structure supported by the Roundway bearings causes wheels on the opposite side to engage the floor and produce a counter-moment. We feel that three gas tube mounts along each of the lower two gas storage tubes should provide necessary stability.

\subsubsection{Central Breech Support.}

By far the most demanding component of the light-gas gun to support is the central breech assembly. As presented in Table 3.2 , this assembly weighs far too much (131 MT) to be fabricated in one piece (20 MT limit). Even the central carcass weighs $27.73 \mathrm{MT}$ which requires it to be fabricated in two pieces and shrink-fitted together.

After rejecting many assembly/mounting approaches, we have devised one which seems to meet all established needs. A massively reinforced pit $1.0 \mathrm{~m}$ deep is required in the foundation below where the central breech is to be positioned. If several positions for the central breech are required to accommodate different gun configurations, a series of pits may be required in the range room floor. Adjacent to the side walls of each pit massive concrete blocks are grouted in place that are approximately $1.0 \mathrm{~m}$ square by $4.0 \mathrm{~m}$ long. Note that these blocks can be removed readily when other mounting configurations are required. The entire inner surface and part of the upper surface of each block are faced with steel $75 \mathrm{~mm}$, (3") thick. These plates are welded together and are connected to a dense array of reinforcing bars within the blocks. These concrete blocks are positioned carefully with their edges forming extensions of the vertical pit walls. Four inch diameter Roundway bearing shafts are mounted on thick steel plates which engage the upper surface of the block facing plates. Again, the plates holding the shafts are supported on screws above the blocks for adjustment and are grouted in place with strong epoxy once alignment is achieved. 


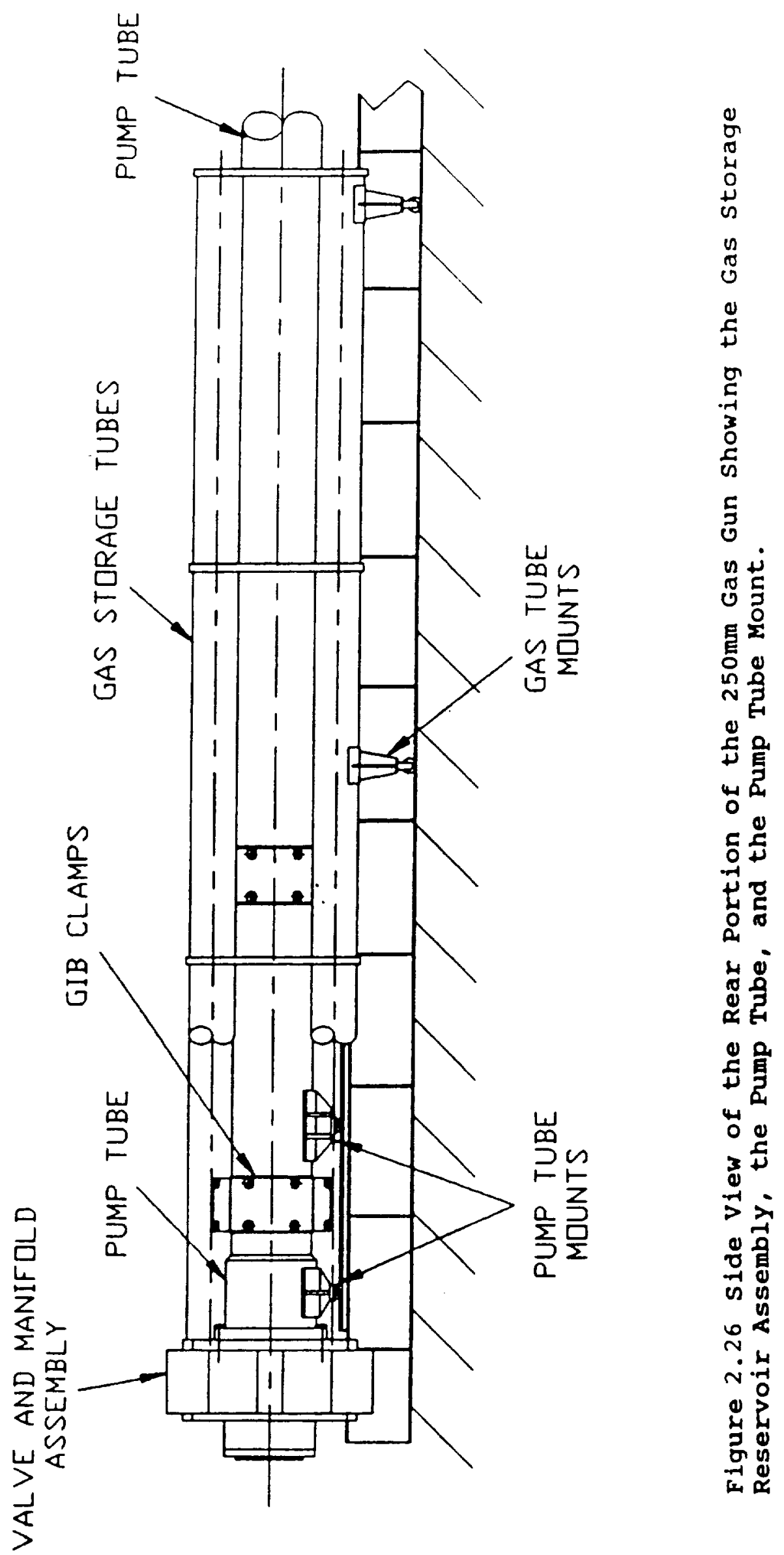


The left-hand bar facing downrange is aligned level and precisely parallel with the range/launcher axis. A massive steel-lined well is installed in the bottom of the pit at approximately its center as is shown in Figure 2.27. A cylinder fits snugly into the well I.D. and has a reduced diameter upper end which fits snugly the bore of the rear end of the central breech. A hydraulic cylinder capable of lifting 200 tons $600 \mathrm{~mm}$ (24") is mounted within/under the moveable cylinder.

In operation, an overhead crane brings the central breech carcass to the pit suspended with its rear end facing downward. The carcass is lowered carefully over the end of the cylinder when the cylinder is in its fully elevated position. Once engagement with the cylinder has been completed, the crane can be removed and the central breech carcass allowed to stand freely. clamps may be used to stabilize the cylinder/central breech carcass joint to protect against later upsetting. At this point, the vacuum seal is installed on the carcass O.D. and the overhead crane is used to lower the first strengthening disk into place around the cylinder as shown in Figure 2.28. Steel flow suppressors in the form of 6 . Omm thick hoops $75 \mathrm{~mm}$ wide are installed to prevent the Wood's metal from migrating between the disks during application of pressure pulses produced by launch stresses. The remaining four disks are installed, each in turn, with vacuum seals and flow suppressors. The fifth and last disk contains a toroidal hydraulic cylinder which must be installed facing downward. Installation of the strengthening disks is completed by inserting the eight-segment disk retainer ring in its groove in the central breech carcass, bolting the segments in place, and energizing the toroidal hydraulic cylinder to clamp the disk stack in place.

The entire central breech assembly is now wrapped with heating tapes and then with thermal insulation blankets. The heating tapes are energized to bring the temperature of the assembly from that of the range room to slightly above $100^{\circ} \mathrm{C}$. A total of 4.1 GJ of energy is required to heat the central breech assembly. This heat can be supplied (with no losses) in just under 24 hours if a total of $50 \mathrm{Kw}$ of heating tapes are employed. Practically, $50 \mathrm{Kw}$ of heating tapes can provide the necessary temperature rise in 30-36 hours. A vacuum is now drawn in the space between the disks and the central breech carcass through passages not shown in Figure 2.28. Once the vacuum of 20 torr is achieved, Wood's metal melted in a pot located well above the central breech may be valved through a heated tube into its volume within the central breech assembly. Approximately $700 \mathrm{Kg}$ $(1,540 \mathrm{lb})$ is required. Because its space is pre-evacuated, the Wood's metal may be expected to fill the entire volume without producing porosity or air holes. The head pressure produced by the pot's height assures that the metal flows into all volume available to it. The pot is kept filled with metal and is heated (as is the delivery tube) while the breech heating tapes are turned off and insulation is removed from the lowest portion of the central breech carcass. Water from garden hoses may be 


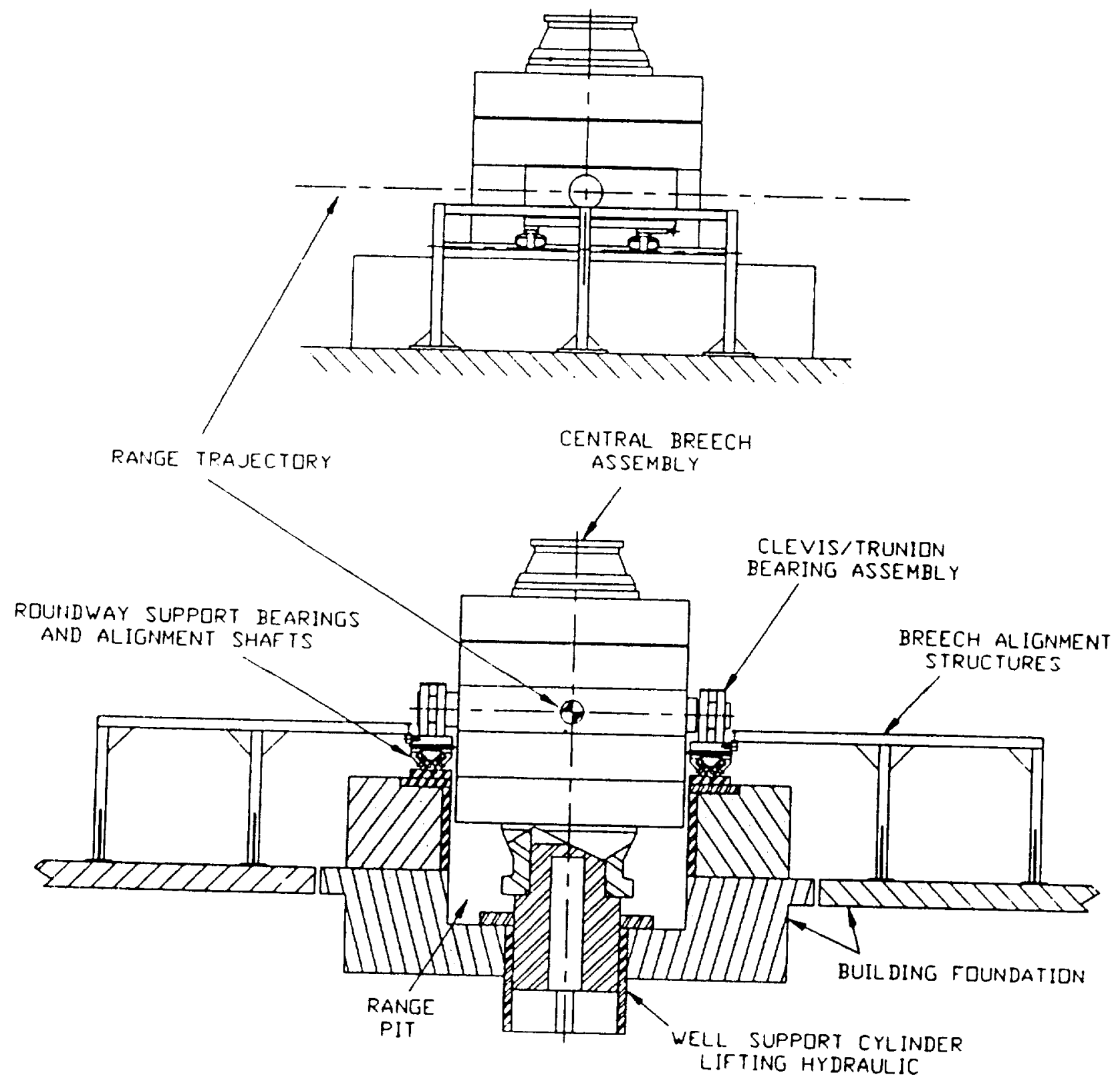

Figure 2.27 Central Breech of the $250 \mathrm{~mm}$ Two-stage Light-Gas Gun in Assembly Position. 


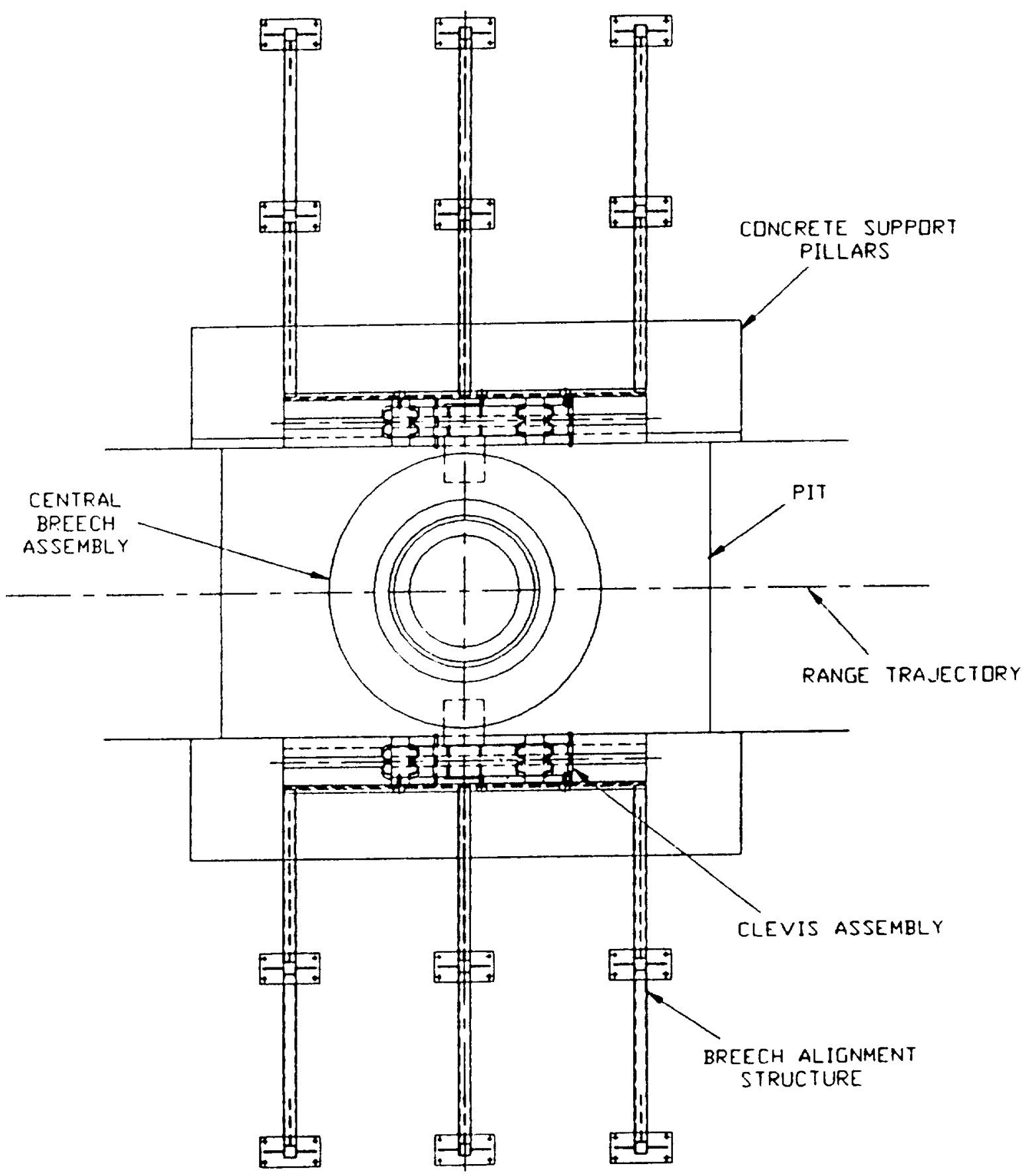

Figure 2.27A Central Breech of the $250 \mathrm{~mm}$ Two-stage Light-Gas Gun in Assembly Position. 


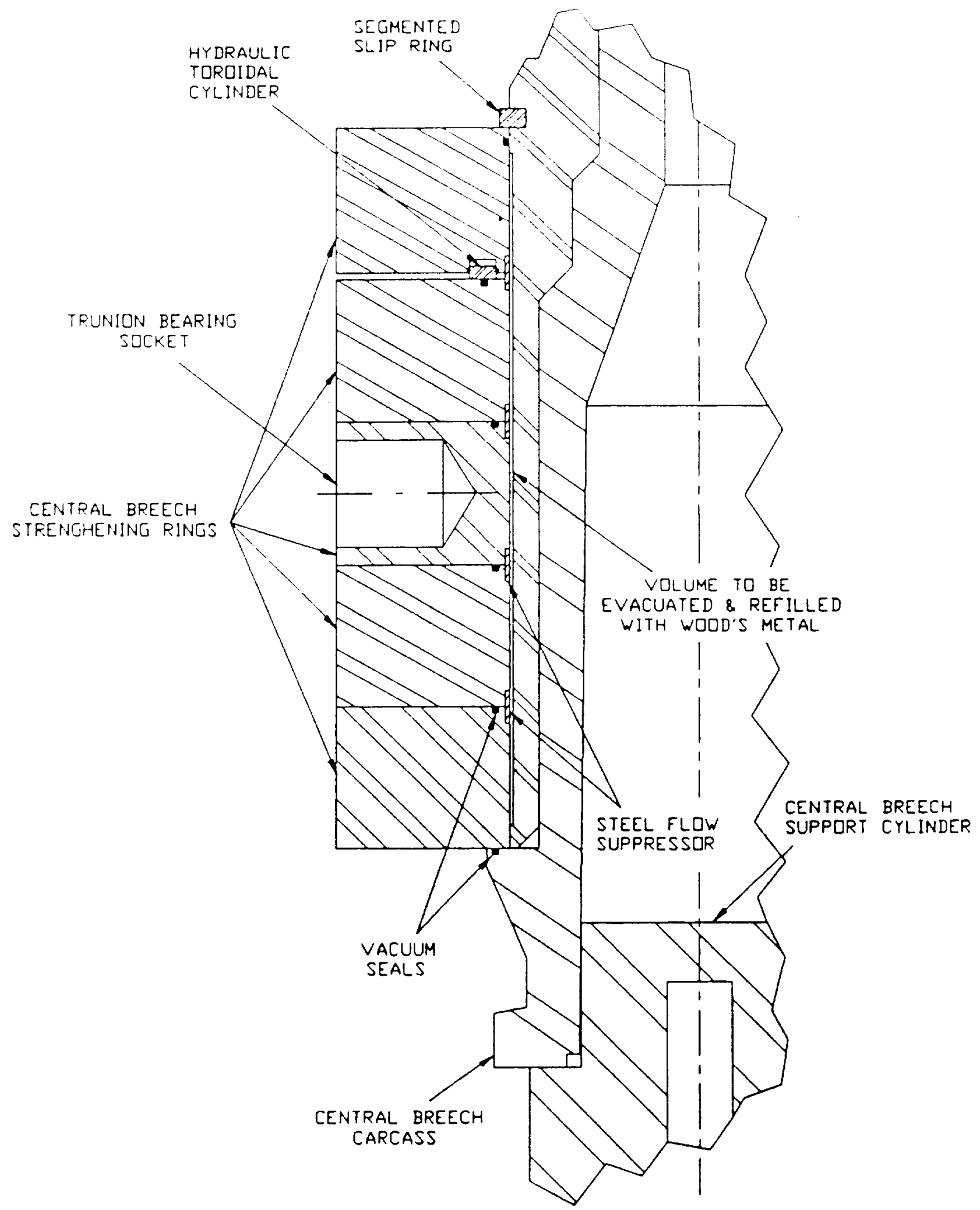

Figure 2.28 Cavity for Wood's Metal with Central Breech Structure of the $250 \mathrm{~mm}$ Two-stage Light-Gas Gun. 
directed on this exposed portion of the central breech to speed the heat removal process. The lower portion of the carcass cools first to a temperature where the Wood's metal freezes and a "wave" then moves up through the structure causing the wood's metal to solidify across it. As the Wood's metal solidifies, it shrinks, but more molten wood's metal is available from above to flow into potential voids. Eventually, the entire carcass cools below melting temperature of Wood's metal (near $91^{\circ} \mathrm{C}$ ) at which point the pot and the delivery tube may be removed safely, thus completing the filling process.

The next step in assembly is insertion of massive trunnion bearing rods into the holes provided for them in the exterior side-wall of the central strengthening disk. (Shown in Figure 2.29) These trunnion bearings are strong and rigid enough to support the entire mass of the central breech assembly without sensible deflection. Their centers are located approximately $10 \mathrm{~mm}$ downstream from the center-of-gravity of the central breech assembly so the unit is stable when positioned with its (upstream) end downward. A pair of $75 \mathrm{~mm}$ thick steel plates spaced $30 \mathrm{~mm}$ apart by welded plates on their upper and lower surfaces serve as clevises when holes in their side walls are slipped over the trunnion shafts. Large Roundway bearings are attached to their lower faces. The left-hand clevis (facing downstream) adjusted so that rotary motion only is available when it engages the shaft used for precision component alignment. The clevis on the opposite trunnion shaft is allowed to translate in/out over a distance of approximately $20 \mathrm{~mm}$ to accommodate variations due to improper Roundway shaft alignments and foundation structure. The Roundway bearings are positioned an equal distance upstream and downstream from the center of the trunnion shaft hole in each clevis so that each bearing absorbs $50 \%$ of the weight transferred to the assembly through the trunnion bearing. One Roundway roller on each clevis is mounted on a hinged plate whose end directly opposite the bearing is supported by a short-throw hydraulic cylinder mounted on the clevis body. These cylinders are capable of lifting $50 \mathrm{MT}$ each. The layout of the clevises is presented in Figure 2.30 .

Once the clevises have been installed on the trunnion shafts, they are rotated so their Roundway bearings are above their respective shafts. The clamps holding the lower (upstream) end of the central breech carcass to the lifting cylinder may now be removed and the cylinder may be lowered until the Roundway bearings on the clevises engage their shafts. The overhead crane may now be used to rotate the central breech assembly horizontal by lifting its upstream end. Two massive dowel pin arrangements are used to clamp ends of each clevis to the strengthening rings to lock the central breech assembly horizontal.

We are concerned that the extreme weight of the central breech assembly (130 MT) may deflect the foundation supporting the Roundway shafts and cause vertical misalignment of the gas gun. This situation can be corrected using a specialized 


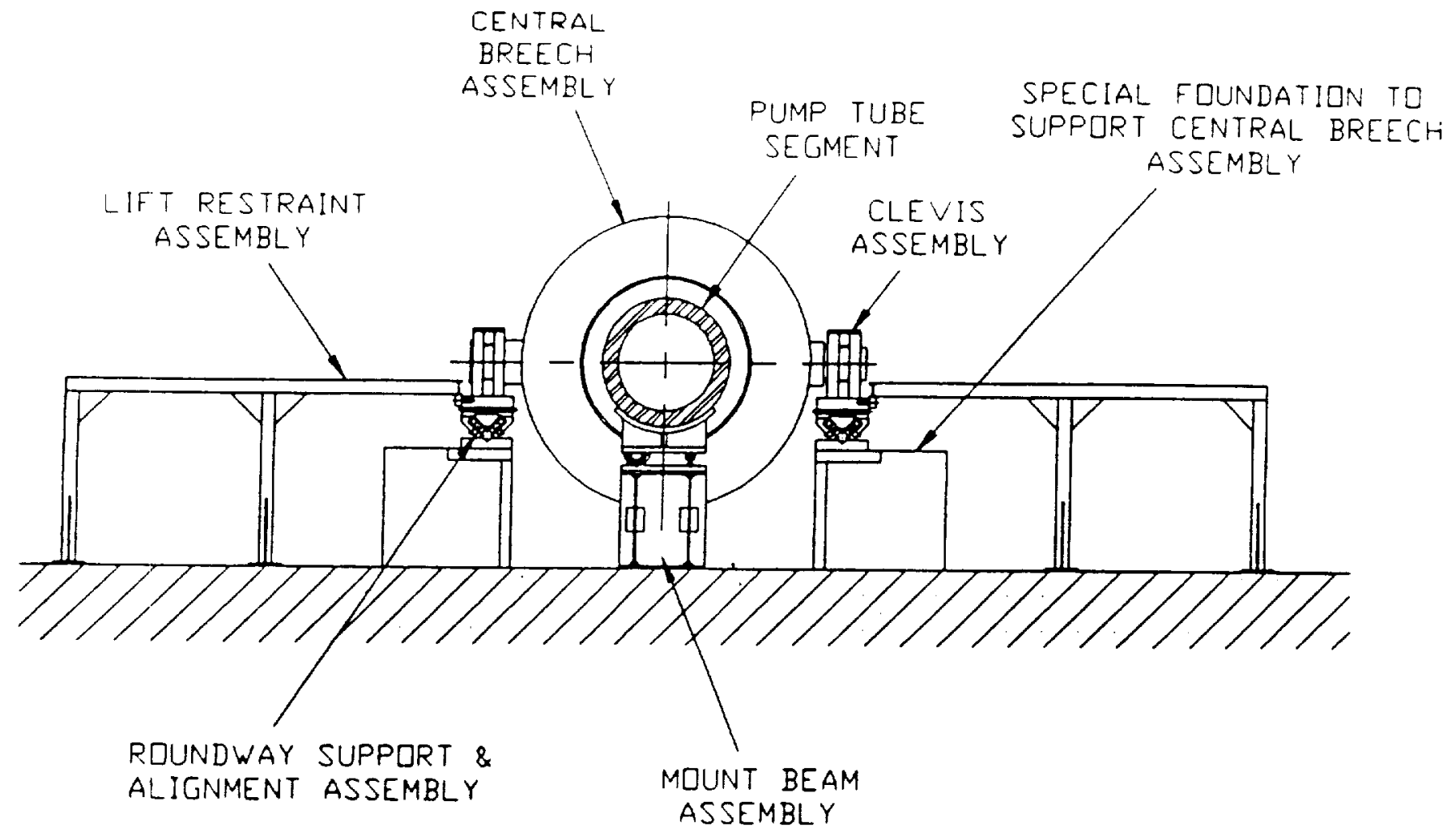

Figure 2.29 section View of the $250 \mathrm{~mm}$ Two-Stage Light-Gas Gun Facing Downstream Near the Downstream End of the Pump Tube. Relevant Detalls of the Trunnion Mount Assembly are Revealed. 


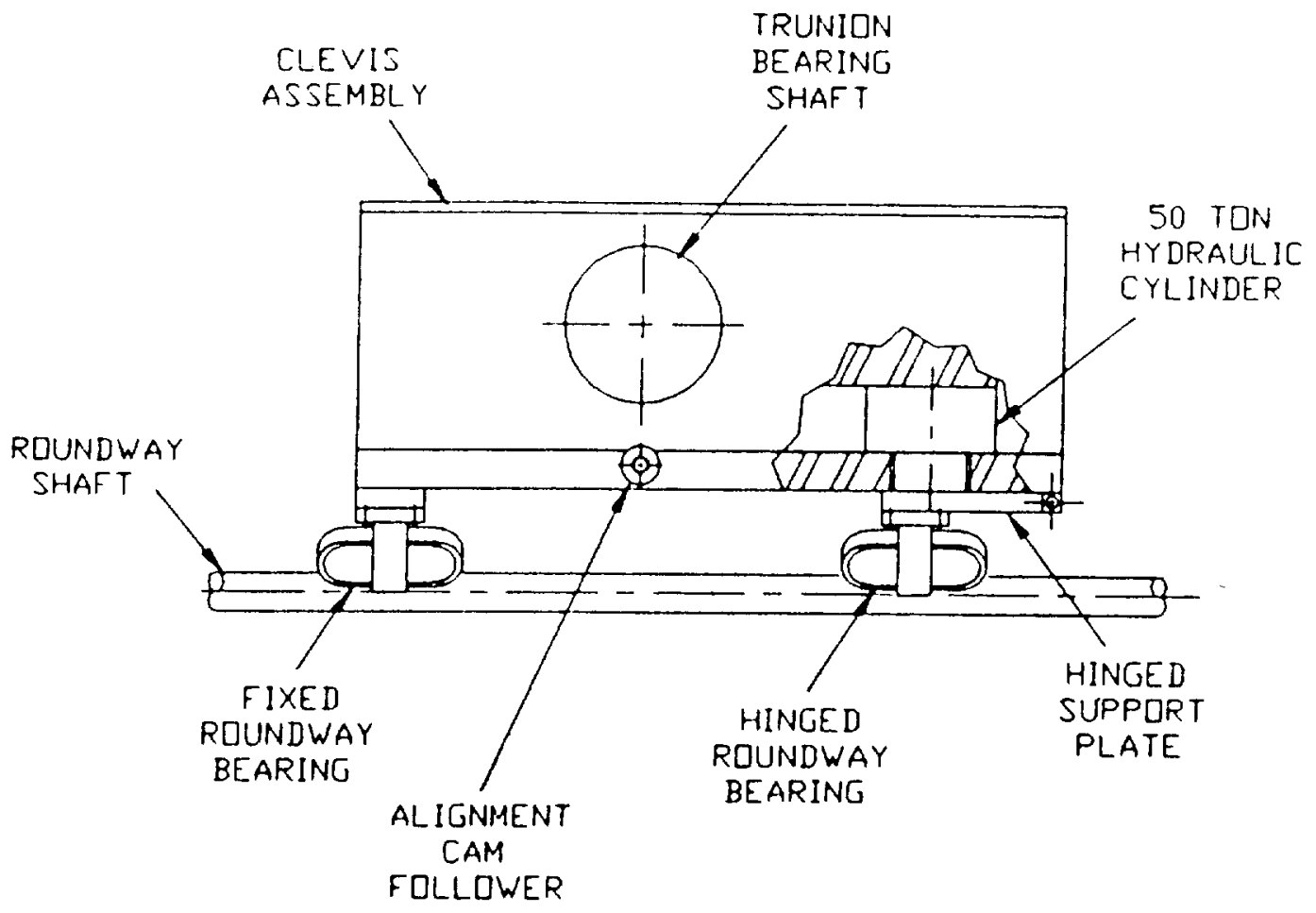

Figure 2.30 Design of the Central Breech Supporting Clevises Showing the Fixed and Hinged Roundway Bearings and the Vertical Alignment Cam Follower. 
positioning system we suggest for the central breech support assembly. Hydraulic pressure is now built up in the cylinders supporting the two clevis bearings until they just lift the central breech assembly. A pair of large cam followers are mounted on the outer edge of each lower clevis support plate directly below the trunnion bearing hole. The bars which each cam follower engages are supported on overhanging structures (1ift restraint structures from Figure 2.29) that are attached to the range room floor some distance away from the portion of the foundation which supports the gas gun structure. This somewhat awkward arrangement was chosen to derive a vertical reference for central breech alignment that would not be deflected by the central breech's weight. The structures holding these shafts are made rigid enough to sustain forces of a few thousand Newtons without flexing more than $50 \mathrm{u} . \mathrm{m}$. or so. By carefully controlling the pressure in the individual lifting cylinders on the central breech clevises, a situation is achieved where only one or two percent of the weight of the central breech assembly need be supported by the alignment system so that it can impart extreme height precision to the central breech assembly.

\subsubsection{Launch Tube Support.}

supporting the launch tube is a relatively straightforward proposition although the supports must be mounted well above the range room floor. We propose to use a dual-layer structure fabricated from I-beams to provide supports for the alignment Roundway shaft (50mm in diameter) and its opposite number (see Figure 2.24). The same grouting procedure used for the pump tube support structure is employed here to assure that the substantial mass of the launch tube composite (176 MT) is distributed broadly across the range room floor slab. Again, individual tube components which weigh less than $20 \mathrm{MT}$ each are supported at two positions by two medium-duty Roundway bearings each.

Operating the $250 \mathrm{~mm}$ light-gas gun requires that the joint between the central breech and the launch tube be uncoupled between every firing and that the launch tube be moved downrange at least $2.0 \mathrm{~m}$ and preferably $3.0 \mathrm{~m}$. Equipment must be installed on the downstream face of the central breech for loosening the compression piston that was previously jammed into the transition cone. The hone for smoothing the launch tube bore must also use this space for its installation. The launch tube must be moved mechanically along its mounting structure since its weight precludes hand operation. The remainder of the light-gas gun must also be returned from its post-fire position to its pre-fire position after each firing, a distance of somewhat less than $0.5 \mathrm{~m}$. Several actuators are available that can be used to move both of these units. Probably the most convenient is a lead screw mounted on one segment of the launch tube support structure. The lead screw engages a half-nut assembly connected to one of the launch tube carriages. Once the half-nut is engaged, the launcher can be driven upstream/downstream over a distance of $7.0 \mathrm{~m}$ or so by clockwise/counter-clockwise rotation 
of the lead screw. A similar unit mounted on a pump tube support system can be used to drive the pump tube/gas reservoir/central assembly upstream/downstream along its mount over distances great enough to accommodate positional shifts caused by gas gun firing.

It is extremely important to note that both of these halfnuts must be disengaged before each firing. Switches on the half-nut assembly must be wired into the range firing interlock system to guard against inadvertent engagement of these assemblies.

\subsection{SUPPORT EQUIPMENT FOR THE TWO-STAGE LIGHT GAS GUN.}

The $250 \mathrm{~mm}$ two-stage light-gas gun under consideration requires several support systems with characteristics unusual enough to call into question their fabricatability and operability. The ones identified to date are:

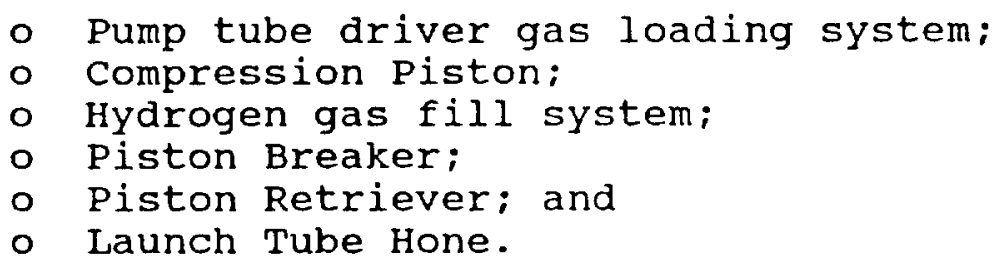

Each of the systems has been considered in some detail and found to be buildable using current technology and capable of being operated effectively with a reasonable servicing staff.

\subsubsection{Pump Tube Driver Gas Loading System.}

The extreme requirement of using 205,000 standard cubic feet (SCF) of helium compressed to $100 \mathrm{MPa}(15,000 \mathrm{psi})$ for accelerating the pump piston infers a very large gas handling system since the cost of the helium (near $\$ 34,000$ ) mandates that the great majority of it must be gathered up after each firing and recompressed for reuse. A large bank of gas compressors is required to conduct the compression exercise. In general, multistage reciprocating compressors with inter-stage coolers are cost-effective for producing helium pressures up to $20.0 \mathrm{MPA}$ (3,000 psi) when they can draw from a source who's pressure is as low as 1.0 MPA (150 psi). Beyond 20.0 MPA, flexing diaphragm compressors prove to be more effective. Conventional flexing diaphragm compressors can be made to operate effectively at pressures up to $100 \mathrm{MPA}(15,000 \mathrm{psi})$ when they are allowed to draw from a more-or-less constant pressure source at $20.0 \mathrm{MPA}$.

Helium is available in large quantities packaged in bottle farms transportable as semi truck trailers. The bottles are valved independently and are connected to central manifold for distribution. A pressure gauge is provided for monitoring amount of gas available. Typically, each trailer contains up to 10,000 SCF of helium and a pressure of $28.6 \mathrm{MPA}(4,200 \mathrm{psi})$. 
These factors have led us to design a helium compressiondelivery system sketched in Figure 2.31. The heart of the system is the column of boxes extending through its center. These boxes specify: a low pressure gas holding tank; a bank of five-stage reciprocating gas compressors with inter-stage coolers that produce helium pressure up to 20.0 MPA; a 20.0 MPA holding tank; and a bank of eight flexing diaphragm compressors capable of delivering helium gas at pressures up to $100 \mathrm{MPA}$ and somewhat above. Taps into the system are available at the low pressure holding tank, the 20.0 MPA holding tank, and the 100 MPA output. one other component is required for the system (as well as the $250 \mathrm{~mm}$ two-stage light gas gun, itself) an array of helium holding tanks capable of storing the entire gas charge (205,000 SCF) must be a permanent part of the facility. These tanks have an aggregate volume of $12.5 \mathrm{~m}^{3}$ and can hold gas at pressures up to $100 \mathrm{MPA}$. They are needed to store the helium reserve during periods when the light-gas gun must be emptied for maintenance or rebuilding.

\subsubsection{System Evacuation.}

A fairly complex series of interconnecting lines, valves, regulators, and gauges is needed to make the system perform all of its required functions. Let us consider a few of them. The first task upon assembling the system is to evacuate the various holding tanks and the two-stage light gas gun. Starting with all valves closed, the vacuum pump is energized. Valve "p" is opened to switch the pump into the main interconnecting line for the system. Valve "L" may now be opened and the holding tanks evacuated (to a pressure of about $20.0 \mathrm{~m} . \mathrm{B} ., 15$ torr). Next, valves " $X, M$, and $Q$ " may be opened, so that the light gas gun reservoir and pump tube maybe evacuated. Note that valve " $Q$ " is the large rotary unit connecting the reservoirs to the pump tube. An alternative to opening " $Q$ " is to open valves "V and $H$ ". Once the gas gun has been pumped down, the two holding tanks of the compressor or system may be evacuated by opening valves " $R$ " and "S". Once vacuums have been achieved in these systems, all valves may be closed and gas filling may commence.

\subsubsection{Initial Gas Loading.}

Gas filling is started by connecting a helium delivery trailer to lines beyond valve " $A$ " and " $B$ " and opening both of these valves. The filling process is started by opening valves "X, M" to admit helium to the light gas gun reservoir. Once the pressure has been equilibrated (at a level well below 20.0 MPA) valve "A" is closed and valves "B, $D$, and $L$ " are opened to allow gas flow into the low pressure holding tank after passing through a regulator. The low pressure compressor bank is started and valve "G" is opened after pressure in the low pressure holding tank exceeds 1.0 MPA as read on gauge " $P_{1}$ ". Pressure gauge " $P_{4}$ " is monitored until pressure is observed, and valve "J" is opened to admit gas to the 20.0 MPA holding tank. Once pressure here exceeds that in the light gas gun, as monitored by gauges " $P_{7}$ " 


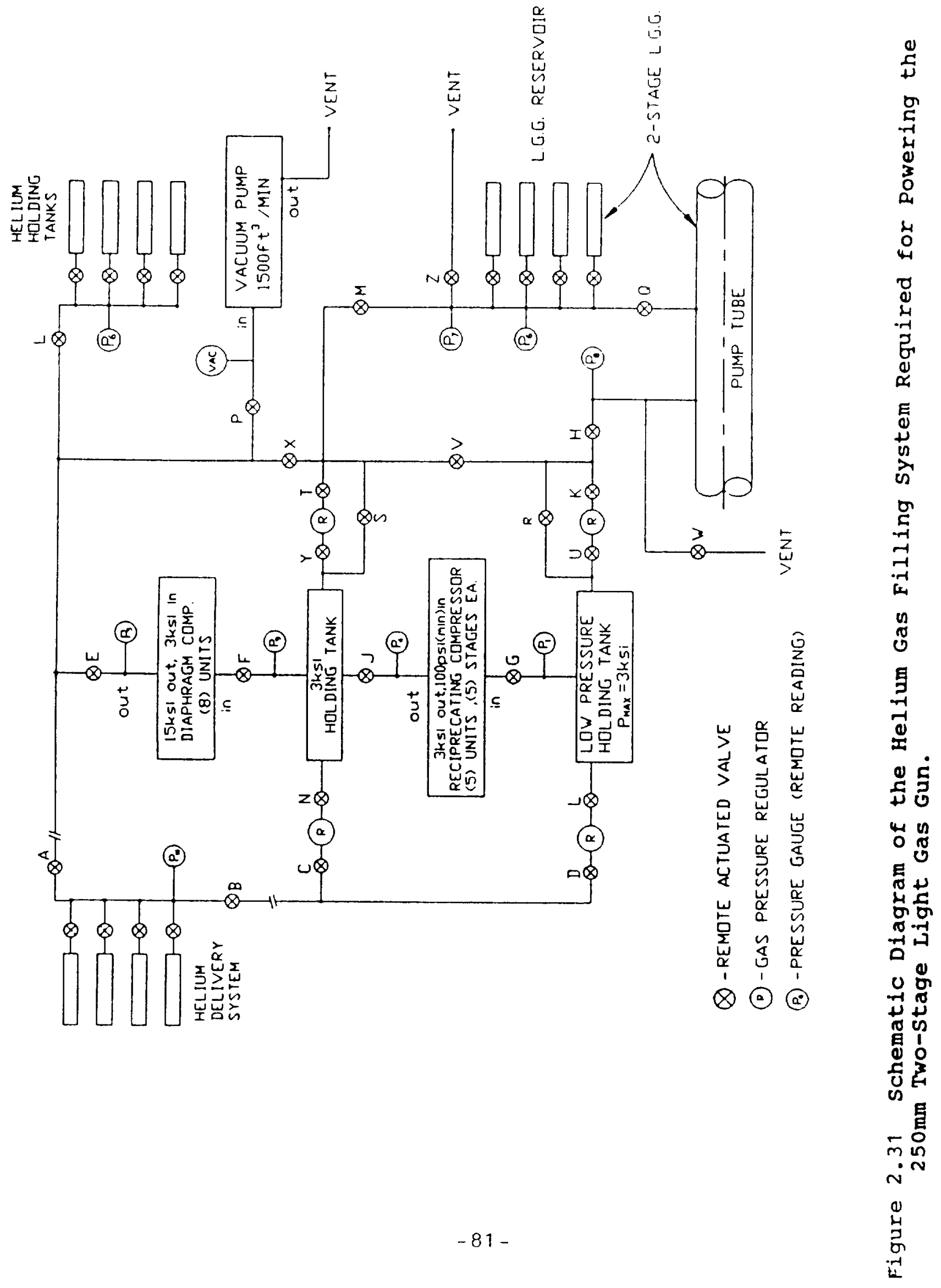


valves " $S, V$, and $H$ " are opened so that higher pressure helium can flow to the light gas gun reservoir. This process is continued until gas pressure in the low pressure holding tank falls below 1.0 MPA signifying that the helium delivery trailer is empty. All valves are then closed, the trailer is removed, and a second full one replaces it.

The process is repeated through several trailers full of gas until the equilibrating pressure after the first step of the filling process reaches 20.0 MPA. At this point valves "D, I, G, and J" are left closed to isolate the low pressure compression system and valves " $C$ and $N "$ are opened to allow regulated helium to fill the 20.0 MPA holding tank to its maximum pressure. Valve "F" is now opened and the high pressure compressor bank is

energized. Once output pressure appears on gauge " $P_{5}$ " the valves "E, X, and $M$ " are opened which switch this pressure to the light gas gun reservoir. This arrangement is maintained until pressure in the 100 MPA holding tank falls below 100 MPA at which point valves "C and $N$ " are closed, valves "D an $L "$ are reopened as well as valve "G" and the low pressure compressor bank is activated followed by opening valve "J". This process is continued until pressure in the low pressure holding tank falls below 1.0 MPA signifying that the helium delivery trailer is empty. This new two-step filling process is continued until pressure in the light gas gun reservoir reaches $100 \mathrm{MPA}$. We estimate that 21 trailers of $10,000 \mathrm{SCF}$ each will be required to complete this process.

\subsubsection{Post-Shot Gas Recompression.}

Let us now consider the situation after a light gas gun firing when the pump tube and reservoir of the light gas gun are filled with helium at a pressure somewhat below 10.0 MPA. The helium compression/delivery system must now be used to transfer gas from the pump tube back to the reservoir. obviously, the main valve between the two units, valve "Q", must be closed as must all other valves in the system. The process is started by opening valves " $\mathrm{H}, \mathrm{K}$, and $U$ " which allow gas from the pump tube to flow into the low pressure holding tank (through a regulator). Valve "G" may now be opened and the bank of low pressure compressors started. Once pressure appears at " $P_{4}$ ", valve "J" many be opened to admit gas to the 20.0 MPA holding tank. When it reaches its rated pressure, valves "S and $M$ " are opened to allow gas flow into the light gas gun reservoir. This process is continued until pressure in the reservoir reaches $20.0 \mathrm{MPA}$ as shown on " $P_{7}$ ", at which point valve " $S$ " is closed, valve "F" is opened and the high pressure compressor bank is started. When pressure appears at " $P_{5}$ " valves " $E$ and $X$ " are opened which allows high pressure gas to flow into the gas gun reservoir. This process is continued until pressure in the pump tube has measured on " $P_{8}$ " falls below 1.0 MPA (which is the minimum effective sucking pressure of the low pressure compressor bank). Valve "H, $\mathrm{U}$, and $\mathrm{K"}$ " should now be closed. The pressure in the light gas gun reservoir as measured by " $P_{7}$ " should now be below, but very near 100 MPA. 
Gas from a helium trailer connected to the system is now valved into either the $20.0 \mathrm{MPA}$ holding tank through valve "C and N" (if trailer pressure is above 20.0 MPA) or through valves "D and $L^{\prime \prime}$ if pressure is below $20.0 \mathrm{MPA}$ and the system pumping is continued with either the high pressure bank or both banks of compressors until pressure in the gas gun reservoir reaches 100 MPA. At this point, all valves are closed and the compressors are shut down. The remaining gas in the light gas gun pump tube is vented out-of-doors by opening valve " $W$ ". Once pressure has reached atmospheric, the gas gun tube may be opened and the piston retrieved.

\subsubsection{Gas Transfer to the Helium Holding Tanks.}

The last procedure considered here involves transferring the gas charge from the light gas gun reservoir to the holding tanks when-and-if gun maintenance is required. The process is started with all valves closed. Valve " $M$ " is opened to connect the gas reservoir with the main gas feed $l$ ines and valves " $X$ and $L$ " are opened to admit gas to the holding tanks. When pressure equilibrates, approximately half the gas will have been transferred. The rest must be routed through the compressor assembly. Valve " $X$ " is closed and valves "Y and $T$ " are opened which allow helium to enter the 20.0 MPA holding tank through an appropriate regulator. The bank of high pressure compressors is started and valve "F" is opened. Once pressure appears at " $P_{5}$ ", valve "E" is opened to allow compressed gas to enter the holding tanks through valve "L", which allows helium (settling pressure in the holding tanks may be monitored by " $\mathrm{P}_{6}$ ").

This process is continued until pressure in the gas gun reservoir (observed at " $P_{7}$ ") falls to 20.0 MPA. At this point, valves "Y and $T$ " are closed and valves "V, $K$, and U" are opened so that pressure-regulated gas may flow into the low pressure holding tank. Valve "G" is then opened and the low pressure compressor bank activated. Once pressure appears at " $P_{4}$ ", valve "J" is opened so that the 20.0 MPA holding tank is refilled as it is drawn upon by the bank of high pressure compressors.

This process is continued until the low pressure tank pressure monitored at " $P_{1}$ " (and pump tube pressure monitored at " $\mathrm{P}_{8}$ ") fall below 1.0 MPA signifying that the light gas gun reservoir has been drawn down to the lowest effective pressure which can be salvaged. At this point, the compressor banks are shut down and all valves are closed. The last $150 \mathrm{psi}$ in the light gas gun reservoir is then vented to atmosphere by opening valve "Z".

\subsubsection{Control Panel Configuration.}

We feel that the entire valving process should be conducted remotely from a panel in the range control room. This condition requires that all valves have remote operating capability and that all gauges provide remote readouts. We are particularly 
impressed with the concept of drawing a diagram of the gas handling system on the control panel with controls and indicators for each of the valves and readouts for each gauge located at appropriate points. We feel further that the valves should be under both individual and collective control. By collective control we mean that the various procedures described in previous paragraphs should be conducted automatically with the operator simply monitoring that all-is-well. These tasks can be programmed into a low level computer called a process controller or they can be controlled by a higher level computer used for running the entire range. Control of individual valves is necessary to allow range operators to respond appropriately to any emergency that might develop or to carry out procedures not anticipated during facility planning and development.

\section{4 .2 Compression Piston.}

The compression piston has been referred to repeatedly in earlier chapters of this report, but its description has been limited to specifying is mass as being $2,268 \mathrm{~kg}(5,000 \mathrm{lbs})$ and its length being near $2.0 \mathrm{~m}$. Perhaps its most outstanding requirements is its ability to withstand crushing forces from the reservoir gas which is applied to its side-wall shortly before firing. Another important characteristic is deformability of its

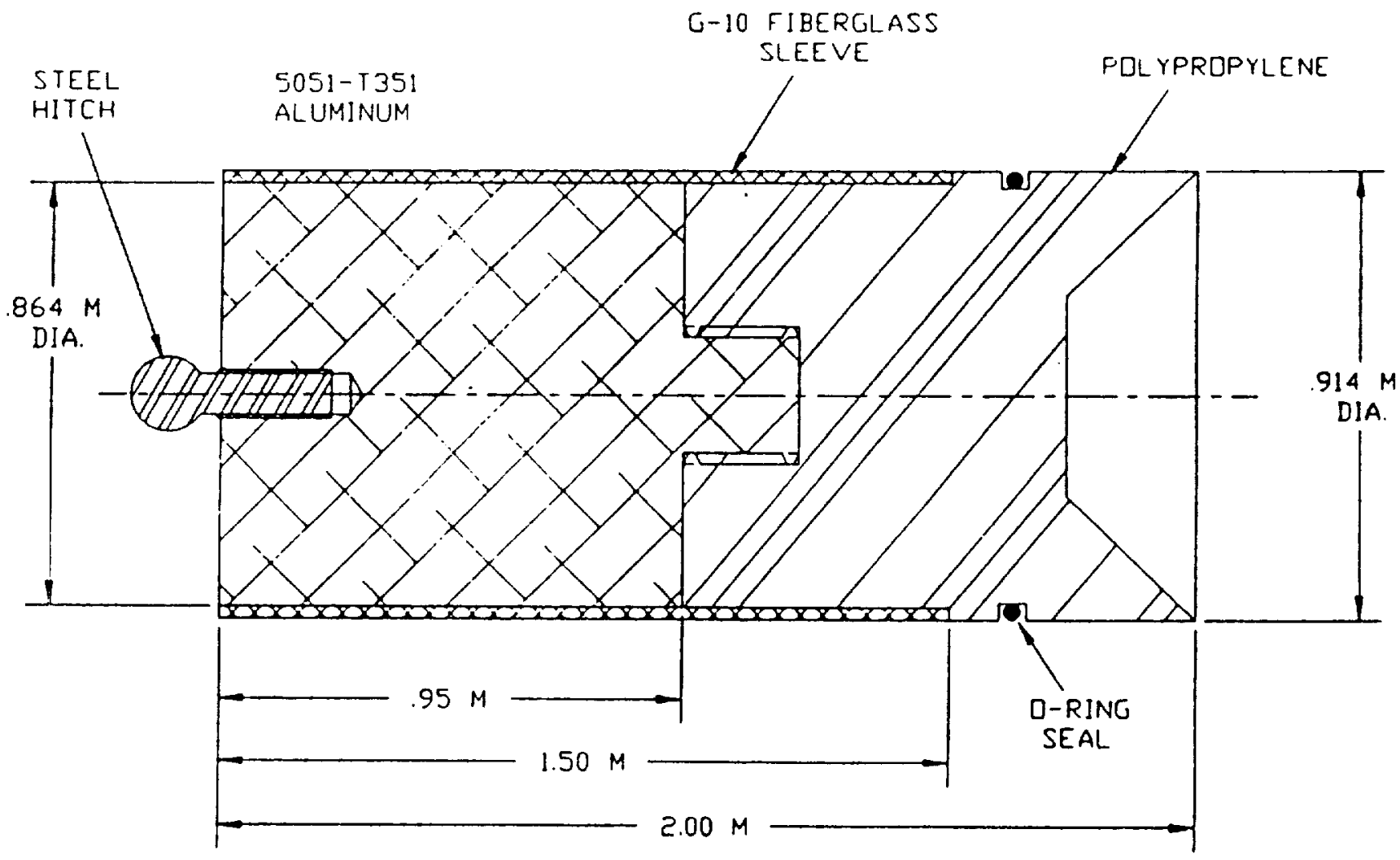

Figure 2.32 Sketch of the Compression Piston to be Used with the $250 \mathrm{~mm}$ Two-stage Light-Gas Gun. 
forward section which engages the taper between the pump tube and launch tube diameters (within the central breech). This section of the piston must resist deformation enough to "soak up" the last of the piston's kinetic energy at the end of the firing cycle but it must neither shatter nor flow so easily that large amounts follow the projectile/sabot package along the launch tube. Finally, the piston must contain a fixture centered on its rear face to facilitate its recovery after firing.

The design chosen for the compression piston is presented in Figure 2.32. The bulk of its mass is contained in an aluminum "slug" at the rear of the structure which is threaded into the fore body. The retrieval device made from hardened steel is threaded far enough into the slug so that it would be difficult/ impossible to pull it out through thread stripping. A sleeve of Gl0 fiberglass/epoxy composite surrounds the aluminum slug and part of the plastic fore body. This sleeve is fabricated by wrapping glass cloth around a mandrel to maximize its axial and tangential strengths. It should be strong enough to withstand gas pressure loading before firing and should also protect the pump tube bore from galling that might occur if aluminum were allowed to touch it.

The piston fore body is a homogenous cylinder with a cut-out in the front face to reduce bore-wall stress in the taper when the piston is driven into it. An o-ring groove in its outer surface near the forward end prevents vacuum and the projectile/sabot driver gas charge from entering the piston structure.

\subsubsection{Hydrogen Gas Fill system.}

The hydrogen gas fill system is used to evacuate the pump tube after the $250 \mathrm{~mm}$ two-stage light gas gun is prepared for firing and to refill it with hydrogen gas to an absolute pressure near $0.68 \mathrm{MPA}(100 \mathrm{psia})$. By far the most important

characteristic of the system is its inherent safety since more than $30.0 \mathrm{~kg}$ of hydrogen gas must be transferred by it before each gun firing. Uncontrolled and rapid release of this hydrogen could produce and explosion or fire of a very serious magnitude.

The hydrogen delivery system is presented schematically in Figure 2.33. It consists of a pressurized bottle-farm similar to the ones used for delivering helium. The bottle-farm and its associated plumbing is located out-of-doors adjacent to the light-gas gun. The location assures that any leak produces a relatively harmless gas cloud that dissipates quickly to a concentration below $5.0 \%$ hydrogen which is the limit of flammability. (5) The associated plumbing includes a pressure regulator for reducing bottle pressure to $10 \%$ above gas filling pressure and a 3-way remote-actuated valve "BB" which vents the gas-fill line when in the powered-down position. When powered up, the valve switches hydrogen into the gas handing system adjacent to the pump tube of the light-gas gun. This valve 


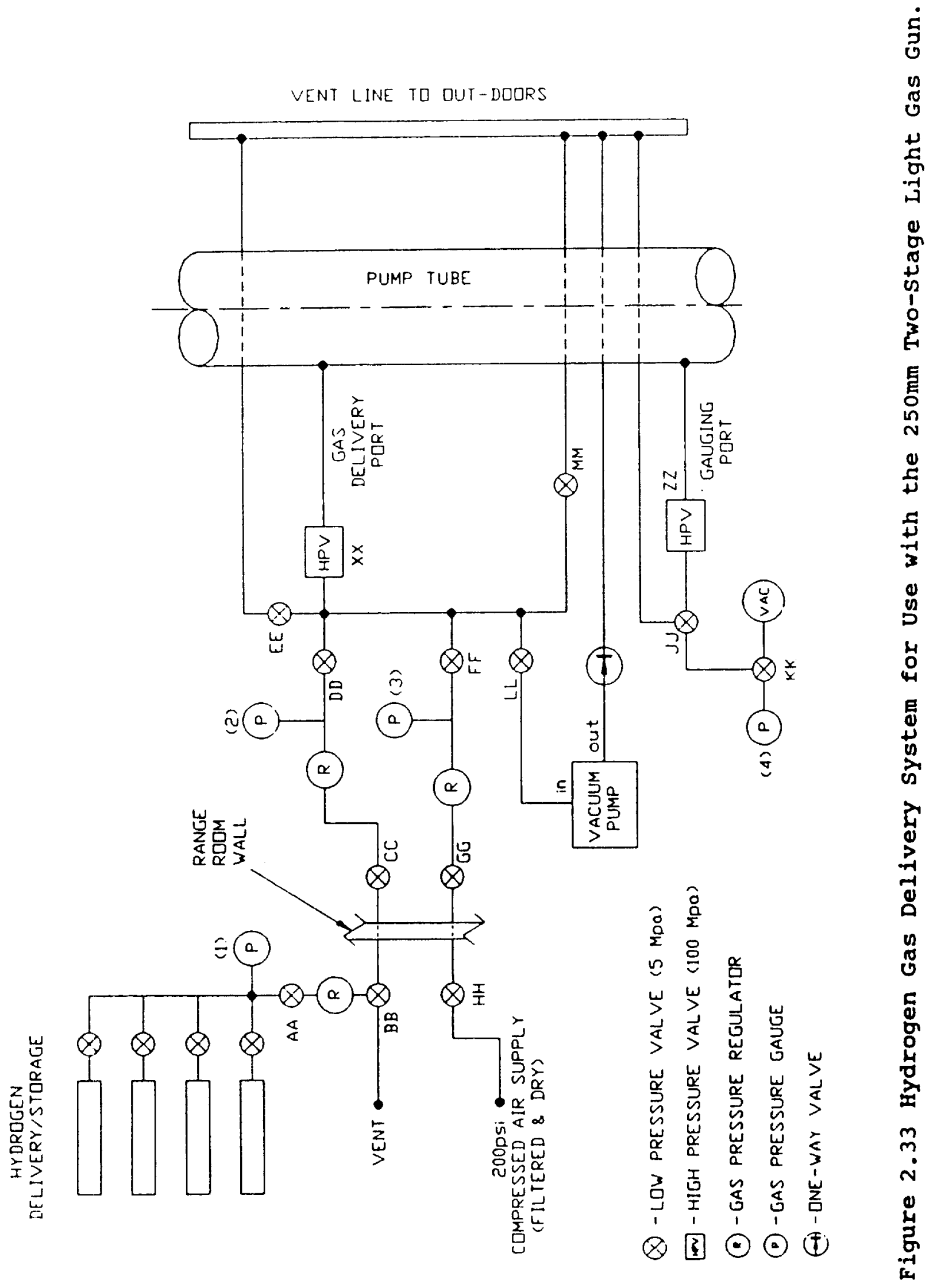


assures that the hydrogen delivery only occurs when it is needed and never inadvertently. The gas entering the range passes through: another cut-off valve, "CC" at the control area along side the pump tube of the light-gas gun; a regulator used to set the gas delivery pressure to the pump tube precisely; an additional cut-off valve; and a high-pressure line leading to the pump tube which is blocked by a high pressure valve " $X$ ". The line is tapped upstream of valve "X" and routed through a cut-off valve "EE" to a vent tube use to expel waste hydrogen. The vent tube is a $76 \mathrm{~mm}$ (3") diameter steel pipe which leads waste gas out of the building. It is made massive enough to withstand a hydrogen explosion (which produces a peak pressure just over 1.25 MPA (180 psi). Another branch upstream of valve "X" leads through cut-off valve "LL" to a vacuum pump used to evacuate the pump tube. The great volume of the pump tube (more than $60 \mathrm{~m}^{3}$ ) requires use of a very large vacuum pump... just as it did with the helium gas handling system described in paragraph 2.4.1.1. Since this pump is so large and expensive, thought should be given to collocating the two gas handling systems and sharing the vacuum pumping system between them.

A second arm of the gas fill circuit starts with a large source of shop air at approximately 265 psi (1.8 MPA) which has been passed through a filter and a dryer. Cut off valves "HH, $G G$, and $F F$, and XX" together with a regulator and a pressure gauge " $\mathrm{P}_{3}$ " are used to conduct this compressed air to the same high pressure valve "XX" used for loading the pump tube. This line is used to check the pump tube assembly for leaks before hydrogen is admitted by prepressurizing it to an elevated

pressure with benign gas. In this way, potentially lethal gas leaks can be observed safely in time for correction. The system is pressurized with air to a level of approximately 1.5 times that anticipated for the hydrogen. The source is cut off and the system is allowed to stand for 5 minutes to detect gas leakage. Any gas leak too small to produce a detectable drop in air pressure over that period is too small to produce a significant risk for the system. The compressed air in the pump tube is then vented through valve "EE" and the evacuation system is energized to evacuate the pump tube in preparation for charging it with hydrogen.

The hydrogen delivery system is completed with a third high pressure valve "ZZ" from the pump tube that is connected to a pair of 3-way valves, "JJ, and KK" which form a sensing arm where pump tube vacuum level is measured as well as its pressure level using gauge " $\mathrm{P}_{4}$ ". We feel that it is important to use two separate inputs to the pump tube: one for filling/emptying it; and the other to sense the results. This configuration has been used widely with two-stage light-gas guns to provide positive assurance that the gauges measure actual conditions in the pump tube volume rather than, simply, in the delivery lines which may or not be actually connected to the pump tube (if a blockage should develop for instance). 
Again, we feel strongly that the hydrogen delivery system should be controlled at least partially from a panel in the control room. The exception may be to switch hydrogen from the source as far as valve "DD" at the light-gas gun pump tube so that the pressure regulator at the light gas gun can be set precisely to the pressure required as monitored by gauge " $\mathrm{P}_{2}$ " Obviously, all of the valves and pressure gauges with the exception of " $P_{2}$ " must have remote-operating capability. Pressure gauge " $\mathrm{P}_{2}$ " may either be a conventional gauge plus a remote reading one or a remote reading gauge with both a local and a remote monitor.

\subsubsection{Piston Breaker.}

The compression piston is always found wedged to one degree or another into the conical taper between the pump tube and the launch tube when a two-stage light gas gun is opened after a firing. Conventional wisdom has held that the piston expends the last of its kinetic energy deforming itself into the taper during the single stroke it makes as part of a gas gun firing. More recently, evidence has accumulated that the piston bounces off of the compressed driver gas used for launching the projectile/sabot package and travels some distance rearward (upstream) along the pump tube. Residual gas pressure in the pump tube plus force from stopping the oncoming driver gas charge brings the piston to rest and propels it forward (downstream) a second time.

Meanwhile, the driver gas charge has exhausted down the launch tube so that nothing is left to absorb kinetic energy of the piston at the downstream end of the pump tube except material deformation of its fore-body into the taper. Probably both explanations are correct for explaining actual piston trajectories. The differences between them are functions of the particular launch cycles chosen by the gas gun operator.

In either case, the piston is always found jammed into the central breech and this jam can be severe enough to require special equipment for piston removal. Three approaches have been used for removing pistons from central breeches. The first and oldest is to mount a chamber containing a charge of solid propellant over the front face of the central breech and igniting it. The discharge "fires" the piston out of the taper and propels it rearward (upstream). We feel this approach is inappropriate for use with the $250 \mathrm{~mm}$ L.G.G. for two reasons. First, it launches the piston rearward at an indeterminate but substantial velocity. Stopping such a piston becomes a major problem when its size and weight are those specified in paragraph 2.4 .2 .

The next approach to be developed is to mount a fixture over the front face of the central breech which allows hydraulic fluid to be injected under pressure against the front piston face. The fluid percolates along the entire piston/taper interface to produce a large upstream-directed force which moves the piston gently. This approach has much to be said for it, but it has one 
weakness which represents a major problem in this particular case. The hydraulic fluid used for displacing the piston is injected into the downstream end of the pump tube where its removal can become a major problem if operators do not choose to open the joint between the pump tube and the central breech.

The approach we recommend is to use a hydraulic driven cylinder to force the compression piston rearward far enough to "break it free" of its engagement to the taper and then remove it through the L.G.G. breech at the upstream end of the pump tube. A fixture shown schematically in Figure 2.34 is clamped over the downstream end of the central breech after a firing when the launch tube has been uncoupled and moved downstream several meters. The same automatic gib clamps used for coupling the launch tube to the central breech are used for coupling the "piston breaker" fixture. The heart of the fixture is a massive dual-action hydraulic cylinder capable of producing forces up to 200 tons when powered by oil pressurized at $67.0 \mathrm{MPA}(10,000$ psi). A series of $240 \mathrm{~mm}$ diameter extensions for the piston are available so that the piston face may be brought close to the downstream face of the compression piston before hydraulic force is exerted. The hydraulic piston is then advanced to produce a massive upstream force on the downstream face of the compression piston which breaks it free of the taper and allows it to slide upstream a few centimeters. The hydraulic actuator is then retracted, the gib clamps opened, and the fixture is set aside pending the next firing.

The fixture can either be mounted on a cart which also contains a sump for excess hydraulic fluid and a pump for pressurizing it. Adjustments must be provided so that the "piston breaker" can be aligned precisely with the downstream face of the central breech when the cart is rolled into proper position. Alternatively, the piston breaker can be lifted into position by an overhead crane while it is clamped tight with the automatic gib clamps and the hydraulic lines are connected to the cylinder via quick-disconnects.

\subsubsection{Piston Retriever.}

Once the piston has been broken free from the taper between the pump tube and the launch tube, it must be drawn upstream along the pump tube so that it can be removed through the main breech of the light-gas gun. A special fixture mounted on the upstream end of all compression pistons allows them to be gripped by a "claw" arrangement simply by pressing the "claw" against the gripping assembly. The claw is connected to a substantial steel cable unwound from a windless located behind the L.G.G. A substantial force can be applied to the rear of the piston by activating the windless for drawing the used piston upstream through the pump tube. 


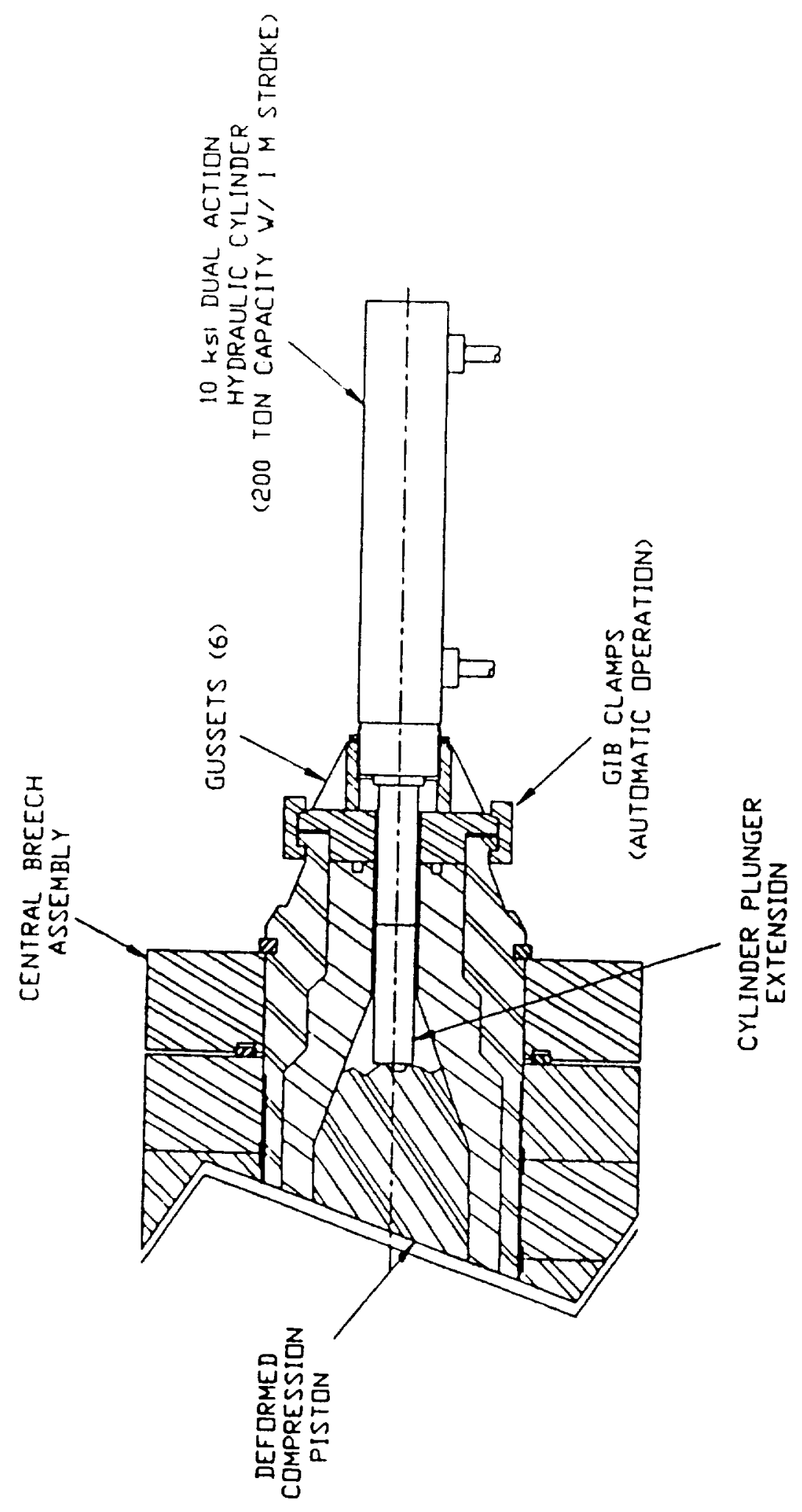

胥

产

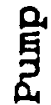

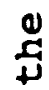

톤

号

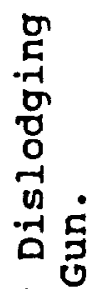

ํำ

ن

号足

ชै

$\stackrel{0}{\circ}$

䓪苟

- 1

पै

苍莡

บ

जै

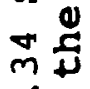

N s

U

券哭 
The problem now becomes "How is the claw to reach the base of the piston some $100 \mathrm{~m}$. down a $.91 \mathrm{~m}$. hole. We suggest that a rubber-tired crawler be employed for this purpose as sketched in Figure 2.35. The crawler contains two pair of pneumatic-tired wheels which engage the bore wall $+/-45^{\circ}$ from vertical downward. A third pneumatic tire mounted on a pivoting arm engages the pump tube bore wall directly above the launch tube axis. This wheel is pressed tightly against the upper bore surface and is driven by an air motor through a substantial gear reduction. Rotation of the wheel causes the "crawler" to move along the pump tube bore pulling the cable along the tube behind it. As the "crawler" approaches the upstream end of the piston the claw mounted facing forward on the tube axis engages the gripper at the rear of the piston. The air motor on the claw is then reversed, and the piston is drawn upstream under power of the air motor backed up by that of the windless/cable system.

\subsubsection{Launch Tube Hone Assembly.}

As discussed in paragraph 2.1.3.2 the smoothness of the launch tube bore must be improved from time to time through use of a spring-actuated hone assembly. The spring-actuated hone consists of a series of fine abrasive stones which are driven over the surface of the tube in a spiral path while being lubricated continuously with kerosene. The extreme length of the launch tube assembly $(75 \mathrm{~m})$ preclude the use of conventional honing equipment for carrying out this task. Instead, we have chosen to consider developing a special honing engine that drives a rotating honing head from one end of the tube to the other as honing is conducted.

The launch tube is prepared for accepting the honing engine by connecting short extensions of the bore to each end. These extensions allow the hone to begin and end each stroke in a portion of the bore that is not critical. Eventually these bore sections will "bell mouth". The extensions need be only somewhat longer than the honing engine itself $(0.75 \mathrm{~m})$. The honing engine consists of a five-wheel vehicle which is, essentially, a scaleddown version of the one used in the pump tube for piston retrieval (as discussed in paragraph 2.4.5). The vehicle contains a second air-operated motor and gear reduction which drives the honing head mounted to the forward end of the "crawler". The stones are pressed against the bore wall with springs and rotate around the bore axis.

In operation, the crawler is installed in the up-stream launch tube extension end and low dams (50mm high) are installed at the extreme ends of both launch tube extensions. Kerosene is flowed into the launch tube to a depth of approximately $30 \mathrm{~mm}$. Both air motors are actuated on the honing assembly and it begins its motion along the launch tube as the spring-actuated head containing the stones is rotated. The hone pulls a rubber air delivery hose from a reel containing $75 \mathrm{~m}$ of it as the crawler progresses along the tube. When the engine assembly reaches the 


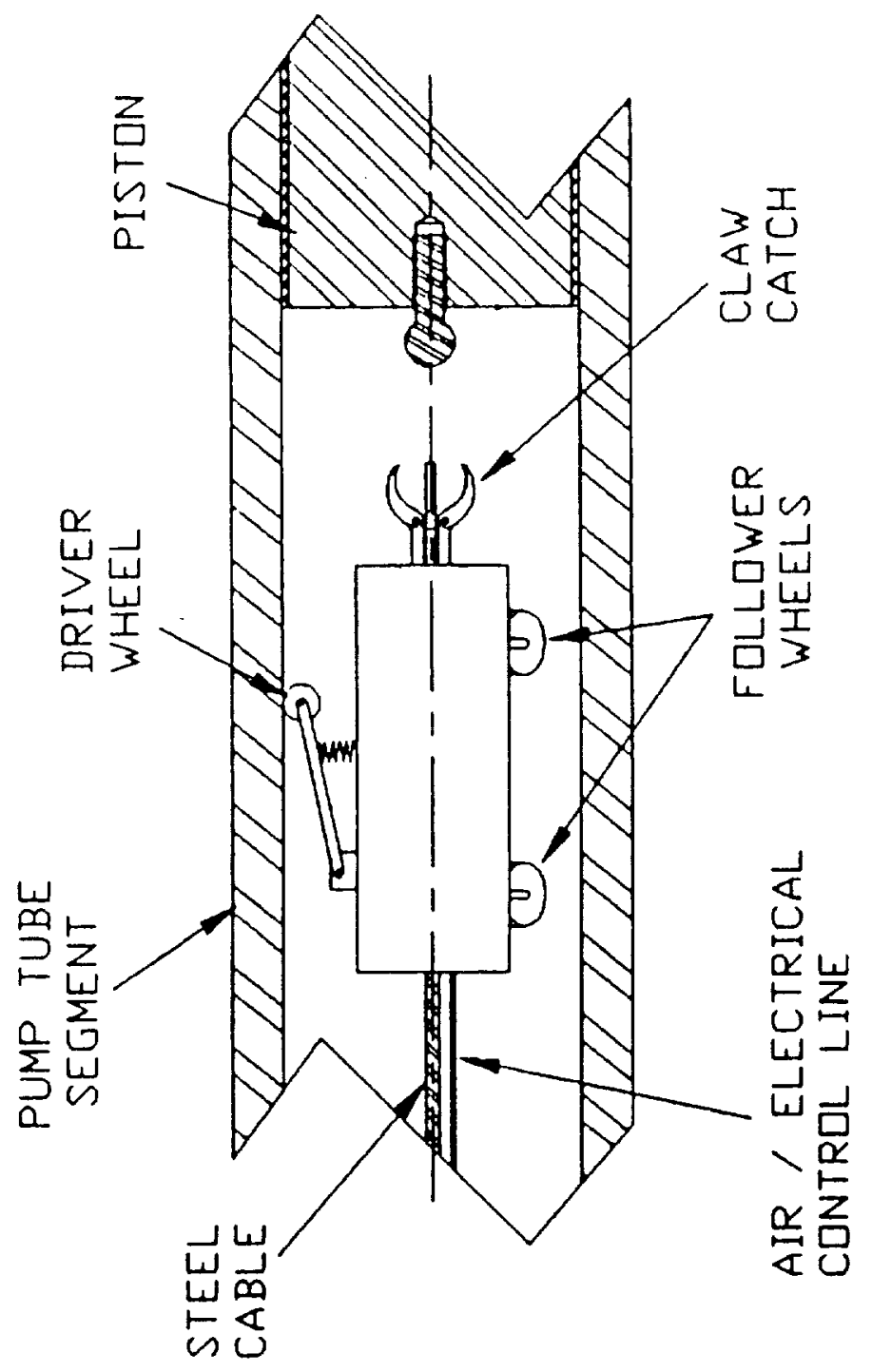

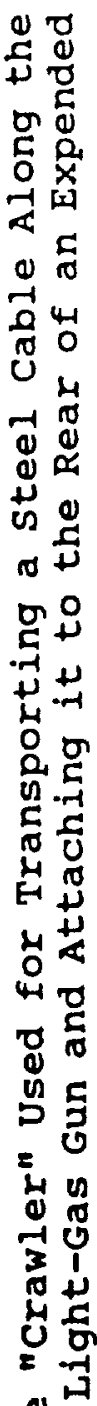

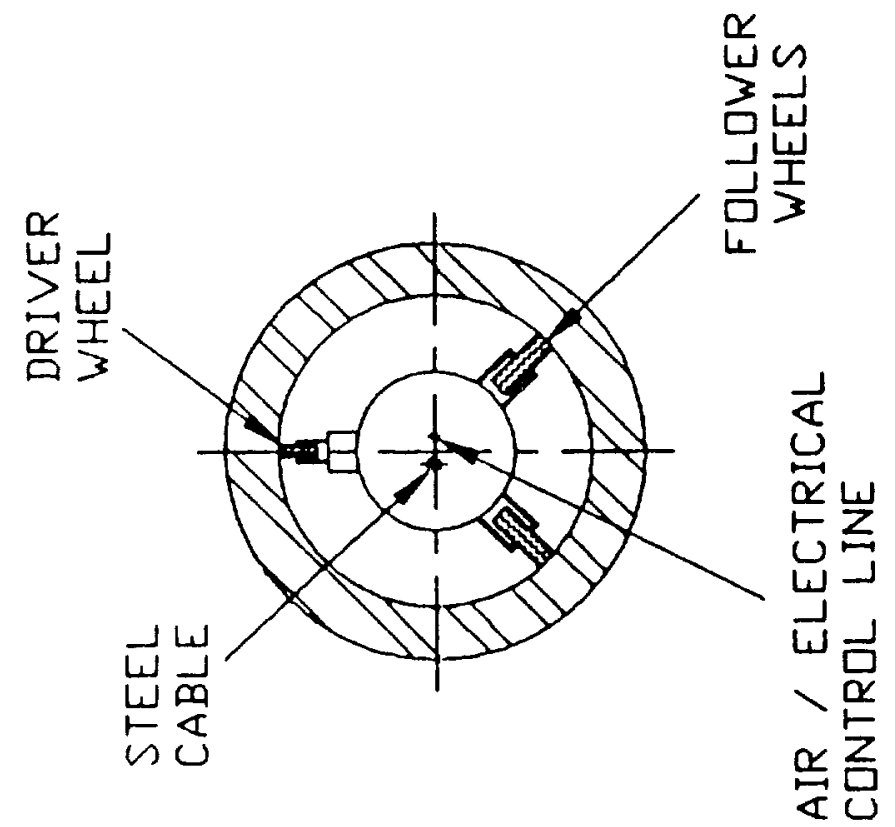

号

แ晨

동

牙

通

잉당

- $0 \cdot \sigma$

起易 
muzzle end of the launch tube and enters the muzzle extension, a reversing valve on the air motor responsible for vehicle propulsion is activated by a push rod which engages the forward dam. The reel mounted behind the upstream end of the launch tube "takes up" the air delivery hose as the honing engine progresses upstream along the launch tube. Upon reaching the upstream end of the tube, it progresses into the tube extension and the same push rod which actuated the reversing switch at the muzzle now extends out of the rear of the assembly and engages the upstream dam. Thus, the hone engine's travel is re-reversed for a second pass along the tube.

The pressure of the stones against the wall of the tube is maintained constant by their springs and splashing of the hone head assembly through the kerosene maintains lubrication between the stones and the bore wall. Approximately 100 passes are required to clean up the pump tube wall. These can be accomplished in one 8 -hour shift if the hone assembly is set to proceed along the tube at a rate of $1.0 \mathrm{~km} / \mathrm{hr}$.

The honing operation is completed by: opening the up-stream dam and draining the kerosene into drums for reuse; and cycling the engine one more time with the stones replaced with a continuous rubber boot that "squeegees" the bore dry and forces removal of the last of the kerosene. Finally, the hone is operated for one final cycle with a polishing cloth to complete the cleaning sequence. 


\subsection{RANGE COMPONENTS.}

All of the activities of the contemplated ballistic range must take place within tanks whose atmospheric pressure and chemical make-up can be predetermined precisely. The first tank, located immediately downrange from the launch tube muzzle, must be dedicated to absorbing the hydrogen gas charge used for launching the model from the two-stage light-gas gun. The blast absorption tank must have a volume of $514 \mathrm{~m}^{3}$ to maintain peak pressure excursions within safe limits. If the tank is made with a diameter of $4.0 \mathrm{~m}$, it must have a length of $41.0 \mathrm{~m}$. Such a tank is too large to be delivered in one piece. Segments $10 \mathrm{~m}$ long each must be welded together end-to-end on-site to achieve the final geometry required.

The launch package is supported on four rails as it slides along this portion of the range tankage. The rails prevent the sabot from opening and assure that the package remains precisely on the range axis. A fast-operating valve (FOV) at the downstream end of this tank effectively isolates the hydrogen charge within the "blast tank" so that it can be disposed-of safely. Normally, the guide tracks end at the Fov.

The second tank in line is used for separating sabots surrounding launched models from the models themselves when experiments requiring model free-flight are conducted. Two means for achieving sabot separation can be accomplished within this tank. The tank can be provided an atmosphere of inert gas such as helium, argon or air at sufficient pressure to provide aerodynamic forces on the windward face of the sabot which allows its segments to first pivot around their rear ends away from the model then travel laterally away from the model. When model-sabot separation has grown large enough, the segments can be intercepted and destroyed without disturbing the model as it continues its travel downrange. Free-flight lengths near $30 \mathrm{~m}$ are required to provide adequate separations of heavy sabot segments using acceptable atmospheric densities within the tank. The model also experiences flight through the sabot-separating atmosphere which produces aerodynamic heating and may even produce ablation. Interactions between the model and shockwaves from separating sabot segments may also affect model orientation. The alternative approach to sabot separation is to evacuate the sabot separation tank to high vacuum and produce sabot pivoting and separation by allowing its outer portions to pass through very low density solid material mounted at the upstream end of the tank. This technique effectively eliminates model disturbances produced by aerodynamic sabot separation.

The down-range end of the sabot separation tank must be dedicated to destroying the sabot segments which supported the model during its launch. Sabot destruction must be accomplished without either damaging the tank or affecting the model's flight. 
The approach chosen involves allowing the model to enter a smalldiameter pipe extending some distance upstream from the

downstream end of the tank while the sabot elements continue to fly downstream between the pipe and the tank side-wall. The sabot elements are then allowed to encounter a sheet of liquid water or an intense field of water droplets whose impacts cause the segments to disintegrate (and, possibly, to vaporize). Certainly, much of the water intercepted by the sabot segments is also vaporized so both the model containment tube and the external tank wall surrounding the sabot disruption area must be built strong enough to sustain the battering received during each firing. A total "flight distance" of $10 \mathrm{~m}$ is required for achieving full sabot breakup and kinetic energy dissipation. Thus, the sabot tank must have a total length of $40 \mathrm{~m}$. A diameter of $3.0 \mathrm{~m}$ should be sufficient for energy dissipation and for providing room for sabot excursions. Again, the tank must be assembled on-site.

A second Fast opening Valve (FOV) is required at the downstream end of the sabot separation tank to separate the portion of the range used for aerodynamic and aerophysical measurements from that used for operations associated with model launching.

The main portion of the evacuated range lies downstream of the second Fov. It starts with a tank a few tens of meters long which allows the model to outrun any residual gases and vapors that may have accompanied it from the launch operation portions of the range tankage. The model then enters the main range flight path which is made large enough in diameter $(3.30 \mathrm{~m})$ to accommodate its maneuvers and long enough to allow its aerodynamics to be exercised. After some consideration, a total distance of $330 \mathrm{~m}$ flight path was chosen by determining that this distance was just sufficient to allow a maximum-size model of the space shuttle launched by the light-gas gun to undergo one complete oscillations in pitch.(14)

obviously, the main flight tank must be made up of many segments joined end-to-end. Lips around the inside edges of the downstream segment ends are available for installing diaphragm mounts which allow portions of the tankage interior to be separated from one another so that different atmospheric pressures and gas mixtures can be prepared within them. Launched models can then be exposed to a variety of atmospheric conditions during a single flight along the range axis. The diaphragms are made from sheets of moldable plastic such as lexan to assure that even very thin sections are absolutely hole-free. Very thin diaphragms which separate small pressure differentials can be left in place during a firing. Oncoming models perforate them without receiving significant damage. Thicker diaphragms which are required to separate different gas pressure levels must be cut mechanically as oncoming models approach them. The pressure differential across the diaphragm forces it aside out of the way of the oncoming model which is allowed to pass freely. 
Unfortunately, the speed at which triggered diaphragm valves can be made to open decrease rapidly with clear aperture diameter. For this reason it is advantageous to make the clear apertures as small in diameter as possible to decrease open time needed before projectile passage which causes gas spillage from the highpressure portion of the range to the low-pressure one.

Each segment of the flight tank is equipped with a sealable doorway through which operators can enter the tank structure. Ample provisions are made within the structure for bolting instrumentation and groups of windows arranged opposite one another in orthogonal pairs are provided for photographic and radiographic instrumentation to observe the flight path.

One exciting new advance in data systems is the development of miniaturized, g-hardened, solid-state data recorders. (9) These recorders could be mounted within the test models to record signals from onboard instruments. It appears feasible to recover these onboard recorders(1) so that the data can be read out after the test. Basically, the launched models are decelerated after the experimental portion of their flight by allowing them to pass through dense atmospheres. A drag enhancement device, such as a ballute, is deployed which pulls a package containing the data recorder out of the model shell. Aerodynamic heating is expected to destroy the model shell, but the blunt package containing the recorder can be made to survive and be decelerated to where it impacts soft material and is recovered for post-test readout of the data. Initial estimates of the required length of the deceleration section are $150 \mathrm{~m}$ for initial model velocity of 6.0 $\mathrm{km} / \mathrm{sec}$ and $550 \mathrm{~m}$ for an initial model velocity of $12 \mathrm{~km} / \mathrm{sec}$. The diameter of the model deceleration portion of the tank must be at least as large as the flight portion.

Another experimental approach involves launching the model mounted on the front face of a sabot in the form of a borefitting cylinder. The cylinder remains with the model during its entire "flight" along the range which is conducted on extensions of the blast-tank rails. $(10,11)$ This procedure assures that the model flies precisely along the range axis. It can then be examined minutely as it passes range-side instrumentation. Its attitude relative to its flight axis can be maintained precisely throughout its "flight".

Care must be taken for the design of the rail system since it must reside within the sabot separator and flight tanks. When deployed, it must occupy the volume surrounding the range axis. When folded away, it must leave this area completely clear. Additionally, it must be almost precisely straight when deployed to avoid placing unacceptable centripetal acceleration loads on launched model packages. Large-diameter tanks tend to shift position slightly when they are evacuated. These movements would almost certainly destroy rail alignment. An effective "fix" for this problem is to support the rail system when in operation on posts that extend through the side wall of the range tankage to the building foundation. Rubber boots make vacuum seals between 
the tank wall and each rail support. In this way, the rails are related dimensionally directly to the building foundation and are specifically unaffected by small movements of the range tankage.

Finally, models launched along rails can be captured after flights along the range axis with relative ease using a "gasdynamic" sabot catcher". Basically, the model is conducted into a second bore-diameter tube after its experiment flight which is filled with gas at some low-to-moderate initial pressure. The cylindrical sabot acts as a piston in the tube which produces a shockwave in the gas column. The behind-shock pressure decelerates the piston (and the model) and eventually brings them to rest where they can be recovered virtually intact. Thus, rail launchers allow certain models to be examined minutely both in flight and post flight. on-board instrumentation can be operated with data recorders that can be played back post real-time. Finally, effects of the flight environment on the model can be observed post-flight using lengthy test procedures that are both non-destructive and destructive. The rails section in the blast tank is connected to similar units mounted in the sabot separator and flight tanks.

Rail-launching of models is especially useful for investigating ablation and mechanical erosion phenomena because the most intense effects occur near stagnation points which are relatively small. . . even on full-size space-traveling vehicles. Many studies require relatively long exposures to destructive environments to achieve and study steady-state recessive processes. Such exposure times translate to long flight path-lengths which are attainable during rail-guided ballistic "flight". (12) For this reason, space should be made available at the Extremely Large Aerophysics Range for up to several kilometers of projectile guidance rails beyond the downstream end of the range tankage. The rails can be enclosed in tankage as small as $1.0 \mathrm{~m}$ in diameter which can operate outof-doors for the most part. Small buildings located every $100 \mathrm{~m}$ to $200 \mathrm{~m}$ along the tank can be used to house model-observation instrumentation. Large tankage evacuation stations must be located at $1.0 \mathrm{~km}$ intervals for achieving and maintaining proper atmospheric conditions within the range volume.

The most down-stream tank in the range when it is configured for conventional operation is dedicated to catching launched projectiles and destroying them. The method for destroying them is nearly identical to that used to destroy sabots in the sabot separation tank. A sheet of water falling from a tank above the range covers the range cross-section. The oncoming model impacts the water and is shattered. The resulting fine debris is diverted over a substantial cone and allowed to impact a massive dual-plate structure.

The overall tankage system required for the range is very large. Listed in Table 3.1 are the individual tanks, their lengths, diameters, and volumes. 
TABLE 3.1: BASIC SPECIFICATIONS OF RANGE TANKAGE ELEMENTS.

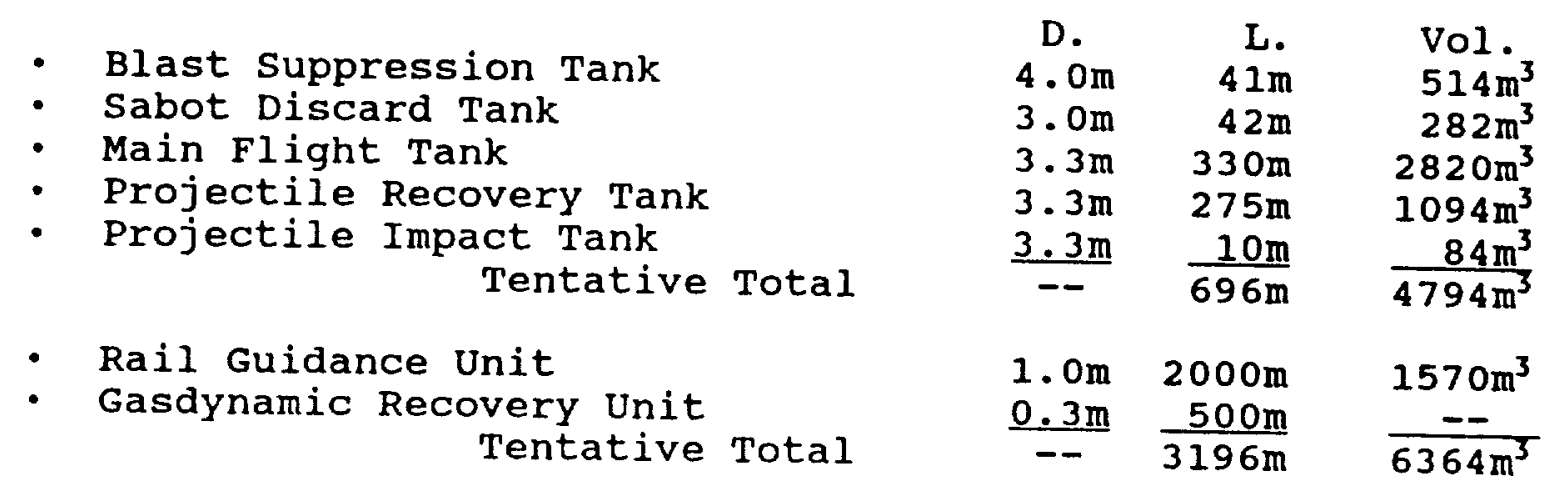

Very extensive facilities are required for supporting operation of the range tankage described above. Perhaps the largest system is that required for evacuating the range. Much of the range tankage can be operated with only moderate evacuation (5-15 torr) which can be achieved readily by large single-stage fore pumps. This category includes: the Blast Suppression tank $\left(514 \mathrm{~m}^{3}\right)$; the Sabot Discard Tank $\left(282 \mathrm{~m}^{3}\right)$; the Projectile Recovery Tank $\left(1094 \mathrm{~m}^{3}\right)$; and the Projectile Impact Tank $\left(84 \mathrm{~m}^{3}\right)$. Their combined volume of $1460 \mathrm{~m}^{3}$ is spaced widely along the range. For this reason, we recommend dividing evacuation capability into several autonomous units and mounting each on a semi-portable pallet whose positions along the range can be shifted from time to time. The remainder of the range tankage including: the Main Flight Tank $\left(2820 \mathrm{~m}^{3}\right)$; and Rail Guidance Unit $\left(1570 \mathrm{~m}^{3}\right)$ must be evacuated to pressure levels as low as $10^{-4}$ torr upon occasion. Since these units are relatively long and may not be used continuously, installation of multiple high vacuum evacuation equipment systems on semi-portable pallets is also indicated.

The range tankage must also be ventilated after firings to allow men to enter safely. Generally, ventilation is accomplished through a different system from that used for evacuation since vacuum pumps degrade relatively rapidly when required to pump against atmosphere.

Finally, substantial gas delivery systems are required for producing particular atmospheric chemistries since volumes of the range components are so large. For instance, establishing an atmospheric pressure of 15 torr of a non-atmospheric gas in the 
free-flight tank requires a total of just over 2,860 standard $\mathrm{ft}^{3}$ (SCF) of gas. Thus, substantial quantities of a variety of different gases used for simulating atmospheric conditions of interest must be maintained on-hand and special equipment must be employed for mixing these gases as they are injected into the range. Improper or inadequate gas mixing produces pockets of volume within the range whose atmospheric chemistry differs from nominal by significant degrees. Days are required to assure that such pockets dissipate to provide proper mixing once they are formed.

The remainder of this report describes the range tankage and its required support systems. The report ends with comments on the range facility building requirements to accommodate equipment already described and other items that may be needed to upgrade facility capability in the future.

\subsubsection{Tankage Used for Supporting Launcher operations.}

The blast tank and sabot tank are different from the other range tankage in that they are intended to support launcher operation as apposed to extracting aerodynamic and aerophysics data from models in-flight or for capturing them (destructively or non-destructively) post-flight.

\subsubsection{Blast Tank.}

The largest-diameter tank of the facility is the blast tank into which the launcher muzzle is mounted. As stated earlier, its task is to disperse and dissipate the muzzle gas from the launcher and to transport the sabot package along its length without allowing the sabot to deviate from the range axis, shift orientation, or to open. Since models often protrude from the front (downstream) end of closed sabots, we wish to operate the blast tank at as high vacuum as is feasible to minimize model preheating. If possible, the blast tank should be operated at pressures well below 10.0 torr.

The sabot packages are, typically, made up of four segments each of which has a cross-section of a quarter-circle. Together they surround the model and provide a close fit to the bore of the launch tube. At the launch tube muzzle, the sabot package leaves the closed tube and enters the opening between an array of four rails whose inner surfaces are aligned precisely with the bore wall of the launch tube (see Figure 3.1 ). The $0.75 \mathrm{~m}$ inner tube diameter contains four rectangular steel rails whose thicknesses and widths are controlled precisely. The rails are bolted directly opposite one another with their outer edges in contact with the bore wall of the surrounding tube. Many largediameter holes are cut in the tube wall between the rails so that the muzzle gas from the launcher may escape freely into the blast tank. This relatively rigid and expensive rail construction is needed in areas where muzzle gas from the gas gun exerts considerable force. It continues for approximately $12.0 \mathrm{~m}$ along 


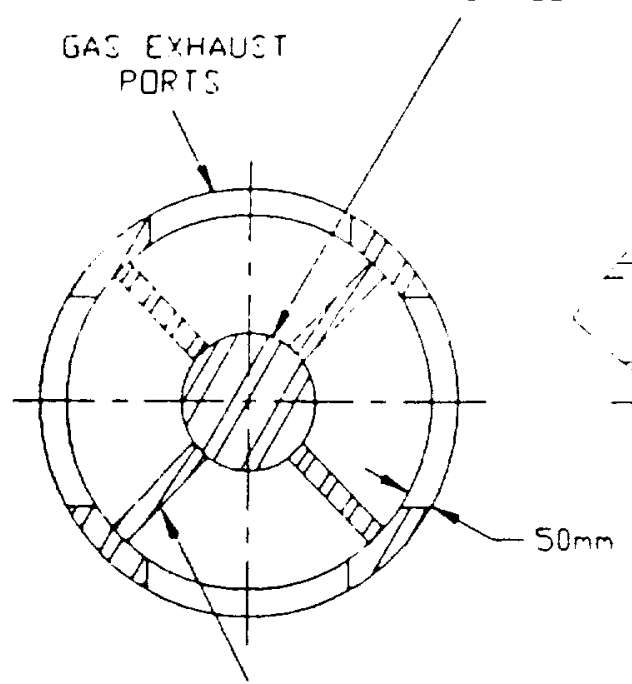

PROJECTILE PACKAGE GUIDE RAILS (4) EA.

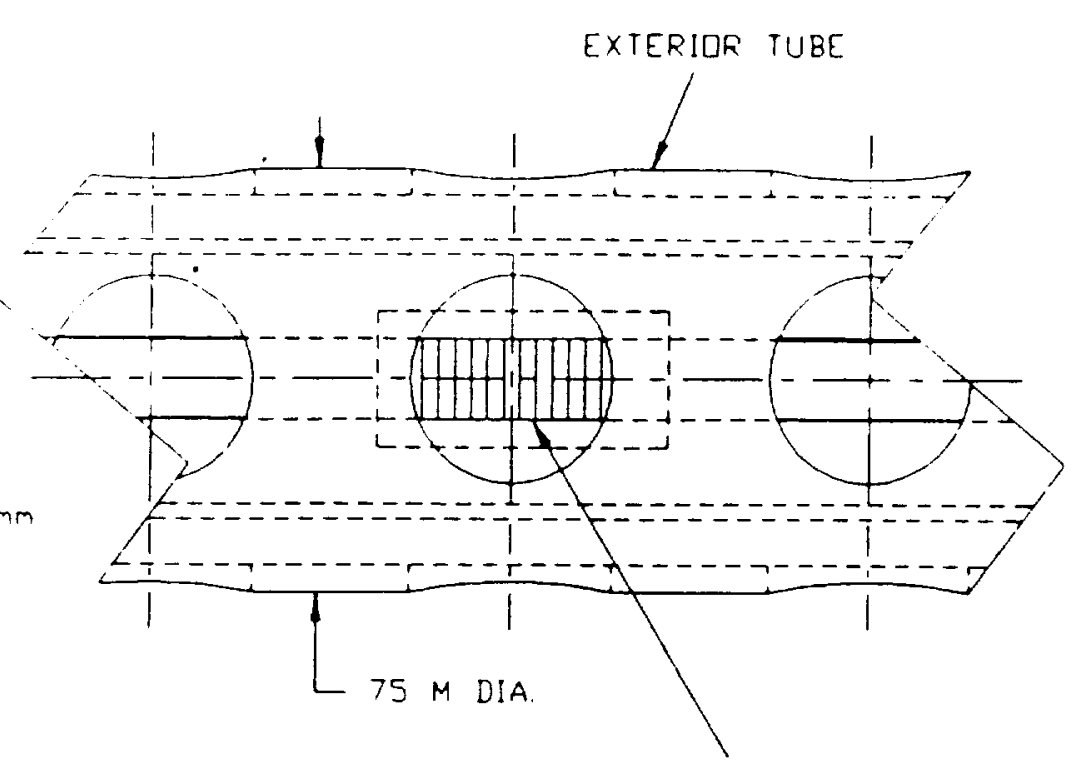

PROJECTILE TRAVELING ALONG RAILS

Figure 3.1 Enclosed Guidance Rail Assembly for $250 \mathrm{~mm}$ Diameter Projectile Packages.

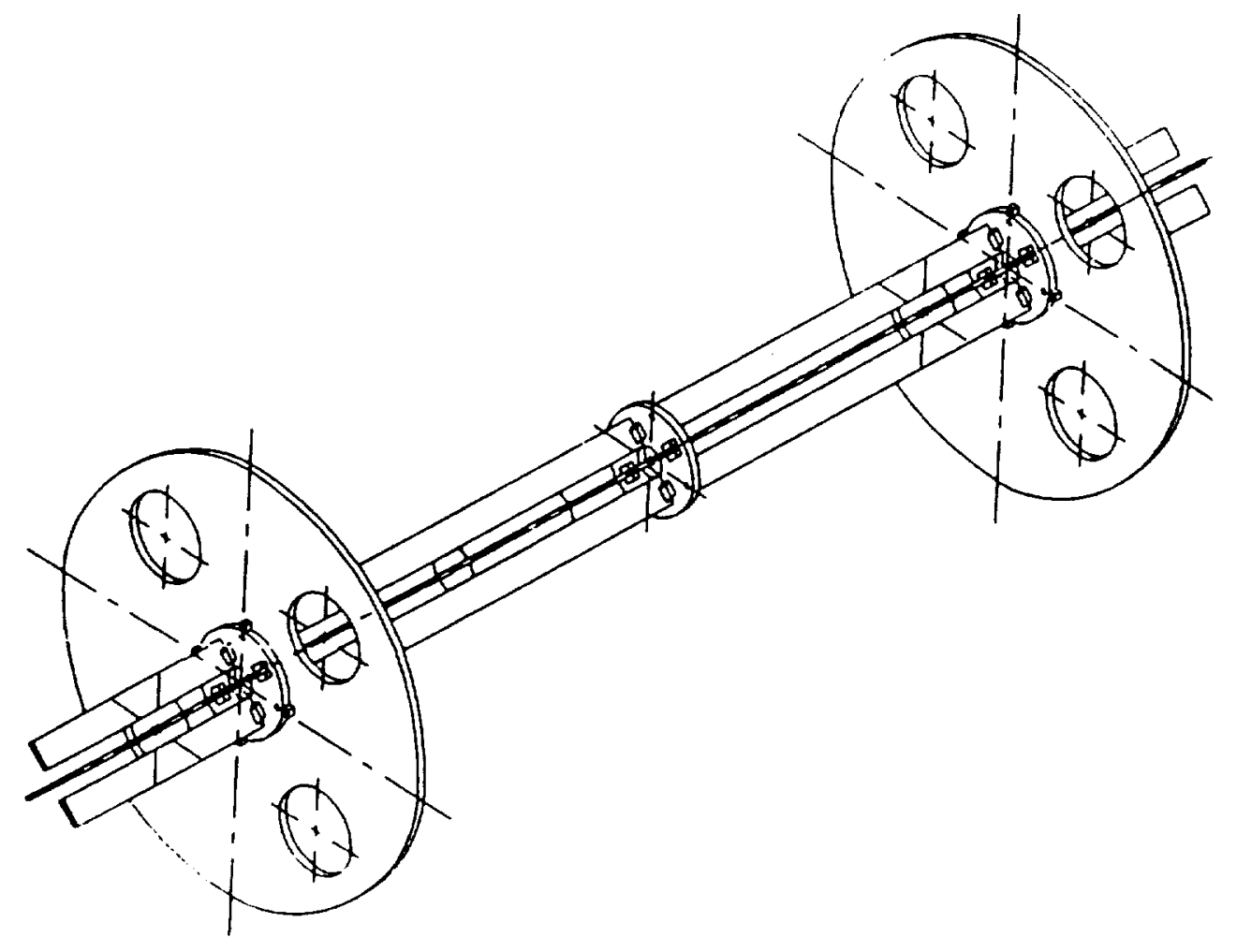

Figure 3.2 "Open" Guidance Rail Assembly for $250 \mathrm{~mm}$ Diameter Projectile Packages. 
the blast tank axis. The tube passes through three baffles within the blast tank which are mounted across the tank diameter every $4.0 \mathrm{~m}$ along its $41.0 \mathrm{~m}$ length. The pressure of the driver gas charge has dropped substantially by the time the projectile package reaches the end of the first rail section so a simpler and less expensive "open" arrangement may be used for supporting the remainder of the rails (see Figure 3.2). Here, $50 \mathrm{~mm}$ thick steel plates are used to support $50 \mathrm{~mm}$ by $150 \mathrm{~mm}$ rails in precise positions with respect to one another. Each $8.0 \mathrm{~m}$ long section of open rail structure is attached to the baffles of the range and to one another at $2.0 \mathrm{~m}$ intervals along its length. A total of seven such sections span the remaining length of the blast tank. The rails are maintained in precise alignment with the bore of the L.G.G. launch tube by securing them to each tank baffle with adjustable supports presented schematically in Figure 3.3 .

Let us now establish the size required for the blast tank (which is quite substantial). We start the analysis by evaluating the maximum energy that can appear in the driver gas emitted by the two-stage light-gas gun, $E_{g}$ from Equation 3.1 . The maximum energy that can appear in the gas, $E_{g}$ is just the kinetic energy of the compression piston which is the source of the driver gas energy less the kinetic energy of the projectile package.

$$
E_{g}=E_{p i}-E_{p}=0.5\left(M_{p i} U_{p i}^{2}-M_{p} U_{p}^{2}\right)
$$

where:

$$
\begin{aligned}
& \mathrm{E}_{\mathrm{pi}}=\begin{array}{c}
6.378 \times 10^{8} \mathrm{~J}=\text { kinetic energy in the compression } \\
\text { piston; }
\end{array} \\
& \mathrm{E}_{\mathrm{p}}=2.521 \times 10^{8} \mathrm{~J}=\text { kinetic energy of the projectile; } \\
& \mathrm{M}_{\mathrm{pi}}=2268 \mathrm{Kg}=\text { piston mass; } \\
& \mathrm{M}_{\mathrm{p}}=14.0 \mathrm{Kg}=\text { projectile package mass; } \\
& \mathrm{U}_{p i}=750 \mathrm{~m} / \mathrm{sec} .=\text { maximum piston velocity; and } \\
& U_{\mathrm{p}}=6000 \mathrm{~m} / \mathrm{sec} .=\text { projectile velocity. } \\
& \hline \mathrm{E}_{\mathrm{g}}=3.858 \times 10^{8} \mathrm{~J}
\end{aligned}
$$

This value for the energy in the gas admitted to the blast tank represents an absolute upper limit of possibility since a significant portion of it is expected to be transferred as heat to the gas gun structure and the blast tank hardware. We feel that it is wise, however, to use this energy loss as a safety factor by not considering it. 


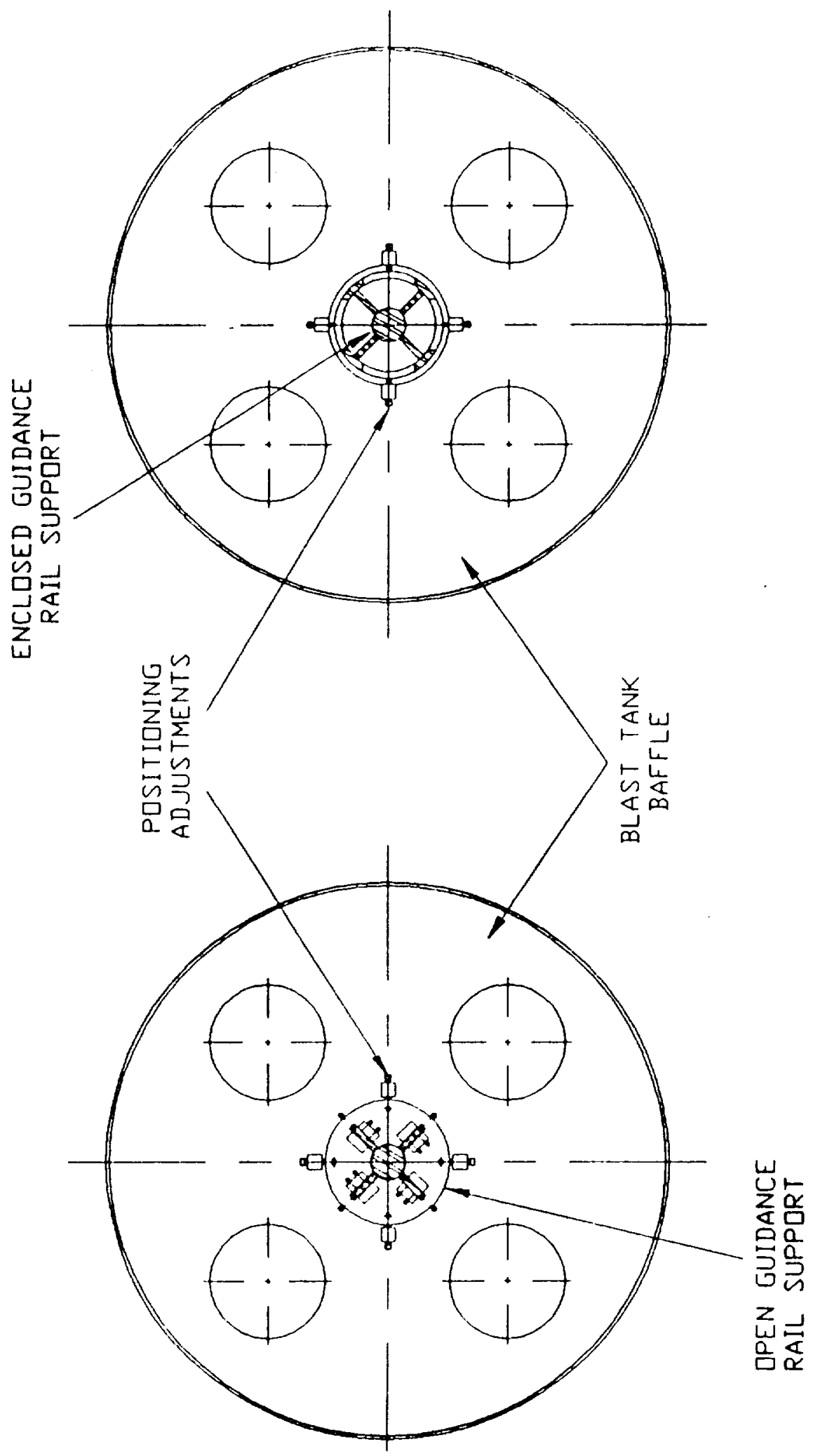

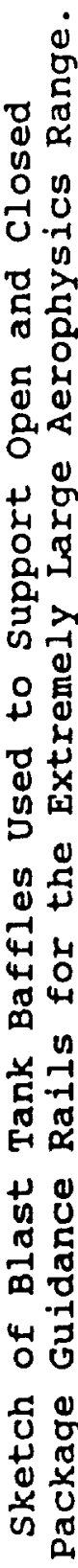

$m 0$

$\dot{m} \cdot \vec{H}$

o U

늠

웅 
We may next calculate the volume of the blast tank, $v_{\text {bt }}$ required to absorb energy from the driver gas while producing a limited pressure change as is presented in Equation 3.2. The assumption governing derivation of Equation 3.2 is that the hydrogen gas, as it exists in the blast tank, is ideal.

$$
V_{b t}=\frac{(\gamma-1) E_{g}}{\delta P_{b t}}
$$

where:

$$
\begin{aligned}
& \gamma=1.4=\text { ratio of gas specific heats; } \\
& \delta \mathrm{P}_{\mathrm{bt}}=0.3 \mathrm{MPa}=\begin{array}{c}
\text { maximum permissible pressure rise in the } \\
\text { blast tank; }
\end{array}
\end{aligned}
$$$$
\overline{V_{b t}}=514.3 \mathrm{M}^{3}
$$

This required volume for the blast tank is substantial! The largest diameter tank that can be mounted conveniently in the range is $4.0 \mathrm{~m}$. Such a tank must be $41.0 \mathrm{~m}$ long in order to meet volumetric requirement. This volume is so large that we chose to examine it further to determine whether or not it is reasonable. We used the perfect gas law equation (a combination of Boyls' and Charles') law solved for the final gas temperature, $T_{f}$, to check the results as presented in Equation 3.3 .

$$
T_{f}=\frac{T_{o} V_{f} P_{f}}{P_{o} V_{o}}
$$

where:

$$
\begin{aligned}
& \mathrm{T}_{0}=295^{\circ} \mathrm{K}=\begin{array}{c}
\text { original temperature of the gas charge as } \\
\text { loaded into the gas gun; }
\end{array} \\
& \mathrm{P}_{0}=0.680 \mathrm{MPa}=\begin{array}{c}
\text { original pressure of the gas charge in } \\
\text { the gas gun; }
\end{array} \\
& \mathrm{V}_{0}=60.05 \mathrm{M}^{3}=\begin{array}{c}
\text { volume of the gas charge within the gas } \\
\text { gun; }
\end{array} \\
& \mathrm{P}_{f}=0.30 \mathrm{MPa}=\text { maximum gas pressure in the gas tank; and } \\
& \mathrm{V}_{f}=\mathrm{V}_{\mathrm{bt}}=514.3 \mathrm{M}^{3} \\
& \mathrm{~T}_{f}=1114^{\circ} \mathrm{K}
\end{aligned}
$$

This final gas temperature is $3.77 \mathrm{x}$ absolute room temperature. As such, it represents quite a reasonable temperature excursion for the gas just as it enters the blast tank. The gas may be expected to cool within a few minutes to room temperature at 
which point its pressure falls to $.080 \mathrm{MPa}$ which is near $80 \%$ of room pressure. Choice of a blast tank volume not quite filled to atmospheric pressure by a gun's driver gas correspond quite closely to normal practice for smaller evacuated ballistic ranges. Since pressure excursions at local points within the blast tank during and shortly after gas injection are much higher than the ones computed here, we feel that it is only prudent to specify the tank size conservatively.

obviously, the tank cannot be built $4.0 \mathrm{~m}$ in diameter by $41.0 \mathrm{~m}$ long prior to installation in the range. We feel that it should be made in three sections of approximately $13 \mathrm{~m}$ length each and welded together on-site as shown in Figure 3.4. standard practice for such tanks is to fabricate them from steel $2.5 \mathrm{~cm}$ thick to promote their stability. Maximum expected stress in the tank side wall produced by a firing may be calculated using a modification of thick wall tube theory as presented in Equations $3.4,3.5,3.6$, and 3.7 .

$$
\begin{gathered}
\sigma_{t}=\frac{P_{i} d_{t}}{2 t_{t}} \\
\sigma_{a}=\frac{P_{i} d_{t}}{4 t_{t}} \\
\sigma_{r}=-P_{t} / 2 \\
\sigma_{v m}=\frac{1}{\sqrt{2}} \sqrt{\left(\sigma_{t}-\sigma_{a}\right)^{2}+\left(\sigma_{a}-\sigma_{r}\right)^{2}+\left(\sigma_{r}-\sigma_{t}\right)^{2}} \sim \frac{0.433 P_{i} d_{t}}{t_{t}}
\end{gathered}
$$

where:

$$
\begin{aligned}
& \mathrm{p}_{i}=\text { internal pressure; } \\
& \mathrm{d}_{\mathrm{t}}=\text { tank diameter; } \\
& t_{t}=\text { tank wall thickness; } \\
& \sigma_{t}=\text { tangential component of wall stress; } \\
& \sigma_{\mathrm{s}}=\text { axial component of wall stress; } \\
& \sigma_{r}=\text { radial component of wall stress; and } \\
& \sigma_{v m}=\text { von Mesis equivalent wall stress. }
\end{aligned}
$$

The analysis provided by the foregoing equations is, basically, a simplification of the thick tube analysis described in Chapter 2 where it is used for evaluating wall stresses in light-gas gun tubes. The von Mesis formalism provides an estimate of the 

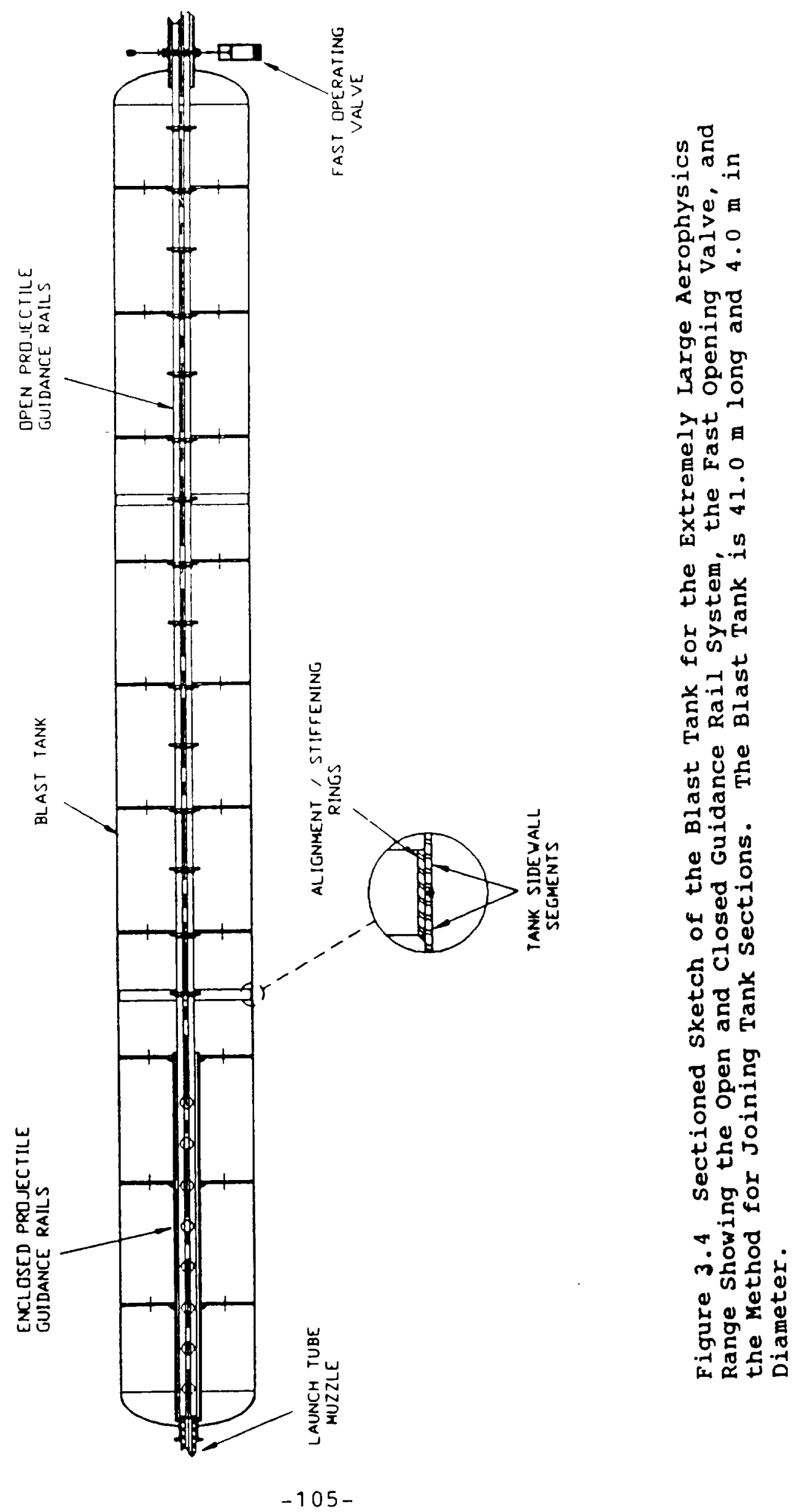
equivalent stress to which the tank wall is subjected.

Calculated using the "exact" expression in Equation 3.7 produces an equivalent stress of $\sigma_{\mathrm{m}}=20.91 \mathrm{MPa}(3,074 \mathrm{psi})$. The approximate expression from Equation 3.7 is $\sigma_{\mathrm{vm}}=20.78 \mathrm{MPa}$

$(3,055 \mathrm{psi})$. Both of these values are somewhat less than $3.6 \%$ of the nominal yield strength for the high strength boiler steel we plan for the range tankage so we feel that tank strength is more than adequate to provide safe containment of the gas gun's driver gas (the ASME boiler code requires that computed stresses within the walls of pressure tanks be less than or equal to one-quarter the nominal material yield strength).

Relatively little work need be accomplished inside the blast tank so we have chosen to provide only two man-accessible doors into the tank at the one-third and two-third points along its length. The five central baffles within the tank contain holes large enough to allow a man to climb between interior sections of the tank.

The tank is supported by four cradles which help to maintain its circular shape and spread its floor loading. The lower surfaces of these cradles are shimmed into correct position above the floor and are bolted into place with lag bolts.

\subsection{Fast opening valve (FOV).}

The projectile package is expected to travel in a straight line along the axis of the blast tank from its upstream end to its downstream end due to rail guidance. Its velocity is expected to remain almost constant since the rails produce nearly zero drag(12) and the atmospheric drag is reduced to negligible by removing virtually all of the atmosphere within the tank during range preparation. Muzzle gas on the other hand, is expected to expand radially outward from the range trajectory to encounter baffles in the tank and to generally follow a circuitous route to the far end of the tank. Thus, we expect at least the vast majority of the hydrogen driver gas to arrive at the downstream end of the tank several tens of milliseconds after the projectile has exited the tank. This delay time is used to seal the tank with a fast-closing valve sketched in Figure 3.5. Prototype design for this valve was developed at the General Motors Defense Research Laboratory. (13)

Basically, a sheet of aluminum is arranged to close the juncture between two flanged pipes, thus forming a closed valve. The sheet extends a significant distance above the flanges and has an elongated hole through it whose width corresponds to the clear aperture of the flanges. The upper part of the sheet is continuous and is more-or-less a mirror image of its lower portion. The extreme upper end of the plate is held between a pair of jaws which are pulled tightly shut with an explosive bolt which can be broken by detonating a small explosive charge within it. The lower edge of the plate is connected to a rod which extends into a large pneumatic cylinder and is connected to a 


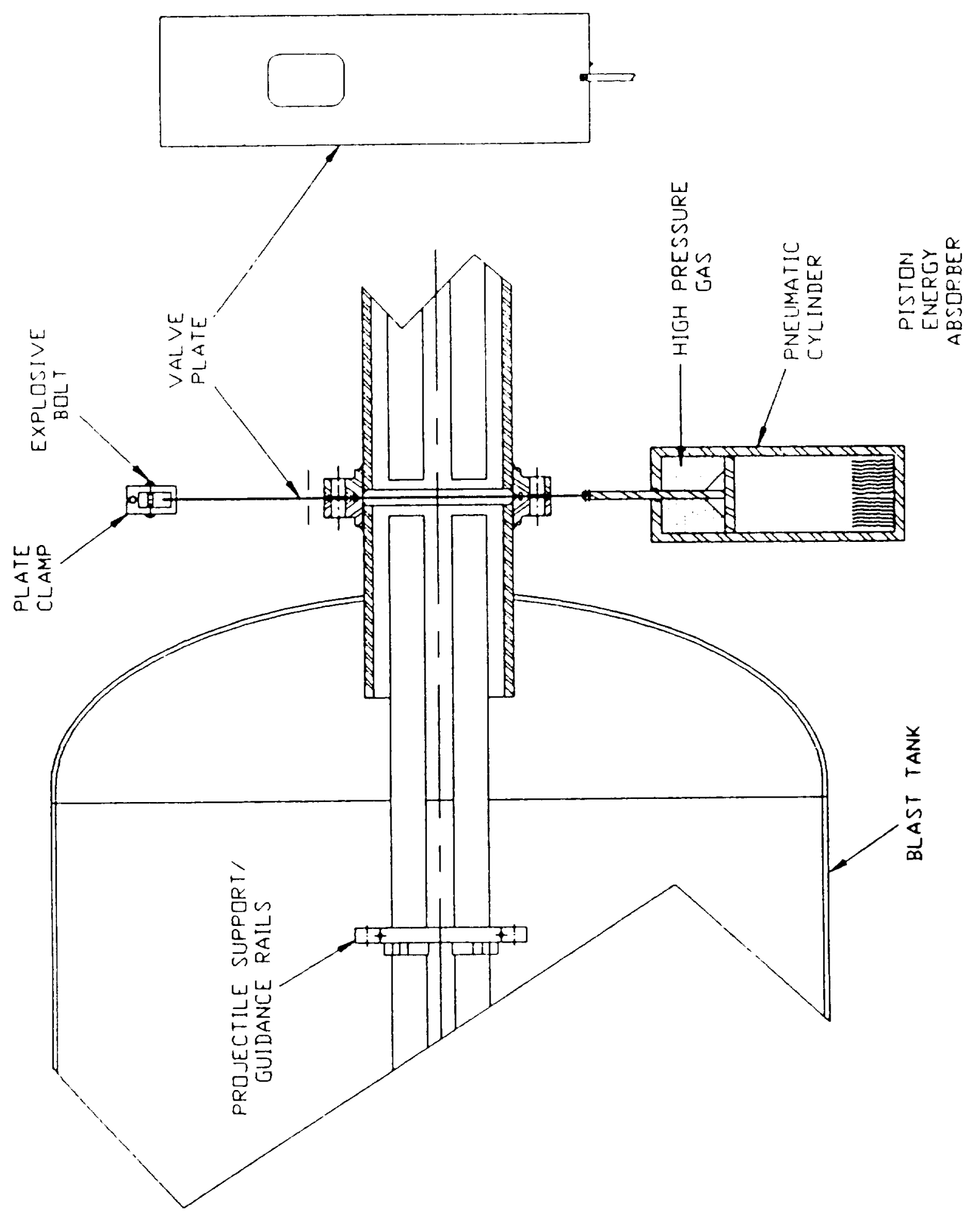

4

足

D

$\stackrel{0}{\circ}$ O

年

$>$ 这

б

न 50

a) $\propto$

م

落

o

स E

o 잉

म4

t)

मै 0 궁

ํํำ

पे

ह日

>

어

约

o $4-1$

$4 \times$ 苗

0 国

웡

声

的出造

$-155$

O

藏

$\rightarrow \pi$

艺苟导

贶

届年

요

in

O

.

ว

Бึ

的分 
piston mounted near the upper end. High pressure air is injected into the cylinder above the piston that produces a substantial downward force on the metallic sheet which is restrained from moving by the jaw at its upper end. The bottom end of the cylinder contains a crushable cardboard structure used to absorb kinetic energy from the moving piston. The valve is triggered by firing the explosive bolt which releases the upper end of the metaliic sheet. The sheet accelerates rapidly as the piston begins its downward movement. After a short travel distance, the hole in the sheet enters the area between the flanged pipes to start valve opening. The valve continues to open until the forward edge of the hole reaches the bottom of the flanged opening. Shortly thereafter, valve closure begins as the rear end of the hole reaches the top of the opening between the pipes. closure is completed when the rear end of the hole passes the bottom of the pipe opening. At this moment, the piston reaches the cardboard structure in the pneumatic cylinder and decelerates rapidly as the cardboard is crushed. Plate deceleration occurs at the same time which brings the plate to rest with its upper continuous portion across the gap between the flanged pipes. Thus, the valve has opened and closed during a single operating cycle. Researchers at GMDRL report that valves with $250 \mathrm{~mm}$ apertures have been made to operate successfully in time periods as short as $10^{-2}$ sec.(13) This size is just large enough for the task of closing the downstream end of the blast tank of the range being contemplated. We feel for this reason that we can depend upon achieving tank closure within half this time period ( $5 \times 10^{-3}$ sec.) after projectile passage. We feel, however, that $10.0 \mathrm{~m} . \mathrm{sec}$. valve closure is a prudent number to consider.

Let us consider here, the worst situation that could arise from gas escaping the blast tank during the period of time from projectile passage to valve closure $\left(\tau_{\mathrm{e}}=10.0 \mathrm{~m} . \mathrm{sec}.\right)$. The maximum reasonable velocity of gas traveling behind the projectile is the projectile velocity. Gas density, $p_{\alpha}$ is Iimited fundamentally to density of the gas if all of it was compressed into a tubular volume the diameter of the launch tube and the length of the launch tube plus the length of the blast tank. This last assumption is extremely conservative because it fails to take into account any lateral expansion of the gas into the very large evacuated volume of the blast tank. We feel safe in dividing this density by 10 to account for the substantial amount of lateral gas expansion which must occur. Under these still conservative assumptions, we find that a maximum of only $0.52 \%$ of the gas charge can leave the blast tank before the valve closes, i.e., at least $99.5 \%$ of the gas charge is retained within the blast tank after a firing.

3.1.1.1.2 Driver gas expulsion from the blast tank.

The problem of removing hydrogen gas from the blast tank has potentially serious consequences because a misstep in this area could produce an enormous fire/explosion. As derived earlier, the final settling hydrogen pressure is somewhat over $0.08 \mathrm{MPa}$ 
and a total of 381.4 standard cubic meters $(13,500$ SCF) must be removed safely. We suggest that one of the pumping units used for evacuating the range tankage be dedicated to the blast tank (and, possibly, also the sabot separation tank). The outlet from the pumping system should be enclosed in thick-walled steel pipe strong enough to withstand an internal peak pressure from a stoichiometric hydrogen-air explosion of $1.22 \mathrm{MPa}(180 \mathrm{psi})$ which is the maximum to be expected from a hydrogen ignition at original room pressure. (5) The tube should lead directly from the vacuum pump system out-of-doors, be turned upward, and continue to $5.0 \mathrm{~m}$ above the roof line of the building (where it may be protected from atmospheric entry with a weighted flap-valve). (15) The only other modification for the pump system is addition of an inlet to the vacuum intake between the pump and the range cut-off valve. This inlet is connected to a source of nitrogen gas available through a high-flow regulator adjusted to produce approximately $0.1 \mathrm{MPa}$ ( 1.0 atmosphere) output pressure.

The pump is started with the inlet valve to the range closed. The pumping system evacuates the air from the inlet line quickly and also from cavities within the pump and its piping. The valve to the nitrogen supply is then opened which starts the pump "evacuating" the nitrogen source that has been designed to deliver nitrogen as fast as the pump can accept it. The system is operated in this manner for several minutes during which time cavities within the pump and the exhaust line are purged with pure nitrogen. At this point, the nitrogen flow may be cut off and the valve to the blast tank opened so that the nitrogen gas flowing through the pump is replaced by hydrogen. Note that this procedure prevents hydrogen gas from being exposed to atmospheric oxygen at any point in the blast tank/evacuation system up to the end of the output tube some distance above the roof-line of the range building. Hydrogen gas escaping, at this point, mixes with the surrounding air as it rises through it due to its lowvolumetric density (low molecular weight). Once concentration of this hydrogen/air mix falls below 5\% hydrogen, gas ignition becomes impossible. $(5,15)$ currently, a Hydrogen Safety Handbook is being produced by NASA headquarters(15). One provision is that no more than $0.5 \mathrm{lb} / \mathrm{sec}$ of hydrogen may be released through an appropriate stack without igniting it. This flow rate is equivalent to an initial vacuum pumping rate of somewhat more than $11,700 \mathrm{ft}^{3} / \mathrm{min}$ which is well in excess of the pumping rate needed for the blast tank. Flow rates fall to very low values as ultimate vacuum levels are approached during blast tank

repumping. A weighted flap-valve at the top of the stack assures that little or no atmospheric air can reenter the stack and mix with residual hydrogen to produce an ignitible mixture. The evacuation process is continued until pressure in the blast tank falls below 10.0 torr. At this point, the valve to the blast tank is closed and nitrogen flow is resumed for several minutes to flush the evacuation system of hydrogen before it is shut down. Other valves may now be opened to admit atmospheric air into the blast tank since the amount of residual hydrogen in the 
tank is so small that it can be counted upon to mix with the air at percentages of well under $5 \% \mathrm{H}_{2}$. Ventilation equipment may then be started to prepare the tank's atmosphere for human entry.

3.1.1.2 Sabot Discard Tank.

The sabot discard tank is mounted directly downstream from the first fast opening valve (FOV) at the downstream end of the blast tank.

We have chosen somewhat arbitrarily to allot a flight path of $33.0 \mathrm{~m}$ for separating projectiles from their sabots and we've assumed that sabots are fabricated in four quadrants. The rail system from the blast tank terminates just upstream of the FOV so the model emerges into the sabot separation tank in free-flight. As was stated in paragraph 3.1, two techniques are available for separating models from their sabots: aerodynamic; and pseudoaerodynamic.

\subsection{Aerodynamic sabot separation.}

The oldest and most common method of sabot separation, aerodynamic separation, involves leaving a residual atmosphere within the sabot separation tank which produces a strong shockwave over the face of the oncoming sabot package, a sketch of which is presented in Figure 3.6. Aerodynamic sabot separation has been considered theoretically in references (16) and (17). The discussion in the remainder of this paragraph is a modernization and upgrade of the original analysis which follows more closely the physics of the separation process. Hence, it is expected to be more reliable for predicting action of sabots much larger than ever handled before. Gas pressure behind the shockwave fills the female conical void at the downstream end of the sabot package quickly and applies a force perpendicular to the conical surface. This force can be resolved into a component parallel to the sabot axis (and its flight direction) and a components directed radially outward from each sabot quadrant. The longitudinal components causes mild deceleration for the entire package. The radial components cause the sabot segments to rotate outward about their rear corners at accelerating angular velocities. The sabot segments remain in contact with each other during early rotation which allows their angular displacements to be translated into outward-directed linear velocities of their C.G.'s. As the angles between the sabot segments increase, a point is reached where separation velocity causes the segments to loose contact with one another. After this, the segments travel in nearly straight lines whose directions are determined by the vector sums of their downstream velocity and the maximum outward-directed radial velocity they achieved before separation occurred.

The analysis described above was performed for homogenous sabots which consist of four cylindrical quadrants connected together to form a cylindrical entity suitable for launching in a light-gas gun. The assembled sabots have internal cavities suitable for enclosing and supporting model payloads. 

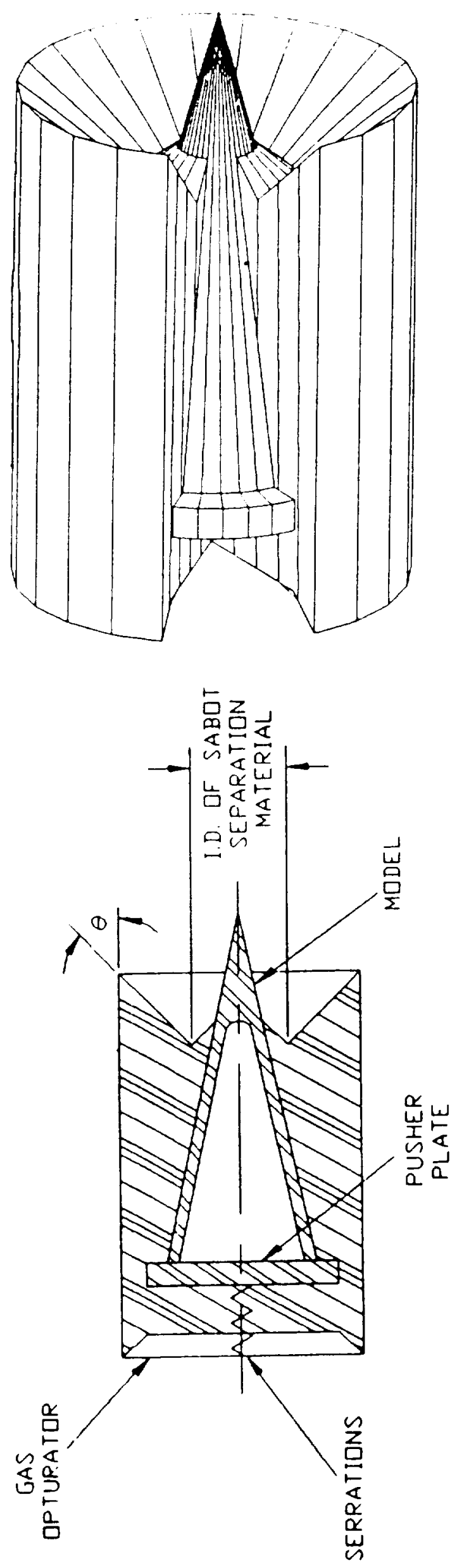

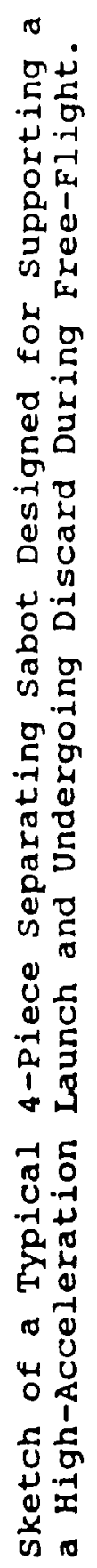

点 
The first step for analyzing aerodynamic separation of a sabot is to establish the stagnation pressure behind the bow shock which surrounds the sabot during its travel through an atmosphere. An expression for this pressure, $P_{\text {sh }}$, derived under assumptions of perfect gas is presented in Equation 3.8.

$$
P_{s h}=P_{\infty}\left[1+\frac{2 \gamma}{\gamma+1}\left(\frac{U_{s}^{2}}{a_{0}^{2}}-1\right)\right]
$$

where: $P_{\infty}=$ ambient pressure within the sabot tank;

$\gamma=$ ratio of specific heats for the tank atmosphere;

$\mathrm{U}_{\mathrm{s}}=$ projectile velocity; and

$a_{0}=$ gas sound speed.

The classic expression for gas sound speed, $a_{0}$, is presented in Equation 3.9 .

$$
a_{0}=\sqrt{\frac{\gamma R T}{m}}
$$

where:

$$
\begin{aligned}
& \mathrm{R}=8.314 \text { Joule } / \mathrm{mol}^{\circ} \mathrm{K}=\text { universal gas constant; } \\
& \mathrm{T}=\text { absolute temperature; and } \\
& \mathrm{m}=\text { average molecular weight of the atmospheric mixture. }
\end{aligned}
$$

Figure 3.7 is a $\log / \mathrm{log}$ plot of the ratio of shock pressure to atmospheric pressure in the tank vs. projectile velocity. Note that a projectile traveling $6.0 \mathrm{~km} / \mathrm{sec}$ through room-temperature air produces a shockwave with pressure behind it 250 times that of ambient atmosphere.

The analysis of sabot motion may best be started by considering the force component directed radially outward that the shock pressure exerts on each sabot segment, $F_{r}$. If a foursegment sabot is considered, this force may be expressed as Equation 3.10 .

$$
F_{I}=\frac{P_{s h} D_{s}^{2}}{4 \sqrt{2} \sin \theta}
$$

where:

$D_{s}=$ diameter of the closed sabot package; and

$\theta^{s}=$ angle between the sabot axis and the conical surface at its forward end (defined in Figure 3.10). 


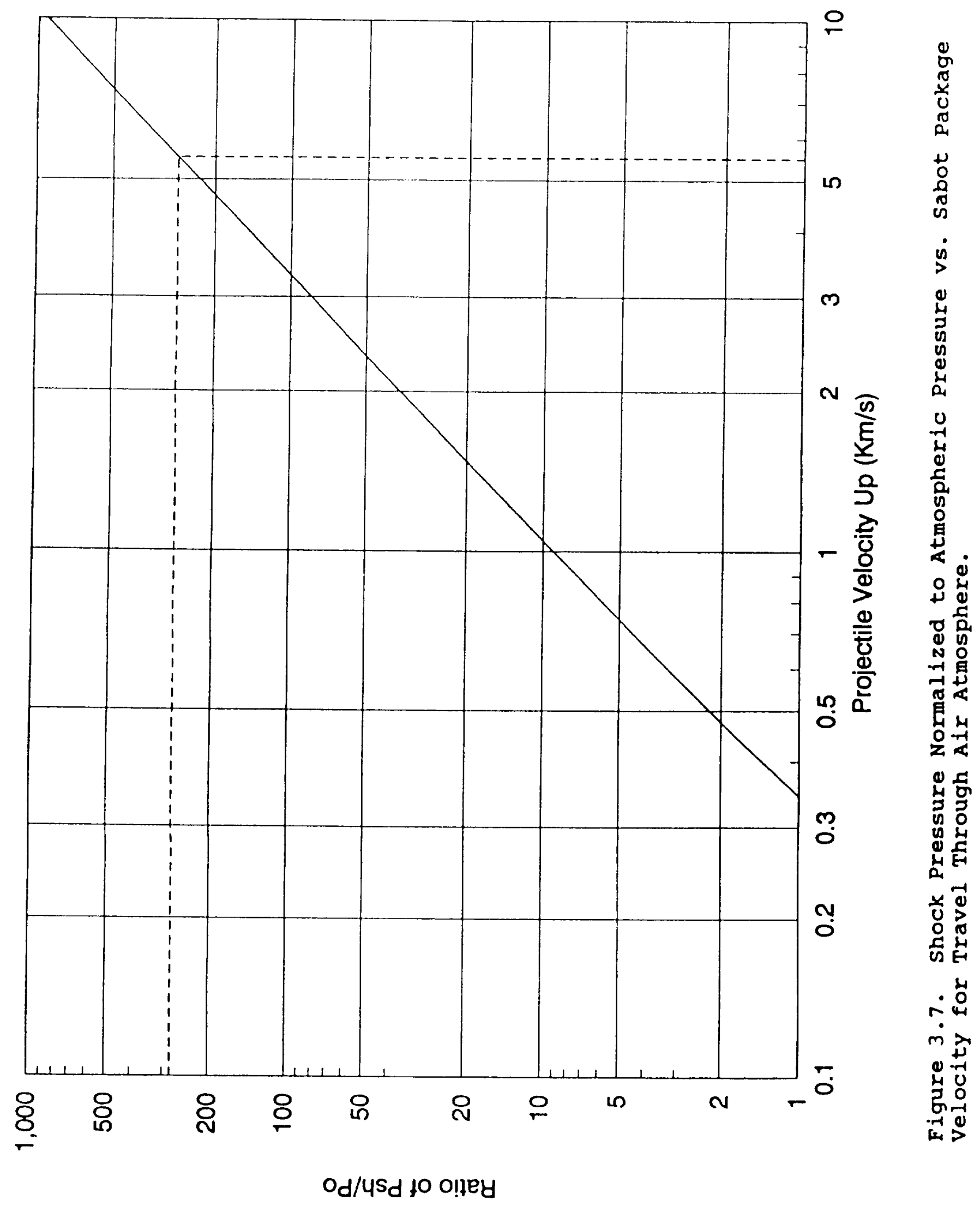


The torque, $T$, produced by this force may now be estimated by calculating the length of the vector from the hinge point at the rear of the sabot to a normal drawn perpendicular from the centroid of the conical surface and multiplying this length by the force, $F_{r}$. This torque operates against the moment-ofinertia, $I_{s}$, of the sabot segment to produce an angular acceleration of the sabot as it swings away from the model it has supported during the launch process, $\mathrm{d}^{2} \phi / \mathrm{dt}^{2}$. The resulting expression is presented in Equation 3.11 .

$$
\frac{d^{2} \phi}{d t^{2}}=\frac{T_{r}}{I_{s}}=\frac{6 \sqrt{2} P_{s h} D_{s}^{2} L_{s}}{m_{s}\left(15 / 4 D_{s}^{2}+4 L_{s}^{2}\right) \tan \theta}
$$

where:

$\phi=$ angle between the sabot flight direction and each sabot segment;

$\mathrm{T}_{r}=$ torque produced on a sabot segment by $\mathrm{F}_{r}$;

$\mathrm{L}_{\mathrm{s}}^{\mathrm{r}}=$ equivalent sabot length;

$m_{s}=$ total mass of the sabot; and

$I_{s}=$ sabot segment moment-of-inertia about its hinge axis as it swings away from a launched model.

Expression 3.11 may be integrated once with respect of time to produce an expression for angular opening velocity, $d \phi / d t$, and again with respect to time to produce an expression for $\phi$ itself. The results are presented in Equations 3.12 and 3.13 .

$$
\begin{aligned}
& \frac{d \phi}{d t}=\frac{X}{U_{p}} \frac{d^{2} \phi}{d t^{2}}=\frac{6 \sqrt{2} P_{s h} D_{s}^{2} L_{s} X}{m_{s} U_{p}\left(15 / 4 D_{s}^{2}+4 L_{s}^{2}\right) \tan \theta} \\
& \phi=\frac{X^{2}}{2 U_{p}^{2}} \frac{d \phi}{d t}=\frac{3 \sqrt{2} P_{s h} D_{s}^{2} L_{s} X^{2}}{m_{s} U_{p}^{2}\left(15 / 4 D_{s}^{2}+4 L_{s}^{2}\right) \tan \theta}
\end{aligned}
$$

where:

$\mathrm{x}$ = distance downrange from sabot release.

Equation 3.12 may be transformed readily to provide determination of sabot velocity in the radial direction as a function of its position, $x$, along the uprange portion of the sabot separation tank. The outward velocity, $U_{r}$ is just equal to the angular velocity $\mathrm{d} \phi / \mathrm{dt}$ times the radial component of the vector between the hinge point and the center-of-mass of each segment. The radial vector decreases from its original length when the sabot is closed to zero when the sabot has opened through $\phi=90^{\circ}$ according to the cosine of the angle. The radial velocity of the segments, $U_{r}$, may be evaluated using Equation 3.14 . 


$$
U_{r}=\frac{L_{s} X}{2 U_{p}} \frac{d^{2} \phi}{d t^{2}} \cos \left(\frac{X^{2}}{2 U_{p}^{2}} \frac{d^{2} \phi}{d t^{2}}\right)
$$

The situation which causes the sabot segments to separate from one another is the termination of outward acceleration of the segments' centers-of-mass.

The criterion for the sabot segments separating from one another is, simply, that their outward velocities $U$ reach a maximum. The position of the sabot package along the range when separation occurs, $x_{s}$, may now be evaluated by differentiating Equation 3.14 with respect to sabot position, $x$ and setting the derivative equal to zero. The result is presented in Equation 3.15 .

$$
X_{s}^{2}=\frac{U_{p}^{2}}{d^{2} \phi / d t^{2}} \cot \left(\frac{X_{s}^{2}}{2 U_{p}^{2}} \frac{d^{2} \phi}{d t^{2}}\right)
$$

Note that $x_{s}$ appears on both sides of Equation 3.15 and is buried deeply enough to prevent its extraction using conventional algebra. For this reason, we have chosen to extract $x_{s}$ numerically for a variety of input parameters. Once $x_{s}$ is known, Equation 3.14 may be used to calculate the outward-directed velocity components of the sabot segments when separation occurs. Equation 3.13 can then be used to determine the opening angle, $\phi$, when sabot separation occurs. This factor, together with simple geometry, allows calculation of the radial separation of the sabot segments' centers-of-gravity at separation. We then assume that the sabot segments travel in straight lines along vectors whose downstream component are $U_{p}$ and whose radial outward component is $U_{\text {rmax }}$ evaluated using Equation 3.14 at the point of segment separation, $x_{s}$. Calculation of separation at the end of such a flight, $R_{s}$ then becomes straightforward using Equation 3.16 .

$$
R_{s}=R_{0}+U_{r \max } \frac{X_{t}-X_{s}}{U_{p}}
$$

where:

$$
\begin{aligned}
& \mathrm{R}_{0}=\text { distance from the sabot sogment conter-of-gravity from } \\
& \text { the range axis when separation occurs. } \\
& \mathrm{U}_{\text {rmax }}=\text { sabot segment separation velocity; and } \\
& \mathrm{X}_{t}=\text { total length of sabot travel in the separator tank. }
\end{aligned}
$$


Figure 3.8 presents a series of plots of sabot separation distance at a downstream distance of $x_{t}=33 \mathrm{~m}$ vs. ambient pressure within the sabot separation tank for a variety of sabot masses ranging from $2.0 \mathrm{Kg}$ to $14.0 \mathrm{Kg}$. Successful sabot interception requires an absolute minimum separation distance of $0.3 \mathrm{~m}$. Ideal separation occurs with $0.5 \mathrm{~m}$ separation, and sabot segments impact the side walls of the tank at separation distances near $1.5 \mathrm{~m}$. Note that substantial air pressures ranging from 90 torr to 670 torr are required to produce ideal separation distances for various sabot masses. Heating from hypervelocity flight through such atmospheres is expected to be severe which significantly limits effectiveness of conventional aerodynamic sabot separation for the range being considered.

\subsection{Sabot separation via mild impact.}

After some consideration, we decided that aerodynamic sabot separation is unacceptable for many experiments to be conducted in the extremely large aerophysics range. For this reason, a second approach was considered which has been used occasionally with more conventional ballistic ranges. Sabot packages with their female cones on the downstream ends are launched into masses of very low density material which imparts impulse into the sabot segments along vectors normal to their conical surfaces. These outward-directed impulses give the sabot segments angular rotation velocities which causes them to rotate about their rear corners as they open away from the model. This rotation imparts an outward velocity component to the c.g. of the sabot segments which causes them to move radially away from the range axis which, in turn, produces the same separation that is normally produced by aerodynamic interactions. The "solid material" sabot separation scheme does not rely upon atmosphere within the sabot separation tank so the tank may be operated under full vacuum.

Normally, a hole is provided in the solid material large enough to allow free passage of whatever portions of the model protrude through the downstream end of the sabot. The hole diameter is made small enough so that the outer portions of the sabot intercept the low-density material. In this way, the model is spared interaction with the material used to produce sabot separation. Since the model has been exposed only to relatively high vacuums during its passage through the blast tank and the sabot separation tank, sabot separation can be accomplished without either disturbing the model or preheating its external surfaces.

The first step in designing the solid-material sabot separator system is to establish the pressure applied to the front face of the sabot as a function of sabot velocity and material density of the separating medium. The analysis is started by calculating the rate of mass increase of the sabot system, $\dot{m}_{t}$, as it sweeps out solid material using Equation 3.17 . 


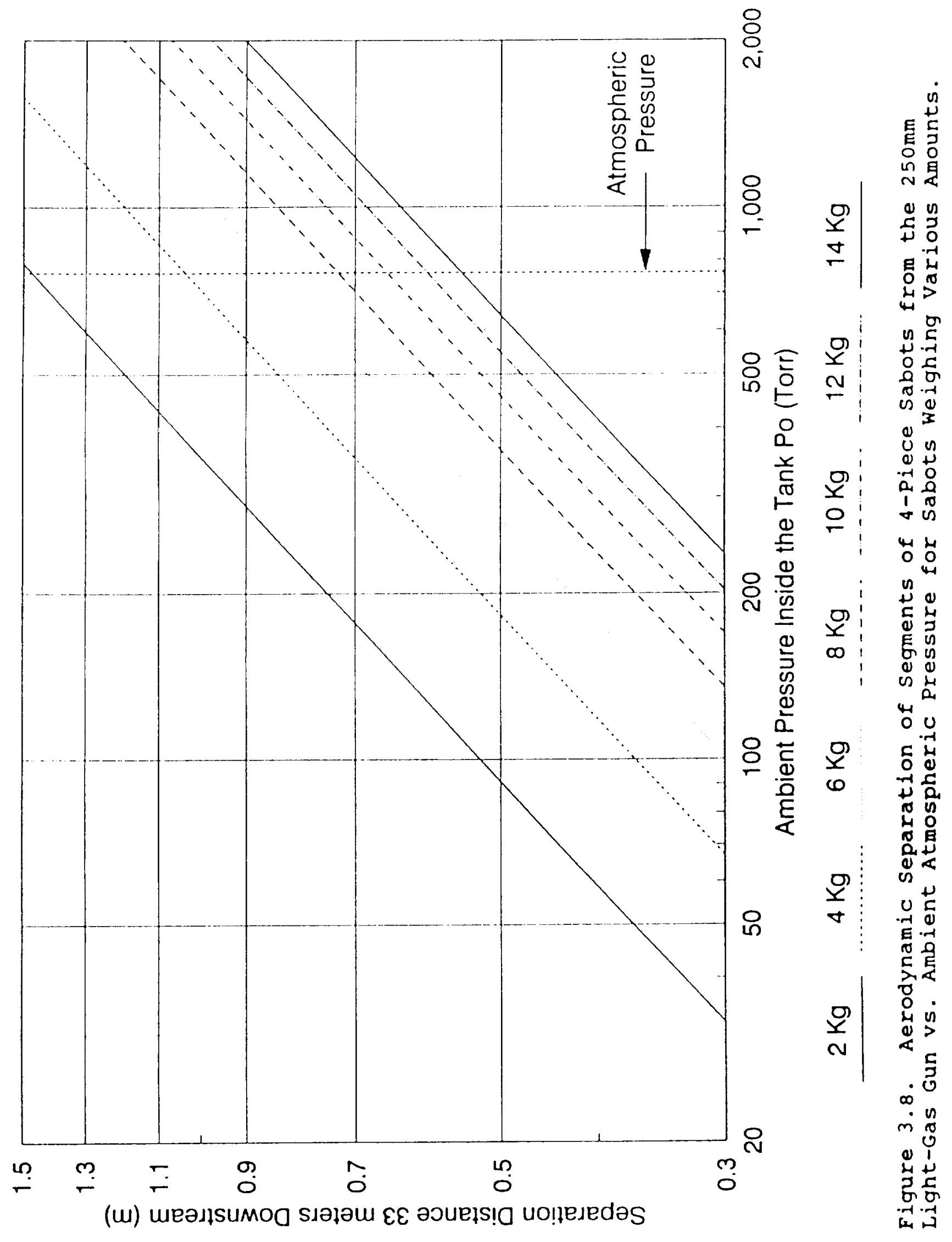




$$
\dot{m}_{t}=\frac{\pi \rho_{m} U_{p}}{4}\left(D_{\theta}^{2}-D_{h}^{2}\right)
$$

where:

$\rho_{m}=$ density of the sabot separation material;

$D_{s}^{m}=$ sabot diameter (closed): and

$D_{h}=$ Diameter of the hole in the separation mass.

If we assume this mass rides with the sabot, momentum is conserved so that sabot deceleration, $a_{s}$, as may be evaluated using Equation 3.18.

$$
a_{s}=\frac{m_{t} U_{p}}{m_{s}}=\frac{\pi \rho_{m} U_{p}^{2}}{4 m_{s}}\left(D_{s}^{2}-D_{h}^{2}\right)
$$

where: $m_{s}=$ sabot mass

The force producing this deceleration divided by the area subtended by the sabot material provides a measure of the pressure produced by the sabot "plowing through" the sabot material, $P_{s}$, as presented in Equation 3.19.

$$
P_{s}=\rho_{m} U_{p}^{2} \sin \theta
$$

where:

$\rho_{\mathrm{m}}=$ density of the undisturbed sabot separation material; and

$\boldsymbol{\theta}^{m}=$ sabot cone angle (defined in Figure 3.6 ).

It is somewhat surprising to note that this pressure depends only upon density of the sabot separation material and projectile velocity (plus a geometric factor involving the shape of the sabot face). Actually, this relationship is an application of the classic Bernoulli equation. The results from Equation 3.19 are presented in Figure 3.9 where pressure on the face of a sabot cone is plotted vs. density of the sabot separating material for various female cone angles.

The dashed line represents density of atmospheric air under standard conditions which produces a pressure of $43.3 \mathrm{MPa}(6,365$ psi) which in the order of the maximum pressure that can be applied to a sabot face made of low-density material without destroying it. This average material density is, clearly, too small to be produced effectively as a more or less continuous foam product. Instead, we suggest that the average material density be achieved with a volume filled with thin plastic sheets that are spaced at regular intervals along the trajectory through which the sabot must travel. For instance, mylar sheets $25 \mu \mathrm{m}$. (.001") thick produce an average material density of $1.0 \mathrm{Kg} / \mathrm{m}^{3}$ when they are spaced $2.5 \mathrm{~cm}$ (I") apart along the sabot trajectory. More generally, the average density of the sabot separating volume, $\rho_{m}$ is related to the film density, $\rho_{f}$, film thickness, $t_{f}$ and film spacing, $s$ by Equation 3.20 . 


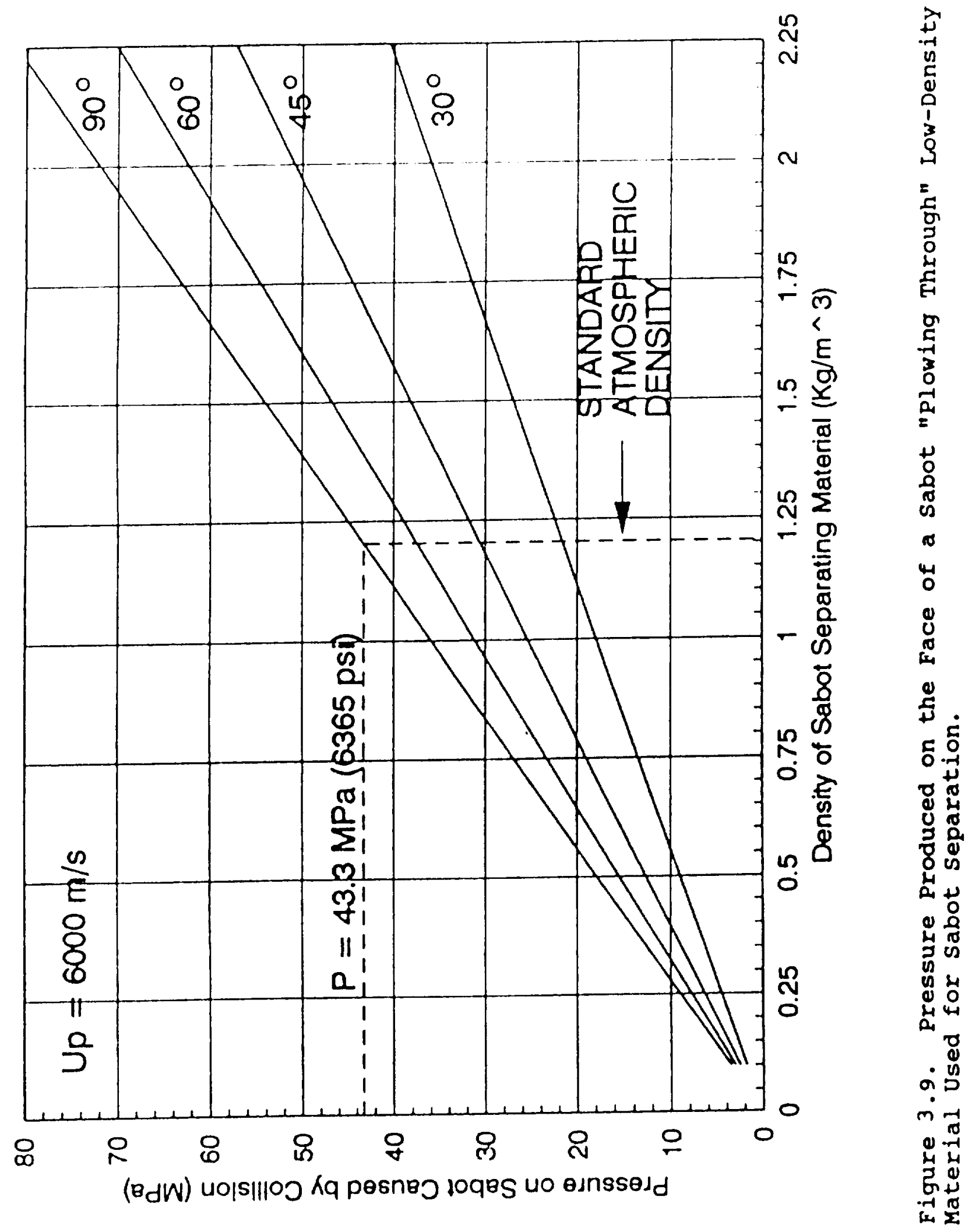




$$
\rho_{m}=\frac{\rho_{f} t_{f}}{S}
$$

In operation, very intense shockwaves are produced by the sabot impacting the individual sheets. These waves disperse rapidly as they propagate through the compressible plastic sabot material and quickly degenerate into a more-or-less continuous pressure wave defined by Equation 3.19.

Figure 3.10 is a presentation of one method for producing such a sheet array. Basically, a row of rods spaced twice their own diameter apart is mounted a distance considerably more than one sabot radius above and below the range axis. A thin sheet of plastic material (such as mylar) whose width exceeds the sabot diameter by a substantial amount, is threaded around the rods. Its free ends are taped into place after the sheet has been pulled tight. A special fixture is used to pass a tube with a heated wire mounted at its forward end through the array to burn a hole in it somewhat larger than the diameter of the model exposed at the front of the sabot. The hole need not be circular if the exposed portion of the model is not circular. The requirement is, simply, that sabot separator material must not intercept the model during passage of the sabot through the separator assembly.

A component of the average force applied to the sabot face is directed radially outward away from the sabot axis. This component produces a torque which tends to rotate the sabot elements radially outward away from the model as they pivot about their rear corners. Essentially no angular movement occurs during the very short time period the sabot is subjected to the opening torque. Thus, conventional impulse approximations may be applied to describe subsequent motion of the sabot segments with respect to the model after the sabot interacts with the separator assembly. Basically, the angular velocity achieved by the sabot elements is the torque applied to them times the interaction time divided by the moment-of-inertia of the sabot segments. This angular velocity infers an outward-directed velocity component for the sabot segments' centers-of-mass. Thus, the sabot segments both rotate about their centers-of-mass and move outward away from the range trajectory as they proceed downrange at, essentially, their original velocity. Separation distance as a function of downrange position may now be calculated using Equation 3.21 .

$$
R_{s}=\frac{3 \pi \rho_{m} X_{m} X_{\tau} L_{s}^{2}\left(D_{s}^{2}-D_{H}^{2}\right)}{8 m_{s} \tan \theta\left[3.75 D_{s}^{2}+4 L_{s}^{2}\right]}
$$



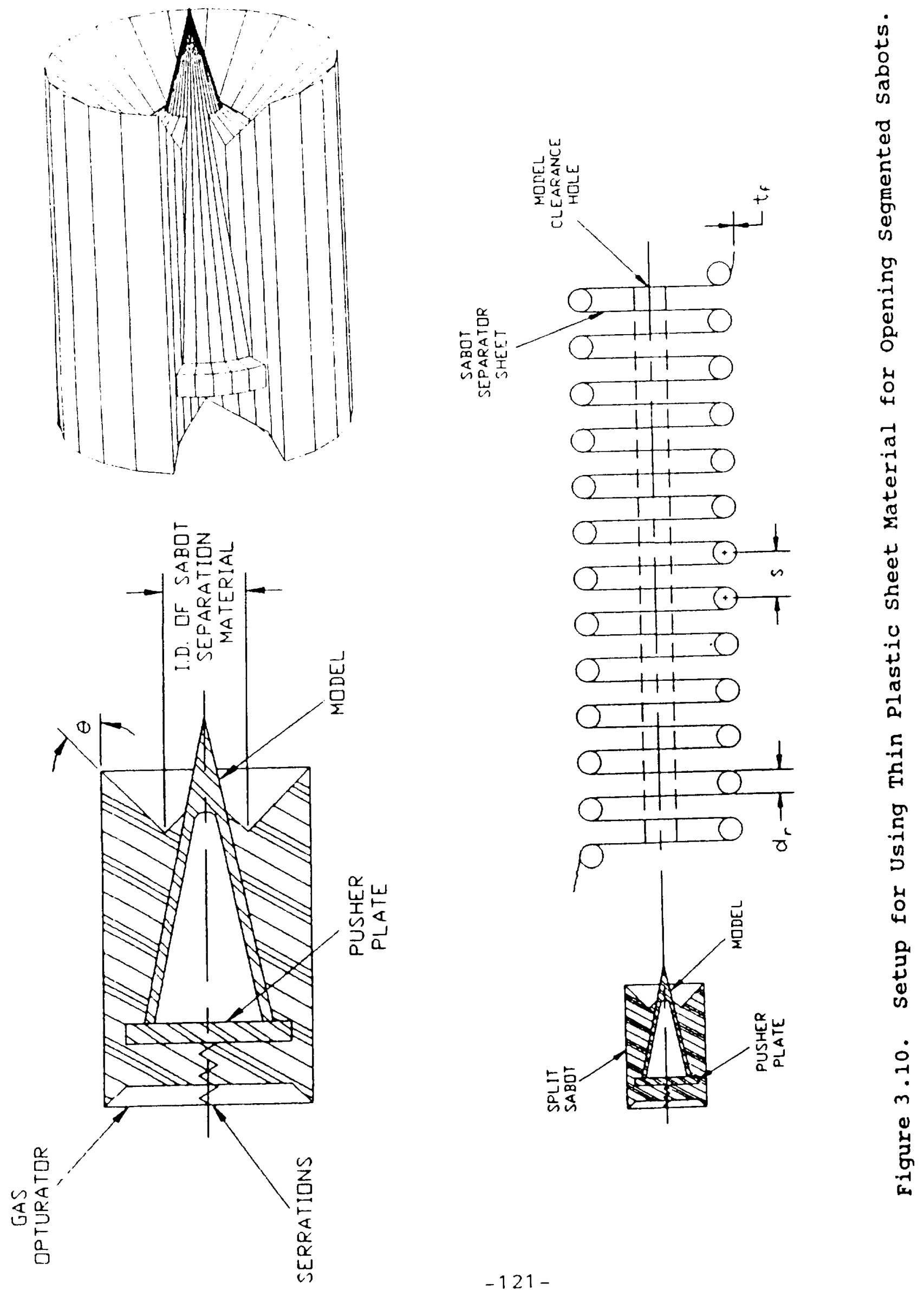
where:

$\mathrm{x}_{\mathrm{m}}=$ length of the sabot separator material (along the range axis) :

$\mathrm{X}_{\mathrm{t}}=$ flight path length available to the separating sabot; and

$\mathrm{L}_{\mathrm{s}}=$ equivalent length of the sabot segments.

The consequences of Equation 3.21 are presented in Figure $3.11,3.12,3.13,3.14$ and 3.15 . In Figure 3.11 , the diameter of the hole needed to protect the model from interacting with the sabot separator sheet is considered. We postulate a gross material density for the sabot separator volume of $2.0 \mathrm{Kg} / \mathrm{m}^{3}$; a sabot separator length of $3.0 \mathrm{~m}$; a sabot free flight length of $30 \mathrm{~m}$; a sabot diameter of $25 \mathrm{~cm}$; a sabot length of $38 \mathrm{~cm}$; and a female cone angle on the forward end of the sabot of $40^{\circ}$ (as defined in Figure 3.6). Notice that separation distance is strongly dependent upon hole diameter . . decreasing at progressively more rapid rates as hole diameter increases. obviously, all of these curves are expected to approach zero separation with a hole radius of $0.125 \mathrm{~m}$. It is also obvious that lighter sabots open much more rapidiy than do more massive ones. The heaviest sabot considered weighs $14.0 \mathrm{Kg}$ which is the nominal launch mass for the range.

The effect of sabot separation material length (depth) is investigated in Figure 3.11 where separation of the sabot segments from the range axis is plotted vs. sabot separator length for a variety of total sabot masses. When the material density of the sabot separator is $2.0 \mathrm{Kg} / \mathrm{m}^{3}$; the separation length is $30 \mathrm{~m}$; and the hole diameter is $15 \mathrm{~cm}$ (6"), a standard sabot geometry of $25 \mathrm{~cm}$ diameter by $38 \mathrm{~cm}$ long has been chosen.

The effects of adjusting the female cone angle, $\theta$ defined in Figure 3.6 are investigated in Figure 3.13 where separation distance is plotted vs. sabot angle for a standard situation where the gross material density is $2.0 \mathrm{Kg} / \mathrm{m}^{3}$; the material length is $3.0 \mathrm{~m}$; separation distance is $30 \mathrm{~m}$; the hole diameter is $15 \mathrm{~cm}$ and the sabot is of standard shape. As expected, separation distance grows fairly rapidly, but not linearly with sabot angle for the various sabot masses.

Density of the sabot stopping material is investigated in Figure 3.14 where separation distance is plotted against sabot separator material density for the standard situation. Note the density of air is shown as a vertical line at $\rho_{a}=1.204 \mathrm{Kg} / \mathrm{m}^{3}$.

Finally, the effects of free-flight distance within the sabot tank downrange from the separator are investigated in Figure 3.15 where segment separation distance from the range axis is plotted vs. distance from the sabot separator to the tank end wall for sabots of standard configuration with masses between $2.0 \mathrm{Kg}$ to $14 \mathrm{Kg}$. Note that the heaviest sabot segments progress just $0.5 \mathrm{~m}$ off the range axis at a distance of $30 \mathrm{~m}$ downrange. It was this plot that lead us to choose a length of $30 \mathrm{~m}$ for the
sabot separation tank. 


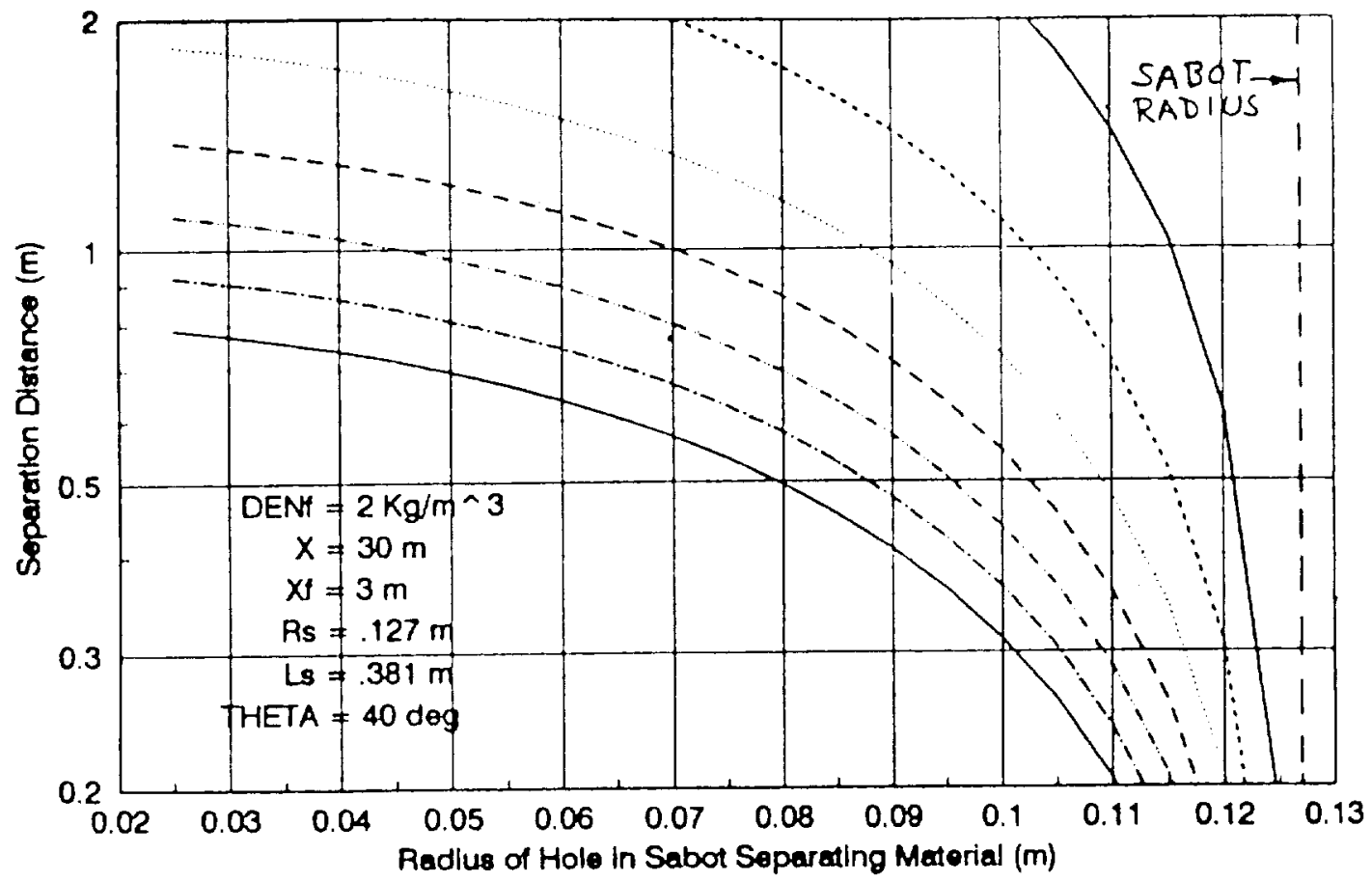

$2 \mathrm{Kg} \quad 4 \mathrm{Kg} \quad 6 \mathrm{Kg} \quad 8 \mathrm{Kg} \quad 10 \mathrm{Kg} \quad 12 \mathrm{Kg} \quad 14 \mathrm{Kg}$

Figure 3.11. Effect of Hole Size in Sabot Separator Material Upon Segment separation Distance.

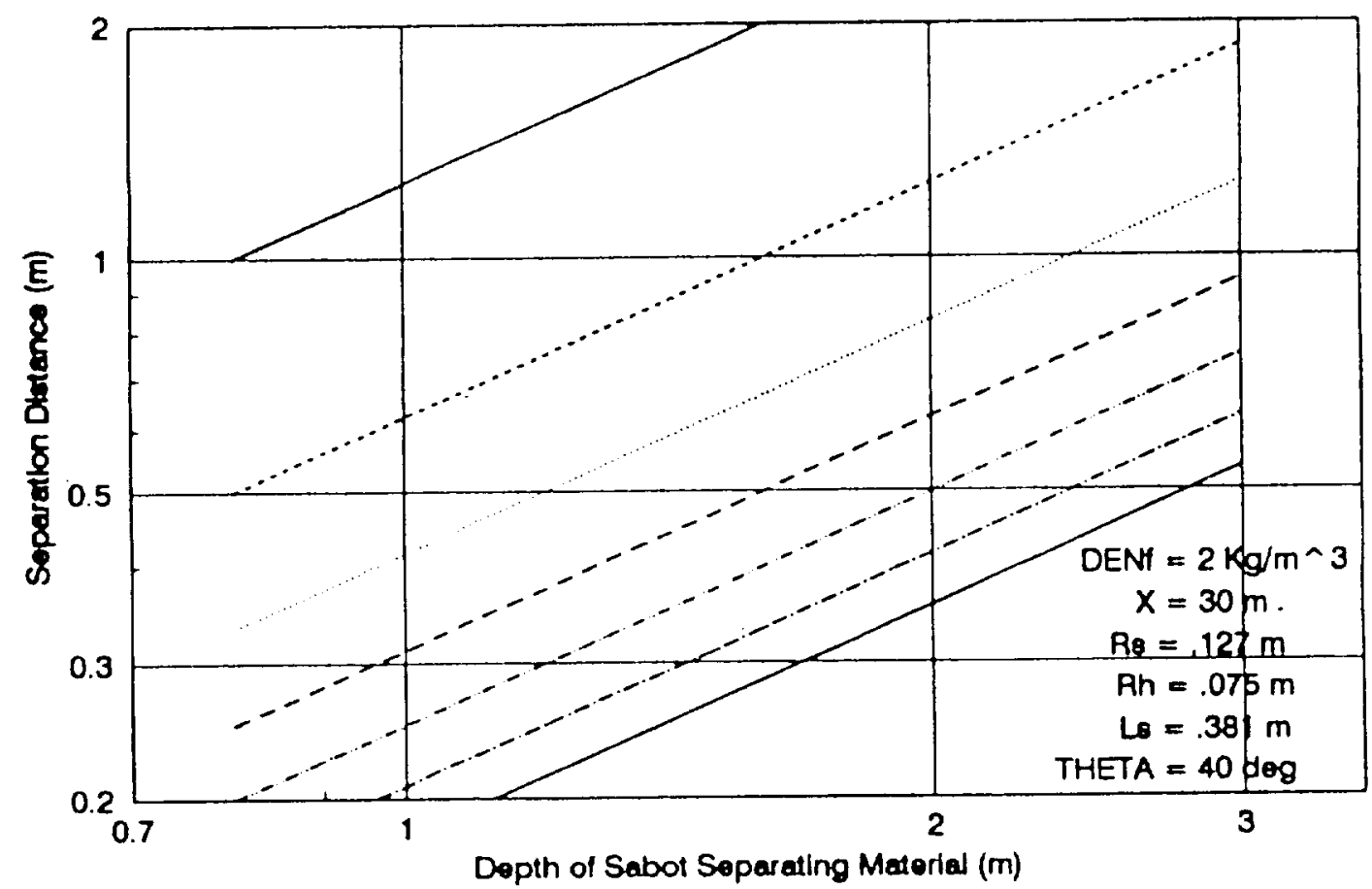

$2 \mathrm{Kg} \quad 4 \mathrm{Kg} \quad 6 \mathrm{Kg} \quad 8 \mathrm{Kg} \quad 10 \mathrm{Kg} \quad 12 \mathrm{Kg} \quad 14 \mathrm{Kg}$

Figure 3.12. Effect of Sabot Separation Material Length (Depth) Upon Segment Separation Distance. 


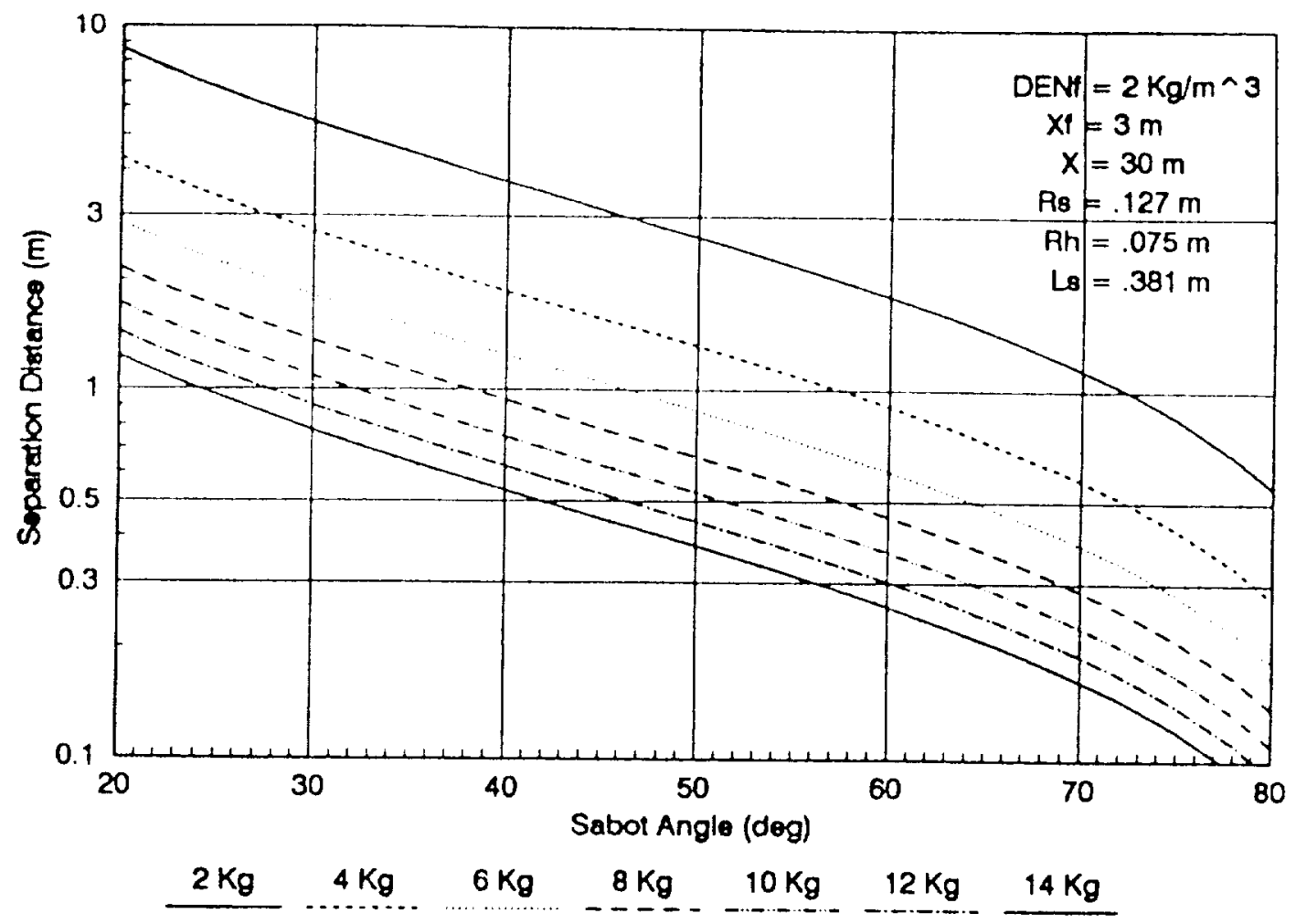

Figure 3.13. Effect of Sabot Cone Angle Upon Segment separation Distance.

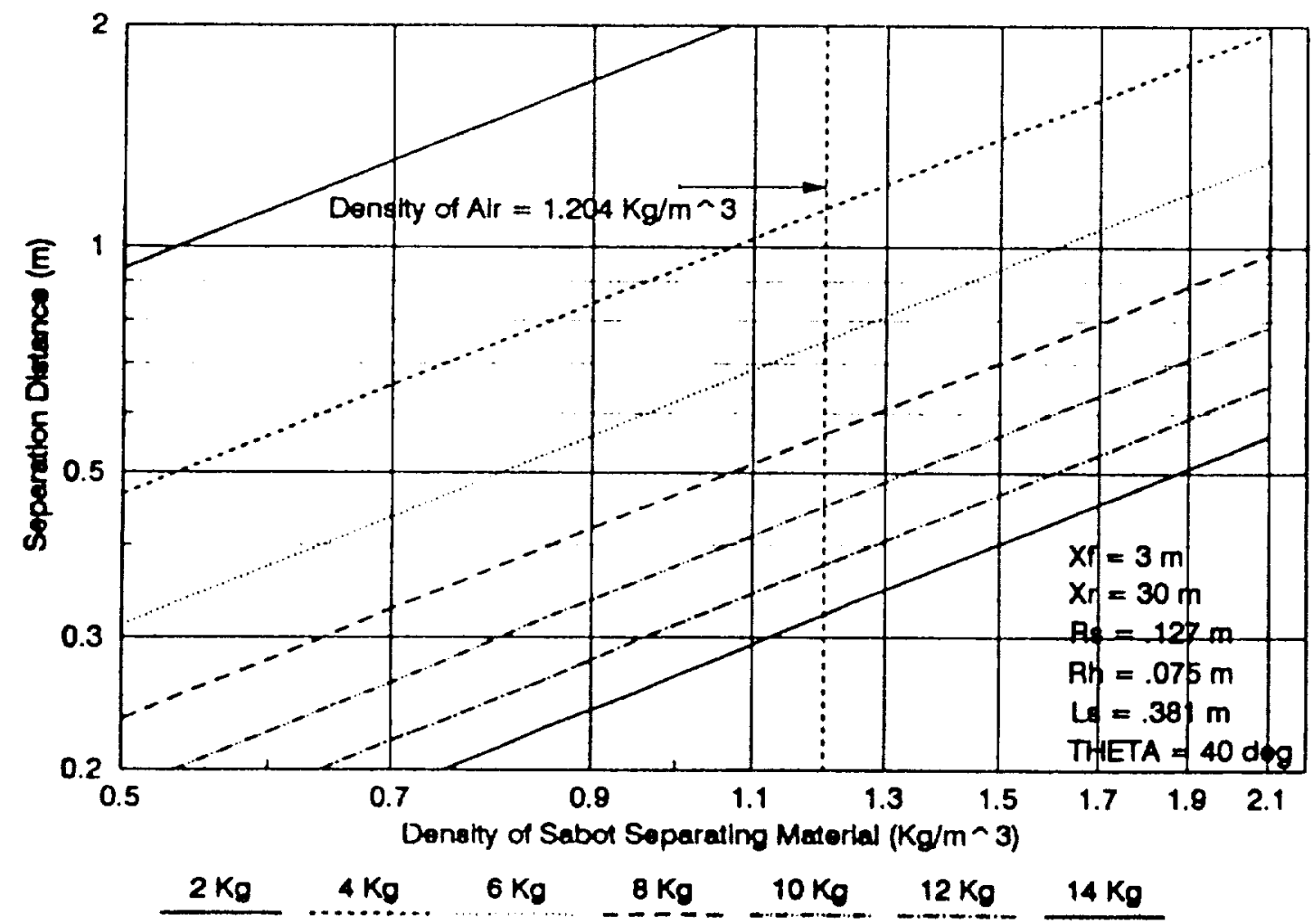

Figure 3.14. Effect of Sabot Separator Material Density Upon Segment Separation Distance. 


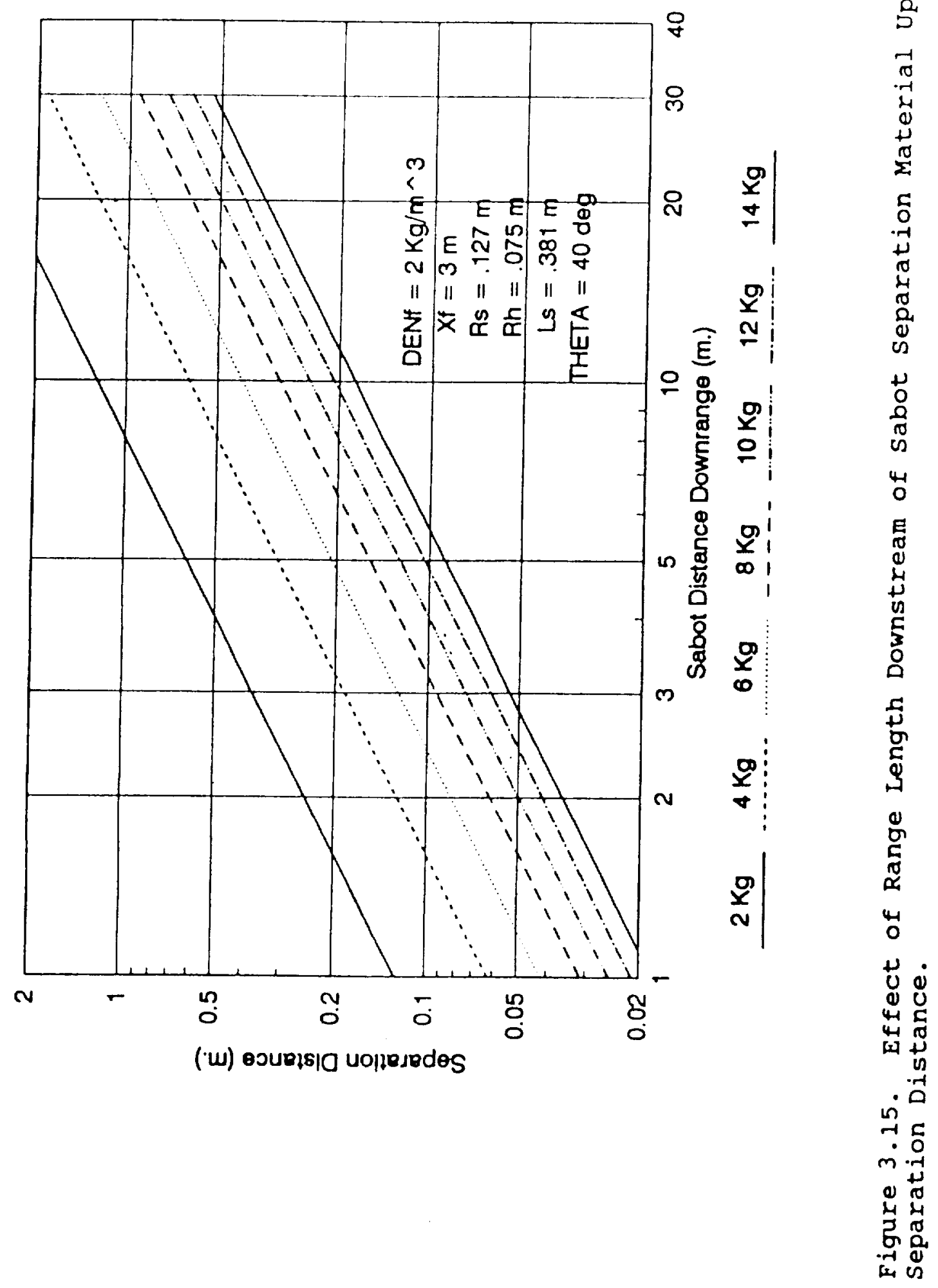




\subsection{Sabot segment disruption.}

Either aerodynamic or material impact separation of sabot segments from the launched model leave them flying downrange on trajectories that diverge slowly from that of the model. Ideally, they have separated approximately $0.5 \mathrm{~m}$ from the model once they have reached the far end of the free-flight path ( 30 to $33 \mathrm{~m}$ downrange from the sabot tank entrance). The sabot segments contain significant kinetic energy and directed impulse which must be dissipated in a controlled manner if the model is to be unaffected by the sabot capture/destruction process and the range structure is to escape damage. One classic technique for eliminating sabot segments is to have them impact solid material. While this represents a possible solution to the problem, it is probably infeasible because of the amount of material required (more than $10 \mathrm{~m}^{3} / \mathrm{shot}$ ). Material cost is a substantial factor as is the operational difficulty of installing/removing it from the range tankage.

A second approach which may be somewhat more feasible is to allow the sabot segments to impact a large mass of divided material such as steel lathe turnings which tear apart the oncoming segments through thousands of hypervelocity impacts. The immense amount of material required and its large surface area (a cylindrical volume $3 \mathrm{~m}$ in diameter by $2-3 \mathrm{~m}$ thick) requires that the material be held in place with a membrane of some sort. Such a large-diameter membrane can be installed readily, but it must be perforated four times per firing so that it must be replaced regularly even if it can be repaired between firings. Another problem with the divided material approach is expending kinetic energy of the sabot segments. Should a substantial fraction of their kinetic energy appear as explosive expansion of gas, tankage required to contain it safely must be extremely large (several times the $3 \mathrm{~m}$ diameter tentatively chosen for the sabot separation tank).

Another sabot disruption approach which has been used occasionally involves destroying oncoming sabot elements with dual-layer meteoroid armor. Here, the sabot segments strike a membrane with enough mass-per-unit-area to assure their complete disruption (typically .375 times that of the sabot segments). (18) The sabot material, together with material under the sabot segment's projection on the membrane, is launched behind the membrane in an expanding bubble which strikes the second layer of the shield spaced some distance behind the first one over an extended area. The bubble material stagnates on this surface and gives up the great majority of its kinetic energy as radiation in the infrared, visible, ultraviolet, and possibly in the soft $x-$ ray regions of the electromagnetic spectrum. This approach bears careful consideration since it provides the only "safe" means for expending kinetic energy of the sabot segments. It also benefits significantly from its ability to spread impulse of the sabot segments over a broad area in a controlled manner. once spread out, this impulse can be absorbed safely. 
The last problem to be considered is the membrane used to "break" the incoming sabot segments. Again, a solid membrane offers substantial operational difficulties. A more appealing approach is to employ a sheet of more-or-less homogeneous water to form the sabot breaking structure since it can be deployed readily and it can be removed after a firing in a straightforward manner.

A conceptual sketch of the rear end of the sabot tank is presented in Figure 3.16. Note that the water is stored in a thin tank (150mm, 6" thick) mounted in the upper part of the sabot tank side-wall near its downstream end. A trap door in the bottom of the water tank is activated to start the gun firing process. The water falls from the tank more-or-less in a sheet across the trajectory. The sheet's height and width, as defined by the tank, are sufficient to completely cover the $3 \mathrm{~m}$ diameter cross-section of the main sabot tank except for a small area directly under the model protection tube. This area is covered by thin plastic tubes filled with water that are hung or stood in place.

The debris plumes emanating from the sabot/water impacts impinge upon a braced massive metal disk mounted four meters downstream from the water sheet assembly. This impingement plate is fabricated in multiple sections and is spaced ahead of a second structure with rubber stand-off material. The second structure serves to transmit the time-elongated impulse to the sabot tank itself from which it is retransmitted to the facility foundation.

A very strong tube centered on the range axis pierces the entire sabot stopping structure. Its bore diameter is large enough to accommodate passage of the oncoming model without contacting it (perhaps $\left.400 \mathrm{~mm}, 16^{\prime \prime}\right)$. The walls of the tube are made strong enough to survive impingement of the debris plumes from the sabot's impact with the water curtain without disturbing the interior volume of the tube. The tube projects far enough upstream from the water curtain so that material "kick back" from the sabot/curtain impacts cannot enter its upstream end until the material has propagated all the way to the upstream end of the sabot tank and returned (a time delay of at least 15 to 20 m.sec). A fast-closing valve similar to the one between the blast tank and the sabot tank, but larger, is mounted just beyond the tube at the downstream end of the sabot tank structure. This valve is set to close shortly after model passage, thus effectively isolating the experimental portions of the range tankage from the sabot separation and interception processes.

Let us now consider requirements for the sabot interception hardware. The first question of interest is whether sabot impacts with a curtain of homogeneous water can be counted upon to destroy the sabot material. This question has been considered at length by a variety of investigators(18, 19, 20,21,22). Basically, the material is subjected to shock loading to pressure far higher 


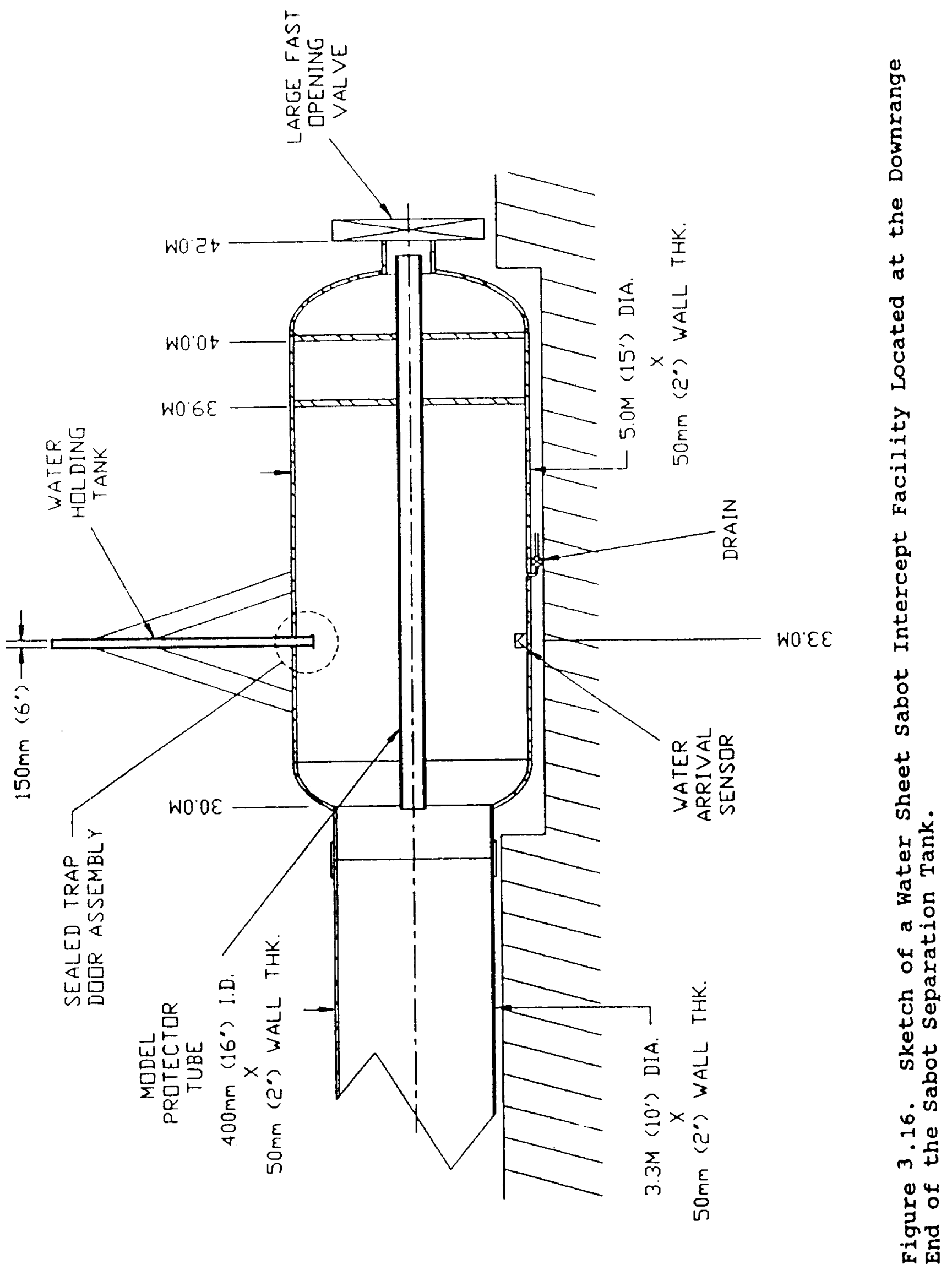


than the material can withstand structurally. Hugoniot analysis is used for evaluating these pressure levels. (20) It indicates that peak shock pressures from water/solid material impacts at 6 $\mathrm{km} / \mathrm{sec}$ vary from $23.0 \mathrm{GPa}(230 \mathrm{~Kb})$ for plastics to $60.0 \mathrm{GPA}$ (600 $\mathrm{Kb})$ for steel. The shockwaves produced by such impacts are intense enough to increase the entropy of the material through which they pass. (19) Release waves which return the material to zero pressure are isentropic which effectively traps the shockinduced entropy within the shocked material. The residual entropy in the material appears as thermal energy when pressure (stress) returns to near zero. Moderate levels of thermal energy produce temperature rises large enough to soften the materials which aids the break-up process. Larger amounts typical of shockwaves produced by hypervelocity impact leave enough residual heat in the oncoming material to melt it so it divides into droplets of negligible individual impact importance. Analysis of the situation at hand indicates that plastic sabot material should melt or vaporize during impact with water at velocities down to at least $4.0 \mathrm{~km} / \mathrm{sec}$. Portions of sabot segments fabricated from stronger materials such as titanium or steel model support plates will be disrupted massively by water impact at velocities over $4.0 \mathrm{~km} / \mathrm{sec}$ and the disruption becomes progressively more complete as velocities are increased. An analysis for predicting the number and size distribution of debris from impact shattering is presented in Reference 21 . Typically, such plates break into thousands of pieces with the largest, perhaps, $1.0 \%$ of the original mass. Individual fragments remain solid and produce craters when they strike the secondary plate. For this reason, we feel the secondary plates should be made in multiple sections so that seriously damaged segments can be removed from time-to-time if-and-when deep pitting becomes a problem.

Critical plate thickness to provide adequate protection against single-impact perforation can be estimated in a more-orless straightforward manner by assuming that individual impacts are in the hypervelocity range with conventional cratering efficiencies, and that plate perforation occurs when the plate thickness falls below 150\% of crater depth.(19) An expression for evaluating critical steel plate thickness, $P_{c}$, is presented as Equation 3.22.(19)

$$
P_{c}=0.931\left[\frac{G G_{e f} M_{p 1} U_{p}^{2}}{n_{f}}\right]^{1 / 3}
$$

where:

$$
\begin{aligned}
& G \approx 10^{-10} \mathrm{cc} / \mathrm{erg}=\text { cratering efficiency; } \\
& G_{e f} \approx 5=\begin{array}{c}
\text { ratio of max. fragment mass to average fragment } \\
\text { mass; }
\end{array} \\
& \mathrm{n}_{\mathrm{f}} \approx 5,000=\text { number of fragments produced when a plate } \\
& \mathrm{M}_{\mathrm{pl}} \approx 2,500 \mathrm{gm}=\text { mass of model support plate within a sabot. }
\end{aligned}
$$


For the severe/average situation suggested, minimum plate thickness to avoid perforation is $P_{c}=4.48 \mathrm{~cm}$. This minimum thickness is far short of the $7.50 \mathrm{~cm}$ thickness chosen for the plates.

The next problem to consider is production and characteristics of the debris plume produced behind the water curtain by sabot impact. Reference 22 contains a description of a theory which has proven effective for analyzing spaced thin plate hypervelocity armor impacted by relatively soft hypervelocity projectiles. It starts by asserting that momentum is conserved during the impact process between the incoming projectile on the one hand and the projectile and curtain material projected behind the curtain on the other hand. The velocity of the center-of-gravity (c.g.) of the debris projected behind the curtain, $U_{c m}$, may be evaluated directly using Equation 3.23 .

$$
U_{c m}=\frac{U_{D}}{1+K G^{2}}
$$

where:

$$
\begin{aligned}
\mathrm{U}_{\mathrm{p}}= & \text { sabot segment impingement velocity; } \\
\mathrm{K}^{=} & \text {ratio of the curtain mass-per-unit-area to that of the } \\
& \text { sabot; and } \\
\mathrm{G}= & \text { ratio of instantaneous hole diameter in the curtain that } \\
& \text { contributes energetic material to sabot segment } \\
& \text { diameter. }
\end{aligned}
$$

Insertion of the original momentum into the larger mass of the projectile-plus-curtain material leads to an energy shortfall, $E_{r}$, evaluated in Equation 3.24 .

$$
E_{x}=E_{p}\left(\frac{K G^{2}}{1+K G^{2}}\right)
$$

where:

$E_{p}=$ kinetic energy of the sabot segment

This energy shortfall provides the energy for producing all of the phenomena associated with hypervelocity impacts of thin plates. The great majority of this energy is expended in an explosion which propels projectile and target material away from the c.g. of the debris cloud. Experience with many hypervelocity impacts against thin targets shows that the debris plumes they produce are thin-walled, i.e. all material projected in a given direction leaves at one time with a nearly unique velocity. This factor allows the size of the debris cloud to be calculated once its general shape has been assumed. The simplest shape to consider and the one which serves the current purpose admirably 
is to assume that the "explosion" is spherically symmetric. The material velocity directed outward from the c.g., U, may then be calculated by equating the energy available to the kinetic energy associated with outward movement as is accomplished in

Equation 3.25.

$$
U_{e}=\frac{U_{p} G \sqrt{Q K}}{1+K G^{2}}
$$

where:

$$
\begin{aligned}
Q= & \text { ratio of energy used to produce outward-directed motion } \\
& \text { to energy available from momentum conservation. }
\end{aligned}
$$

It proves to be conservative to assume that all the available energy appears as kinetic energy of expansion, i.e. $Q=1$. The half-angle of the debris cloud as viewed from the original impact site, $\phi_{\psi_{2}}$ may now be evaluated very simply as appears in

Equation 3.26 .

$$
\phi_{1 / 2}=\sin ^{-1} G \sqrt{Q K}
$$

Finally, the maximum and minimum velocities of the foremost and rearmost portions of the debris cloud may also be evaluated as appears in Equations 3.27 and 3.28 .

$$
\begin{aligned}
& U_{\max }=U_{p}\left(\frac{1+G \sqrt{Q K}}{1+K G^{2}}\right) \\
& U_{\min }=U_{p}\left(\frac{1-G \sqrt{Q K}}{1+K G^{2}}\right)
\end{aligned}
$$

Now, the impulse intensity (momentum-per-unit-area) delivered to the rear plate of the structure, $P_{c}$ may be evaluated by: determining the mass-per-unit-area of the debris cloud when it strikes the second plate; and multiplying it by the maximum impingement velocity, $U_{\max }$ as presented in Equation 3.29 .

$$
P_{c}=\frac{M_{p} U_{p}(1+G \sqrt{Q K})^{3}}{4 \pi X^{2} G^{2} Q K}
$$

where:

$M_{p}=$ mass of the sabot segment; and

$\mathrm{x}^{\mathrm{P}}=$ separation between the curtain and the substructure. 
The physical analysis becomes quite complex when considering the assertion that energy from the debris cloud which impinges upon the plate behind the impact curtain appears almost entirely as electromagnetic radiation. Details of the analysis are presented in reference (22).

Now, let us consider application of the aforementioned theory to impact of a maximum-mass sabot segment into the water curtain at the maximum design velocity of $U_{p}=6.0 \mathrm{~km} / \mathrm{sec}$. The maximum mass of a sabot segment is $M_{p}=3.5^{p} \mathrm{~kg}(1 / 4$ of a $14 \mathrm{Kg}$ payload dominated by the sabot mass). The ratio of the sabot segment's mass-per-unit-area to that of the $150 \mathrm{~mm}$ thick water curtain is $K=.526$. The ratio of the area of the minimum sabot projection on the curtain to the area of the curtain producing energetic material is near $G=2.0$. We assume that functionally all of the energy available through momentum exchange is used up providing outward-directed kinetic energy for the impact

explosion, $i . e . Q=1.0$. Results of applying this situation to the analysis discussed above show that the velocity of the debris cloud's center-of-gravity as it progresses rearward behind the curtain is $\mathrm{U}_{\mathrm{e}}=4.24 \mathrm{~km} / \mathrm{sec}$. The maximum velocity of the debris cloud as it impinges upon the substructure is $U_{\max }=7.165 \mathrm{~km} / \mathrm{sec}$ and the minimum velocity of the rear wall of the cloud is $U_{\min }=$ imaginary, which indicates that the rear surface of the debris cloud never leaves the immediate area of the curtain. Likewise, the angle subtended by the cloud is not defined. The peak momentum-per-unit-area on a substructure located

$4.0 \mathrm{~m}$ behind the curtain is $\mathrm{P}_{\mathrm{f}}=731.0 \mathrm{~N} . \mathrm{sec} / \mathrm{m}^{2}(7,130 \mathrm{taps})$. This impulse intensity is negligible. It is just sufficient to impart a maximum local instantaneous rearward velocity to the $7.5 \mathrm{~cm}$ thick front plate of the substructure of $1.25 \mathrm{~m} / \mathrm{sec}$.

since the water curtain technique is capable of absorbing both the energy and impulse associated with dismembering the heaviest sabot segments traveling at their highest velocities and the only regularly expended commodity associated with its operation is water, we feel that the water curtain dual-target sabot interception system represents the best approach for stopping oncoming sabots.

Figure 3.17 is an approximately scale drawing of the sabot separator tank as described in this paragraph. It, together with the blast tank, form the portion of the range tankage used to service the launcher. The remainder of the tankage is used to enclose models during their portions of flight where aerodynamic/thermodynamic measurements are made. 


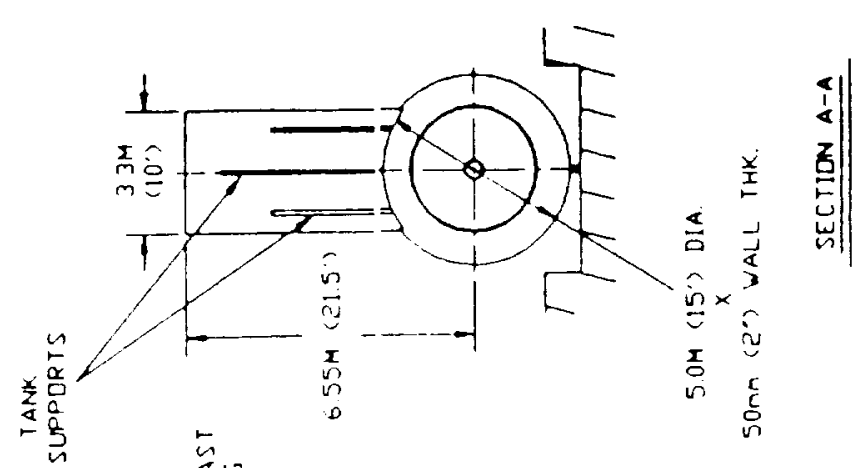

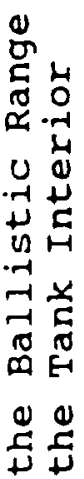

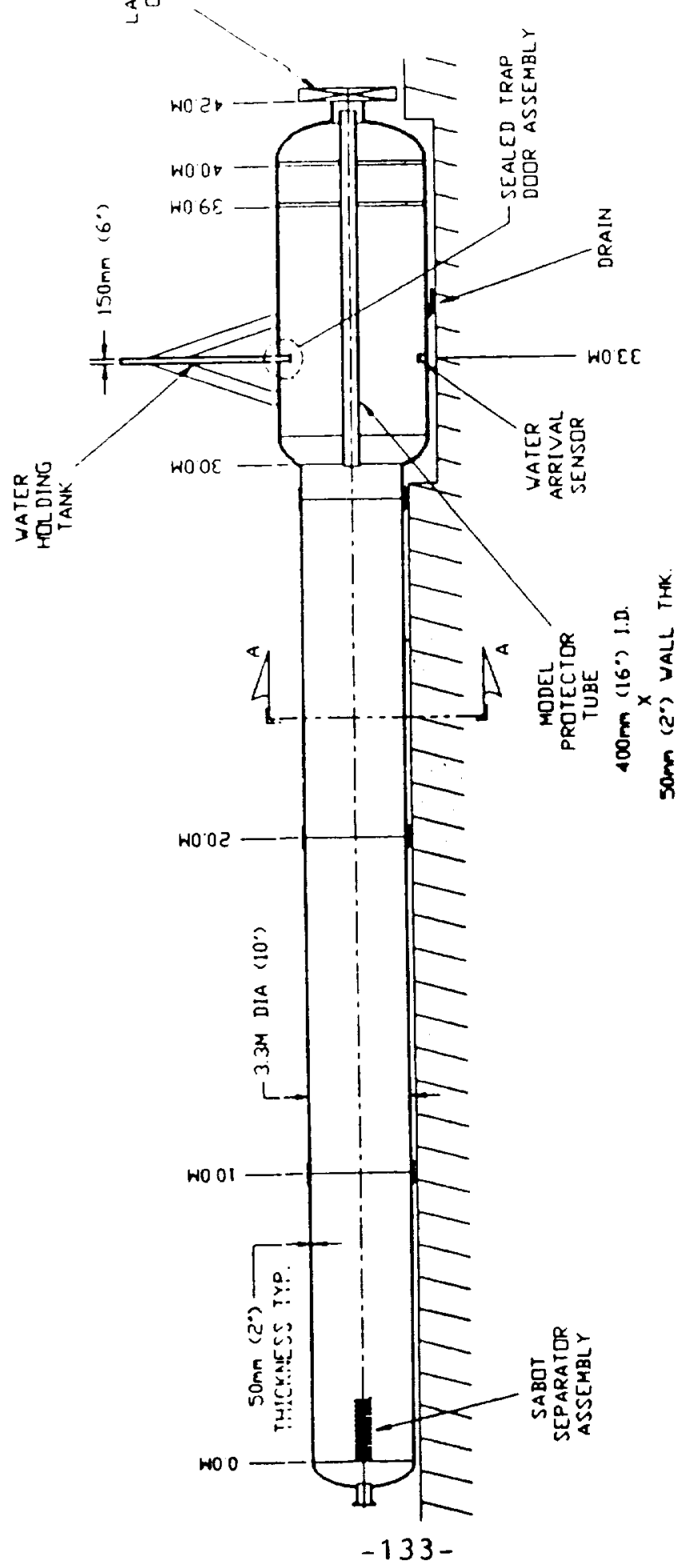

4

×.

它

$\Leftrightarrow>$

c.

-1

㟧

(1)

욤

जे

$+$

$0 .-1$

is 4

0

D $\frac{0}{2}$

$4 N$

o

ड़

崩

政

导

o

苛的

o 0

जz

西它总

我.

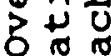

4

.

$\therefore$ 뭉

$\Rightarrow 0$

ले ठ

$m 80$

म4

हु ㅇํ

क्ष 9 


\subsubsection{Tankage Used for Performing Experiments.}

The tankage used for performing experiments includes the main trajectory tank and an extension of it used to contain extended guide rails. Basically, the main experiment tank is a continuous tube $3.3 \mathrm{~m}$ in diameter by $480 \mathrm{~m}$ long. The forward $330 \mathrm{~m}$ is given over to conventional experimentation exclusively. Windows are mounted periodically along both horizontal walls opposite one another so that the trajectory can be viewed conveniently at a number of points. Instrumentation which either "looks" at passing models directly or observes silhouettes of them when they are illuminated from the opposite direction. Some windows are used for transferring signal electronics into and out of the tankage volume. Radio-frequency antennae are used to transmit information to passing models and to receive information from them. Wave-guides are used for operation in the microwave regime to power radar and microwave interferometry experiments that provide information for diagnosing plasma produced by model/atmosphere interaction. Finally, optical sensors mounted inside the tank are used for observing radiation from the model, its surrounding gas, and its wake from directions that cannot bé reached by detectors operating outside of the range. One special use for optical detectors is communication with onboard model instrumentation which transmit experimental data off-board in coded sequences using either solid-state lasers or light-emitting diodes. Such real-time data transmission may represent the least expensive alternative for acquiring dynamic data from on-board sensors during model flights.

The final $275 \mathrm{~m}$ of the tank is used for aerodynamic recovery of recorders within flight models. (1) The model passes through a diaphragm covering the tank cross-section into an intense atmosphere which causes its rapid deceleration as well as its intense aerodynamic heating. Shortly after passing through the diaphragm, a ballute is deployed from the rear of the model which enhances greatly deceleration of a hardened package within the model which contains a digital storage unit used to record data during the experimental portion of model flight. As the model breaks up, the ballute draws the recorder package out of its rear so that the recorder separates from the ongoing model and its component fragments. Over $150 \mathrm{~m}$ of flight, the ballute decelerates the recorder package to the point where it can be recovered (in-tact) after its impact into soft material such as rug remnants that are placed at the far end of the tank. Data can then be read out from the recorder to reveal various flight parameters characteristic of the model's travel through the experimental portion of its flight.

Alternatively, models may be destroyed as they approach the rear end of the recovery portion of the range. Their resulting fragments may be scattered and absorbed via impacts into hard material using an analogous process to interception of sabot segments described in paragraph 3.1.1.2.3. In this case, a tank as wide as the range diameter and $150 \mathrm{~mm}$ thick is mounted above 
the range. A trap door encompasses the entire bottom surface of the tank. Moments before projectile firing, the door is allowed to open so that the water drops in a more-or-less continuous sheet $150 \mathrm{~mm}$ thick. The oncoming model impacts the water at some velocity over $4.0 \mathrm{~km} / \mathrm{sec}$ and is shattered to fine debris. Much of the debris is melted and some of the impacted water is vaporized. The remaining solid debris is scattered through a cone of substantial included angle to impact a pair of massive plates mounted across the entire rear cross-section of the tank. These plates absorb the impulse of the fragment cloud and transmit it safely to the range room foundation. The vast majority of the energy associated with the model impact leaves the recovery plate in the form of electromagnetic energy radiated in the infrared, visible, and ultraviolet portions of the spectrum. The plate assembly is faced with an array of steel targets, each of which is thick enough to absorb individual impacts without perforation. These plates, each of which is small enough to be manhandled, may be expected to survive many firings but must be replaced periodically during the facility's operational lifetime.

A second mode of facility operation involves launched models being confined on an extension of the rail system used to conduct them through the blast tank.(10.11) Basically, the rail system consists of four rectangular rails mounted orthogonal parallel to the range axis and to one another around the trajectory. Spacing is maintained at precisely the bore diameter as sketched in Figure 3.2 and the axis of the rail system is maintained precisely coaxial with the launch tube of the model accelerator. The model, itself, either forms the front face of a cylindrical bore-fitting sabot or it is supported on a short thick shaft ahead of the sabot. In either case, the outer cylindrical surface of the sabot engages the rails over its entire travel which results in the model maintaining its position and orientation with respect to the range axis. This feature allows instrumentation with notably small view-fields to be used for making detailed model observations even when the model has traveled far from the launcher muzzle. It also allows aerodynamically unstable models to be "flown" along the range without encountering problems associated with their trajectory diverging to an unacceptable degree from the range axis. The use of guide rails also allows the range to be extended economically so that very long model flights can be achieved ${ }^{(12)}$. . . which are, occasionally, necessary for studying materials interaction with energetic gas flows. Finally, the use of guide rails allows models to be recovered in-tact through gasdynamic deceleration ${ }^{(10)}$. The cylindrical sabot is allowed to enter a closed atmosphere-filled tube. The sabot produces a shockwave within the atmosphere which pressurizes the gas behind it. This pressure bears upon the front face of the sabot and decelerates it until the entire package is either brought to rest or has its velocity reduced to the point where it can be caught via more conventional means. Experience with this sabot deceleration technique has been amazing. Models travelling initially at 
velocities up to $6.0 \mathrm{~km} / \mathrm{sec}$ have been recovered with essentially zero damage which allows recorded data from onboard instruments to be extracted easily. Expensive model configurations can be reused for multiple firings if they have not been damaged either during launch or during flight through test environments. Since recovery adds virtually no post-flight damage to launched models, details of model and materials degradation produced by test flights can be examined through destructive evaluation of recovered models and their component parts.

The following paragraphs contain notes and analyses required for effective design of each of the systems described in this paragraph.

\subsubsection{Main Experiment Tank.}

The diameter of the main experiment tank was chosen somewhat arbitrarily at $3.3 \mathrm{~m}$ because this was the size needed to contain the flight of a space shuttle model with a $25-\mathrm{cm}$ wing span that weighed $10.0 \mathrm{~kg}$ and was launched into a $330 \mathrm{~m}$ tunnel at an initial velocity of $6.0 \mathrm{~km} / \mathrm{sec}$ and a pitch angle of $+40^{\circ}$ (14) $^{(14)}$

As with the gun blast tank and sabot separation tank, the main blast tank must be delivered in $10 \mathrm{~m}$ long segments that can be interconnected readily on-site. We choose, in this case, to install the tank segments by bolting them together since the assembly is so long. A typical joint is sketched in Figure 3.18. outward facing flanges are provided at each end of each section so that they may be bolted together. Since extremely high vacuum levels must be achieved within the composite tank each of these joints contains dual seals with an oil-bath interface. The seals we have selected are inflatable rubber tubes which can be installed in their respective glands and evacuated internally to cause them to withdraw from the outer edges of their glands. The joint may now be closed with little fear of pinching the seal bladders. The seal may then be inflated to produce the required sealing action. Once the seals are closed, silicone oil with extremely low vapor pressure is flowed into the space between the seals so that any residual openings across the seal faces must draw relatively viscus oil through them rather than low-viscosity air.

In general, the flanges will not be pulled against one another all the way around each joint because they cannot be positioned during fabrication precisely perpendicular to the tube axis or parallel to the one on the other end of the tank segment. If each segment is $10 \mathrm{~m}$ long, a total of 33 segments is required for the main tank plus 15 segments for the model deceleration portion of the range and a single segment for the model destruction/recorder recovery section. Each of the tank segments is supported on its own cradle which holds its axis at the desired height above the range floor. The cradles are made adjustable in height so that the axis of each tank segment may be aligned precisely with that of the range. The tank segments are 


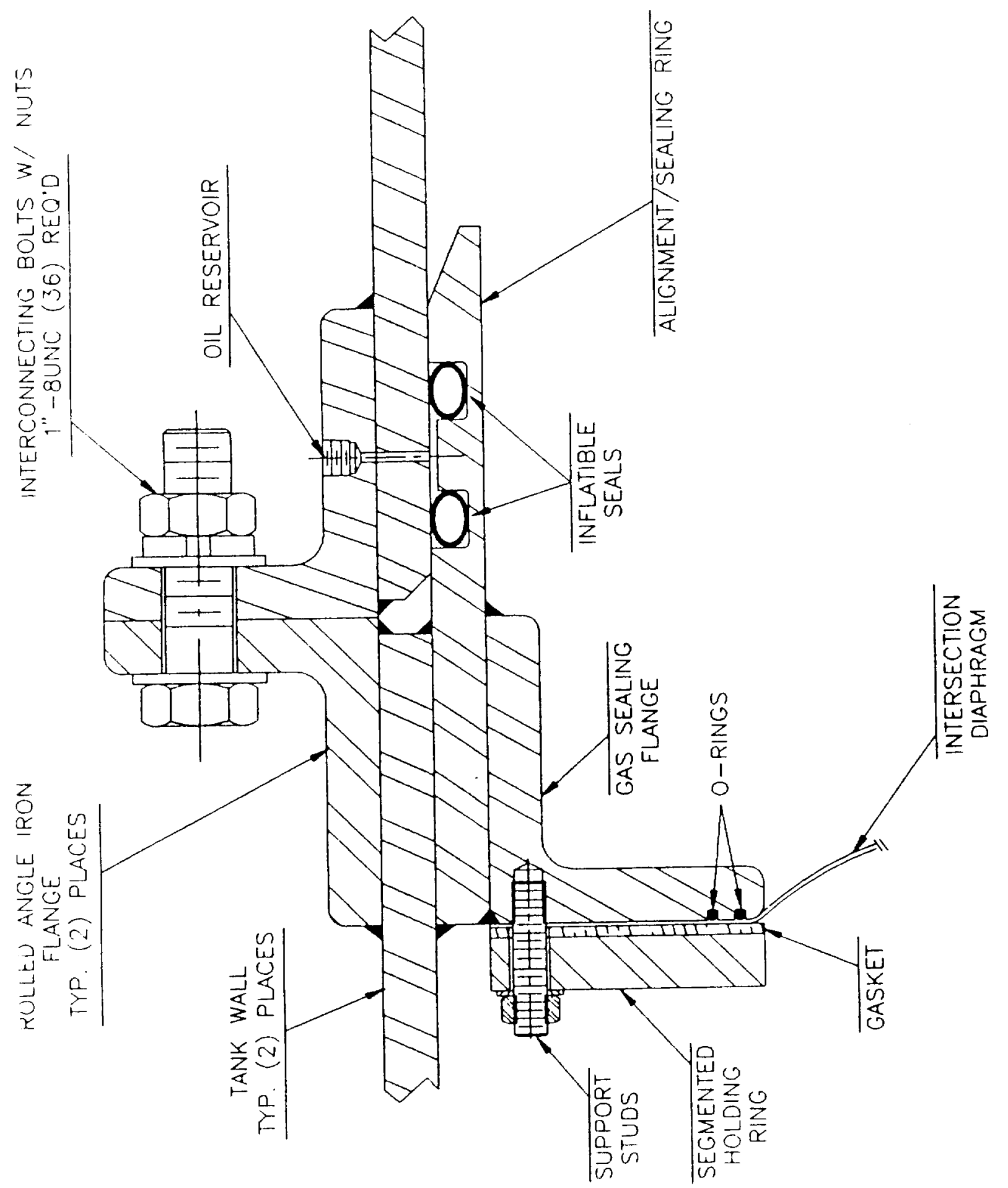

$\begin{array}{r}c \\ 0 \\ -7 \\ 1 \\ 0 \\ 0 \\ 0 \\ 4 \\ 0 \\ + \\ 5 \\ \hline\end{array}$

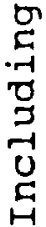

E्

峁

-

임

告

$\Sigma$

岂

넝

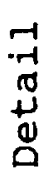

点

'०

- О

$\infty \sum$

ल E

o)

$3 \frac{1}{2}$

का 
allowed to move axially along their supports so that joints may be opened/closed, segments may be removed and replaced, and thermal expansion may be accounted for. The new segment to be installed at the downrange end of the tank assembly is moved into position until the alignment sealing ring at the downstream end of the next segment upstream engages its upstream end. Threaded rods are then passed through apposing holes in several of the flange bolting sites. Nuts are screwed onto the rods and are torqued toward each other as the joint is drawn closed. (Mild vacuum is applied to the inflatable seals during this process so that they are drawn out-of-the-way into the rear portion of their grooves.) This drawing up process is continued until the two flanges meet at one point around their circumference. The nuts are then released: threaded rods are removed; and bolts, flat washers and nuts are installed in all of the flange holes. The bolts are drawn wrench tight in apposing pairs near quadrature with one another as the joint is drawn tight. Once the joint is tight, shop air is valved into the seal bladders which causes them to inflate and engage. After inflation, the space between the seals is evacuated and silicone oil contained in a reservoir is valved into the space between the seals to complete the segment closure process. Pressure is maintained on all seals as nearly perpetually as can be arranged. The level of silicone oil in each reservoir is recorded accurately after the joint has set for several hours. This level is monitored from time-to-time during operation of the range to verify that it remains constant - . which further demonstrates that the seal remains tight.

Pairs of stable supports are required every $4.0 \mathrm{~m}$ along each tank segment to provide for precise alignment of folding structures for carrying projectile guidance rails. Columns bolted to the range facilitity foundation extend upward through holes in the tank side wall as shown in Figure 3.19. Rubber boots are secured around the columns and to the tank wall to assure vaccum integrity of the tankage.

\subsubsection{Diaphragms for Separating Range Tankage Atmospheres.}

Various segments of the blast tank may be evacuated and repressurized at a variety of levels in order to meet experimental requirements. Peak gas pressures added to the range may vary from near zero up to $0.3 \mathrm{MPa}$ ( 3.0 bars). Such pressure can produce extremely high separation forces between the tank segments which must be borne by the bolts that hold the range together. We recommend that a total of 36 , each 1 -inch in diameter bolts be used to hold each segment of the main experiment tank to its neighbor. These bolts are stressed to 191 $\mathrm{MPa}(28,100 \mathrm{psi})$ when a pressure of $0.3 \mathrm{MPa}(45 \mathrm{psi})$ is added to the tank.

Just in-board from the alignment/sealing ring is a flange which extends continuously around the interior circumference of the tank (see Figure 3.18). This plate is used to support diaphragms that segregate portions of the main experiment tank 


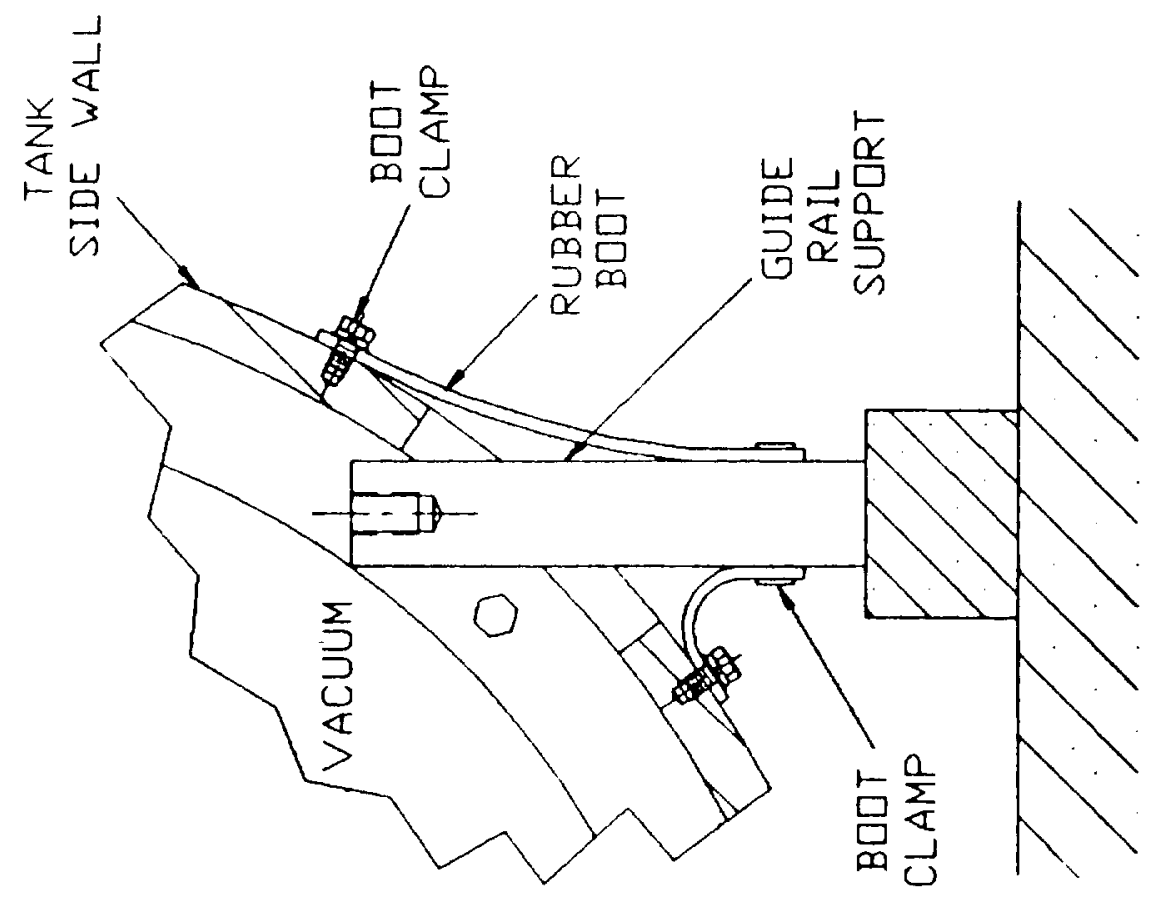

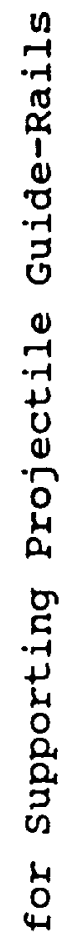

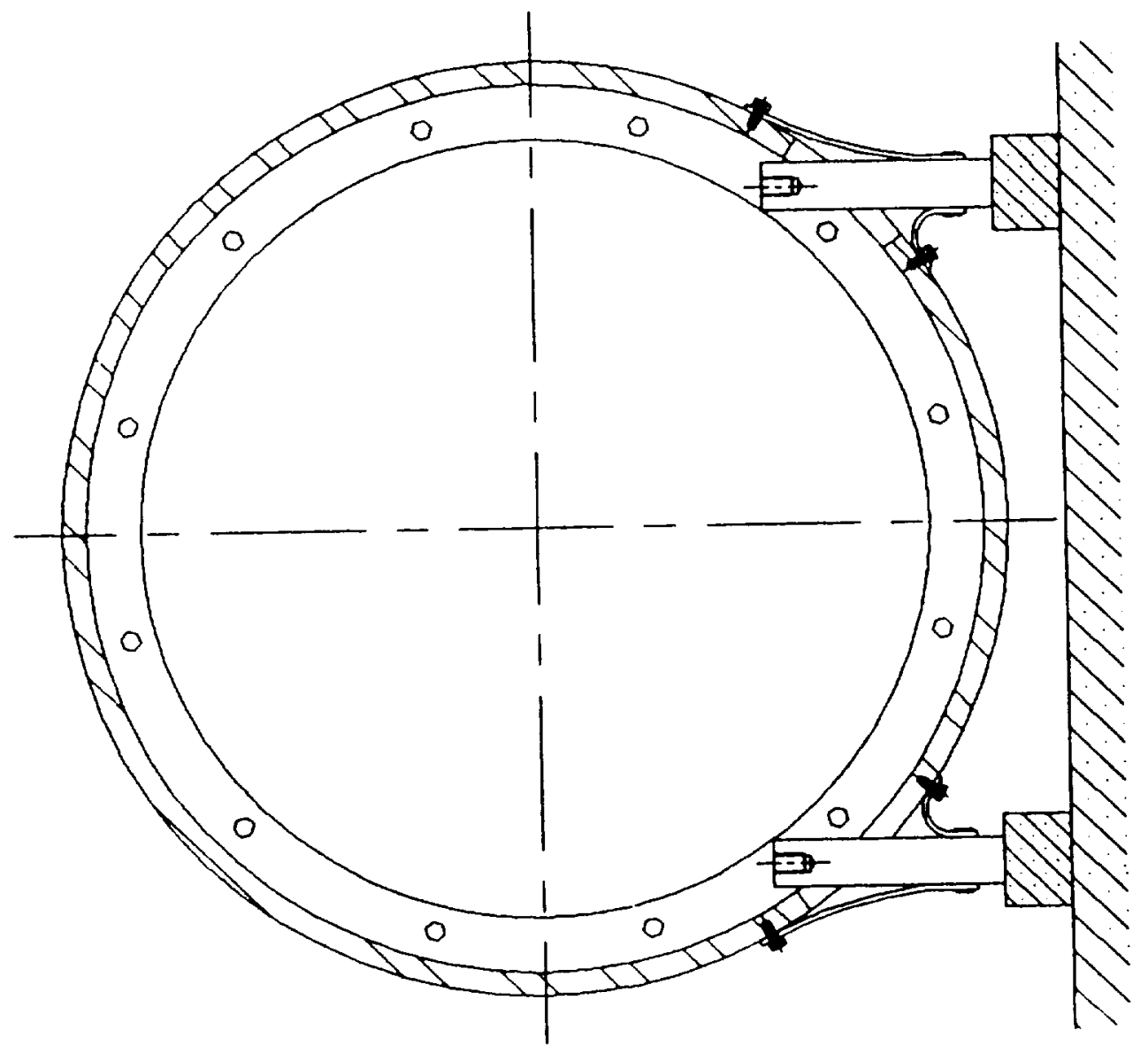

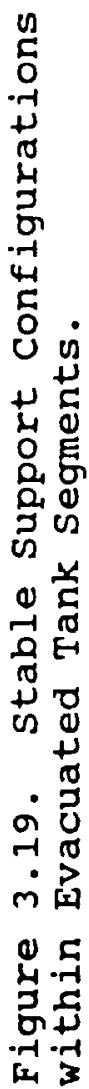


from one another so that different pressure levels and different gas chemistries and pressures can be installed in each. Sunken gaskets are provided in the upstream ends of each flange near their inner edge. A segmented ring is used with a continuous gasket to hold the diaphragm in place. The segmented flanges, in turn, are held in place with a total of 36 studs which engage the segmented flange and nuts with flat washers. Drawing the nuts tightly onto the studs assures that the gaskets are compressed and that the seal is gas-tight and mechanically strong enough to withstand the pressure differential.

The question now presents itself, "How thick must the diaphragm be to hold off particular pressure differentials?" Diaphragms made from strong and malleable plastic such as mylar, kapton, and polycarbonate have been observed to bulge to full hemispheres before they rupture as pressure differential across them increase. Peak strain levels in stressed diaphragms occur at their centers. A maximum value for this strain, $\epsilon_{b}$ may be calculated by considering elongation of a diameter across the original planar surface as the surface is extended to a hemisphere as is presented in the first line of Equation 3.30. The octahedral equivalent strain, $\epsilon$ eq may be calculated at the same point using the von Mesis formalism as is presented in the second line of Equation 3.30. Finally, minimum thickness of the stretched diaphragm, $t$ may be calculated in terms of the original diaphragm thickness, $t_{0}$ and the 1 inear strain, $\epsilon_{b}$ under the assumption that the diaphragm material deforms at constant volume as is presented in the third line of Equation 3.30.

$$
\begin{gathered}
\epsilon_{b}=\frac{I_{t}-d}{d}=\frac{\pi}{2}-1 \text { (for hemispherical expansion) } \\
\epsilon_{\theta q}=\sqrt{2} \epsilon_{b}=\frac{\pi-2}{\sqrt{2}} \text { (for hemispherical expansion) } \\
t_{f}=\frac{t_{0}}{\left(1+\epsilon_{b}\right)^{2}}=\frac{4 t_{o}}{\pi^{2}} \text { (for hemispherical expansion) }
\end{gathered}
$$

where:

$l_{f}=$ length of diametral trace on hemisphere surface and;

$\mathrm{d}=$ diaphragm diameter.

Under these conditions, the pressure differential $p_{c}$ that can just be supported by circular plastic diaphragms may be related to the original diameter of the diaphragm, $d$, its original thickness $t_{0}$, and the material's tensile strength $\sigma_{t}$ by Equation 3.31. Obviously, $p_{c}$ cannot be used directly for diaphragm design since it would lead to many spontaneous diaphragm ruptures. For this reason, a safety factor, $\eta$ has been introduced in the definition of $P_{c}$, the pressure that may be held off by a practical diaphragm.

Plots of practical diaphragm thickness, $P_{c}$, vs. diaphragm diameter are presented in Figure 3.20. Mylar polyester diaphragm 


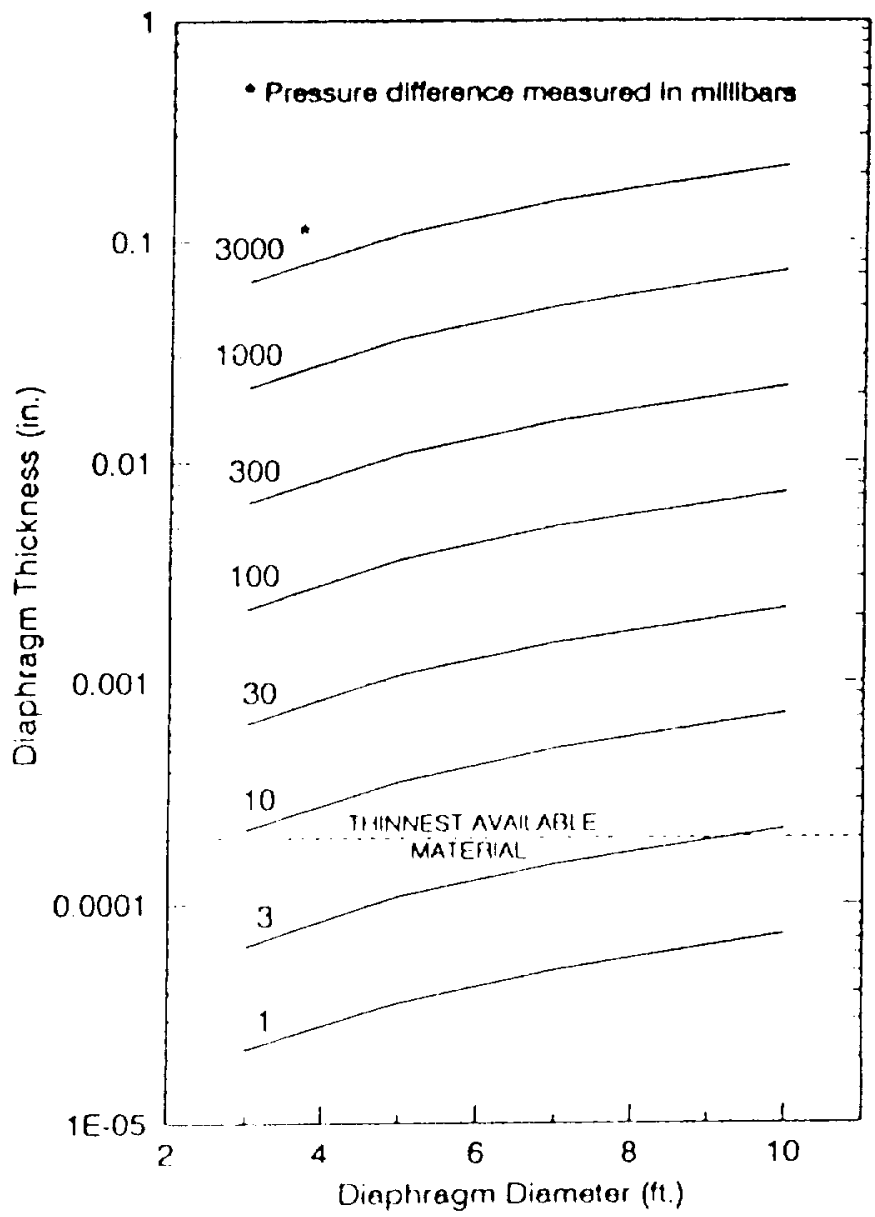

Figure 3.20. Diaphragm Minimum Practical Thickness vs. Span Diameter for Mylar Diaphragms subjected to Various Pressure Differentials.

$$
\begin{aligned}
& p_{c}=\frac{4 \sigma_{t} t_{o}}{\left(1+\epsilon_{b}\right)^{2} d}=\frac{16 \sigma_{t} t_{o}}{\pi^{2} d} \text { (for hemispherical expansion) } \\
& P_{c}=\frac{4 \sigma_{t}(1-\eta) t_{o}}{\left(1-\epsilon_{b}\right)^{2} d}=\frac{16 \sigma_{c}(1-\eta) t_{o}}{\pi^{2} d}
\end{aligned}
$$

material strength was evaluated as $\sigma_{0}=179.3 \mathrm{MPa}(26,000$ psi)which is an extreme published value and a safety factor of $\eta=0.45$ was chosen. Individual plots consider specific pressure differentials ranging from $P_{c}=100 \mathrm{~Pa}\left(1 \mathrm{~m}\right.$.bar) to $P_{c}=0.3 \mathrm{MPa}$ (3.0 bars). Mylar plastic is available at full tensile strength in thicknesses up to only $0.12 \mathrm{~mm}(.005 ")$. When higher diaphragm break pressures are required, multiple layers can be used.

Many of the experimental diaphragm requirements may be met with diaphragm thicknesses so small that models can be allowed to burst through them without risk of damage. Larger pressure differentials and/or use of extremely delicate models opens the 
possibility that model collision with diaphragms may cause unaccoptable damage. In these cases, diaphragms must be opened before the model reaches them. Reference 23 presents an AEDC-developed design for a diaphragm cutting apparatus that can be triggered a short time before the model reaches the diaphragm site. The diaphragm remains are forced out of the range axis to provide a clear aperture so that the model may pass without encountering solid material. Unfortunately, diaphragm opening takes time, so gas flow from the portion of the main experiment precharged to higher pressure must occur into lower pressure areas before model arrival. This flow may or may not prove serious depending upon the experiment under consideration.

Let us start the analysis of diaphragm opening by evaluating time required for the diaphragm to open after it has been cut. This time, $T$ may be evaluated by Equation 3.32 in terms of diaphragm material density, $\rho_{d}$ span, $d_{d}$ original thickness, $t_{0}$ and pressure differential, $\mathrm{p}_{\mathrm{c}}$.

$$
\tau=\sqrt{\frac{3 \rho_{d} d_{d} t_{o}}{\left(1+\epsilon_{b}\right)^{2} p_{c}}}=\frac{4}{\pi^{2}} \sqrt{\frac{3 \rho_{d} d t_{o}}{p_{c}}} \begin{aligned}
& \text { (for hemispherical } \\
& \text { expansion) }
\end{aligned}
$$

It is, perhaps, more instructive to solve Equation 3.31 for $t_{0}$, the critical thickness of diaphragm that can be used safely in the range and substitute it into the Equation 3.32 to define a critical minimum diaphragm opening time, ${ }^{\tau_{c}}$.

$$
\tau_{c}=\frac{d}{2} \sqrt{\frac{3 \rho_{d}}{\sigma_{t}(1-\eta)}}
$$

Equation 3.33 is graphed in Figure 3.21 for the case of Mylar polyester diaphragms $\left(\sigma_{\mathrm{t}}=179 \mathrm{MPa}, 26,000 \mathrm{psi}\right)$.

Occasionally entrances must be provided in the side wall of the composite experiment/instrument retrieval tank that are large enough to allow entry of men and equipment. Typically, such entrances are $.6 \mathrm{~m} \mathrm{(24")} \mathrm{wide} \mathrm{by} 1.5 \mathrm{~m}\left(60^{\prime \prime}\right) \mathrm{high}$. They, and the windows are covered with hatch plates that are supported by hinges so that they can be rotated horizontally. Hinges must be of double pin construction to allow the covers to be positioned precisely parallel to the surface sealing both at the beginning and completion of seal engagement. The hatch covers are held in place tightly enough to engage the seals and to resist opening forces produced by positive internal pressures with sequences of bolts installed around their peripheries outside of the seal surfaces. A sketch of a typical opening with a hinged cover is presented in Figure 3.22. The seals for all hatches associated with the main experiment tank are of dual o-ring design. A pair of grooves are machined in the hatch covers one just inside the other. o-rings are cut and glued together to fit the grooves. In this way, damage to a single o-ring does not cause a leak in the tankage system. Mounting the o-rings on the hatch covers allows them to be swung out-of-harms-way when equipment is moved into and out of the tanks. They are also exposed to the 


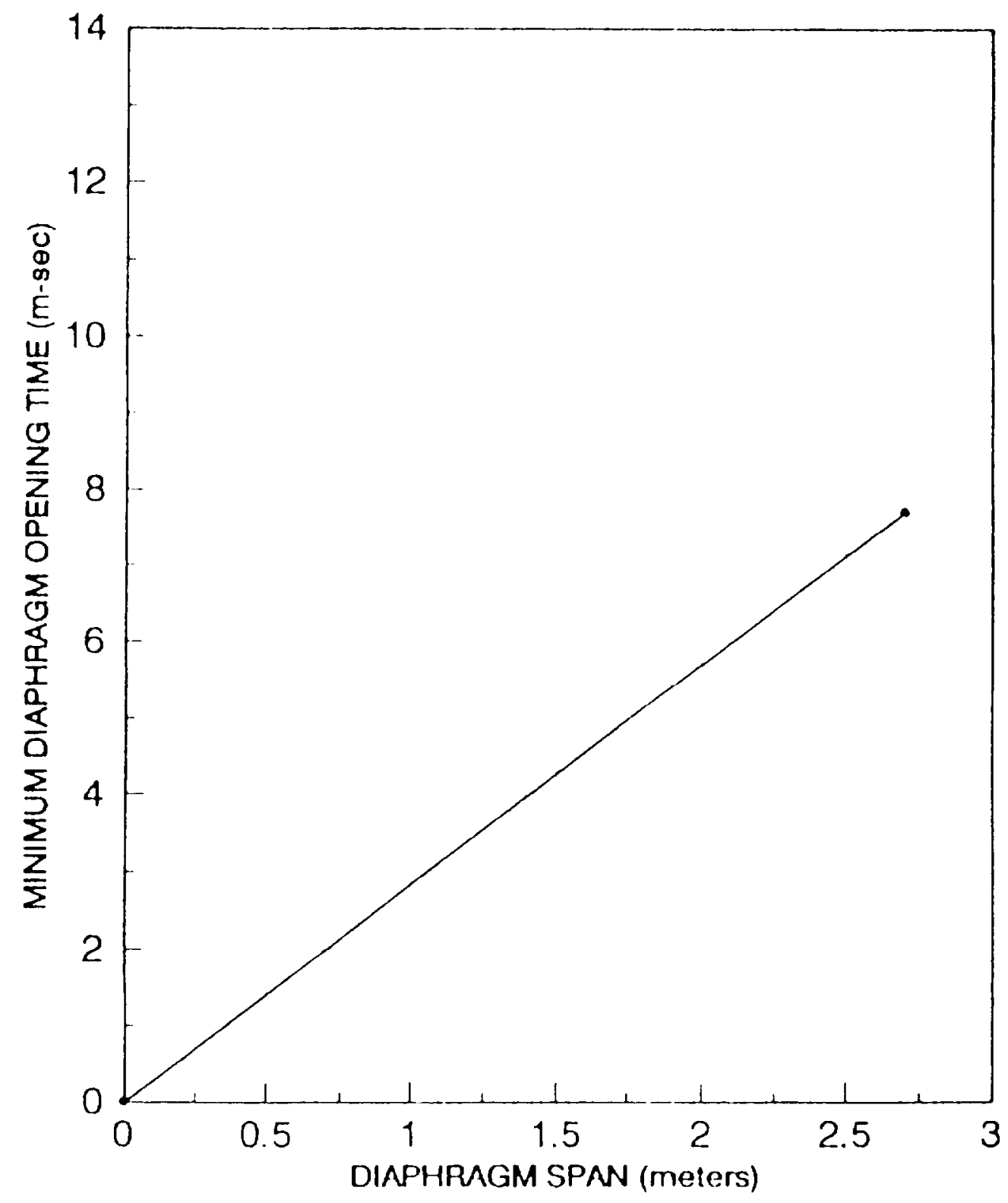

Figure 3.21. Minimum Practical opening Times for Rupture Diaphragms Made From Mylar Polyester vs. Span Diameter. 


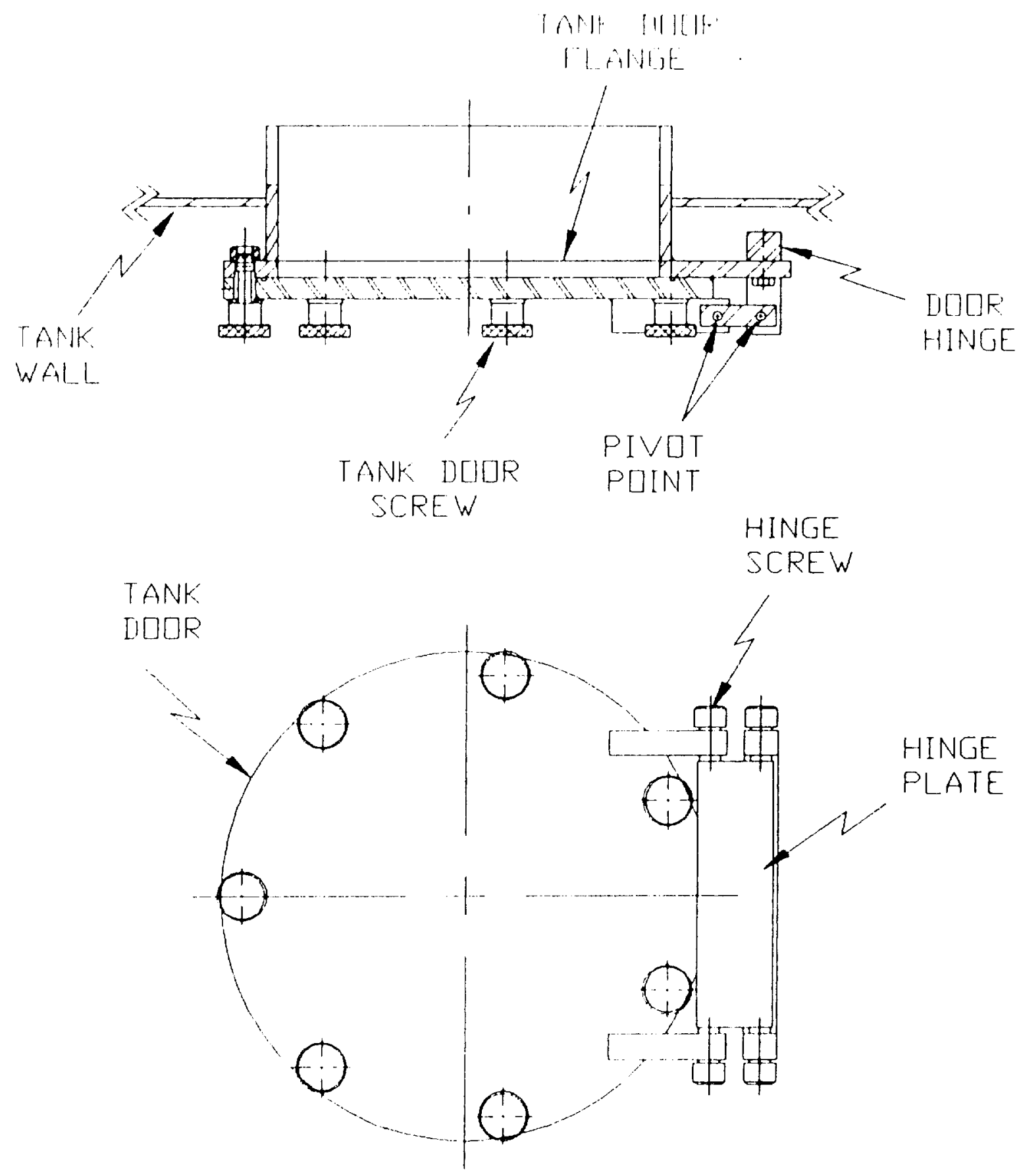

Figure 3.22. Sketch of a Typical Door for a Large Tank Supported by a Dual-Pivot Hinge that $\lambda$ ssures Proper seal Engagement. 
operators view during each hatch opening. Care must be taken to inspect the o-rings carefully and to replace ones that become scratched or nicked.

The trajectory observation windows for the range must be large enough to allow ready viewing of the trajectory near the center of the main experiment tank. Often windows of exceptional optical clarity and/or homogeneity are required which are not available in large diameters. For this reason, we recommend that the window covers be designed for simple and inexpensive construction and made from boiler steel. These "blanks" can be mounted readily to hinges on the range tank after they have been pierced and machined to accept windows required for specific instrumentation tasks. In this way, a single opening in the range can be made to serve a variety of instrumentation functions by providing a variety of covers each of which is optimized to provide qualities needed for particular experiments.

Basic tank geometry dictates that the windows must be located at least $1.7 \mathrm{~m}$ from the range axis. This distance appears to be small enough for serving the needs of most instruments that have been conceived to date for supporting freeflight investigations. They may prove inadequate, however for more precise instrumentation that can be developed to support guided rail studies. For these situations, specialized unhinged window mounts are required which contain tunnels that allow the windows to be mounted well inside the tank walls as shown in Figure 3.23. Instrumentation used with these tunnels must be configured to fit within them $(<75 \mathrm{~cm} \mathrm{dia.} \max$.$) and to be$ serviced from outside the main tank structure. Generally, viewing ports on such tunnels are made unopenable so that they must be cleaned by operators who enter the tank through one of the man-access ports described earlier.

\subsubsection{Rail Guided Firings.}

A second mode of operation of the range involves launching models mounted on special sabots onto guide-rails which extend virtually the entire length of the range tankage. Such rails allow model trajectories to be maintained precisely along the range axis regardless of whether the models are aerodynamically stable or unstable. Since the trajectory is defined precisely, potential exists for launching models over distances greater than the length of the main range tankage by enclosing the rails in small-diameter tubes (near $1.0 \mathrm{~m}$ diameter) which can be extended over great lengths at minimum cost. Such extreme trajectory lengths may prove useful for studying materials response to hypersonic gas flows where transient ablation regimes, steady state regimes, and transitions between them are of interest.

Perhaps the most important advantage of guided-trajectory firings is the potential for decelerating launched models smoothly and slowly so that they can be recovered after a launch in-tact. Such capability allows recovery of models and 


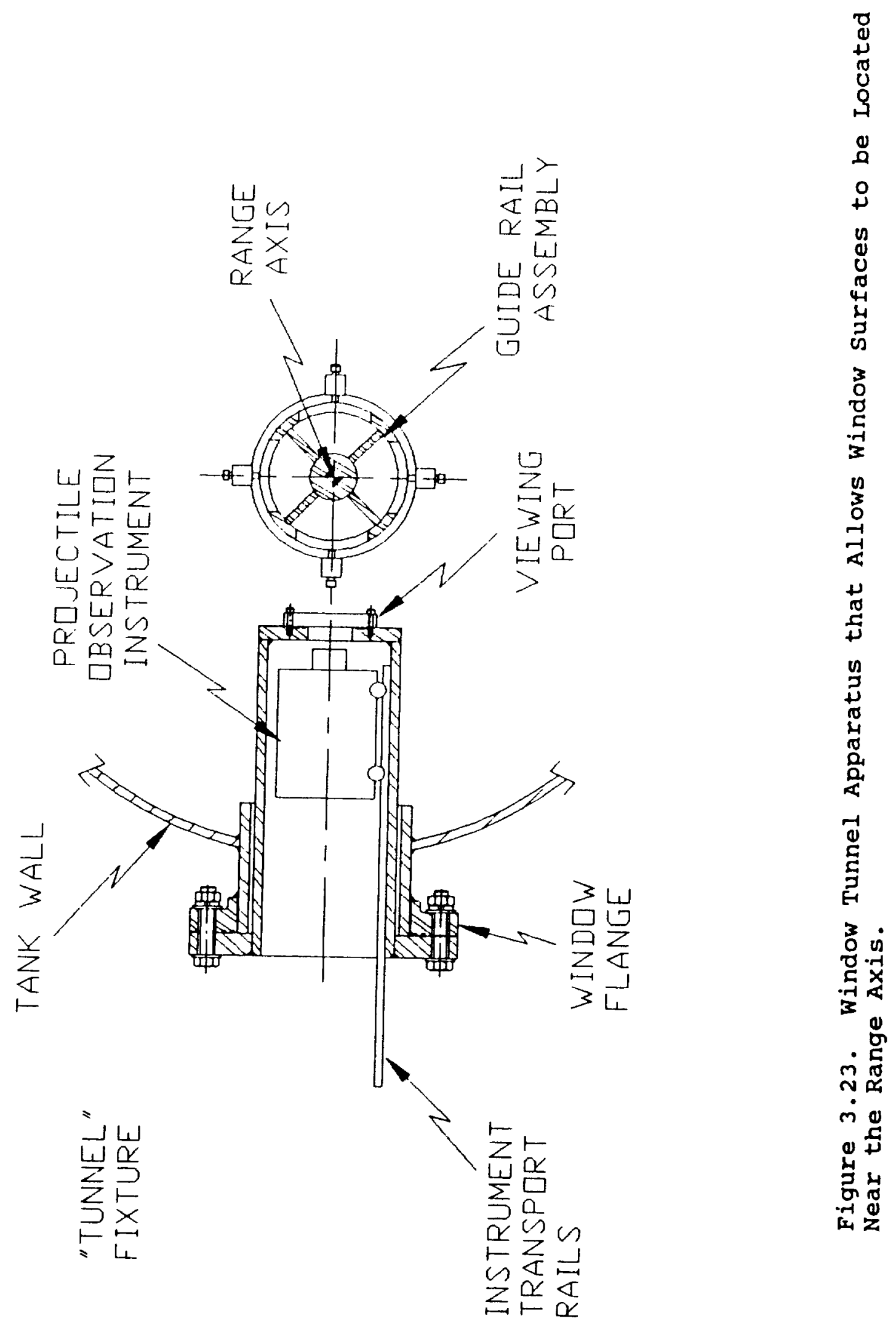


instrumentation recording packages so gently that they may occasionally be reused and also allows launch and flight damage to be evaluated through direct observation.

The rail system itself is functionally identical to the one employed in downstream portions of the blast tank (see paragraph 3.1.1.1). The only difference is that rail systems downstream from the blast tank must be supported on structures which can be folded to move both themselves and the model support rails away from the range axis and against the side wall of the enclosing tank when conventional free-flight studies are conducted. This requirement effectively limits lengths of individual guide-rail segments to approximately $10.0 \mathrm{~m}$. Rail segments that span tankage junctures where space is restricted such as at each end of the sabot tank must be removed for conventional firings. These folding rail systems must extend from the upstream end of the sabot separation tank all the way to the far end of the freeflight portion of the range. Care must be taken to provide precise alignment of individual rail segments both with the range axis and with one-another so that oncoming models are not subjected to centripetal acceleration and do not meet positive steps. This anti-step requirement can be supported significantly by bending the rails outward at the upstream end of each segment by $100 \mu-200 \mu$. The rails are oriented $45^{\circ}$ above and below horizontal on both sides of the trajectory so that horizontal and vertical windows in the range tankage can be provided with unobstructed views of the range axis.

A typical rail guided sabot/model package is sketched in Figure 3.24. The non-discarding sabot is a solid plastic cylinder of gun-bore diameter. Its rear face may be cut away to

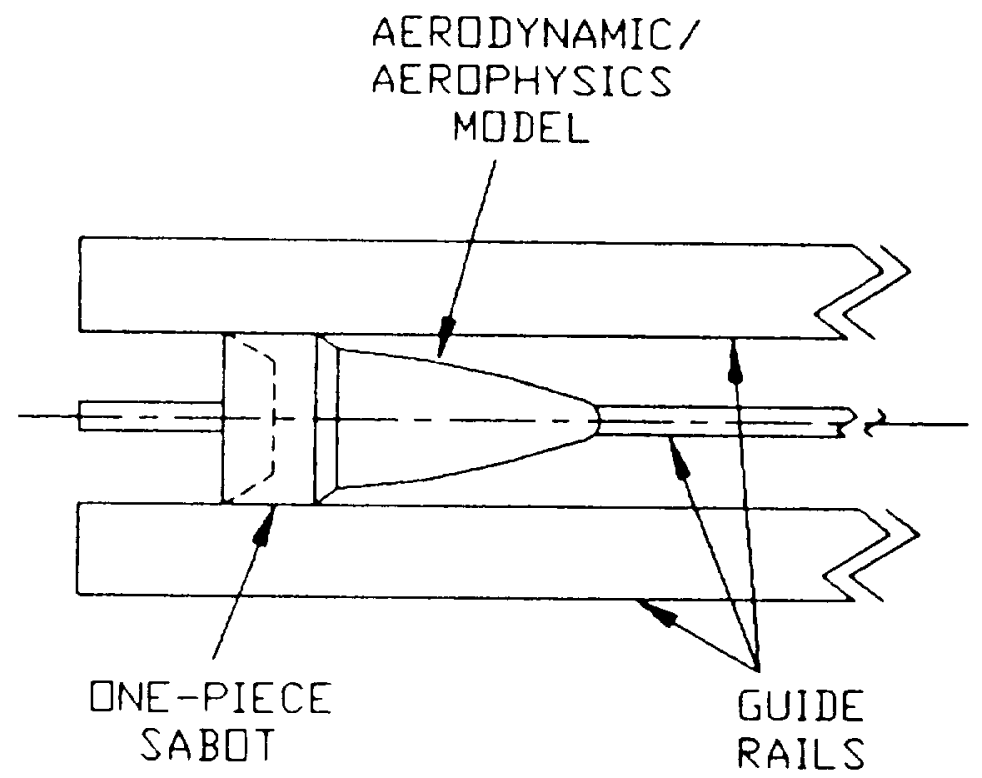

Figure 3.24. Sabot-Model Package for Flight through the Range on Guide-Rails. 
provide obturation during launch and to reduce total package mass. The model is mounted on its front face. Interaction between the sabot and the guide rails assures that the launched models "fly" precisely along the range axis with predetermined orientations. The facility is large enough, in principal, to allow relatively small aerodynamic models to be mounted on pivots so that their orientations can be shifted during flight along the range axis. Equipment used for conducting such operations must be designed with great care since it must be both light and robust enough to survive launch and forceful and quick enough to shift model orientation significantly during very limited flight periods.

A technique has been developed for decelerating and stopping rail-guided models gently after they have traversed the range trajectory (10,11). Basically, the package is conducted into the end of a closed tube after it has completed its transit of the guidance rails. The tube contains an atmosphere $\left(\mathrm{N}_{2}\right)$ at a predetermined density (typically near 1 atmosphere). The sabot effectively closes the tube so it produces a shockwave in the atmosphere a head of it since it advances at hypersonic velocity. The sabot experiences the shocked gas pressure over its forward surface without a balancing pressure at its rear surface. The model, on the other hand is bathed in the pressurized gas behind the shockwave. Thus, the sabot and the model attached to it are decelerated and finally come to rest.

The following analysis serves as a basis for calculating the operation of a gasdynamic decelerator. If the atmosphere within the sabot deceleration tube is assumed to be perfect gas, the mach number of the shockwave, $M_{\text {sh }}$ may be calculated using Equation 3.34 .

$$
M_{s h}=\frac{M_{s I}+\sqrt{M_{s I}^{2}}+4}{2}
$$

where:

$$
\begin{aligned}
& M_{s r}=(\gamma+1) U_{s} / 2 a_{0} \\
& \gamma=\text { ratio of specific heats; } \\
& U_{s}=\text { instantaneous sabot velocity; and } \\
& a_{0}=\text { sound speed in the undisturbed gas. }
\end{aligned}
$$

The pressure experienced by the front face of the sabot, $P_{\text {sh }}$ may then be evaluated using Equation 3.35.

$$
P_{s h}=P_{0}\left[1+\frac{2 \gamma}{\gamma+1}\left(M_{s h}^{2}-1\right)\right]
$$

where:

$P_{0}=$ original gas pressure in the decelerator tube.

Results of Equation 3.35 are graphed in Figure 3.25 for the case of projectile deceleration tubes filled with air atmosphere. 


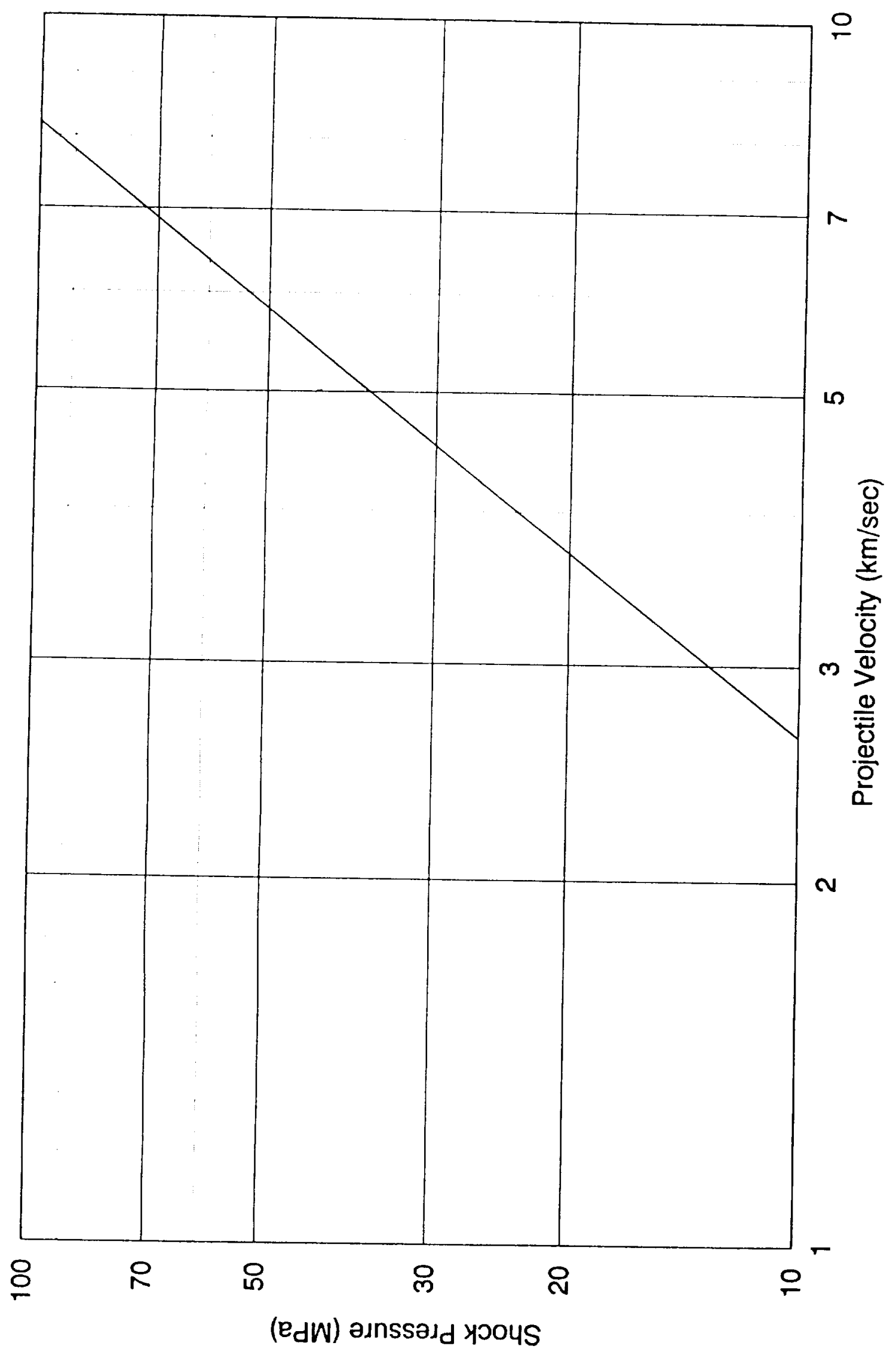

0
-1
4
0
0
0
0
0
E
+

Ho

$\stackrel{4}{-4}$



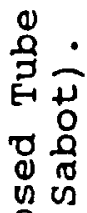

ㅇ-

ه

.

ช్

บ.

ชิํํำ

누

क

00

ป

包岁

ㄴ.

के

ชั

的

in के

$\sim>$

mं

ข

4 in

है

$\rightarrow 4$ 
A method-of-characteristics computer code must be developed for evaluating the performance of sabot decelerator tubes precisely since gas pressure at the forward face of the sabot is dependent upon instantaneous sabot velocity, sabot deceleration, and their time histories. Experience with practical gasdynamic sabot deceleration tubes used with launched models of relatively low scaled masses (as is the case with this facility) indicates that tubes 2000 calibers long $(500 \mathrm{M}$, for the case of the range being considered) are adequate for decelerating practical sabot/model package configurations.

We recommend that a model recovery tube be mounted at the end of the range to allow soft capture of launched models. If the tube is operated open to the atmosphere (as they often are), a suitable muffler must be installed at its downstream end to reduce noise levels from gas output to acceptable values. The extent of the muffler and its complexity must be established by considering the maximum transient sound level requirements of the particular location chosen for the range facility.

Very long range flights can be achieved for studying materials response to hypersonic flow if low drag model configurations are launched along guide rails. The drag of the guide rails on the model is essentially negligible as is predicted in Reference 12. Thus, the velocity reduction of packages launched along the range are due to aerodynamic drag. Such velocity reductions may be estimated by evaluating instantaneous package velocity, $v_{x}$ at arbitrary positions, $x$ along the range in terms of its initial velocity, $v_{m}$ and atmospheric parameters using Equation 3.36 .

$$
V_{x}=V_{m} \exp -\left[\frac{\pi d_{p}^{2} C_{d} X M P_{0}}{8 m_{p} R T_{0}}\right]
$$

where:

$\mathrm{V}_{\mathrm{m}}=$ projectile muzzle velocity;

$\mathrm{d}_{\mathrm{m}}^{\mathrm{m}}=$ sabot diameter:

$c_{d}^{p}=$ drag coefficient of the model/sabot combination;

$\mathrm{x}=$ distance downrange from the gun muzzle;

$M=$ mean molecular weight of the range atmosphere;

$\mathrm{P}_{0}=$ atmospheric pressure within the range;

$\mathrm{m}_{\mathrm{t}}=$ mass of the model/sabot package:

$\mathrm{R}=$ universal gas constant; and

$\mathrm{T}_{0}=$ atmospheric temperature within the range.

Equation 3.36 has been evaluated for launches involving two typical projectile/model configurations flying through air at various pressures. (See Figures 3.26). One has a composite drag coefficient of 0.4 and the other 0.8 . We feel that these drag coefficients effectively span those of practical sabot/model configurations and that air is representative of atmospheric chemistries of interest. The ratio of model velocity at a downrange point, $v_{x}$ to velocity at the entrance of the flight 

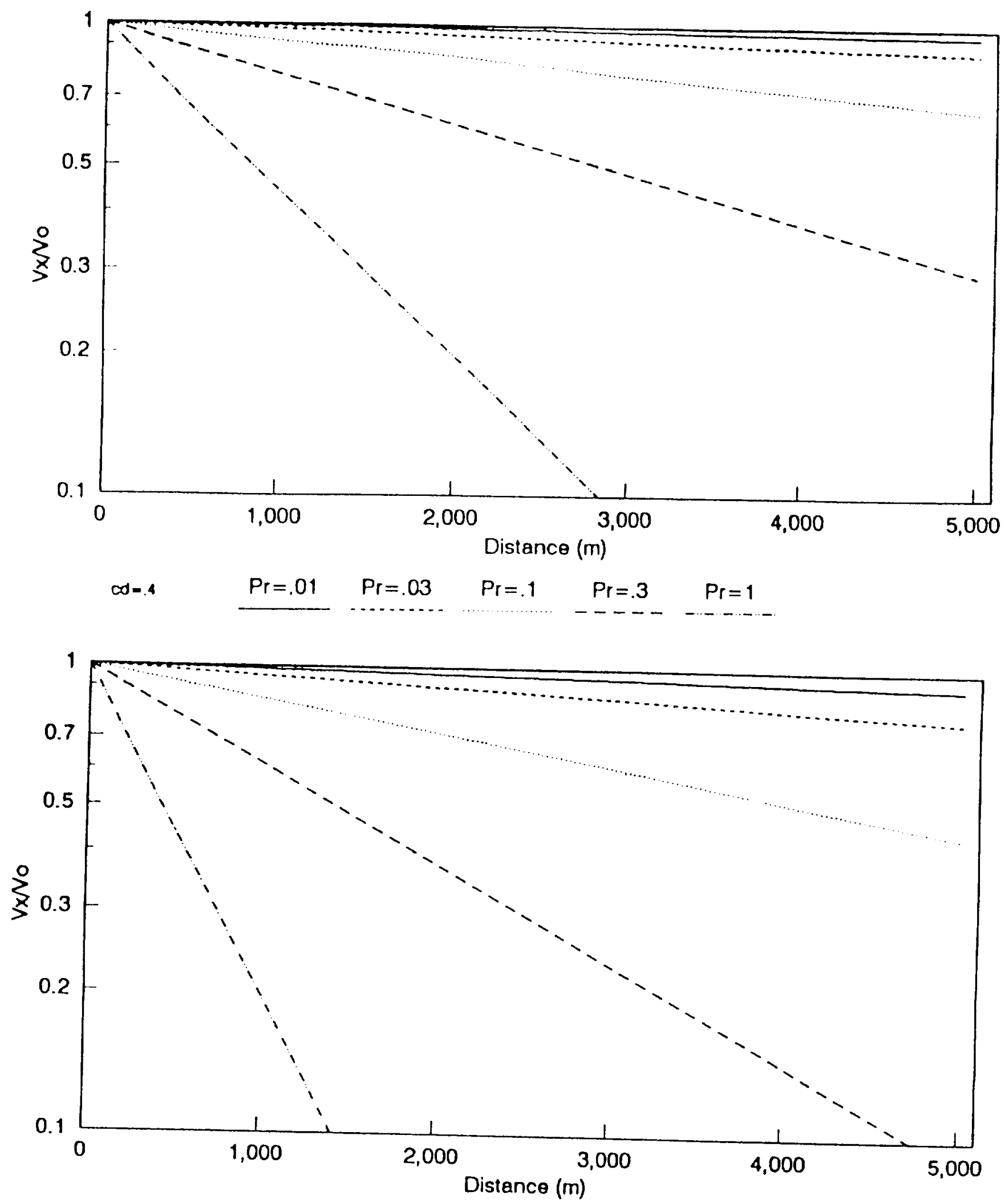

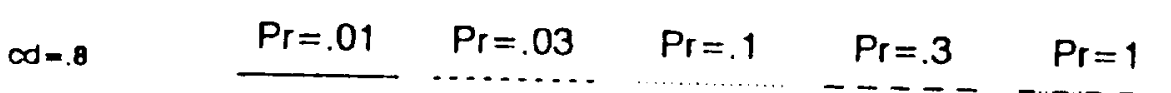

Figure 3.26. Velocity Loss Experienced by Projectiles with Drag Coefficients of $C_{d}=0.4$ and $C_{d}=0.8$ Traveling through Air Atmospheres vs. Trajectory Length. 
range, $v_{0}$ is plotted $v s$. downrange distance for models traveling through a variety of atmospheric pressures ranging from $\mathrm{P}_{r}=.01$ bars ( 7.60 torr) to 1 bar $(760$ torr). Notice that models may be expected to maintain between $90 \%$ and 778 of their initial velocity at distances up to $5.0 \mathrm{~km}$ when pressures are restricted to $\mathrm{P}_{r}=.03$ bars $(23$ tor $r)$. Even pressures above $\mathrm{P}_{\mathrm{r}}=0.1$ bar ( 76 torr) may be traversed by models traveling over $2.0 \mathrm{~km}$ with velocity losses well under $30 \%$ even when high drag configurations are concerned.

The question of whether or not to use a smal1-diameter extension of the range for conducting experiments requiring very long flight paths depends strongly upon the importance attached to materials response experiments. If a decision is made to conduct such experiments, we recommend that the range be extended out-of-doors beyond the end of the building enclosing the facility. Tubular segments $15.0 \mathrm{~m}$ long by $1.0 \mathrm{~m}$ in diameter can be connected together end-to-end with joints similar to those used for connecting segments of the main flight tank. These segments may be supported individually at their centers on piers mounted with their foundations set deep enough into the ground to provide geometric stability. Each segment should contain a pair of ports $0.75 \mathrm{~m}$ in diameter located opposite one another in the side wall adjacent to the downstream end. These ports may be closed with steel plates bolted into position. Some of these ports may contain windows to allow observation of passing models with a variety of instrumentation. Temporary buildings around the range structure (possibly as simple as tents) may be employed to protect instrumentation using the view ports from weather. The far end of the range extension should be equipped with a sabot/model recovery tube. The downstream end of this tube will undoubtedly require a muffler to break up the flow of shocked gas from the downstream end of the tube which otherwise would produce unacceptable noise levels. This muffler can undoubtedly also be supported on a series of piers similar to those used for the main tank.

An evacuation station is required every 500-1000 $\mathrm{m}$ along the range extension to provide adequate pump-down capability for the slender portion of the range. These stations should be contained and relatively permanent buildings which may also house equipment for controlling the pressure and chemistry of gas within the range volume.

\subsection{Range Evacuation Systems (Completed by NASA Langley staff) .}

(This information was not available at the time this document was printed.) 


\section{SITE, BUILDING, AND COST REQUIREMENTS.}

\subsection{SITE REQUIREMENTS.}

Obviously, considerable space is required for a facility of the size described in the previous chapters. The minimum land needed for the basic facility is $400 \mathrm{ft}$. wide by $2,750 \mathrm{ft}$. long (25 acres). This area is sufficient for housing the gun, the main range tankage, its support equipment, and minimal access roadways. More length is required at the downstream end for any extensions installed to enclose track-guided projectile "flying" and for gasdynamic recovery of launched projectiles. This length can be extended fruitfully to as much as 2.5 miles $(4.0 \mathrm{~km})$ beyond the end of the main range tankage. In addition, up to $300 \mathrm{ft}$. $x 500 \mathrm{ft}$. (4 acres) may be needed adjacent to the launcher end of the facility to provide space for building expansion needed to house alternative facility launchers.

If possible, a valley should be chosen for the site which is well drained and reasonably flat. The hills on each side may provide at least partial protection for the surrounding area in the unlikely event of a catastrophic failure of the range or one of its more energetic support systems. Locating the facility remote from population centers may also be expected to contribute significantly to overall system safety. Remote location will inevitably lead to substantial increases in the costs of providing basic communications and utilities, however.

Site preparation costs depend heavily upon nature of the terrain chosen. Distance from electrical and water utilities is also a factor as is requirements for dedicated roadways. The type and stability of the underlying soil plus its distance above bedrock are important factors in establishing needs for ground preparation before concrete slabs are poured. For these reasons, no estimates have been made of the costs for site or for its preparation.

\subsection{BUILDING REQUIREMENTS.}

The building, itself, should be a structure somewhat more than 2,650 ft. long by $50 \mathrm{ft}$. wide. The majority of the building should have a posting of at least $20 \mathrm{ft}$. The range trajectory is set $20 \mathrm{ft}$. from the straight wall which extends the entire length of the building. This placement allows $27 \mathrm{ft}$. of space along the right side (facing downrange) of the gun and $25 \mathrm{ft}$. along the right side for the most of the range tankage. The excess space provides ample room for storage of large components and for installing and removing major range components. Three bays, each 100' by 70' are provided in the right-hand side of the building at the rear end, between $720 \mathrm{ft}$. and $820 \mathrm{ft}$. from the launcher end and at 1,500 to $1,600 \mathrm{ft}$. Partitions separate these bays from the main range room. Finally, an armored segment of the 
building located at the right wall of the building between 600 $\mathrm{ft}$. and $720 \mathrm{ft}$. from the launcher end provides $12,000 \mathrm{ft}^{2}$ of space safe for human occupancy during launcher firings.

The approximate floor plan of a building is presented in Figure 4.1. The building is assembled from sheet steel insulated panels on a steel frame. The main room which contains the gun and tankage, has a posting of $20 \mathrm{ft}$. along most of its length as do the three equipment bays. (Posting $35 \mathrm{ft}$. high is required for $720 \mathrm{ft}$. of the end containing the launcher). Small cupolas may be required over some particular devices along the range such as the water flood gates used for disrupting sabot segments and projectiles.

The first $650 \mathrm{ft}$. of the range room is equipped with overhead bridge crane rails that span the building's $50 \mathrm{ft}$. width. Two bridges are supplied, each of which can lift 10.0 MT. The rails upon which the crane bridges operate are strong enough to support both bridges fully loaded at any position relative to one-another. Each crane hook may be lifted to $32 \mathrm{ft}$. above the range room floor. Each bridge is operated from a switch-board extending downward to near floor level on an electrical pigtail. controls are: forward/rearward along the range building; left/right across the building floor; and up/down. Two speeds are available for each movement.

The concrete foundation for the building is of ordinary industrial construction (with 6" slab thickness and 40 " deep peripheral footers). As discussed in Paragraph 2.3.2.2, "Central Breech Support", a massive section extending above and below floor line with' a central well is provided under the central breech of the light-gas gun launcher. It is located approximately $380 \mathrm{ft}$. from the rear wall of the building. other similar pits must be provided at alternative locations for the light-gas gun launcher.

The three $70 \mathrm{ft}$. by $100 \mathrm{ft}$. bays located through the righthand wall of the main range room are used to house substantial equipment for supporting range operation. The rearmost is provided to contain gas handling equipment for the gas gun pump tube. The bulk of the equipment in this room is the driver gas loading system described in Paragraph 2.4 .1 of this document. Some of the hydrogen gas loading system (described in Paragraph 2.4 .3 , is also contained in this bay although most of it is located out-of-doors behind the left hand wall of the range room opposite the pump tube and on the pump tube mount. The second and third $70 \mathrm{ft}$. $x 100 \mathrm{ft}$. bays are used to house or store evacuation equipment for the main range tankage. Large fans and exhaust ports are mounted in the side-walls of these three bays to circulate the large volumes of air needed to reject heat dissipated by energetic machinery. 


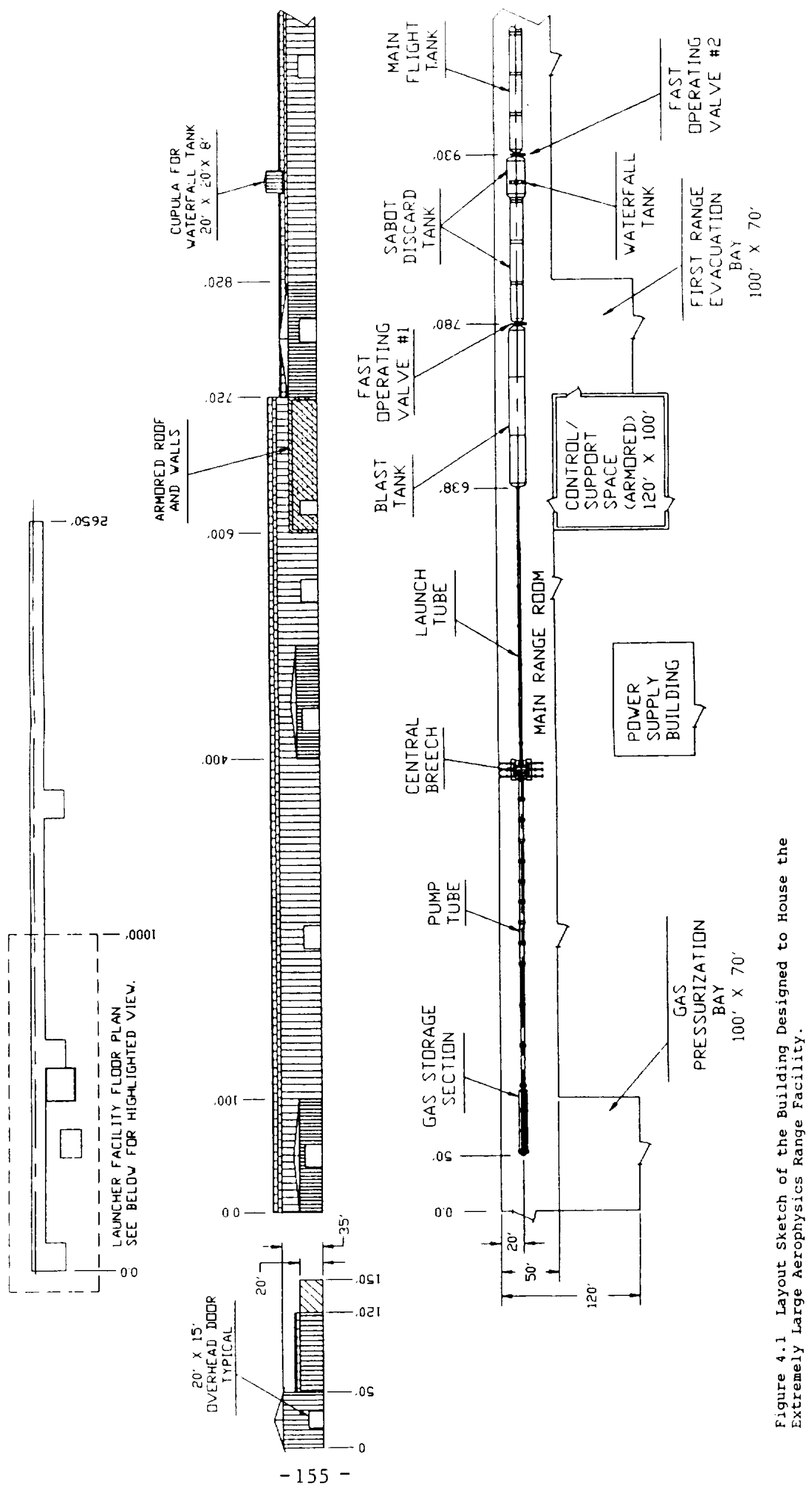


An additional $120 \mathrm{ft}$. by $100 \mathrm{ft}$. control/support structure is located on the right-hand side of the building between $600 \mathrm{ft}$. and $720 \mathrm{ft}$. from the rear end. This area contains the control room, offices, dark room, and laboratory space for the operation crew and visiting scientist/engineers. The walls and ceiling of this area are armored massively to protect personnel from blast and fragments produced by a major equipment failure.

Finally, a separate building is provided for containing the electrical power supplied for the range and for storing hazardous materials needed for range operation. It is located $50 \mathrm{ft}$. from the left wall of the building between 400-500 ft. from the building's rear wall.

\subsection{ELECTRICAL POWER REQUIREMENTS FOR THE RANGE FACILITY.}

Since prudence dictates that the range facility be located more-or-less remotely from other facilities housing large numbers of personnel, supplying large amounts of electrical power needed for gas compression and tankage evacuation becomes a potentially serious problem. Approximately 1,200 horsepower is required by the pumps used to compress helium gas between firings. Another $1,200 \mathrm{hp}$ is needed for evacuating the main range tankage. Since both activities must often be conducted at the same time, a total of $2,400 \mathrm{hp}$ must be drawn which requires electrical service near 2.5 MW. Such power can be drawn directly from an electrical substation or it can be produced by a large engine/generator set. Substations capable of producing $2.5 \mathrm{MW}$ of electrical power cost well over $\$ 2.0 \mathrm{Million}$. High tension transmission lines needed to connect a substation with electrical service nets may add significantly to this figure if the range is located in a truly
remote area.

Engine/generator sets capable of supplying 2.5 MW which use gas turbine or multi-fuel reciprocating engines can be installed for somewhat more than $\$ 1.2$ Million and $\$ 600,000$ respectively. Either system can be fueled with propane or liquified natural gas which can be delivered by tank truck in large enough quantities to serve the facility for several days. Environmental consequences of burning required amounts of either gas are trivial. The engine generator set produces substantial amounts of heat while operating. Turbines or reciprocating engines are no more than $50 \%$ efficient and electric power generation efficiency is limited to $90 \%$ so the entire process is limited to $45 \%$ efficiency, i.e., at least $5.55 \mathrm{MW}$ of heat is produced when the engine/generator set is operating. We also feel that a considerable fire hazard exists associated with storing liquified gas, operating the engines, and housing hazardous materials. These considerations have lead us to suggest that the electric power facility be co-located with storage of hazardous materials needed for overall range operation in a separate building located near enough to the main range complex so that electrical power transmission would be neither expensive to install nor produce significant voltage drop losses. 
We gave some consideration to providing electrical power for the entire facility, thereby freeing it entirely from power nets. This solution may prove practical if the facility is located very remotely where all electrical power requires expensive transmission lines regardless of its level. In this case, a smaller precision engine/generator station will be required that is capable of operating either 8 hours or 24 hours of each day. A more likely scenario is that sufficient electrical power for ordinary facility needs (near $150 \mathrm{KW}$ ) can be provided economically from the mains power net and that only heavy power requirements for large pumping activities require special generating facilities.

\subsection{PROVISION FOR ALTERNATIVE MODEL LAUNCH TECHNOLOGIES.}

The range building has been laid out in a manner that allows additions to be added easily to support alternative model launch technologies which may become available in the future. Two systems appear especially interesting. In the first, the current two-stage light-gas gun is moved upstream into an extension of the current building and a D.C. electromagnetic velocity amplifier is installed between the launcher muzzle and the range blast tank. $250 \mathrm{~mm}$ diameter models with appropriate electrical commutators are launched from the gas gun onto the rails of the velocity amplifier where they are accelerated from $6.0 \mathrm{~km} / \mathrm{sec}$ to significantly higher velocities (up to $12.0 \mathrm{~km} / \mathrm{sec}$ ). They are then allowed to pass through the blast tank, sabot discard tank, and conduct free or guided-rail flights along the main flight tankage. The other technology that shows major promise involves launching models at very low peak acceleration levels to velocities up to $8.0 \mathrm{~km} / \mathrm{sec}$ using a modified ram-jet principal. Here, fuel/oxidizer gas mixture is stored in the gun's launch tube. The mixture is allowed to burn (detonate) around and behind an oncoming model so that the resulting pressure rise accelerates the launch package forward along the launch tube. Again, $250 \mathrm{~mm}$ diameter launch packages are projected into the range tankage where experimental flights are conducted.

\subsubsection{D.C. Electromagnetic Rail Gun Velocity Amplifier.}

The length of the D.C. Electromagnetic velocity amplifier required to achieve a velocity augmentation, $\delta V$ may be calculated using Equation 4.1.

$$
X_{a}=\frac{\delta V Q}{a_{\max }}\left(V_{0}+\frac{\delta V}{2}\right)
$$

where:

$$
\begin{aligned}
& \mathrm{x}_{\mathrm{a}}=\text { required length of the velocity amplifier; } \\
& \mathrm{Q}=\text { piezometric ratio of the velocity amplifier } \\
& \text { (maximum projectile acceleration/average acceleration): }
\end{aligned}
$$


$\mathrm{v}_{0}=$ injection velocity;

$\mathrm{a}_{\max }=$ maximum projectile acceleration.

Figure 4.2 is a plot of velocity amplifier length vs. maximum acceleration level required to accelerate $6.0 \mathrm{~km} / \mathrm{sec}$ packages to $12.0 \mathrm{~km} / \mathrm{sec}$ for a number of piezometric ratios ranging from $Q=1.2$ (an effective theoretical minimum for $\mathrm{EML}$ technology) to $Q=4.0$ which probably represents an engineering maximum. Note that the length available in the building is sufficient for achieving the required velocity differential if peak acceleration levels are limited to $48 \mathrm{~kg}$ 's which is just model package peak acceleration required to launch a maximum-mass Paragraph 2.2.2.3.

Very substantial amounts of stored electrical energy are required to achieve such velocity enhancement. The amount of electrical energy storage is strongly dependent upon the amount of kinetic energy that must be added to the projectile which may

$$
\delta E=\frac{M_{p} \delta U}{2}\left(2 U_{0}+\delta U\right)
$$

where:

$$
\begin{aligned}
& \delta \mathrm{E}=\text { kinetic energy added to the projectile; } \\
& \mathrm{M}_{\mathrm{p}}=\text { projectile package mass; } \\
& \delta \mathrm{U}=\text { desired velocity increase; and } \\
& \mathrm{U}_{0}=\text { projectile package injection velocity. }
\end{aligned}
$$

If $14.0 \mathrm{~kg}$ packages are to be accelerated from $6.0 \mathrm{~km} / \mathrm{sec}$ gas gun velocity to $12.0 \mathrm{~km} / \mathrm{sec}$, kinetic energy of $\delta \mathrm{E}=756 \mathrm{MJ}$ must be described here have not yet been electrical efficiency yet been developed so estimating their optimistic assumption of efficiency is. We feel that an energy storage requirement of $E_{s}=y$ is, $33 \%$ which leads to an but, possibly, more rea only $10 \%$ is achieved whis of $\mathrm{E}_{\mathrm{s}}=7.56 \mathrm{GJ}$. The an electrical driving most straightforward method for achieving electrostatic storage pulse of this magnitude is through

these sizes have not yet a capacitor bank. Capacitor banks of them are already availableen assembled but components for making one manufacturer (Maxwell Laborare undergoing rapid improvement. delivering individual cans $19^{\prime \prime} \mathrm{x}$ ( store $0.5 \mathrm{MJ}$. If these cans are $15 " x 30 "$ deep that can each them in stacks five high with requisite into racks which support total of 2.5 MJ may be contained in floor space gear on top, a If such stacks are combined into in floor space of only $5 \mathrm{ft}^{2}$. space is open, an overall A chane density of $125 \mathrm{~kJ} / \mathrm{ft}^{2}$ would, thus, require a capable of storing $7.56 \mathrm{GJ}$ 


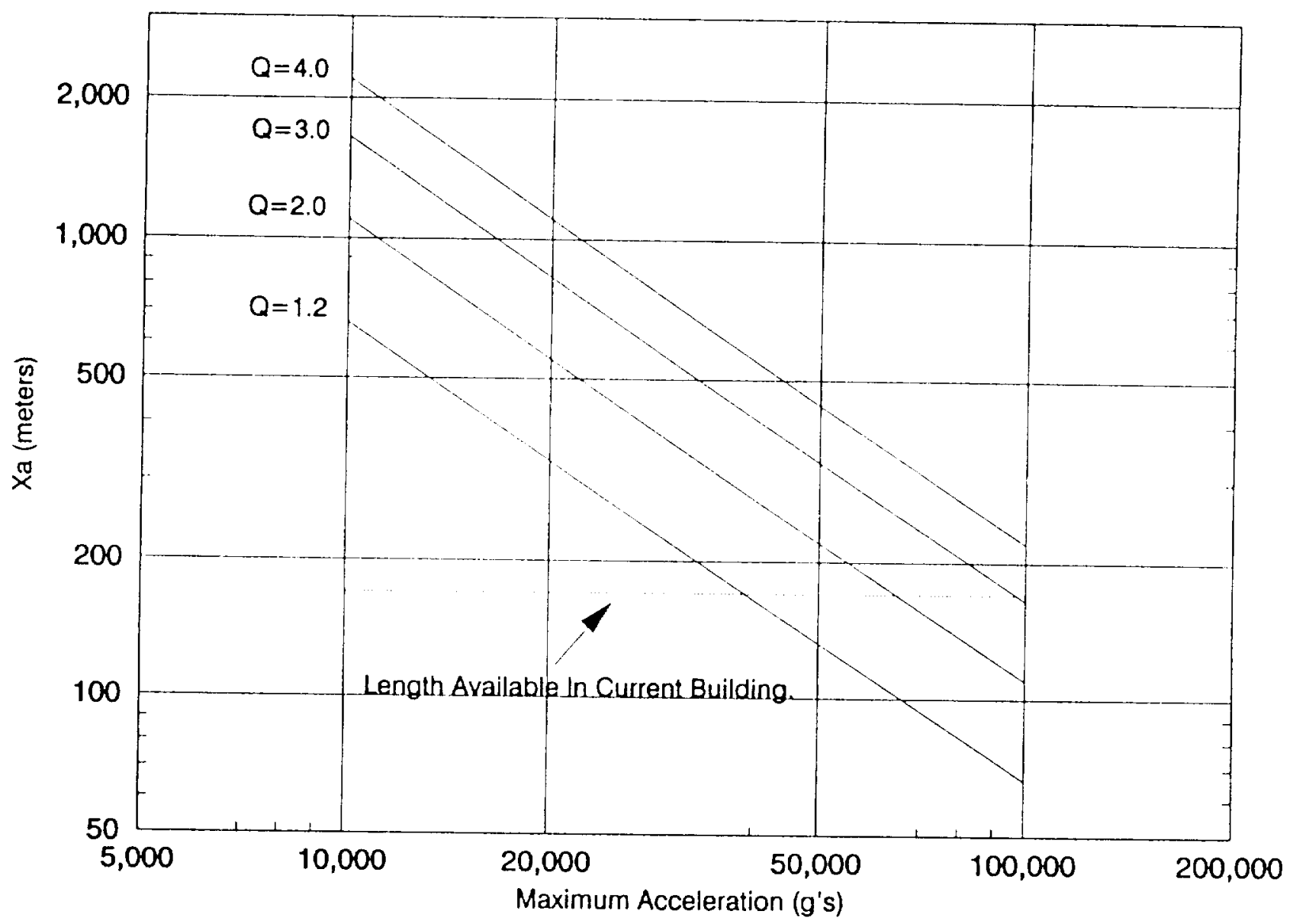

Figure 4.2 Plot of Velocity Amplifier Length Required for Boosting $6.0 \mathrm{~km} / \mathrm{sec}$ Projectile Packages to $12.0 \mathrm{~km} / \mathrm{sec}$ vs. Peak Acceleration Levels Needed for Various Piezometric Ratios. 
a room might be added to the left-hand wall of the main building shown in Figure 4.1 that extends $600 \mathrm{ft}$. along the left-hand wall as is sketched in Figure 4.3. If this building were $100 \mathrm{ft}$. wide, it would provide floor space just adequate for capacitive storage. A small annex of $30^{\prime} \times 100^{\prime}$ at the rear end of this building would suffice to contain power supply and control hardware. The amount of electrical energy required for charging the capacitors is formidable. For instance, the power used for compressing helium gas for the injector (1.25 MW) must be diverted for an hour and 45 minutes to charge the capacitor bank. Thus, choice electromagnetic acceleration as an adjunct to the range requires addition of at least $1.25 \mathrm{MW}$ to the electrical power delivery requirements.

Two alternative technologies are currently available to electrostatic energy storage. In the first, electric batteries such as automobile storage cells are used to develop a massive medium-voltage high D.C. current sources which charges electrical inductors over several seconds. The inductors are then switched across the electromagnetic rail gun where they discharge in fractions of second. Total space requirements for batterypowered energy storage units are comparable to those required for capacitive storage. Electrical power requirements for operating such a system are reduced substantially below capacitive discharge equipment since the batteries can be charged over periods of several hours between firings. A serious failure in the battery system might be expected to produce an environmental disaster! A major short circuit could be expected to lead to a fire which might consume essentially the entire energy storage facility. Release of lead and sulfuric acid from such a conflagration could do incalculable environmental damage. We feel that many expensive safeguards would be required for a facility that amasses such a large amount of potentially toxic materials as would be required for a battery storage system.

Another possibility is to store energy via rotating machinery. One system that has already seen much development involves use of homopolar generators to charge large inductors which are then discharged into the velocity amplifier load. A more advanced and elegant approach is to use compulsators to serve the function of both the homopolar generator and the inductor in a single unit. A substantial advantage of rotating machinery storage is increased compactness of the facility requiring that smaller buildings be constructed. A disadvantage is that very substantial amounts of electrical power are required to charge the system.

\subsubsection{Scramaccelerator.}

The principal operational advantage of a scramaccelerator over light-gas gun for launching models into the range under consideration is its ability to conduct launches at low peak acceleration levels (due to using acceleration profiles with very low piezometric ratios). Relatively small amounts of additional velocity above $U_{p}=6,000 \mathrm{~m} / \mathrm{sec}$ are anticipated at this time. 


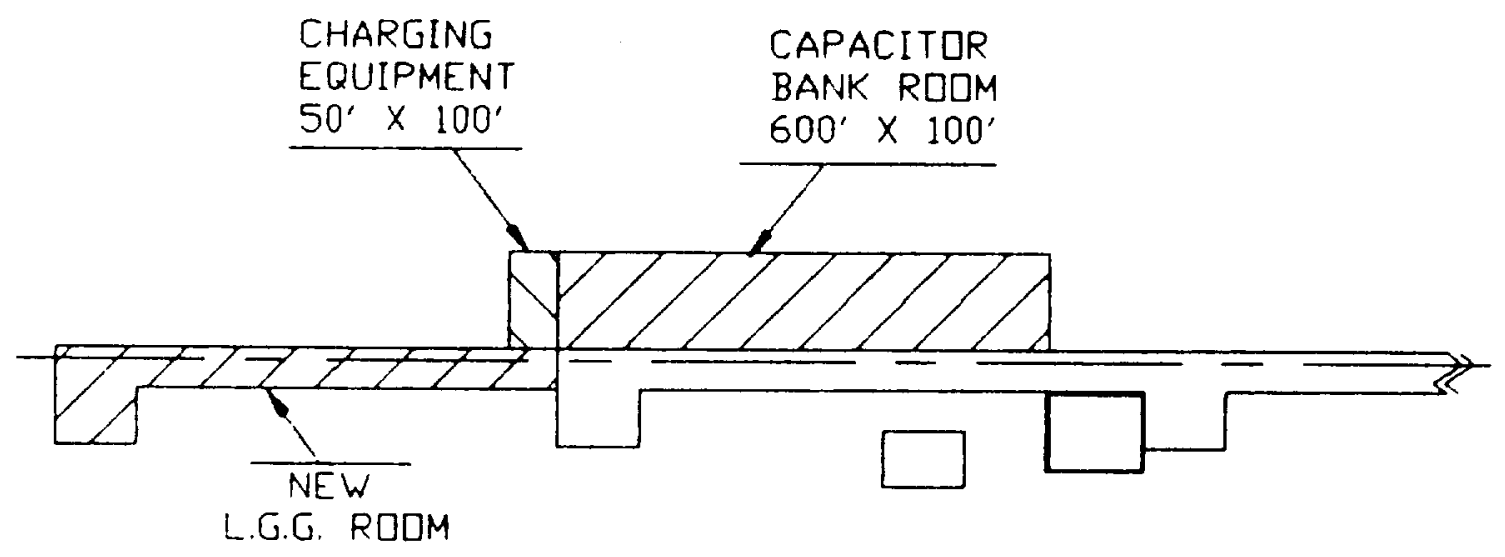

Figure 4.3 Outline Sketch of the Rear Portion of the Range Building with Additions for Housing Equipment Needed for an Electromagnetic Velocity Amplifier. 
Substantial increases in bore diameter cannot be accommodated by the range tankage due to serious limits upon the amount of kinetic energy that can be dissipated during sabot segment stoppages, etc.

Equation 4.1 may be used again to establish length requirements for scramaccelerators since: (1) they require use of low velocity injectors; and (2) their launch profiles may be expressed as peak acceleration, $a_{\max }$, with a finite piezometric ratio, $Q$. Typically, injectors with $250 \mathrm{~mm}$ bore diameters are $30 \mathrm{~m}$ long. This length must, of course, be subtracted from the overall building length when establishing feasibility. Typically, piezometric ratios of scramaccelerator launch profiles range between $Q=1.2$ to $Q=2.0$. Plotted in Figure 4.4 is SCRAM accelerator length requirement vs. maximum acceleration level experienced by a projectile package that is injected a $v_{0}=1.0$ $\mathrm{km} / \mathrm{sec}$ and accelerated to a final velocity of $\mathrm{v}_{\mathrm{m}}=6.0 \mathrm{~km} / \mathrm{sec}(\delta \mathrm{V}$ $=5.0 \mathrm{~km} / \mathrm{sec})$. The individual plots correspond" to particular piezometric ratios between $Q=1.0$ and $Q=2.0$.

Again, equipment has not yet been developed that can use ram and scramaccelerator technology for launching packages to velocities of $6.0 \mathrm{~km} / \mathrm{sec}$ so details of the accelerator cannot be specified. One problem which must be addressed however, is disposition of burn products expelled from the launcher during and shortly after firing. Another subject which must be considered is safety associated with: storing large amounts of fuel and oxidizer gas; mixing them before, during or after insertion into the tube; and consequences of inadvertent release of these gases into the main range tankage, holding tanks, the range room, or out-of-doors. Titan corp. is currently contractbound not to speculate about upcoming advances in scramaccelerator technology. 


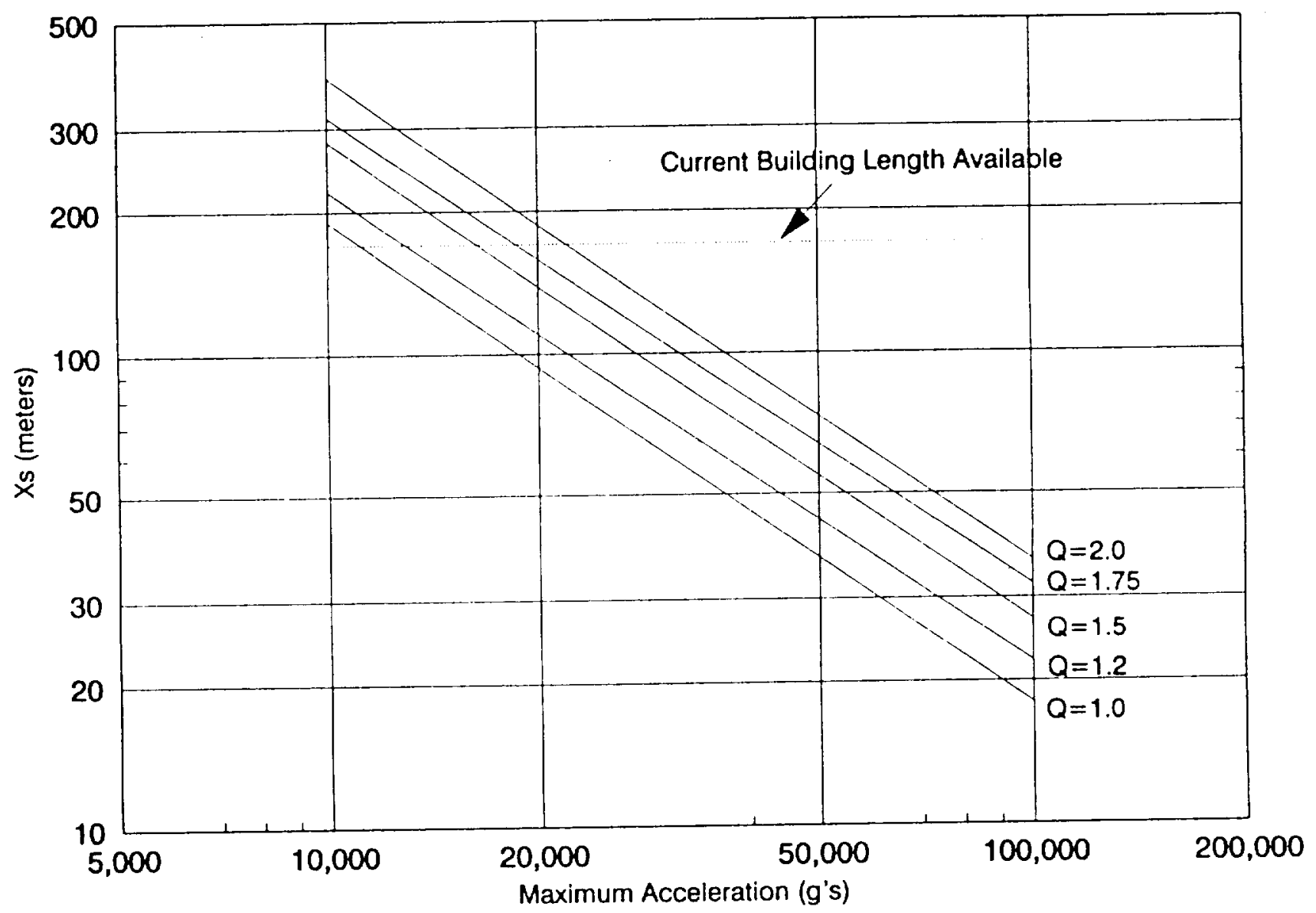

Figure 4.4 Plot of Launcher Lengths Required to Achieve Muzzle Velocities of $V_{m}=6.0 \mathrm{~km} / \mathrm{sec}$ when injected at $V_{0}=1.0 \mathrm{~km} / \mathrm{sec}$ vs. Peak Acceleration Levels for a Variety of Piezometric Ratios. 
REFERENCES

1. Witcofski, R., Scallion, W., and Carter, D., Jr. "An Advanced Hypervelocity Aerophysics Facility: A Ground-Based Flight Test Range." AIAA 91-0296, 29th Aerospace Sciences Meeting, Reno, NV, Jan. 7-10, 1991 .

2. Charters, A.C., Sangster, D.K., "Fortran Computer Program for the Interior Ballistic Analysis of Light-Gas Guns." Informal Manual available from Dr. Charters, July 1973.

3. Leicher, F., Pearson, N., "Performance of Idealized Solid Propellant Ordnance Guns." Frankford Arsenal Technical Report FA-TR-62-038, Frainkford Arsenal, PA, 1963.

4. Bauer, P., Brochet, C., Presles, H., "Detonation study of Gaseous Mixtures at Initial Pressures Reaching $10 \mathrm{MPa}$ " Archivum Combustion, Vol. 4, No. 3, 1984.

5. Hord, J. "Is Hydrogen Safe.?" NBS Report, October 1976, National Bureau of standards, Bolder, CO 80302 .

6. Rast, J , "The Design of Flat-Scored High-Pressure Diaphragms for Use in Shock Tunnels and Gas Guns." NAVORD Report 6865 . USNOL, White Oak, MD, 1960.

7. Bernier, H., "The Two-stage Light-Gas Gun of the Commissariat a l'Energie Atomique, France." Proceedings of the 24 th Meeting of the Aeroballistic Range Association, AEDC, TN, Sept. 1973.

8. Swift, H., and Ford, E., "Concept Definition study for a Large Two-stage Light-Gas Gun," Report to Lockheed Engineering \& Sciences Co. under Contract No. 17GFY900368, March 1991.

9. Fernandez, M. J., Ager, S. A., and Hudson, R. D., "In-Bore Instrumentation/Diagnostics for Large Bore EMLs," 5 th Symposium on Electromagnetic Launch Technology, Sandestin, Florida, April $3-5,1990$.

10. Teng, R.N., Hickman, R.S., and Sutila, G.E., "Development of a Scaled-Up Hypervelocity Guiding and Retrieving'system, "AEDCTR-74-123, Arnold Engineering Development Center, TN, January
1975.

11. Norfleet, G.D., Hendrin, R.E., and Jackson, D. "Development of a Hypervelocity Track Facility at AEDC," AIAA 15th Aerospace Sciences Meeting, Paper 77-151, Los Angeles, CA, January 1977.

12. Boehman, L.I., Barber, J.P., and swift, H.F., "simulation of Friction, Wear, and Gauging for a Hypervelocity Guide-Rail

System," AEDC-TR-78-19, May 1978. 
13. Boutwel1, F., "GMDRL, lligh speed Valve Application," proceedings of the Eighth Meeting of the neroballistic Range Association, Santa Barbara, CA, April 1965.

14. Scallion, W., InSA Langley Research center, Langley, VA, private communication.

15. Ordin, P.M., "Hydrogen Safety llandbook," NASA Headquarters Report (in preparation).

16. Swift, H.F., "Analysis of Sabot operation," Proceedings of the 8 th International symposium on Ballistics sponsored by the ADPA, orlando, FL, October, 1984.

17. Swift, H.F., and strange, D.E., "Sabot Discard TechnologY," proceedings of the 38 th leeting of the neroballistic Range Association, Tokyo, Japan, October 1987.

18. Chou, Pei Chi, and Hopkins, A.J. (EDS), "Dynamic Response of luaterials to Impulsive Loading," Air Force Materials Laboratory, WPAFB, Ohio, August 1972 .

19. Zucas, J., et al, "Impact Dynamics," John Wiley \& Sons, New York City, New York, 1982.

20. Kinslow, R. (ed), "Higl Velocity Impact Phenomena," Academic press, 1976.

21. Swift, I., "On predicting Projectile Breakup During Thin plate Impact." International Journal of Impact Engineering, Volume 10, No. 1-4, 1990, pergamon Press, NYC.

22. Swift, H., Bamford, R., Chen, R., "Designing Dual-Plate Meteoroid Shields - $\Lambda$ Hew nnalysis." JPJ, Publication 82-39, March 1982 .

23. Stewart, J.R. and Cable $\Lambda . J ., " ~ \Lambda$ Large Quick Opening Valve for Use in Aeroballistic lange Testing." Proceedings of the 26th Meeting of the neroballistic Range nssociation, San Leandro, cn, September 1975 . 


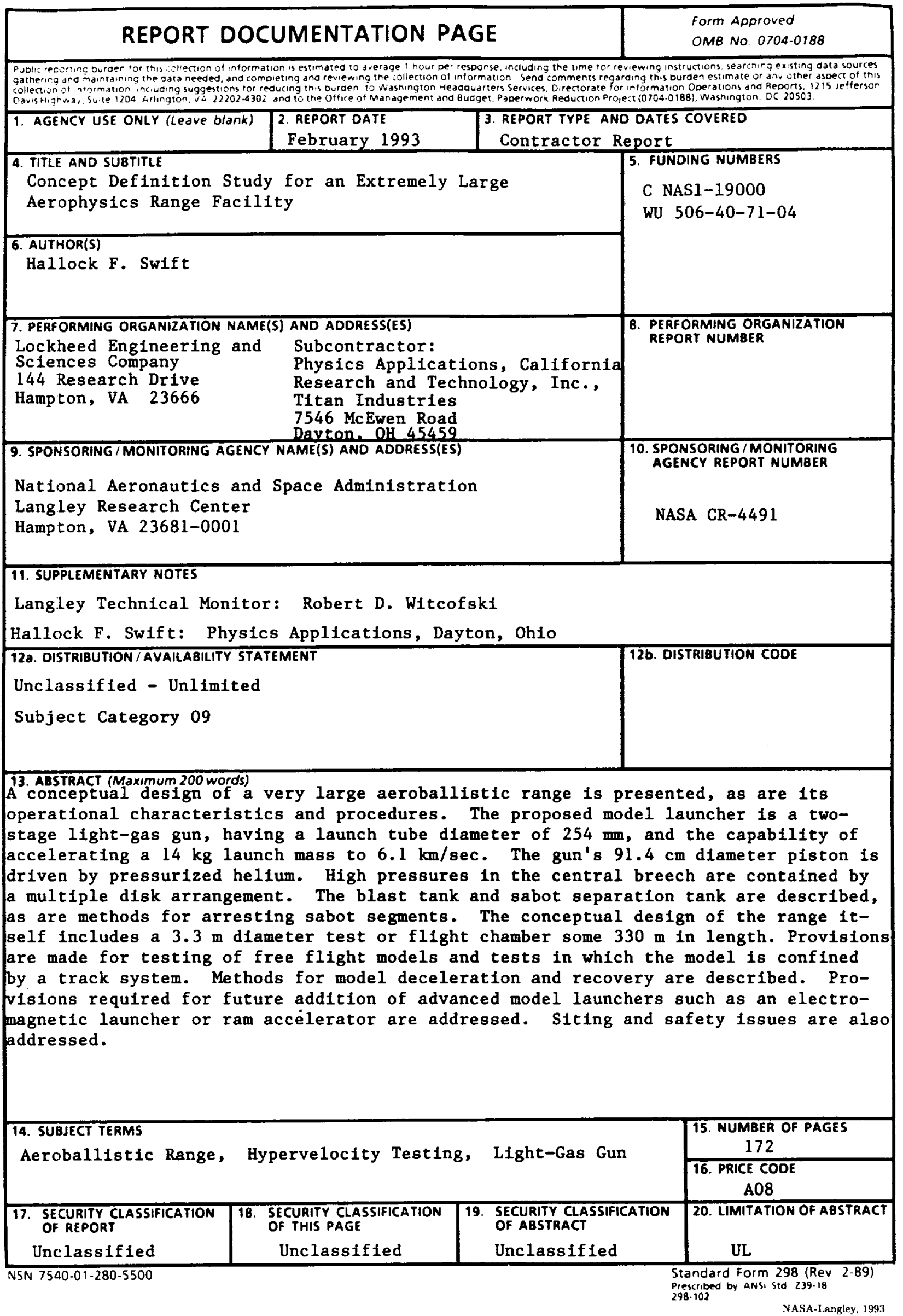

